LBL-36702

UC-401

\title{
Infrared Spectroscopy of Nonclassical \\ Ions and Their Complexes
}

\author{
Doo Wan Boo \\ Ph.D. Thesis \\ Department of Chemistry \\ University of California, Berkeley \\ and \\ Chemical Sciences Division \\ Lawrence Berkeley Laboratory \\ University of California \\ Berkeley, CA 94720
}

January 1995

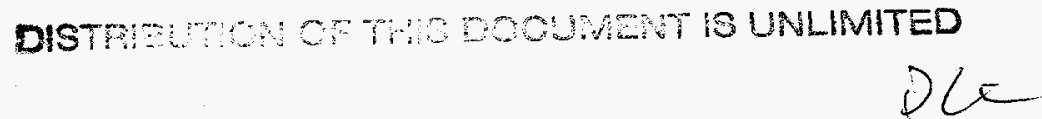

This work was supported by the Director, Office of Energy Research, Office of Basic Energy Sciences, Chemical Sciences Division, of the U.S. Department of Energy under Contract No. DE-AC03-76SF00098. 


\section{DISCLAIMER}

This report was prepared as an account of work sponsored by an agency of the United States Government. Neither the United States Government nor any agency thereof, nor any of their employees, make any warranty, express or implied, or assumes any legal liability or responsibility for the accuracy, completeness, or usefuiness of any information, apparatus, product, or process disclosed, or represents that its use would not infringe privately owned rights. Reference herein to any specific commercial product, process, or service by trade name, trademark, manufacturer, or otherwise does not necessarily constitute or imply its endorsement, recommendation, or favoring by the United States Government or any agency thereof. The views and opinions of authors expressed herein do not necessarily state or reflect those of the United States Government or any agency thereof. 


\section{DISCLAIMER}

Portions of this document may be illegible in electronic image products. Images are produced from the best available original document. 
Infrared Spectroscopy of Nonclassical Ions and Their Complexes

by

Doo Wan Boo

B.S. (Seoul National University) 1985

M.S. (Seoul National University) 1987

A dissertation submitted in partial satisfaction of the

requirements for the degree of

Doctor of Philosophy

in

Chemistry

in the

GRADUATE DIVISION

of the

UNIVERSITY OF CALIFORNIA at BERKELEY

Committee in charge:

Professor Yuan T. Lee, Chair

Professor Richard J. Saykally

Professor John G. Phillips 


\author{
Abstract \\ Infrared Spectroscopy of Nonclassical Ions and Their Complexes \\ by \\ Doo Wan Boo \\ Doctor of Philosophy in Chemistry \\ University of Califormia at Berkeley \\ Professor Yuan T. Lee, Chair
}

This thesis describes an infrared spectroscopic study on the structures and dynamics of the nonclassical ions and their complexes, using ion trap vibrational predissociation spectroscopy.

Chapter One provides an introduction to the experimental apparatus used in this work. Chapter Two describes the previous theoretical and experimental works on the carbonium ion $\mathrm{CH}_{5}^{+}$and our infrared spectroscopic and theoretical works on $\mathrm{CH}_{5}^{+} \cdot \mathrm{CH}_{5}^{+}$ was predicted to scramble constantly without possessing a stable structure. In Chapter Three, the infrared spectra for the molecular hydrogen solvated carbonium ions $\mathrm{CH}_{5}^{+}\left(\mathrm{H}_{2}\right)_{\mathrm{n}}$ $(n=1-6)$ in the frequency region of $2700-4200 \mathrm{~cm}^{-1}$ are presented and compared with the results of ab initio molecular dynamics simulation on $\mathrm{CH}_{5}^{+}\left(\mathrm{H}_{2}\right)_{\mathrm{n}}(\mathrm{n}=0-3)$. The results suggested that the scrambling of $\mathrm{CH}_{5}^{+}$slowed down considerably by the stabilization effects of the solvent $\mathrm{H}_{2}$ molecules, and it was completely frozen out when the first three $\mathrm{H}_{2}$ molecules were bound to the core $\mathrm{CH}_{5}^{+}$. 
Chapter Four presents the complete infrared spectra for the solvated carbonium ions, $\mathrm{CH}_{5}^{+}(\mathrm{A})_{\mathrm{x}}(\mathrm{B})_{\mathrm{y}}\left(\mathrm{A}, \mathrm{B}=\mathrm{H}_{2}, \mathrm{Ar}, \mathrm{N}_{2}, \mathrm{CH}_{4} ; \mathrm{x}, \mathrm{y}=0-5\right)$ in the frequency region of $2500-3200$ $\mathrm{cm}^{-1}$. As the binding affinities of the solvent molecules and the number of the solvent molecules in the clusters increased, the scrambling of $\mathrm{CH}_{5}^{+}$slowed down substantially. The structures of the solvated carbonium ions and the evidence for rapid proton transfer in $\mathrm{CH}_{5}^{+}\left(\mathrm{CH}_{4}\right)$ were also presented.

Chapter Five presents the vib-rotational spectrum for the $\mathrm{H}-\mathrm{H}$ stretching mode of the silanium ion $\mathrm{SiH}_{5}{ }^{+}$. The results suggested that $\mathrm{SiH}_{5}{ }^{+}$can be described as a complex of $\mathrm{SiH}_{3}{ }^{+}$and a freely internally rotating $\mathrm{H}_{2}$, analogous to, but distinct from $\mathrm{CH}_{5}{ }^{+}$. 
This thesis is dedicated to the memory of my father. 


\section{Table of Contents}

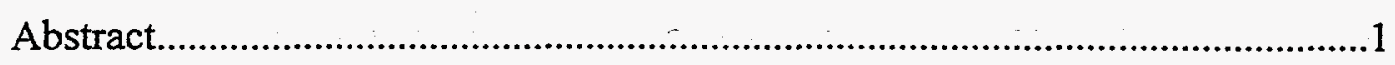

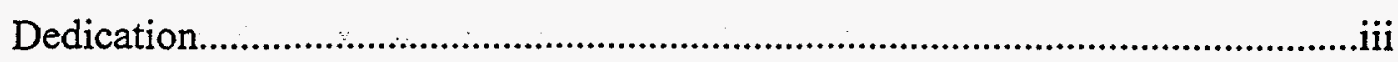

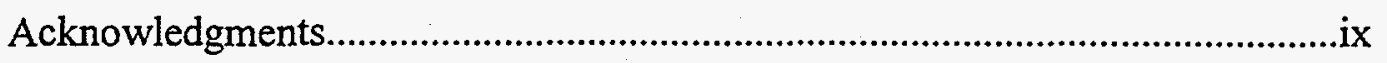

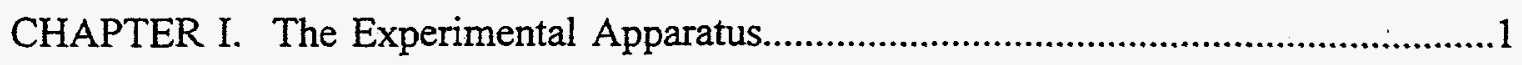

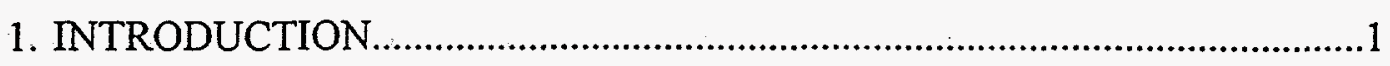

2. THE EXPERIMENTAL APPARATUS........................................................

2.1 The Continuous Corona Discharge Ion Source................................2

2.2 The 1st Mass Selection and Ion Trapping.......................................5

2.3 The 2nd Mass Selection and Ion Detector.....................................

2.4 Infrared Light Source.............................................................

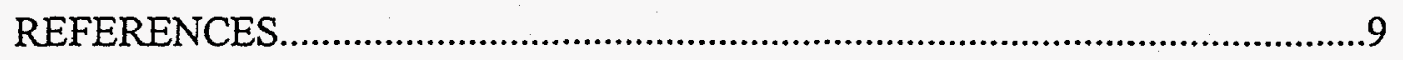

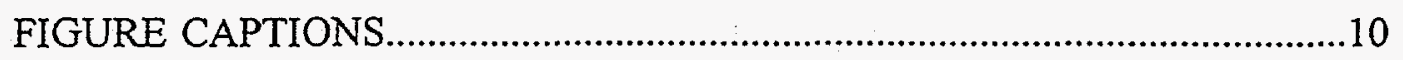

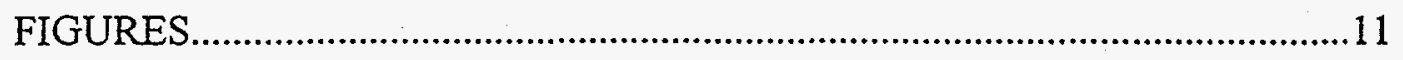

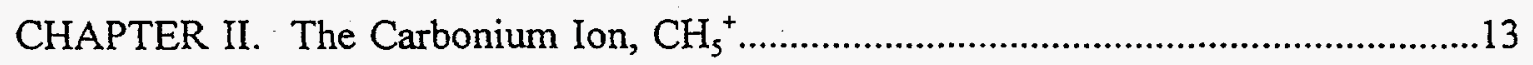

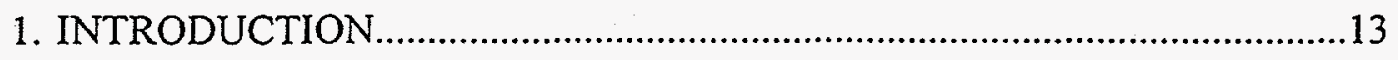

2. AB INITIO MOLECULAR DYNAMICS (MD) CALCULATIONS.............17

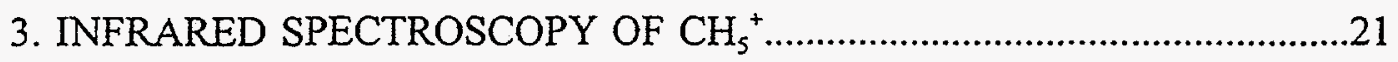




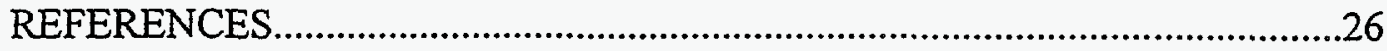

TABLES

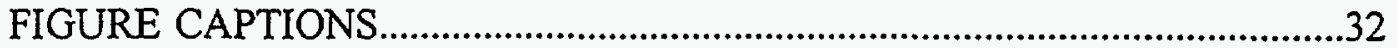

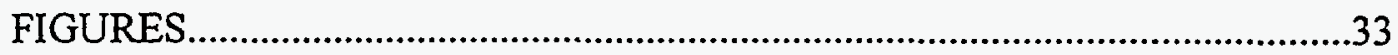

CHAPTER III. Infrared Spectroscopy of the Molecular Hydrogen

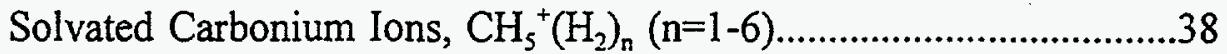

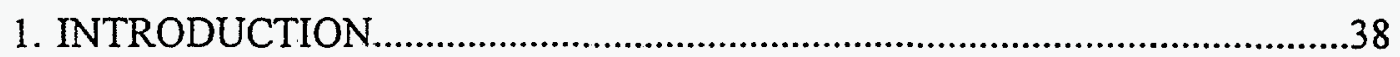

2. EXPERIMENTAL DETAILS....................................................................42

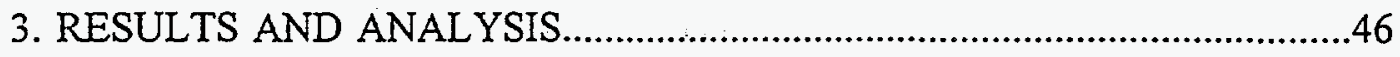

3.1 Internally Cold $\mathrm{CH}_{5}{ }^{+}\left(\mathrm{H}_{2}\right)_{\mathrm{n}}$ Ions.......................................................

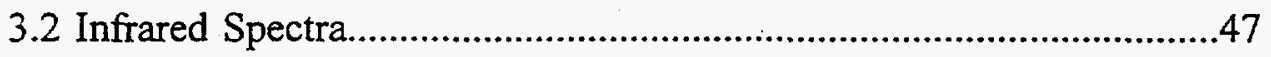

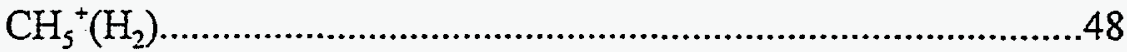

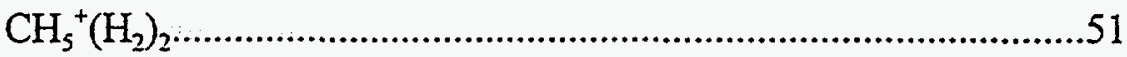

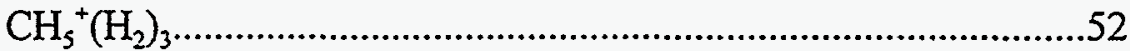

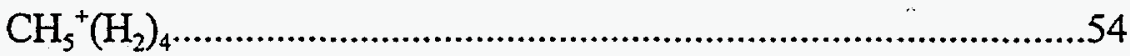

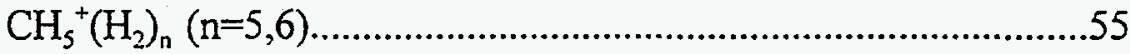

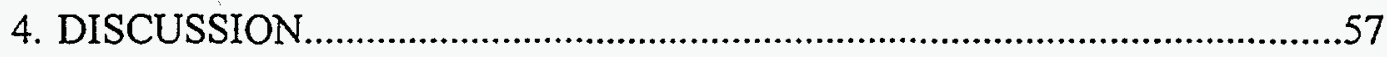

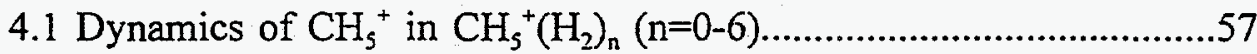

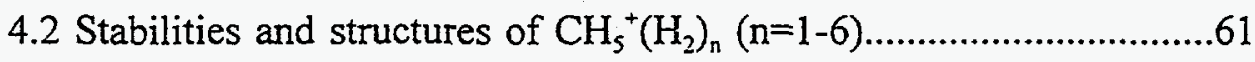

5. SUMMARY

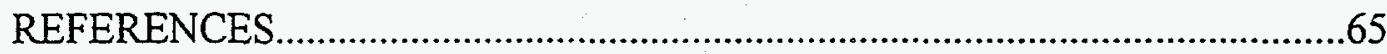




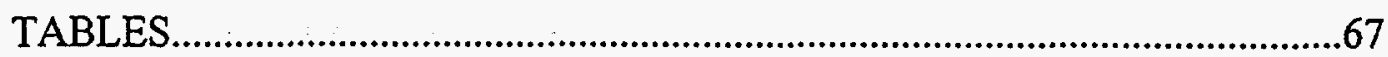

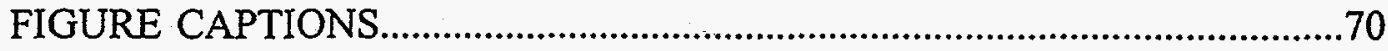

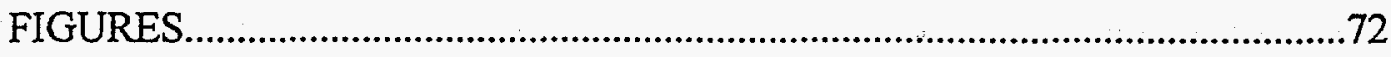

APPENDIX

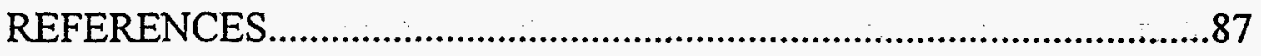

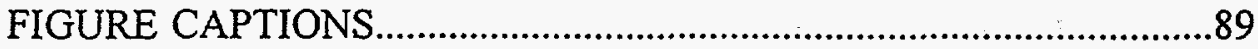

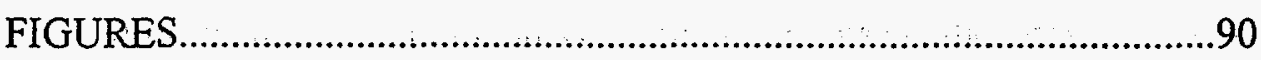

CHAPTER IV. Infrared Spectroscopy of the Solvated Carbonium Ions,

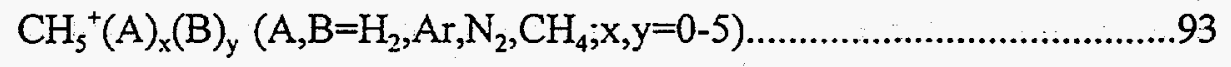

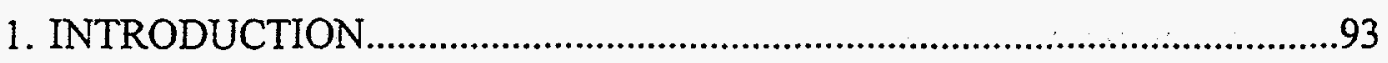

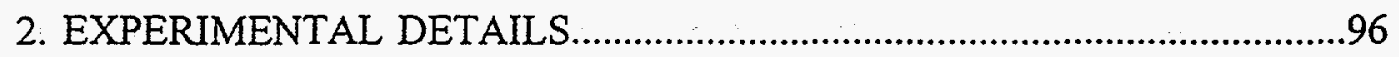

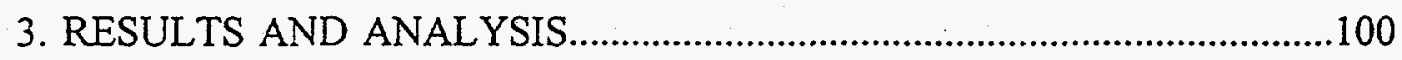

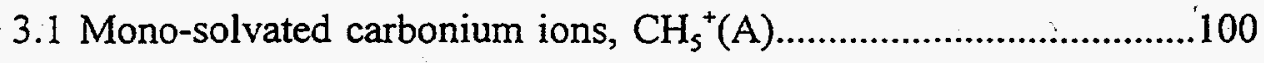

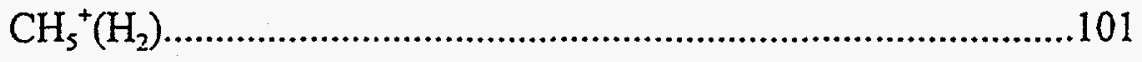

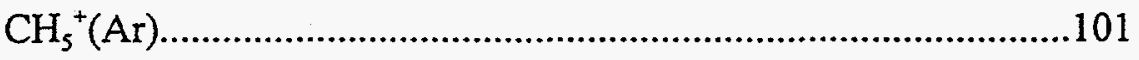

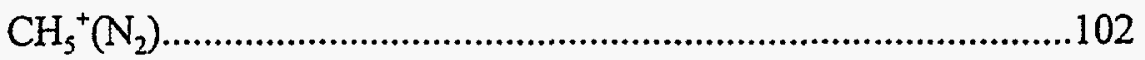

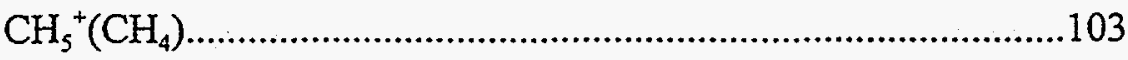

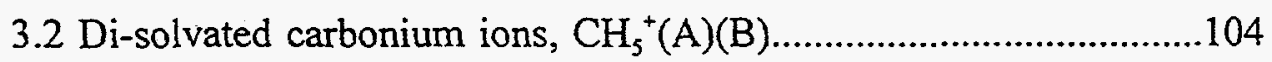

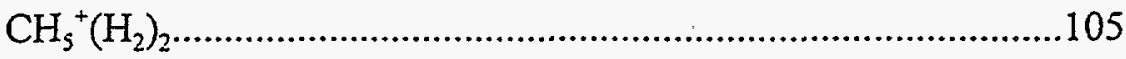

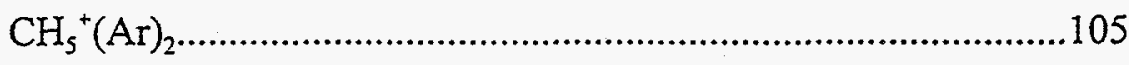

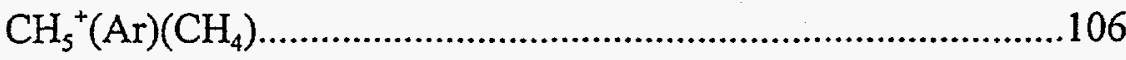




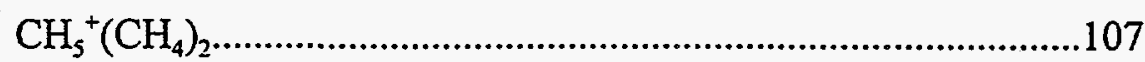

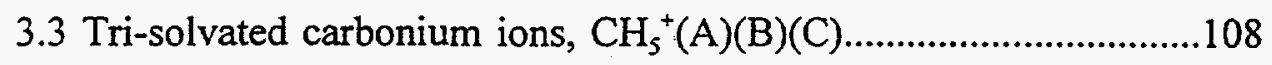

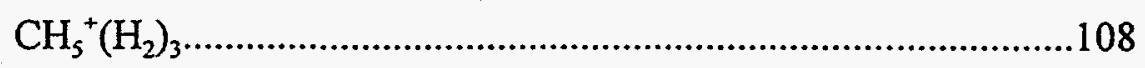

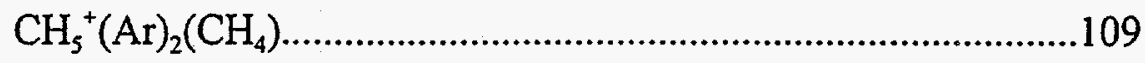

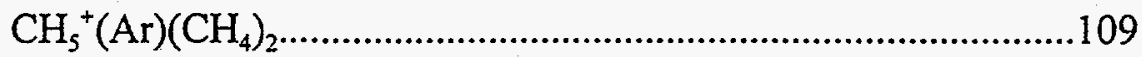

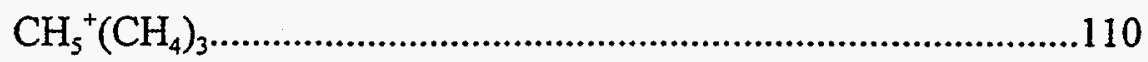

3.4 Tetra- and penta-solvated carbonium ions, $\mathrm{CH}_{5}^{+}(\mathrm{A})_{4,5}\left(\mathrm{~A}=\mathrm{CH}_{4}\right) \ldots .112$

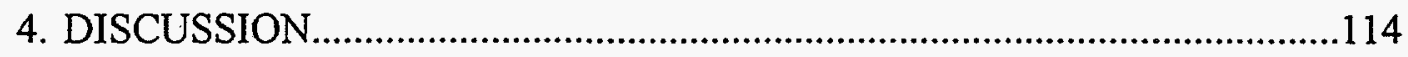

4.1 Vibrational assignment of the feature in $2500-2700 \mathrm{~cm}^{-1} \ldots \ldots \ldots \ldots \ldots . .114$

4.2 Dynamics of $\mathrm{CH}_{5}^{+}$cores in $\mathrm{CH}_{5}^{+}(\mathrm{A})_{\mathrm{x}}(\mathrm{B})_{y}$

$$
\left(\mathrm{A}, \mathrm{B}=\mathrm{H}_{2}, \mathrm{Ar}, \mathrm{N}_{2}, \mathrm{CH}_{4} ; \mathrm{x}, \mathrm{y}=0-5\right)
$$

4.3 Structures of $\mathrm{CH}_{5}{ }^{+}(\mathrm{A})_{\mathrm{x}}(\mathrm{B})_{\mathrm{y}}\left(\mathrm{A}, \mathrm{B}=\mathrm{H}_{2}, \mathrm{Ar}, \mathrm{N}_{2}, \mathrm{CH}_{4} ; \mathrm{x}, \mathrm{y}=0-5\right) \ldots \ldots \ldots \ldots .120$

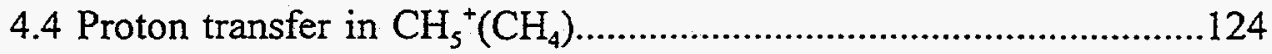

5. SUMMARY

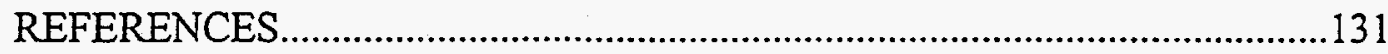

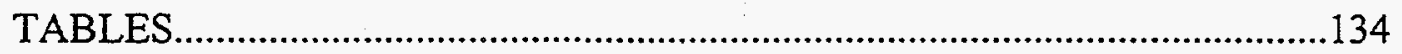

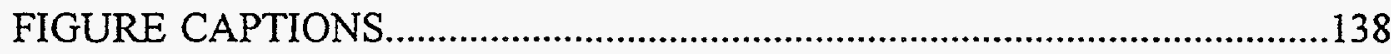

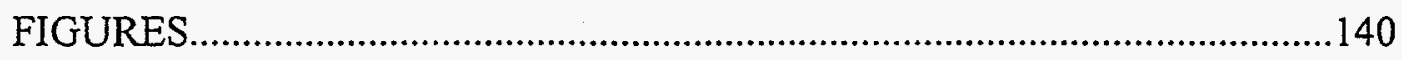

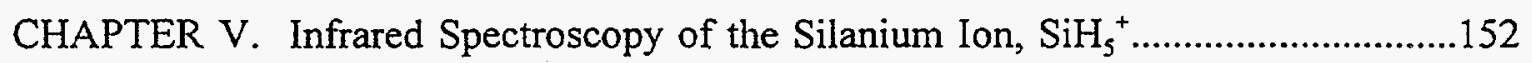

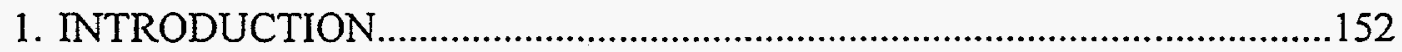

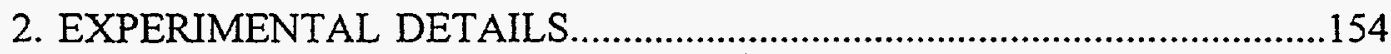




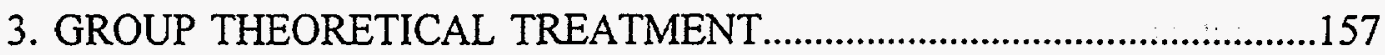

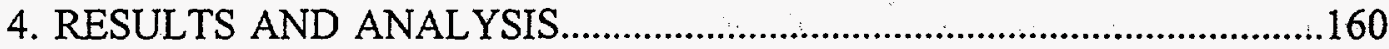

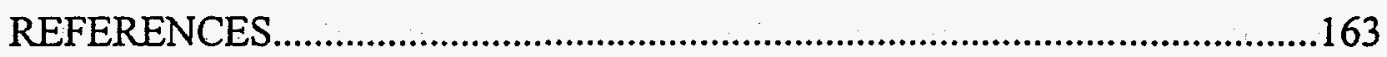

TABLES

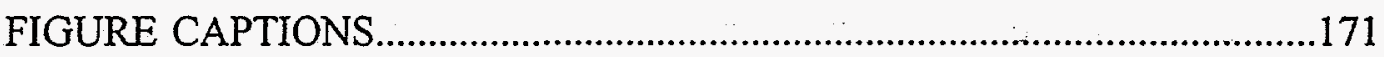

FIGURES 


\section{ACKNOWLEDGEMENTS}

I am deeply indebted to Prof. Yuan T. Lee for his scientific guidance, encouragement, and infinite patience throughout my years at Berkeley. When I met him for the first time, I was greatly inspired by his humbleness, in spite of the tremendous success in science. Since then, he has been a model for me to be a scientist with both intelligence and compassion. I also enjoyed the freedom he afforded to me for creating my own ideas and pursuing them during the entire years.

My family has been a constant driving force throughout the many years. Their love and support has been endless, and was always there whenever I needed it. My wife, Yun Jeong, and my daughter, So Jeong, now five month old, have been a great pleasure in my life, and provided the place for resting my tired mind and body from the long and restless experiments. My mother and other families in Cheju, Korea have been always supportive, and my parents-, brother- and sister-in-laws in Seoul, also contributed importantly to our lives in Berkeley. I also thank my Korean friends here, with whom I enjoyed the discussions about the broad range of topics - politics, sports, and science over the beers.

Research in the Lee group is a collaborative adventure, and I have benefitted from all the other Lee group members for sharing the instruments and learning other experiments. I thank them all. Those who I worked with closely deserve my special thanks. John Price was a senior student in the ion spectroscopy lab when I joined this project. He was kind and patient in teaching me how to operate the machine in my first 
year. Dr. Mark Crofton and Dr. Gereon Neidner-Schatteburg, postdoctoral fellows at that time, were kind enough to share their experience in experimental physical chemistry with me, and also introduced me the Berkeley style of life, which has been a important part of my life since then. I thank Dr. Zhi-Feng Liu, a postdoctoral fellow who joined this project last year, and also largely contributed to the theoretical part in this thesis, for his assistance and kindness during our fruitful collaboration. I also thank Dr. John Tse in NRC, Canada, for giving me the opportunity to run his density functional programs.

Cheryl Longfellow and Laura Smoliar deserve my special thanks for their help in preparing the draft for this thesis in Taiwan. I thank Dr. Arthur Suits, now in charge of the Lee group, and Allan Bracker for their help in reviewing this thesis. Dr. Andy Kung, a laser expert and now in Taiwan, helped me in understanding the basics of nonlinear optical processes. Other members of the Lee group, whose names are not listed here, deserve a special note of thanks for their assistance and kindness throughout the many years. I also thank Ann Lawhead for her help in solving all the bureaucratic problems.

Many others outside the Lee group provided the services that kept the Lee group working. Harry Chiladaskis, a head of building management, helped in running the Lee group smoothly. I also thank everyone in the Chemistry machine shop, glass shop, instrument repair shop, and electronics shop for their assistance in the designing, machining, and repairing.

Finally, I dedicate this thesis to the memory of my father who taught me a discipline in life, and also the importance of trying my best, regardless of the outcomes. 
This work was supported by the Director, Office of Energy Research, Office of Basic Energy Sciences, Chemical Sciences Division, U.S. Department of Energy under Contract No. DE-AC03-76SF00098. 


\section{CHAPTER I}

\section{The Experimental Apparatus}

\section{INTRODUCTION}

In this chapter, I describe the experimental apparatus used in this work. The apparatus is called ion trap, vibrational predissociation, or consequence spectroscopy machine. It was originally built by Bustamente, Carlson, Gerlich, and Lee, and is described in detail elsewhere.' The performance of the machine has been improved time to time by its successors, namely Okumura ${ }^{2}, \mathrm{Yeh}^{3}$, Price $^{4}$ and me. The apparatus, shown schematically in Figure 1, is composed of the ion source, the magnet sector, the octapole ion trap, the quadrupole mass filter and ion detector. Each component of the machine will be described in detail below. Briefly, the ion source produces internally cold ions and then mass-selected with the magnet sector. The mass-selected ions are injected into the octapole ion trap. During trapping the ions are exposed to the infrared irradiation and then vibrationally predissociate. The vibrational predissociation products are massanalyzed and detected by the quadrupole mass filter and ion detector. The observation of the daughter ions as a function of infrared laser frequency is a measure of the infrared absorption of the parent ions. 


\section{THE EXPERIMENTAL APPARATUS}

\subsection{The Continuous Corona Discharge Ion Source}

The ion clusters studied in this work were generated in a continuous corona discharge ion source shown in Figure 2. The ion source is composed of the nickel plated needle, the $\mathrm{Cu}$ source body, the stainless steel nozzle $(75 \mu \mathrm{m}$ hole), a thermocouple, a heating wire wrapping around the source body, a Cu block as a heat sink, and a liquid nitrogen trap. Ionization occurs in a high pressure region between the nickel coated needle tip and the source body. Typical pressures inside the source and the discharge current used were $60-300$ torr and $2-40 \mu \mathrm{A}$, respectively. Also, the pressures in the source chamber were less than $10^{-4}$ torr during the experiment. Temperature of the source body was controlled by heating the source body in contact with the liquid nitrogen. By adjusting the current through heating wires the temperature of the source body was easily controlled in the range of $+100^{\circ} \mathrm{C} \sim-150^{\circ} \mathrm{C}$ within $\pm 3^{\circ} \mathrm{C}$ fluctuation. Unlike other conventional ion sources, the corona discharge ion source produces relatively cold ions, especially with the operating conditions of a low discharge current, a high pressure in the discharge region, and a low temperature in the source body.

The ions produced in the corona discharge undergo a large number of collisions with the carrier gas before they find their way out of the source. Typically, an ion undergoes about $10^{5}$ collisions during the time it takes it to make its way out of the ionization region and through the $0.5 \mathrm{~cm}$ drift region to the $75 \mu \mathrm{m}$ nozzle. The vibrationally hot ions initially formed are expected to be reasonably cooled during this process by collision to the low temperature source body. Subsequently, the ions are 
supersonically expanded through the $75 \mu \mathrm{m}$ nozzle. As a result, the ions became rotationally and vibrationally cold. Typical rotational and vibrational temperatures were equal to or less than $50^{\circ} \mathrm{K}$ and $300^{\circ} \mathrm{K}$, respectively under normal operating conditions. Clustering of neutral solvent molecules around the ionized species also takes place in this region.

The carbonium ion $\mathrm{CH}_{5}^{+}$and its complexes $\mathrm{CH}_{5}^{+}(\mathrm{X})_{1}(\mathrm{Y})_{\mathrm{m}}(\mathrm{Z})_{\mathrm{n}}(\mathrm{X}, \mathrm{Y}, \mathrm{Z}=$ solvent molecules; $1, \mathrm{~m}, \mathrm{n}=0,1,2, .$.$) studied in this work were generated in a corona discharge of$ methane and hydrogen gas mixtures. Mass spectra of the discharge products strongly depend upon the ratio of methane and hydrogen gases used in the discharge. For example, the optimum ratio for $\mathrm{CH}_{5}^{+}\left(\mathrm{H}_{2}\right)_{n}(\mathrm{n}=1-6)$ was $1: 3,000,000$ whereas the optimum ratio for $\mathrm{CH}_{5}{ }^{+}\left(\mathrm{CH}_{4}\right)_{m}(\mathrm{~m}=1-5)$ was 1:2,000-1:10,000. Besides the $\mathrm{CH}_{4} / \mathrm{H}_{2}$ ratio, there are other experimental conditions which are crucial for generating the ion clusters, such as the source body temperature, the gas pressure, the discharge current, and the nozzle-toskimmer potential difference. The details of the experimental conditions will be discussed in the following chapters.

For a discharge of very dilute $\mathrm{CH}_{4}$ in $\mathrm{H}_{2}$, the following reactions are expected to occur inside the ion source and during supersonic expansion:

Main Reactions:
(1) $\mathrm{H}_{2}+\mathrm{e}=\mathrm{H}_{2}^{+}+2 \mathrm{e}$
ionization
$\mathrm{H}_{2}^{+}+\mathrm{H}_{2}=\mathrm{H}_{3}^{+}+\mathrm{H}$
proton transfer
(3) $\mathrm{H}_{3}^{+}+\mathrm{CH}_{4}=\mathrm{CH}_{5}^{+}+\mathrm{H}_{2}$
proton transfer 

(4a) $\mathrm{CH}_{5}^{+}+\mathrm{H}_{2}+\mathrm{M}=\mathrm{CH}_{5}^{+}\left(\mathrm{H}_{2}\right)+\mathrm{M}$
clustering
(4b) $\mathrm{CH}_{5}^{+}\left(\mathrm{H}_{2}\right)_{\mathrm{n}-1}+\mathrm{H}_{2}+\mathrm{M}=\mathrm{CH}_{5}^{+}\left(\mathrm{H}_{2}\right)_{\mathrm{n}}+\mathrm{M}$
(5a) $\mathrm{CH}_{5}^{+}+\mathrm{CH}_{4}+\mathrm{M}=\mathrm{CH}_{5}^{+}\left(\mathrm{CH}_{4}\right)+\mathrm{M}$
(5b)

$$
\mathrm{CH}_{5}^{+}\left(\mathrm{CH}_{4}\right)_{\mathrm{m}-1}+\mathrm{CH}_{4}+\mathrm{M}=\mathrm{CH}_{5}{ }^{+}\left(\mathrm{CH}_{4}\right)_{\mathrm{m}}+\mathrm{M}
$$

Minor Reactions:

(7) $\mathrm{H}^{+}+\mathrm{CH}_{4}=\mathrm{CH}_{3}^{+}+\mathrm{H}+\mathrm{H}_{2}$

(8) $\quad \mathrm{CH}_{4}+\mathrm{e}=\mathrm{CH}_{3}^{+}+\mathrm{H}+2 \mathrm{e}$

(9) $\mathrm{H}_{2}^{+}+\mathrm{CH}_{4}=\mathrm{CH}_{3}^{+}+\mathrm{H}+\mathrm{H}_{2}$

(10) $\mathrm{CH}_{3}^{+}+\mathrm{CH}_{4}=\mathrm{C}_{2} \mathrm{H}_{5}^{+}+\mathrm{H}_{2}$ ionization

dissociative proton transfer

ionization

dissociative proton transfer

clustering

clustering

$\mathrm{C}_{2} \mathrm{H}_{5}^{+}+\mathrm{CH}_{4}+\mathrm{M}=\mathrm{C}_{3} \mathrm{H}_{9}^{+}(\mathrm{II})+\mathrm{M}$

etc.

As seen in the above, the major reactions of a discharge of very dilute methane in hydrogen gas result in the formation of the solvated $\mathrm{CH}_{5}{ }^{+}$ion clusters. However, the formation of $\mathrm{CH}_{3}{ }^{+}$(Reaction 7,8,9) as a side reaction initiates the formation of larger hydrocarbon ions. When the concentration of methane was increased, the formation of 
larger hydrocarbon ions was dramatically increased due to the increased minor reaction channels via $\mathrm{CH}_{3}{ }^{+}$. When the concentration of methane was too low, the absolute number of carbonium ions was decreased, and the carbonium ions were likely to be internally hot since the vibrational cooling via energy transfer from $\mathrm{CH}_{5}^{+}$species to cold $\mathrm{CH}_{4}$ is not efficient. Therefore, it is important to keep the concentration of methane low enough to minimize the formation of larger hydrocarbon ions via $\mathrm{CH}_{3}{ }^{+}$, but high enough for high number density and efficient vibrational cooling.

After supersonic expansion, only the central part of beams were skimmed by 1 $\mathrm{mm}$ diameter skimmer. In order not to excite the ions by the acceleration of ions in the high pressure region, the potential difference between the nozzle and the skimmer was always kept less than $1.0 \mathrm{~V}$ during experiment. After the skimmer, the ion beam enters a second differential pumping region containing extracting, collimating and focusing ion optics. The pressure in this region was typically an order of magnitude lower than that of the source region.

\subsection{The 1st Mass Selection and Ion Trapping}

The ion beam was then accelerated and focused into a third differential pumping region, maintained at $2 \times 10^{-8}$ torr. The cluster distribution of the ion beam was mass analyzed with a $60^{\circ}$ magnet sector. The magnet sector was chosen as a mass separator in part for its excellent beam quality, and also for its adequate resolution and high transmission. In order to enhance the resolution of the magnet sector, two quadrupole lens pairs were employed before and after the magnet sector. The entrance quadrupole 
lens pairs shaped the ion beam into one which was parallel in the z-direction of the magnetic field and was converging in the other, thus focusing the ions onto a line at the middle of the sector magnet. This shaping enhanced not only the resolution of the sector magnet, but also reduced the losses in the magnet sector since no $z$-direction focusing was required. Typical mass resolution of the magnet sector for $350 \mathrm{eV}$ ion energy was $\mathrm{M} / \Delta \mathrm{M}$ $=250$. The exit quadrupole lens pair transform the ion beam back to a collimated beam. Following the mass selection, ions of desired mass were deflected $90^{\circ}$ by a dc quadrupole bending field, then decelerated to $0.5 \mathrm{eV}$ and focused into the octapole ion trap. The octapole trap consists of eight molybdenum rods $(0.32 \mathrm{~cm}$ diameter, $50 \mathrm{~cm}$ long), equally spaced on a $1.25 \mathrm{~cm}$ diameter circle, and two lenses at the entrance and the exit. The octapole rods carry about $350 \mathrm{~V}$ DC, with applied radio frequency of typically $14 \mathrm{MHz}$ and $200 \mathrm{Vpp}$. Alternate rods of the octapole are at opposite phases. The leads are connected to a coil, and the octapole acts as the capacitor in the resulting resonant LC circuit. For an ideal radio frequency electric multipole field with $2 \mathrm{n}$ poles, ${ }^{\prime}$ the effective potential is given by

$$
U_{e n r}(r)=n^{2} K\left(r / r_{0}\right)^{2 n-2}
$$

where

$$
K=q^{2} V_{0}^{2} /\left(4 m \omega^{2} r_{o}^{2}\right)
$$

for a particle of charge $q$ and mass $m$ inside a multipole of radius $r_{o}$. The voltage of the rf is $V_{o}$, the frequency $\omega$. For an octapole field used in this work, the effective potential varies as $\left(\mathrm{r} / \mathrm{r}_{0}\right)^{6}$ while for a quadrupole field, it varies as $\left(\mathrm{r} / \mathrm{r}_{0}\right)^{2}$. The octapole trapping well is four times deeper than the quadrupole well at the same frequency, voltage, and 
mass. The octapole potential is flatter in the center and has steeper walls than the quadrupole effective potential. The depth of the trap also depends inversely on the mass; therefore, the fragment ions created by photodissociation will be trapped in a deeper potential well than the heavier parent ions.

Two lenses at the entrance and the exit of the octapole trap were used for confining the ions inside the trap by applying about $8 \mathrm{~V}$ above the dc bias of the rods $(-350 \mathrm{~V})$. When the ions were trapped, the average energy of the ions was about 0.65 $\mathrm{eV}$. For most of the experiment, the trapping times were about $2 \mathrm{msec}$ after the potential of the entrance lens was raised. Typical pressures in the octapole region were kept less than $1 \times 10^{-8}$ torr so that the ions did not undergo a single collision during trapping.

\subsection{The 2nd Mass Selection and Ion Detector}

After the ions left the octapole trap, the ions were focused into the a quadrupole mass spectrometer (Extranuclear Laboratories). The quadrupole mass filter was used to separate the daughter ions produced from photodissociation of the parent ions. The massselected daughter ions were detected using a Daly ion detector. ${ }^{5}$ The Daly ion detector has a high gain and stability and also is unaffected by reactive gases. The ion counting efficiency is $90-95 \%$ of an ion, almost independent of the ion mass. ${ }^{6}$ The number of the daughter ions monitored as a function of infrared laser wavelength is proportional to the product of the absorption cross section of the parent ions and the dissociation probability after absorption at the laser wavelength. The dissociation probability depends on the coupling between the vibrationally excited modes and the dissociation coordinates such 
as the stretching of van der Waals bonds. Since the ions were trapped for about $1 \mathrm{msec}$ after laser pulse, which is long enough for the photon energy to be redistributed among the low frequency modes, the dissociation probability would be constant, regardless of the vibrational modes excited. Therefore, the number of the daughter ions detected as a function of laser wavelength is a measure of the absorption cross section of the parent ions.

\subsection{Infrared Light Source}

A Quanta-Ray Infrared Wavelength Extender (IR WEX) was used as a tunable infrared light source. The infrared wavelength was generated in a $\mathrm{LiNbO}_{3}$ crystal that takes the difference frequency between a Lambda Physics pulsed dye laser (Model FL3002E) and the $1.06 \mu \mathrm{m}$ fundamental of a Continuum Nd:YAG laser. The IR resolution was $0.2 \mathrm{~cm}^{-1}$ and $0.04 \mathrm{~cm}^{-1}$ without and with an intracavity etalon, respectively. The pulse duration was about $6 \mathrm{nsec}$ with a $20 \mathrm{~Hz}$ repetition rate, and the laser power was $0.5-3.5 \mathrm{~mJ} / \mathrm{pulse}$ in the $2500-6500 \mathrm{~cm}^{-1}$ region. For the strongly bound species, two high power $\mathrm{CO}_{2}$ lasers were used to pump the vibrationally excited molecules over the dissociation threshold. The first was a $\mathrm{cw} \mathrm{CO}_{2}$ laser (MPB technologies, $6 \mathrm{~W}$ ) and the second was a pulsed TEA $\mathrm{CO}_{2}$ laser (Lumonics, $1 \mathrm{~J} /$ pulse). 


\section{REFERENCES}

1. S.W. Bustamente, Ph.D. Thesis, University of California, Berkeley, 1983.

2. M. Okumura, Ph.D. Thesis, University of California, Berkeley, 1986.

3. L.I-C., Yeh, Ph.D. Thesis, University of California, Berkeley, 1988.

4. J.M. Price, Ph.D. Thesis, University of California, Berkeley,1990.

5. N.R. Daly, Rev. Sci. Instrum. v.31, 264(1960).

6. Y.T.Lee, J.D.McDonald, P.R. LeBreton, and D.R. Herschbach, Rev. Sci. Instrum. v.40, 1402(1969). 


\section{FIGURE CAPTIONS}

Fig. 1 Schematic diagram of the experimental apparatus, i.e. the ion trap spectrometer. It shows most of the ion optics used as well as the major components of the spectrometer such as the ion source, the magnetic sector, the octapole ion trap, the quadrupole mass filter, and the detector.

Fig. 2 Schematic diagram of the corona discharge ion source. It shows the discharge elements, the cooling elements, and the nozzle for supersonic expansion. 


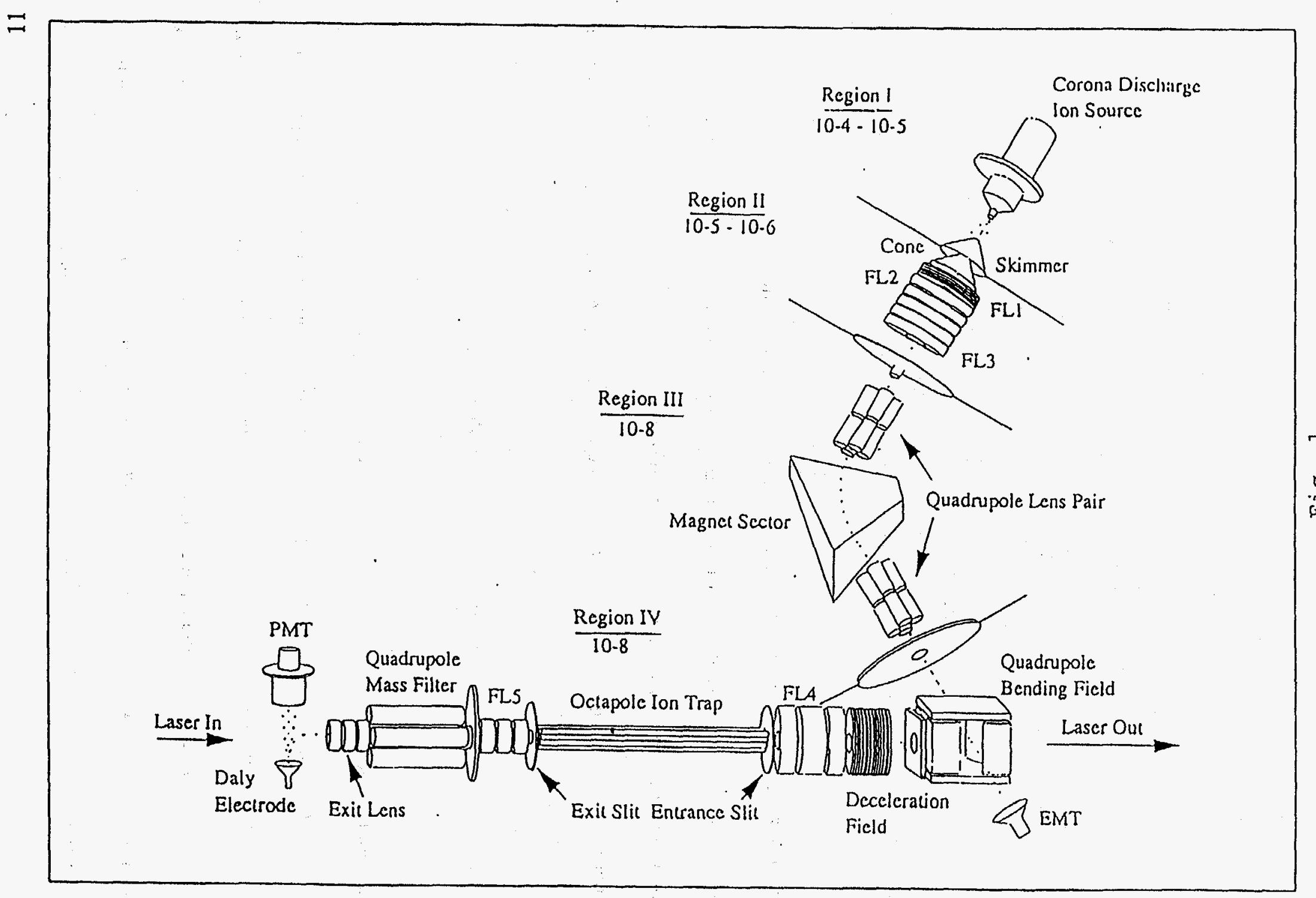




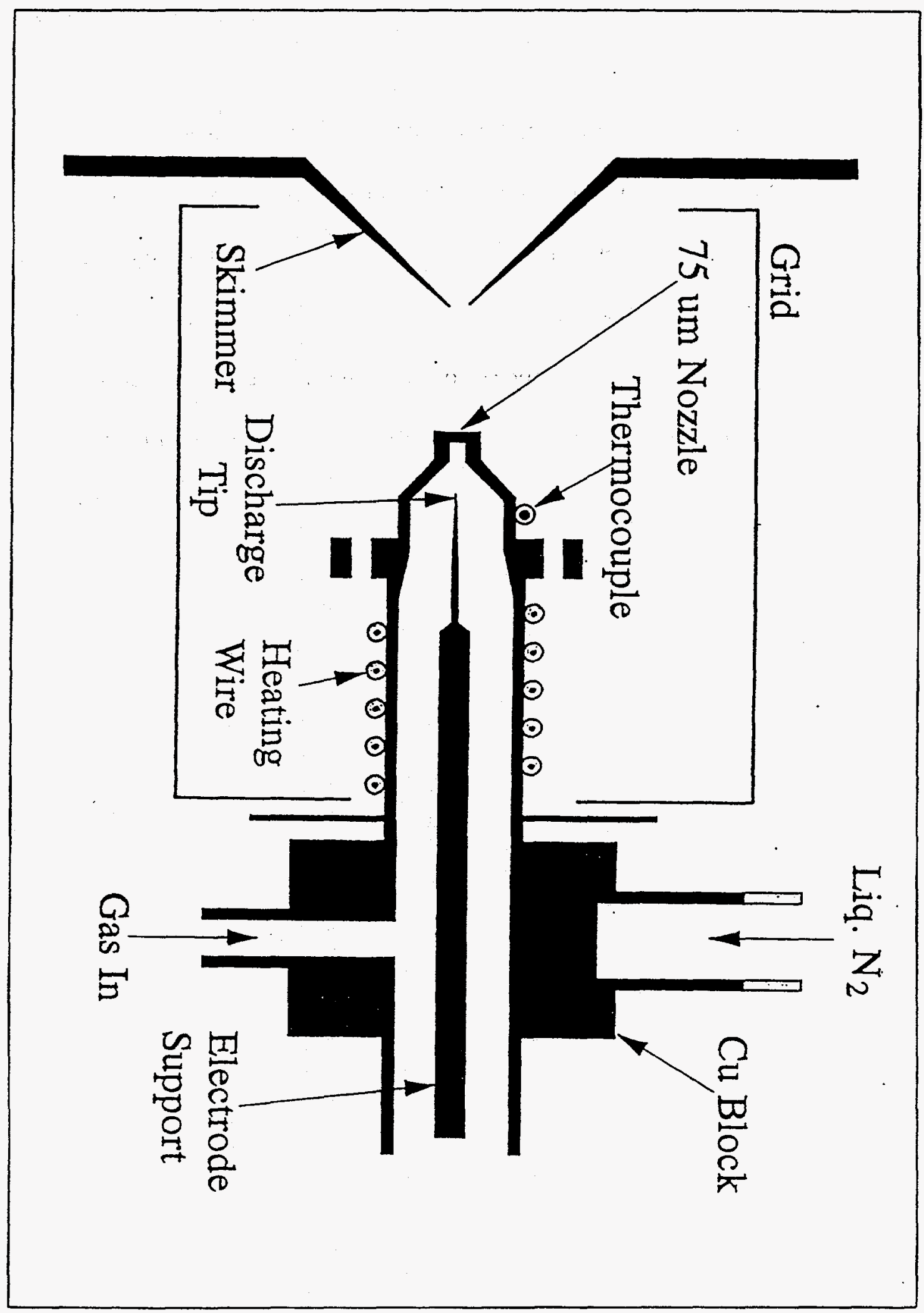

Fig. 2 


\section{CHAPTER II}

\section{The Carbonium Ion, $\mathrm{CH}_{5}^{+}$}

\section{INTRODUCTION}

In this chapter, I describe the previous works and our infrared (IR) spectroscopic and theoretical studies on the carbonium ion, $\mathrm{CH}_{5}^{+}$. The carbonium ion $\mathrm{CH}_{5}^{+}$was discovered in the gas phase during the mass spectrometric studies by Tal'roze and Lyubimova in 1952.' Olah and coworkers proposed the existence of $\mathrm{CH}_{s}{ }^{+}$in the solution phase as an intermediate of the reaction of methane with super acids such as $\mathrm{FSO}_{3} \mathrm{H}$ $\mathrm{SbF}_{5 .}{ }^{2}$ Since then, $\mathrm{CH}_{5}{ }^{+}$and other protonated alkanes have been known to play important roles as intermediates in acid-catalyzed electrophilic substitution reactions. ${ }^{3}$ As an analytical species it is now used as a source in chemical ionization mass spectrometry. ${ }^{4}$ This species is also of considerable astrophysical interest in that it may serve as an intermediate for the formation of methane and formaldehyde in the cold galactic molecular clouds. ${ }^{5}$

Since 1970 , a considerable number of theoretical works have been carried out in order to elucidate the structure and thermodynamic properties of $\mathrm{CH}_{5}{ }^{+6-9}$ The theoretical calculations suggested that the eclipsed $\mathrm{C}_{\mathrm{s}}\left(\mathrm{e}-\mathrm{C}_{\mathrm{s}}\right)$ symmetry structure (denoted as $\mathrm{C}_{\mathrm{s}}(\mathrm{I})$ in Fig. 1), which can be regarded as a complex between $\mathrm{CH}_{3}^{+}$and $\mathrm{H}_{2}$, was the global minimum energy structure. In this structure, the carbon atom is hypercoordinate in that it is bonded directly to five hydrogen atoms but uses only four valence shell atomic 
orbitals. Its carbon atom can be regarded as $\mathrm{sp}^{3}$ hybridized, using three hybrid orbitals to form normal two-center two-electron $\mathrm{C}-\mathrm{H}$ bonds and the fourth hybrid orbital to form a three-center two-electron $(3 \mathrm{c} 2 \mathrm{e}) \mathrm{C}-\mathrm{H}$ bond to the remaining two hydrogen atoms. ${ }^{10}$ However, due to the flatness of the potential surface around the minimum energy structure, the energy differences between the $\mathrm{e}-\mathrm{C}_{\mathrm{s}}$ structure and other low lying structures such as the staggered $\mathrm{C}_{s}\left(s-\mathrm{C}_{s}\right)$ (denoted as $\mathrm{C}_{s}(\mathrm{II})$ in Fig. 1) and $\mathrm{C}_{2 v}$ structures were difficult to predict accurately. Recently, Schaefer, Schleyer, and coworkers performed a high level ab initio calculation using large basis set (TZ2P $+\mathrm{f} C \mathrm{CSD})$, and found that the energy differences of the e- $C_{s}, s-C_{s}$ and $C_{2 v}$ structures were almost negligible when the zero point energies were corrected. ${ }^{11,12}$ Since the $s-C_{s}$ and $C_{2 v}$ structures are regarded as the transition states of the scrambling of the five hydrogen atoms in $\mathrm{CH}_{5}{ }^{+}$, this result suggested that $\mathrm{CH}_{5}{ }^{+}$scrambles considerably even near the zero point energy level, without possessing a stable geometry. Based on these results, Scuseria emphasized later that $\mathrm{CH}_{5}{ }^{+}$ is a unique molecule which does not have a definite equilibrium geometry. ${ }^{13}$ Some of the ab initio results for the relative energies of the $\mathrm{CH}_{5}{ }^{+}$structures are collected in Table 1.9 .11 .12

In contrast to the numerous theoretical works on $\mathrm{CH}_{5}^{+}$, only a few experiments on the $\mathrm{CH}_{5}{ }^{+}$structure have been performed previously by three groups, namely Sefcik et al., ${ }^{14}$ Futrell et al., ${ }^{15}$ and Heck et al. ${ }^{16}$ using Fourier Transform Ion Cyclotron Resonance (FTICR) mass spectrometry. In these works, the product ion branching ratio $\left[\mathrm{BH}^{+}\right] /\left[\mathrm{BD}^{+}\right]$associated with the proton/deuteron transfer reaction of $\mathrm{CH}_{4} \mathrm{D}^{+}$and $\mathrm{CD}_{4} \mathrm{H}^{+}$ to the base $B$ was measured as a function of the average number $(<n>)$ of primary 
ion/molecule collisions $\left(\mathrm{CH}_{4}{ }^{+} / \mathrm{CD}_{4}\right.$ and $\left.\mathrm{CD}_{4}{ }^{+} / \mathrm{CH}_{4}\right)$. The idea of these studies was that if significant potential barriers exist for the scrambling motions of $\mathrm{CH}_{5}^{+}$, the D atom in $\mathrm{CH}_{4} \mathrm{D}^{+}$and the $\mathrm{H}$ atom in $\mathrm{CD}_{4} \mathrm{H}^{+}$would be located at one of the two $\mathrm{H}$ atoms forming the $3 \mathrm{c} 2 \mathrm{e}$ bond in the $\mathrm{C}_{\mathrm{s}}$ structure, and the branching ratio will be $1: 1$ for both $\mathrm{CH}_{4} \mathrm{D}^{+}$and $\mathrm{CD}_{4} \mathrm{H}^{+}\left(\mathrm{C}_{\mathrm{s}}\right.$ model). On the other hand, if small or no barriers exist for the scrambling motions, the branching ratio will be $4: 1$ and $1: 4$ for $\mathrm{CH}_{4} \mathrm{D}^{+}$and $\mathrm{CD}_{4} \mathrm{H}^{+}$cases, respectively (randomized model). However, the results, as shown in Table 2, were.inconsistent in that Sefcik's ${ }^{14}$ and Heck's results ${ }^{16}$ supported the $C_{s}$ model whereas Futrell's results ${ }^{15}$ favored the randomized model. One of the reasons for the inconsistency is due in part to the uncertainties in the internal energies of $\mathrm{CH}_{4} \mathrm{D}^{+}$and $\mathrm{CD}_{4} \mathrm{H}^{+}$produced in these experiments. The internal energies of $\mathrm{CH}_{4} \mathrm{D}^{+}$and $\mathrm{CD}_{4} \mathrm{H}^{+}$even at the $\angle \mathrm{n}>=0$ limit could be significant since the primary ions $\left(\mathrm{CH}_{4}^{+}\right.$and $\left.\mathrm{CD}_{4}{ }^{+}\right)$, produced by the electron impact source without supersonic expansion, were expected to be internally hot, and the primary proton and deuteron transfer reactions were exothermic, resulting in the substantial internal energies of $\mathrm{CH}_{4} \mathrm{D}^{+}$and $\mathrm{CD}_{4} \mathrm{H}^{+}$. As predicted by the ab initio calculations, ${ }^{11,12}$ these internal energies could induce an extensive scrambling of $\mathrm{CH}_{s}{ }^{+}$. Therefore, their results could be affected by the conditions of the ions produced in the experiments. In addition, the isotope effects on the structures of $\mathrm{CH}_{5}{ }^{+}$should be considered.

Because of the difficulties in the indirect characterization of the structure of $\mathrm{CH}_{5}{ }^{+}$, we employed ion trap IR spectroscopy to get information directly on the structure and dynamics of $\mathrm{CH}_{5}{ }^{+}$, with the use of supersonic expansion in an effort to produce the internally cold $\mathrm{CH}_{5}{ }^{+}$ions. In addition, with the collaboration with Dr. Zhi-Fung Liu and 
Dr. John Tse, we performed ab initio molecular dynamics (MD) calculations on $\mathrm{CH}_{s}{ }^{+}$. The ab initio MD method allowed us to directly see the scrambling motions of $\mathrm{CH}_{s}{ }^{+}$at finite temperatures on the Born-Oppenheimer ground electronic potential energy surface, improving the limitation of the conventional quantum chemistry calculations which essentially treat a molecular or ionic system as a static entity. 


\section{AB INITIO MOLECULAR DYNAMICS (MD) CALCULATIONS ${ }^{17-20}$}

Molecular dynamics (MD) simulations have been widely used in many different fields, which range from physical chemistry to solid-state physics, to study the microscopic behavior of temperature- and time-dependent phenomena. ${ }^{21}$ A great deal of work has been carried out using semiempirical or empirical potentials between atoms, determined from particular bonding situations. The main drawback of these potentials is that they can fail to give an appropriate description when the chemical environments are changed. Therefore, it is desirable to have a MD scheme in which the variations of the electronic structure are accounted for during the simulation.

In 1985, Car and Parrinello proposed a method to perform classical molecular dynamics in which the electronic structure is described quantum mechanically in the framework of density functional theory. ${ }^{17}$. The only assumptions in this method are the validity of classical mechanics to describe ionic motion and the Born-Oppenheimer (BO) approximation to separate nuclear and electronic coordinates. In density functional theory, the Born-Oppenheimer electronic potential surface is defined by the minimum with respect to the wavefunction $\psi_{i}$ of the Kohn-Sham (KS) energy functional,

$$
E\left[\left\{\psi_{i}\right\},\left\{R_{I}\right\}\right]=\sum_{i} \int_{\Omega} d^{3} r \psi_{i}^{*}(r)\left[-\left(h^{2} / 2 m\right) \nabla^{2}\right] \psi_{i}(\mathbf{r})+U\left[n(r) ;\left\{R_{1}\right\}\right]
$$

where $\left\{R_{\mathrm{l}}\right\}$ indicate the nuclear coordinates and the electron density $n(\mathbf{r})=\sum_{\mathrm{i}}\left|\psi_{\mathrm{i}}(\mathbf{r})\right|^{2}$. The functional $U$ contains the internuclear Coulomb repulsion and the effective electronic potential energy, including external nuclear, Hartree, and exchange and correlation 
contributions. In the Car-Parrinello (CP) method, the minimization of the KS energy functional is performed by using a simulated annealing strategy based on MD, which may be called "dynamical simulated annealing", with the coefficients of the expansion of the $\mathrm{KS}$ orbitals in plane wave basis set and the ionic coordinates as the variational parameters. The parameters $\left\{\psi_{\mathrm{i}}\right\},\left\{\mathrm{R}_{\mathrm{l}}\right\}$ in the energy functional are considered to be timedependent, and the Lagrangean can be written by the following equation:

$$
L=\sum_{i}^{1} / 2 \mu \int_{\Omega} d^{3} r\left|\dot{\psi}_{i}\right|^{2}+\sum_{1}^{1} 1 / 2 M_{1} \dot{R}_{1}^{2}-E\left[\left\{\Psi_{i}\right\},\left\{R_{1}\right\}\right]
$$

where the $\psi_{i}$ are subject to the holonomic constraints $\int_{\Omega} d^{3} r \psi_{i}^{*}(r, t) \psi_{j}(r, t)=\delta_{i j}$. Here, the dot indicates time derivative, $M_{1}$ are the physical ionic masses, and $\mu$ is an arbitrary parameter for the fictitious electronic kinetic energy. The Lagrangian generates a set of equations of motion for the parameters $\left\{\psi_{i}\right\},\left\{R_{1}\right\}$ as the follows:

$$
\begin{aligned}
& \mu \ddot{\Psi}_{i}(\mathbf{r}, \mathbf{t})=-\delta E / \delta \psi_{i}^{*}(\mathbf{r}, t)+\sum_{k} \Lambda_{i k} \psi_{k}(r, t) \\
& M_{1} \ddot{R}_{t}=-\nabla_{R} E
\end{aligned}
$$

where $\Lambda_{\mathrm{ik}}$ are Lagrange multipliers introduced in order to satisfy the orthonormal constraints of $\left\{\psi_{i}\right\}$. The Lagrangean also defines a potential energy $E$ and a classical kinetic energy $\mathrm{K}$ given by 


$$
K=\sum_{i}^{1} 1 / 2 \mu \int_{\Omega} d^{3} r\left|\dot{\psi}_{i}\right|^{2}+\sum_{l}^{1} 1 / 2 M_{l} \dot{R}_{l}^{2}
$$

The equilibrium value $\langle\mathrm{K}\rangle$ of the classical kinetic energy can be calculated as the temporal average over the trajectories generated by the equations of motion and related to the temperature of the system by suitable normalization. By the variation of the velocities of the parameters, the temperature of the system can be slowly reduced and for $T \rightarrow 0$ the equilibrium state of minimal $E$ is reached. At the equilibrium $\ddot{\psi}=0$, the electronic structure describes the Born-Oppenheimer surface. Finally, the finite temperature $\mathrm{MD}$ simulations on the ground state $\mathrm{BO}$ surface can be accomplished by allowing the ions move at a given temperature under the action of Hellman-Feynman forces (or BO forces) while the kinetic energy of the electronic variational parameters remains equal to zero.

Fig. 2 shows the snap shots of the $\mathrm{CH}_{s}{ }^{+}$structures during the simulation at $150^{\circ} \mathrm{K}$. The $150^{\circ} \mathrm{K}$ corresponds to the average vibrational energy of $\sim 0.15 \mathrm{kcal} / \mathrm{mole}$. The evolution of the $\mathrm{H}-\mathrm{H}$ distances during 40,000 time steps ( $\sim 3 \mathrm{psec})$ of simulation is plotted in Fig. 3. Initially, the $\mathrm{H} 1, \mathrm{H} 4$, and $\mathrm{H} 5$ atoms formed three strong $\mathrm{C}-\mathrm{H}$ bonds while the $\mathrm{H} 2$ and $\mathrm{H} 3$ formed a $3 \mathrm{c} 2 \mathrm{e}$ bond, so the $\mathrm{H} 2-\mathrm{H} 3$ distance was smaller than other $\mathrm{H}-\mathrm{H}$ distances. During the simulation, all of the $\mathrm{H}-\mathrm{H}$ distances fluctuated between 1.0-2.2 $\AA$, and the $3 \mathrm{c} 2 \mathrm{e}$ bond could be formed among any pair of $\mathrm{H}$ atoms. This suggests that $\mathrm{CH}_{s}{ }^{+}$ scrambles considerably at this temperature, without possessing a stable geometry, consistent with the $a b$ initio calculations. Furthermore, it will be shown in Chapter III that this method can be applied to simulate the slow down of the scrambling of $\mathrm{CH}_{5}{ }^{+}$by 
attaching the solvent molecules to the core $\mathrm{CH}_{5}{ }^{+}$. 


\section{INFRARED SPECTROSCOPY OF $\mathrm{CH}_{5}^{+}$}

The experimental apparatus has been described in detail in Chapter I. The $\mathrm{CH}_{5}^{+}$ ions were generated in a high pressure corona discharge source with the gas mixture of $\mathrm{CH}_{4}: \mathrm{H}_{2}=1: 2,000$. Fig. 4 shows the mass spectrum containing the $\mathrm{CH}_{5}{ }^{+}$ions, obtained with $20 \mu \mathrm{A}$ discharge current, 150 torr source pressure, and $-40^{\circ} \mathrm{C}$ source temperature. The absolute number of the $\mathrm{CH}_{5}{ }^{+}$ions generated in this experiment was around $10^{7}$ counts per sec.

The dissociation reaction of $\mathrm{CH}_{5}{ }^{+}$to $\mathrm{CH}_{3}{ }^{+}+\mathrm{H}_{2}$ is the only low energy dissociation channel for $\mathrm{CH}_{5}^{+}$, but it still requires $40-45 \mathrm{kcal} / \mathrm{mole}\left(14,000-15,750 \mathrm{~cm}^{-1}\right)$, according to the experimental ${ }^{22}$ and theoretical data on $\mathrm{CH}_{5}{ }^{+}{ }^{11}$ Because of the large binding energy, the absorption of single photon $\left(-3,000 \mathrm{~cm}^{-1}\right.$ for $\mathrm{C}-\mathrm{H}$ stretching modes $)$ from the tunable IR laser was not enough to cause the vibrational predissociation. In our previous work on strongly bound clusters such as $\mathrm{H}_{3} \mathrm{O}^{+}\left(\mathrm{H}_{2} \mathrm{O}\right)$ (dissociation energy $=31.6 \mathrm{kcal} / \mathrm{mole}$ ) and $\mathrm{NH}_{4}^{+}\left(\mathrm{NH}_{3}\right)$ (dissociation energy $=27 \mathrm{kcal} / \mathrm{mole}$ ), a line tunable $\mathrm{cw} \mathrm{CO}$ laser was used to drive the clusters excited by the tunable IR laser over the dissociation limit through the absorption of multiple $\mathrm{CO}_{2}$ laser photons. In this case, the multiple photon process should not modify the absorption spectrum by the tunable IR laser. This requires that the energy of one tunable IR photon should be higher than the threshold of quasi-continuum states defined by the energy level where the density of states of the system is equal to the inverse of the laser resolution.

As the first trial, I employed the same technique by incorporating the $\mathrm{cw} \mathrm{CO}$ laser (8W@10P(20)) along with the tunable IR laser, as schematically shown in Fig. 5. The 
tunable IR laser was tuned to the frequency for the maximum of the $\mathrm{C}-\mathrm{H}$ stretching feature of $\mathrm{CH}_{5}{ }^{+}$core in $\mathrm{CH}_{5}{ }^{+}\left(\mathrm{H}_{2}\right)$ which was observed previously, and the individual lines of the $\mathrm{CO}_{2}$ laser were used one by one to drive the $\mathrm{CH}_{5}{ }^{+}$ions vibrationally excited by the tunable IR laser over the dissociation limit. However, the $\mathrm{CH}_{3}{ }^{+}$signal correlated with the tunable IR laser was not observed for any line of the $\mathrm{CO}_{2}$ laser, and the use of slightly different frequencies for the tunable IR laser could not improve the results. At this point, it was concluded that the 11-13 photon absorption process from the $8 \mathrm{~W} \mathrm{cw} \mathrm{CO}_{2}$ laser, required to drive the $\mathrm{CH}_{5}^{+}$ions over the dissociation limit, was unfavorable.

As the second trial, I employed a high power line tunable pulsed TEA $\mathrm{CO}_{2}$ laser (Lumonics Inc., 1-3 J/pulse, $\sim 1 \mu \mathrm{sec}$ bandwidth) along with the tunable IR laser, in order to improve the multiple $\mathrm{CO}_{2}$ laser photon process. The $\mathrm{CO}_{2}$ laser has about $3 \times 3 \mathrm{~cm}^{2}$ beam shape just after the output coupler, and it was focused down to $0.01 \mathrm{~cm}^{2}$ at the center of the interaction region. At the focal point, the intensity of the $\mathrm{CO}_{2}$ laser was calculated to be about $200 \mathrm{MW} / \mathrm{cm}^{2}$. The same scheme of the frequencies as the first trial was used for the tunable IR laser and the $\mathrm{CO}_{2}$ laser, but it was also unsuccessful. In spite of the large number density of the $\mathrm{CH}_{5}{ }^{+}$ions, five times more than the number densities used in the previous study on $\mathrm{H}_{3} \mathrm{O}^{+}\left(\mathrm{H}_{2} \mathrm{O}\right)$ and $\mathrm{NH}_{4}{ }^{+}\left(\mathrm{NH}_{3}\right)$, the unsuccessful results suggested that significant bottleneck effect could exist in the $\mathrm{CO}_{2}$ multiphoton processes of the $\mathrm{CH}_{5}^{+}$ ions. Such bottleneck effect has been observed previously in small molecules due to the small density of states, resulting from lack of low frequency modes, and $\mathrm{CH}_{5}{ }^{+}$could also belong to this category. The density of states for polyatomic molecules can be calculated as a function of energy by a number of approximations. Perhaps the most often used is 
the Witten-Rabinovich (WR) approximation for $\rho(E){ }^{23}$ The WR approximation has the following form,

$$
\rho(E)=\left\{\left[E+E_{0}(1-\beta W(n))\right]^{(s-1)} /\left[(s-1) ! \Pi_{i=0}^{s} \omega_{i}\right]\right\} x[1-\beta W(n)] .
$$

Here, $s$ is the number of vibrational degrees of freedom, and the vibrational energy $E$ is measured relative to the zero point energy, i.e. $E_{0}=1 / 2 \sum_{i=1}^{s} \omega_{i}$. The parameter $\beta$ is expressed by $\beta=\llbracket(s-1) / s \rrbracket \times \llbracket\left\langle\omega^{2}>\right|\langle\omega\rangle^{2} \rrbracket . W(n)$ is a numerical parameter which depends on the degree of excitation above the zero point level. It is a function of the variable $\eta=E / E_{0}$ and may assume the values:

$$
\begin{gathered}
\left(5 \eta+2.73 \eta^{1 / 2}+3.5\right)^{-1}, \quad 0<\eta<1 \\
\operatorname{Exp}\left(-2.42 \eta^{1 / 4}\right), \quad 1<\eta<8 \\
0, \eta>8
\end{gathered}
$$

The density of states $\rho(E)$ for $\mathrm{CH}_{5}{ }^{+}$using the vibrational frequencies calculated at $\mathrm{TZ2P}+\mathrm{f}$ CCSD level are shown in Table $3 .{ }^{12}$ For comparison, the density of states for $\mathrm{H}_{3} \mathrm{O}^{+}\left(\mathrm{H}_{2} \mathrm{O}\right)$ and $\mathrm{NH}_{4}{ }^{+}\left(\mathrm{NH}_{3}\right)$ are also listed as a note in Table $3 .^{24}$ The density of states of $\mathrm{CH}_{5}{ }^{+}$were calculated in two limiting cases: (i) case of the torsional vibration (a high barrier limit), and (ii) case of free internal rotation (a low barrier limit). According to the ab initio calculations, the energy difference between the e- $C_{s}$ structure and the $s-C_{s}$ structure, the transition state along the internal rotation path, was negligible when the zero point 
energies were corrected. This suggested that the lowest frequency mode is no longer a vibration, but is likely to be a free internal rotation. In the case (ii), the torsional frequency was not included in the calculation of the density of vibrational states. Rigorously, the density of the vibration-rotation states should be considered in the case (ii) (a free internal rotation), but they are not calculated in this work. As seen in Table 3., the $\rho(E)$ 's of $\mathrm{CH}_{5}^{+}$for the two cases at $3000 \mathrm{~cm}^{-1}$, which corresponds to the fundamental transitions of the $\mathrm{C}-\mathrm{H}$ stretching modes, were only 0.147 and $2.18 \times 10^{-2}$, respectively. Since the resolution of the tunable IR laser and the $\mathrm{CO}_{2}$ laser used in this work was $0.2 \mathrm{~cm}^{-1}$ and $-0.03 \mathrm{~cm}^{-1}$, respectively, the $\rho(E)$ 's of $\mathrm{CH}_{5}^{+}$at $3000 \mathrm{~cm}^{-1}$ were well below the quasi-continuum threshold for both cases. In contrast, the density of states for $\mathrm{H}_{3} \mathrm{O}^{+}\left(\mathrm{H}_{2} \mathrm{O}\right)$ and $\mathrm{NH}_{4}^{+}\left(\mathrm{NH}_{3}\right)$ at $3500 \mathrm{~cm}^{-1}$, which corresponds to excitation of the $\mathrm{O}-\mathrm{H}$ or N-H stretching modes, were 232 and 459, respectively, beyond the quasi-continuum threshold. Even at $6000 \mathrm{~cm}^{-1}$, which corresponds to the first overtone transitions of the $\mathrm{C}-\mathrm{H}$ stretching modes, the $\rho(\mathrm{E})$ 's of $\mathrm{CH}_{5}{ }^{+}$are 2.58 and 0.282 , respectively, still below the quasi-continuum threshold for both cases. Therefore, significant bottleneck effect due to the low density of states could exist in $\mathrm{CH}_{5}^{+}$, blocking the multiphoton process from driving the vibrationally excited $\mathrm{CH}_{5}^{+}$ions to the dissociation limit.

As a future study, the combination of the second, third, or higher order overtone transitions by the tunable IR laser and the multiphoton process by the pulsed $\mathrm{CO}_{2}$ laser would be one of the possible schemes with which the bottleneck effect of $\mathrm{CH}_{s}^{+}$can be overcome. The use of low resolution lasers will help in lowering the threshold of the quasi-continuum states. In addition, it is desirable to produce the $\mathrm{CH}_{5}^{+}$ions in extremely 
cold forms since $\mathrm{CH}_{5}{ }^{+}$is expected to scramble considerably even at modest temperatures. The conventional collisional cooling for the internally hot $\mathrm{CH}_{s}^{+}$ions may not be efficient due to the lack of the low frequency modes in $\mathrm{CH}_{5}^{+}$. The use of $\mathrm{CH}_{4}$ as a collision partner for internally hot $\mathrm{CH}_{5}^{+}$ions could enhance the cooling of the $\mathrm{CH}_{5}^{+}$ions via resonance energy transfer, since the two molecules are similar in the vibrational frequencies. However, one should be cautious not to induce the formation of large hydrocarbon ions due to the high concentration of $\mathrm{CH}_{4}$ in the ionization process, as discussed in Chapter I.

Another way of studying $\mathrm{CH}_{5}{ }^{+}$is to probe the structure and dynamics of $\mathrm{CH}_{5}{ }^{+}$by studying the weakly bound $\mathrm{CH}_{s}{ }^{+}$clusters with inert neutral molecules such as noble gases and $\mathrm{H}_{2}$. The idea of this study is that the interactions between the core ion, $\mathrm{CH}_{5}^{+}$and the solvent molecules are weak enough to cause only a minor perturbation to the structure of $\mathrm{CH}_{5}{ }^{+}$, but strong enough to freeze some of the scrambling motions. Besides the use of cold ion source, the use of an ion trap in the study of the weakly bound clusters will provide a way to measure the spectra for the internally cold ions exclusively. During trapping, the cluster ions with internal energies higher than the small binding energies would dissociate, and also some radiative cooling can take place. In the case of the solvent $\mathrm{H}_{2}$ molecules, a high resolution study on the vibration-rotational transitions of the $\mathrm{H}_{2}$ molecules in $\mathrm{CH}_{5}{ }^{+}\left(\mathrm{H}_{2}\right)_{n}(\mathrm{n}=1,2,3, .$.$) will provide additional information on the structure$ and dynamics of $\mathrm{CH}_{5}{ }^{+}$core since the vibration-rotational transitions are not strongly coupled to the floppy $\mathrm{CH}_{5}{ }^{+}$core, but still sample the structural parameters of the core ion. 


\section{REFERENCES}

1. (a)F.H. Field, Acc. Chem. Res., v.1, 42(1968). (b)F.H. Field and M.S.B. Munson, J. Am. Chem. Soc., v.87, 3289(1965).

2. G.A. Olah, G. Klopman, and R.H. Schlosberg, v.91, 3261(1969).

3. G.A. Olah, Carbocations and electrophilic reactions (Verlag Chemie, Weinheim, 1973).

4. K.R. Jennings, in Gas Phase Ion Chemistry, edited by M.T. Bowers (Academic, New York, 1979) Vol.2, p.123.

5. A. Dalgarno, in Molecular Astrophysics, edited by G.H.F. Dierchsen et al (D. Reidel Publishing Company, 1985) pp 3-22.

6. (a)W.A. Lathan, W.J. Hehre and J.A. Pople, J. Am. Chem. Soc., v.93, 808(1970).

(b)P.C. Hariharan, W.A. Lathan and J.A. Pople, Chem. Phys. Lett., v.14, 385(1972). (c)K. Raghavachari, R.A. Whiteside, J.A. Pople, and P.v.R. Schleyer, J. Am. Chem. Soc., v.103, 5649(1981).

7. K. Hirao and S. Yamabe, Chem. Phys., v.89, 237(1984).

8. V. Dyczmons and W. Kutzelnigg, Theoret. Chim. Acta, v.33, 239(1974).

9. W. Klopper and W. Kutzelnigg, J. Phys. Chem., v.94, 5625(1990).

10. G.A. Olah, Electron deficient boron and carbon clusters (Wiley-Interscience, New York, 1991).

11. P.v.R. Schleyer and J.W.M. Carneiro, J. Comput. Chem., v.13, 997(1992).

12. P.R. Schreiner, S.K. Kim, H.F. Schaefer III, and P.v.R. Schleyer, J. Chem. Phys., v.99, 3716(1993). 
13. G.E. Scuseria, Nature, v.366, 512(1993).

14. M.D. Sefcik, J.M.S. Henis, and P.P. Gasper, J. Chem. Phys., v.61, 4321(1974).

15. R.D. Smith and J.H. Futrell, Chem. Phys. Lett., v.36, 545(1975).

16. A.J.R. Heck, L.J.de Koning and N.M.M. Nibbering, J. Am. Soc. Mass Spectrom., v.2, 453(1991).

17. R. Car and M. Parrinello, Phys. Rev. Lett., v.55, 2471(1985).

18. M.C. Payne, M.P. Teter, D.C. Allan, T.A. Arias, and J.D. Joannopoulos, Rev. Mod. Phys., v.64, 1045(1992).

19. D.K. Remler and P.A. Madden, Mol. Phys., v.70, 921(1990).

20. K. Laasonen, A. Pasquarello, R. Car, C. Lee, and D. Vanderbilt, Phys. Rev. B, v.47, 10142(1993).

21. G. Ciccotti, D. Frenkel, and I.R. McDonald, Simulations of liquids and solids (NorthHolland, Amsterdam, 1986).

22. (a)S.G. Lias, J.E. Bartmess, J.F. Liebmann, et al, J. Phys. Chem. Ref. Data, v.17, 1 (1988). (b)J.C. Traeger and R.G. Mcloughlin, J. Am. Chem. Soc., v.103, 3647 (1981).

23. M.J. Pearson, B.S. Rabinovitch and G.Z. Witten, J. Chem.Phys., v.48, 1427 (1968). 24. J.M. Price, Ph.D. Thesis, University of California, Berkeley, 1990. 
Table 1. Energies of staggered $C_{y}, C_{2 v}$ and $C_{4 v}$ structures relative to eclipsed $C_{s}$ structure.

\begin{tabular}{|c|c|c|c|c|c|c|c|c|}
\hline $\begin{array}{l}\text { Geometry } \\
\text { Optimization }\end{array}$ & $\begin{array}{l}\text { Energy } \\
\text { Calculation }\end{array}$ & $\begin{array}{l}\text { Stagg } \\
\mathrm{C}_{\mathrm{s} \text { stn }} \\
\Delta \mathrm{E}\end{array}$ & $\begin{array}{l}\text { uered } \\
\text { ucture } \\
\Delta \mathrm{E}^{\circ 2}\end{array}$ & $\mathrm{C}_{2 \times} \mathrm{Str}$ & $\Delta \mathrm{E}^{\mathrm{O}^{2}}$ & $\mathrm{C}_{\mathrm{u}_{\mathrm{r}} \mathrm{Str}}$ & $\begin{array}{l}\text { uncture } \\
\Delta E^{\circ}\end{array}$ & Ref. \\
\hline 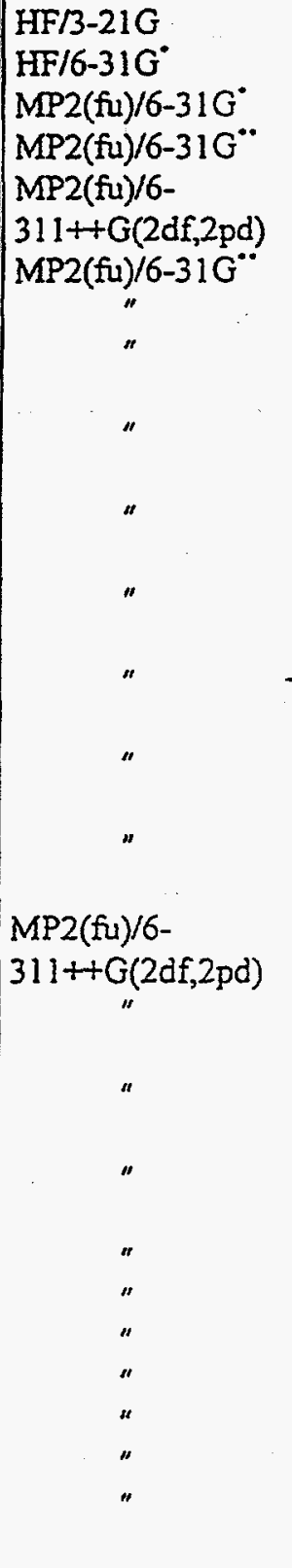 & $\begin{array}{l}\text { HF/3-21G } \\
\text { HF/6-31G } \\
\text { MP2(fu)/6-31G* } \\
\text { MP2(fu)/6-31G* } \\
\text { MP2(fu)/6- } \\
311++G(2 d f, 2 p d) \\
\text { MP3/6-311G** } \\
\text { MP4sdtq/6-311G*. } \\
\text { MP2/6- } \\
311 G(3 d f, 2 p) \\
\text { MP3/6- } \\
311 G(3 d f, 2 p) \\
\text { MP4sdtq/6- } \\
311 G(3 d f, 2 p) \\
\text { MP2/6- } \\
311++G(2 d f, 2 p d) \\
\text { MP3/6- } \\
311++G(2 d f, 2 p d) \\
\text { MP4sdq/6- } \\
311++G(2 d f, 2 p d) \\
\text { QCISD(T)/6- } \\
311++G(2 d f, 2 p d) \\
\text { MP2/6- } \\
311++G(3 d f, 3 p d) \\
\text { MP3/6- } \\
311++G(3 d f, 3 p d) \\
\text { MP4sdtq/6- } \\
311++G(3 d f, 3 p d) \\
\text { QCISD(T)/6- } \\
311++G(3 d f, 3 p d) \\
\text { MP2/cc-pVDZ } \\
\text { MP3/cc-pVDZ } \\
\text { MP4sdtq/cc-pVDZ } \\
\text { QCISD(T)/cc- } \\
\text { pVDZ } \\
\text { MP2/cc-pVTZ } \\
\text { MP3/cc-pVTZ } \\
\text { QCISD(T)/cc-pVTZ }\end{array}$ & $\begin{array}{l}0.14 \\
0.11 \\
0.11 \\
0.09 \\
0.04 \\
0.04 \\
0.13 \\
0.08 \\
0.04 \\
0.06 \\
0.14 \\
0.11 \\
0.11 \\
0.11 \\
0.18 \\
0.16 \\
0.15 \\
0.14 \\
0.12 \\
0.09 \\
0.09\end{array}$ & $\begin{array}{l}-0.10 \\
- \\
\end{array}$ & $\begin{array}{l}0.46 \\
0.80 \\
0.84 \\
0.69 \\
. \\
0.97 \\
\\
1.00 \\
0.53 \\
\\
0.82 \\
\\
1.03 \\
\\
0.88 \\
0.55 \\
\\
0.80 \\
0.82 \\
\\
0.86 \\
0.36 \\
0.58 \\
0.63 \\
0.67 \\
0.54 \\
0.80 \\
0.87\end{array}$ & . & $\begin{array}{r}5.10 \\
6.70 \\
1.92 \\
3.47 \\
. \\
2.48 \\
3.09 \\
3.23 \\
\\
2.74 \\
3.21 \\
3.32 \\
\\
2.60 \\
3.07 \\
3.59 \\
3.26\end{array}$ & 1.08 & $\begin{array}{l}11 \\
11 \\
11 \\
11 \\
11 \\
11 \\
11 \\
11 \\
11 \\
11 \\
11\end{array}$ \\
\hline
\end{tabular}


Table 1.( continued)

\begin{tabular}{|c|c|c|c|c|c|c|c|c|}
\hline $\begin{array}{l}\text { Geometry } \\
\text { optimization }\end{array}$ & $\begin{array}{l}\text { Energy } \\
\text { calculation }\end{array}$ & $\begin{array}{l}\text { Stage } \\
\text { C str } \\
\Delta \mathrm{E}\end{array}$ & $\begin{array}{l}\text { ered } \\
\qquad \Delta \mathrm{E}^{\circ}\end{array}$ & $\left\{\begin{array}{l}\mathcal{C}_{2} \mathrm{st} \\
\Delta E\end{array}\right.$ & cture & $\Delta \mathrm{E}$ & $\Delta E^{\circ}$ & Ref. \\
\hline $\begin{array}{l}\mathrm{C}:[9,5,1 / 5,4,1] \\
\mathrm{H}:[5,1 / 3,1]\end{array}$ & MP2-R12(v) & & & 0.4 & & 3.0 & & 9 \\
\hline “ & MP2-R12 & & & 0.3 & & 2.9 & & 9 \\
\hline $\begin{array}{l}C:[12,7,3 / 8,5,3] \\
H:[7,2 / 5,2]\end{array}$ & MP2-R12(v) & & & 0.2 & & 2.2 & & 9 \\
\hline TZ2P & CISD & 0.01 & 0.08 & 1.64 & 0.63 & & & 12 \\
\hline$"$ & $\mathrm{CISD}(+Q)$ & 0.00 & 0.07 & 1.44 & 0.33 & & & 12 \\
\hline$"$ & CCSD & 0.00 & 0.08 & 1.51 & 0.56 & & & 12 \\
\hline " & $\operatorname{CcsD}(T)$ & 0.00 & 0.08 & 1.30 & 0.31 & & & 12 \\
\hline$T 22 P+f$ & CISD & 0.05 & 0.14 & 1.49 & 0.58 & & & 12 \\
\hline$"$ & $\operatorname{CISD}(+Q)$ & 0.04 & 0.13 & 1.27 & 0.36 & & & 12 \\
\hline$"$ & $\operatorname{CCSD}$ & 0.04 & -0.06 & 1.35 & 0.25 & & & 12 \\
\hline r & $\operatorname{CcsD}(T)$ & 0.00 & 0.08 & 1.13 & 0.03 & & & 12 \\
\hline $\operatorname{TZ2P}(f, d)$ & CISD & 0.08 & 0.17 & 1.26 & 0.35 & & & 12 \\
\hline & $\operatorname{CISD}(\div Q)$ & 0.09 & 0.18 & 1.05 & 0.14 & & & 12 \\
\hline " & $\operatorname{CCSD}$ & 0.08 & -0.02 & 1.13 & 0.03 & & & 12 \\
\hline & $\operatorname{CCSD}(\mathrm{T})$ & 0.09 & -0.01 & 0.90 & 0.20 & & & 12 \\
\hline
\end{tabular}

$\Delta E^{\sigma}=\Delta E+\Delta Z \overline{P E}($ zero point energy $)$ 
Table 2. Comparison of product ion ratio $\left[\mathrm{BH}^{+}\right]\left[\mathrm{BD}^{+}\right]$associated with the proton/deuteron transfer reaction of $\mathrm{CH}_{4} \mathrm{D}^{+}$and $\mathrm{CD}_{4} \mathrm{H}^{+}$to base $\mathrm{B}$

\begin{tabular}{|c|c|c|c|c|c|c|}
\hline \multirow[b]{2}{*}{ Base(B) } & \multicolumn{2}{|c|}{$\underline{\text { Sefcik et al }}{ }^{\mathrm{a}}$} & \multicolumn{2}{|c|}{ Futrell et $\mathrm{al}^{\mathrm{b}}$} & \multicolumn{2}{|c|}{ Heck et al } \\
\hline & $\mathrm{CH}_{4} \mathrm{D}^{+}$ & $\mathrm{CD}_{4} \mathrm{H}^{+}$ & $\mathrm{CH}_{4} \mathrm{D}^{+}$ & $\mathrm{CD}_{4} \mathrm{H}^{+}$ & $\mathrm{CH}_{4} \mathrm{D}^{+}$ & $\mathrm{CD}_{4} \mathrm{H}^{+}$ \\
\hline i-butylene & 3.2 & 1.4 & 4.3 & 3.5 & - & - \\
\hline ethylene oxide & 2.5 & 1.4 & 4.6 & 2.8 & - & - \\
\hline propane & 2.5 & 2.2 & - & - & - & - \\
\hline dimethyl ether & 2.1 & 2.8 & 5.0 & 3.05 & - & - \\
\hline ethylene & - & - & 4.3 & 3.2 & - & - \\
\hline ethane & - & - & 4.2 & 3.85 & - & - \\
\hline methanol & - & - & 4.6 & 3.15 & - & - \\
\hline ammonia, $<\mathrm{n}>^{d}=0.0$ & - & - & - & - & $1.0^{\circ}$ & 1.0 \\
\hline ammonia, $<\mathrm{n}>^{d}=0.5$ & - & - & - & - & 2.5 & 0.2 \\
\hline$<\mathrm{n}>$-dependence & No & No & No & No & Yes & Yes \\
\hline Randomized Model & 4.0 & 0.25 & 4.0 & 0.25 & 4.0 & 0.25 \\
\hline$C_{s}$ Model & 1.0 & 1.0 & 1.0 & 1.0 & 1.0 & 1.0 \\
\hline
\end{tabular}

${ }^{2}$ Ref. 14

${ }^{\text {bRef. } 15}$

'Ref. 16

${ }^{d}<n>$ means the average number of primary ion-molecule collisions 
Table 3. Density of states of $\mathrm{CH}_{5}^{+}$calculated as a function of internal energy using the Witten-Rabinovich equation. The density of states are calculated in two cases: (i) torsion and (ii) free internal rotation. In case of free internal rotation, the lowest frequency mode was omitted from the calculation.

$\rho(E)$ per $\mathrm{cm}^{-1}$

\begin{tabular}{|l|l|l|l|l|l|}
\hline \hline Energy & $\begin{array}{l}3000 \\
\mathrm{~cm}\end{array}$ & $\begin{array}{l}6000 \\
\mathrm{~cm}\end{array}$ & $\begin{array}{l}9000 \\
\mathrm{~cm}^{-1}\end{array}$ & $\begin{array}{l}12000 \\
\mathrm{~cm}^{-1}\end{array}$ & $\begin{array}{l}15000 \\
\mathrm{~cm}^{-1}\end{array}$ \\
\hline $\begin{array}{l}\text { Torsion } \\
\text { Free internal } \\
\text { Rotation }\end{array}$ & $2.47 \times 10^{-1}$ & 2.58 & 22.2 & 128.7 & 572 \\
\hline
\end{tabular}

The vibrational frequencies used in this calculation are $3079,2993,2891,2633,2295,1547,1427$, $1400,1236,1234,856,145 \mathrm{~cm}^{-1}$ at TZ2P $+\mathrm{f} \mathrm{CCSD} \mathrm{level} \mathrm{(see} \mathrm{ref.} \mathrm{12).}$

${ }^{2}$ For comparison, the density of states of $\mathrm{H}_{3} \mathrm{O}^{+}\left(\mathrm{H}_{2} \mathrm{O}\right)$ and $\mathrm{NH}_{4}^{+}\left(\mathrm{NH}_{3}\right)$ are 232, 459 at $3500 \mathrm{~cm}^{-1} ; 447$, 10000 at $7000 \mathrm{~cm}^{-1} ; 3590,2.64 \times 10^{6}$ at $15000 \mathrm{~cm}^{-1}$, respectively. 


\section{FIGURE CAPTIONS}

Fig. 1 Structures of $\mathrm{CH}_{5}^{+}$, predicted by the ab initio calculations.

Fig. 2 Snap shots of the structures of $\mathrm{CH}_{5}{ }^{+}$during the simulation with the ab initio molecular dynamics (MD) method.

Fig. 3 Plots of the $\mathrm{H}-\mathrm{H}$ distances of $\mathrm{CH}_{5}{ }^{+}$during 40,000 time steps ( $\sim 3$ psec) of the simulation. Notice that all of the H-H distances fluctuate between 1.0-2.2 $\AA$.

Fig. 4 Mass spectrum showing the carbonium ion $\mathrm{CH}_{5}{ }^{+}$. The mixing ratio $\mathrm{CH}_{4}: \mathrm{H}_{2}$ was 1:2000, and the source pressure, the source temperature and the discharge current were 150 torr, $-40^{\circ} \mathrm{C}$ and $20 \mu \mathrm{A}$, respectively.

Fig. 5 A schematic of the two color multiphoton processes induced by the tunable IR laser and the $\mathrm{CO}_{2}$ laser. 


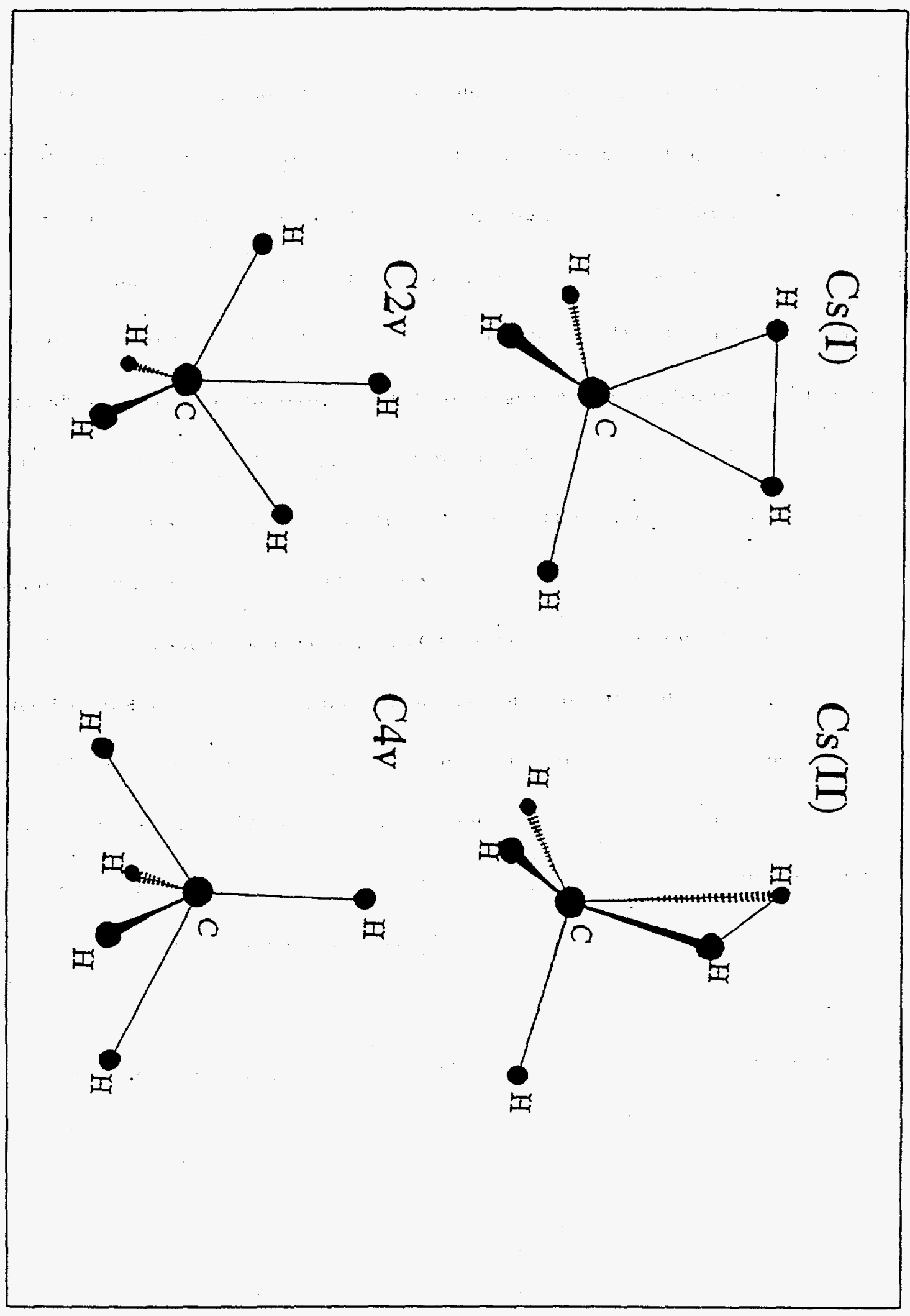

Fig. $i$ 

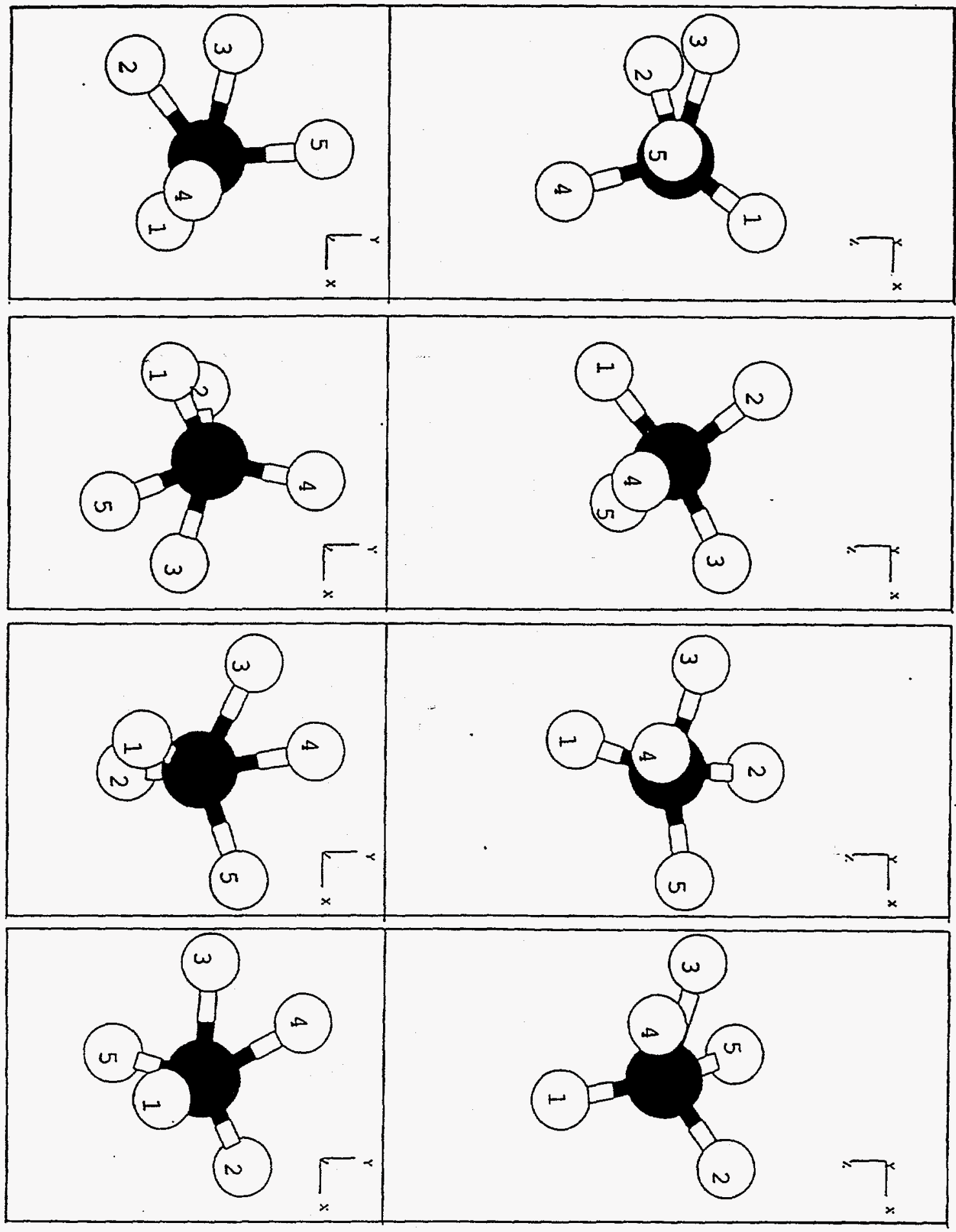

Fig. 2 


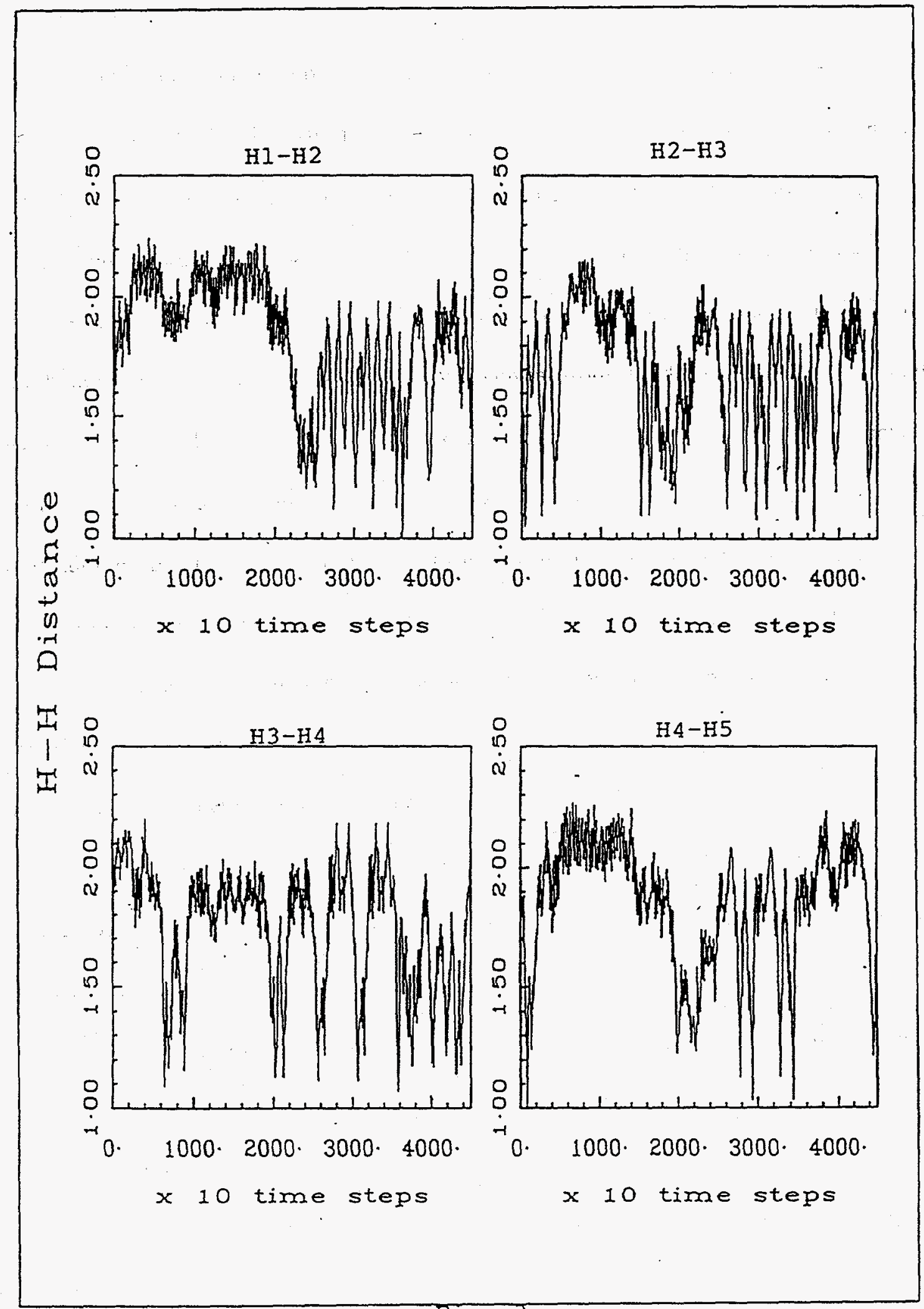

Fig. 3 


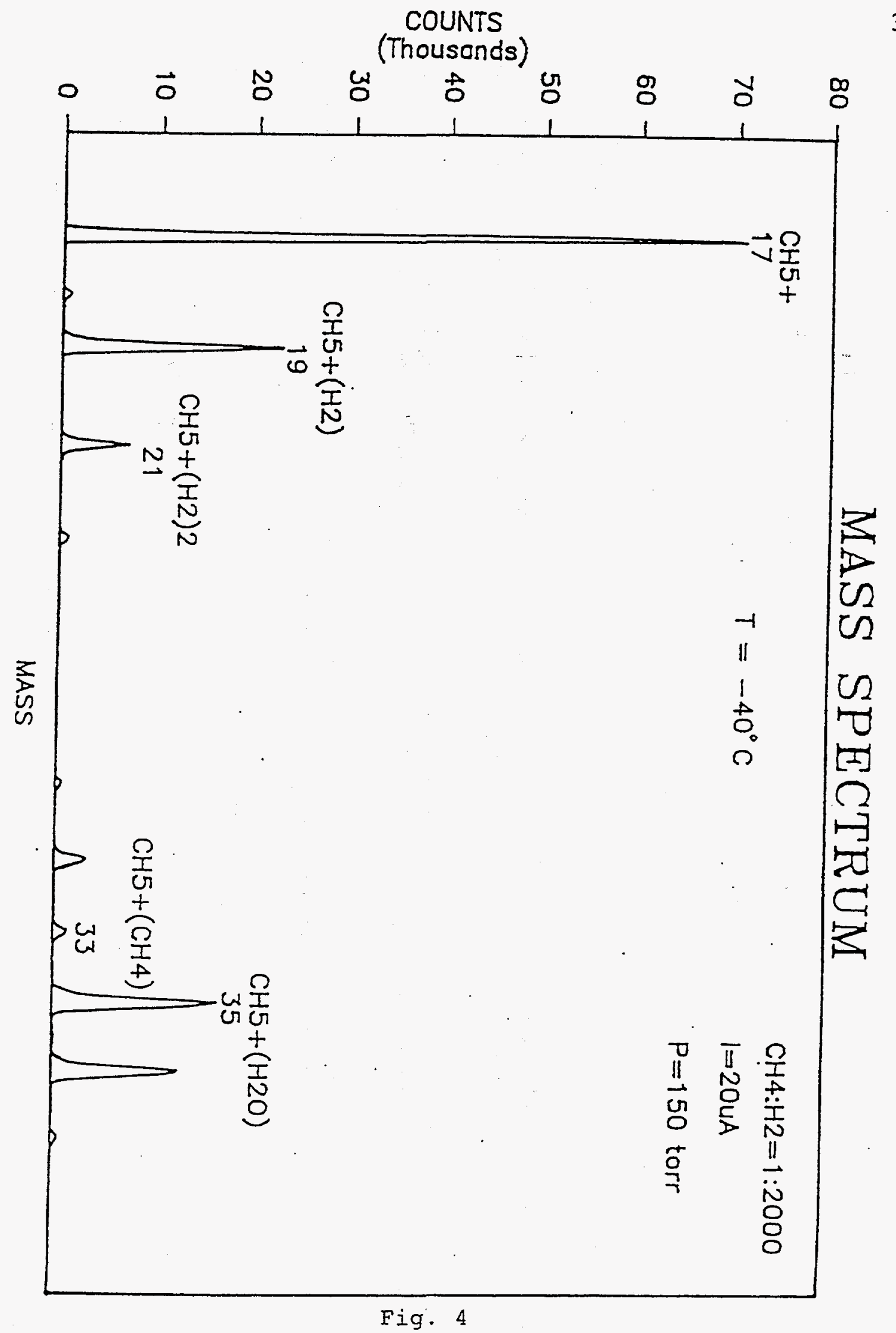




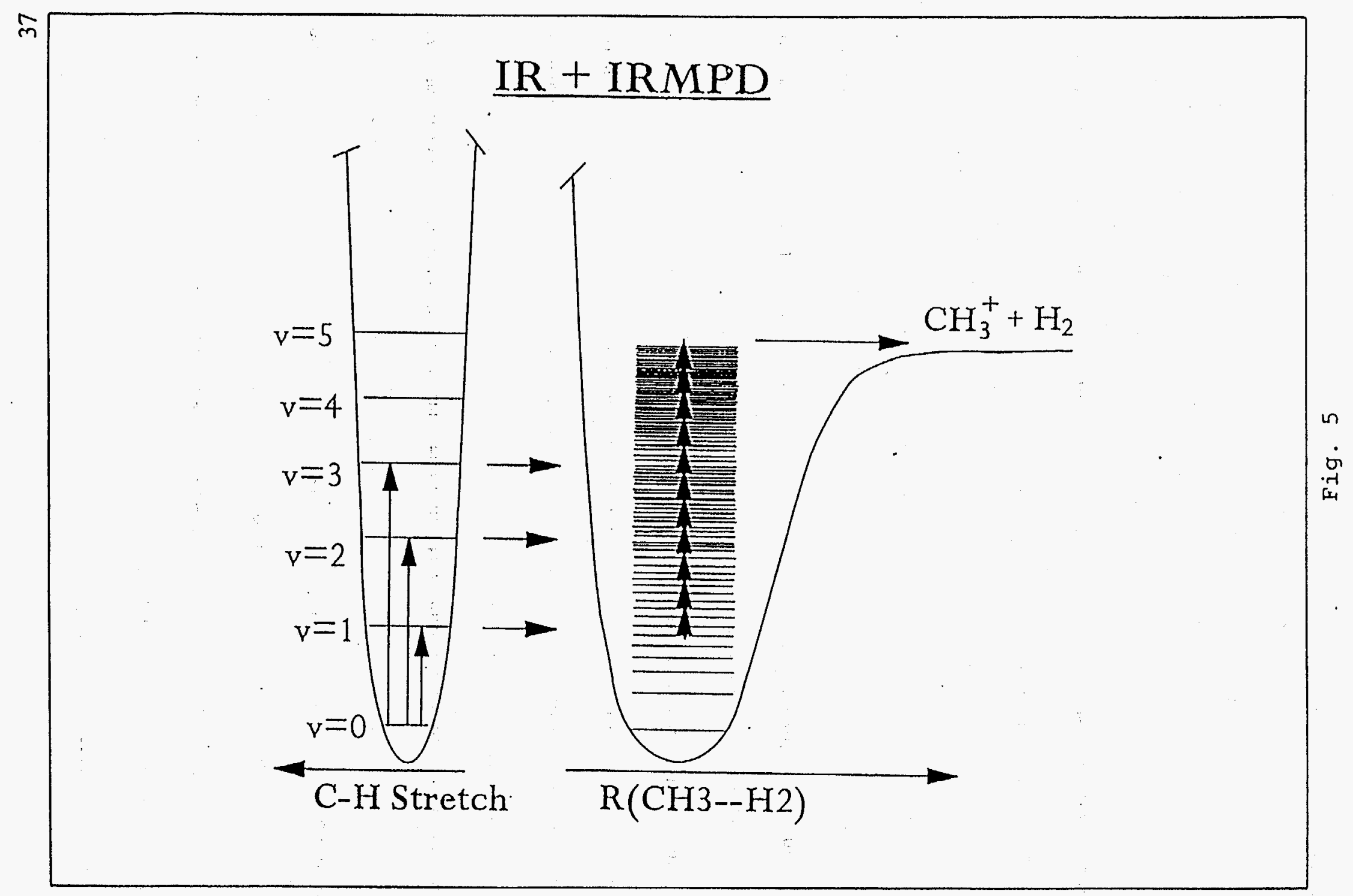




\title{
CHAPTER III
}

\section{Infrared Spectroscopy of the Molecular Hydrogen Solvated}

\author{
Carbonium Ions, $\mathrm{CH}_{5}^{+}\left(\mathrm{H}_{2}\right)_{\mathrm{n}}(\mathrm{n}=1-6)$
}

\section{INTRODUCTION}

The importance of $\mathrm{CH}_{5}^{+}$was described in the Introduction of Chapter II. ${ }^{1-6}$ As also mentioned in Chapter II, a number of the early theoretical calculations on the structures of $\mathrm{CH}_{5}{ }^{+}$consistently suggested that the eclipsed $\mathrm{C}_{\mathrm{s}}\left(\mathrm{e}-\mathrm{C}_{\mathrm{s}}\right)$ symmetry structure was the global minimum energy structure..$^{7-10}$ However, recent ab initio calculations at the most sophisticated level, performed by Schleyer, Schaefer, and coworkers, found that the energy differences between the e- $C_{s}$ structure and other structures such as staggered $\mathrm{C}_{\mathrm{s}}\left(\mathrm{s}-\mathrm{C}_{\mathrm{s}}\right)$ or $\mathrm{C}_{2 \mathrm{v}}$ were very small and became negligible when corrected for zero point energies (see Fig. 1 for the $\mathrm{CH}_{5}^{+}$structures). ${ }^{11,12}$ The $\mathrm{C}_{4 \mathrm{v}}$ and $\mathrm{D}_{3 \mathrm{~h}}$ structures were predicted to be higher in energy than the e- $\mathrm{C}_{\mathrm{s}}$ structure by $1 \mathrm{kcal} / \mathrm{mole}$ and $9 \mathrm{kcal} / \mathrm{mole}$, respectively. As pointed out by Schleyer, Schaefer, and later, by Scuceria, ${ }^{13}$ the early prediction that $\mathrm{CH}_{5}{ }^{+}$is regarded as a complex between $\mathrm{CH}_{3}{ }^{+}$and $\mathrm{H}_{2}$ with a localized 3c2e bond is not valid, but $\mathrm{CH}_{s}{ }^{+}$is likely to scramble constantly through the low lying s-C and $\mathrm{C}_{2 v}$ transition states, without possessing a definite equilibrium structure.

In contrast to the numerous theoretical works on $\mathrm{CH}_{5}{ }^{+}$, only a few experiments have been performed previously to characterize indirectly the structure of $\mathrm{CH}_{5}{ }^{+}$using mass spectrometry. ${ }^{14-18}$ Hiraoka and coworkers measured $\Delta \mathrm{H}_{\mathrm{n}-1, \mathrm{n}}^{\circ}$ and $\Delta \mathrm{S}_{\mathrm{n}-1, \mathrm{n}}^{\circ}$ for the 
clustering reactions $\mathrm{CH}_{5}^{+}\left(\mathrm{CH}_{4}\right)_{n-1}+\mathrm{CH}_{4}=\mathrm{CH}_{5}^{+}\left(\mathrm{CH}_{4}\right)_{\mathrm{n}}$ for $\mathrm{n}=1-9$ using a pulsed electron beam mass spectrometry. ${ }^{14}$ They showed an irregular decrease in the values of $-\Delta \mathrm{H}_{\mathrm{n}-1, \mathrm{n}}^{\circ}$ and $-\Delta S_{n-1, n}^{\circ}$ between $n=2$ and 3 , suggesting a $\mathrm{C}_{s}$ symmetry structure for $\mathrm{CH}_{s}^{+}$which contains a $3 \mathrm{c} 2 \mathrm{e}$ bond, since the two acidic $\mathrm{H}$ atoms of the $3 \mathrm{c} 2 \mathrm{e}$ bond would give the most favorable sites for the first two $\mathrm{CH}_{4}$ ligands. However, this result only suggests the $\mathrm{C}_{\mathrm{s}}$ structure for the core ion $\mathrm{CH}_{5}^{+}$of $\mathrm{CH}_{5}^{+}\left(\mathrm{CH}_{4}\right)_{\mathrm{n}}$, not for free $\mathrm{CH}_{5}^{+}$, because strong interaction between $\mathrm{CH}_{5}{ }^{+}$and $\mathrm{CH}_{4}$ could deform the structure of free $\mathrm{CH}_{5}^{+}\left(\Delta \mathrm{H}_{0,1}^{\circ}=6.87\right.$ $\mathrm{kcal} / \mathrm{mole}$ ). In order to get more reliable information on the structure of $\mathrm{CH}_{5}{ }^{+}$, they also measured $\Delta \mathrm{H}_{n-1, \mathrm{n}}^{\circ}$ and $\Delta \mathrm{S}_{\mathrm{n}-1, \mathrm{n}}^{\circ}$ for the cluster ions $\mathrm{CH}_{s}^{+}\left(\mathrm{H}_{2}\right)_{\mathrm{n}}(\mathrm{n}=1-4)$, which were expected to have much weaker interactions between the core ion $\mathrm{CH}_{5}{ }^{+}$and $\mathrm{H}_{2}$ molecules, as shown in Table I. ${ }^{15}$ Unlike the case for $\mathrm{CH}_{5}{ }^{+}\left(\mathrm{CH}_{4}\right)_{n}$, a gradual decrease of $\Delta \mathrm{H}_{\mathrm{n}-1, \mathrm{n}}^{\circ}$ with $\mathrm{n}$ was observed for $\mathrm{CH}_{5}{ }^{+}\left(\mathrm{H}_{2}\right)_{n}$, though a large gap in the van't Hoff plots was still seen between $\mathrm{n}=2$ and 3. Based upon these observations, they proposed that $\mathrm{CH}_{5}{ }^{+}$still has $\mathrm{C}_{s}$ structure but the positive charge is more delocalized in $\mathrm{CH}_{5}{ }^{+}$when it is complexed by $\mathrm{H}_{2}$.

As mentioned in Chapter II, experiments using a Fourier Transform Ion Cyclotron Resonance (FTICR) mass spectrometry have been performed on the collisionally induced intramolecular randomization of hydrogen and deuterium atoms in $\mathrm{CH}_{4} \mathrm{D}^{+}$and $\mathrm{CD}_{4} \mathrm{H}^{+}$by the groups of Sefcik's, ${ }^{16}$ Smith's, ${ }^{17}$ and Heck's. ${ }^{18}$ In these works, the product ion branching ratio $\llbracket \mathrm{BH}^{+} / /\left[\mathrm{BD}^{+} \rrbracket\right.$ associated with the proton/deuteron transfer reaction from $\mathrm{CH}_{4} \mathrm{D}^{+}$and $\mathrm{CD}_{4} \mathrm{H}^{+}$to the base $\mathrm{B}$ was measured as a function of the average number $(<n>)$ of primary ion/molecule collisions $\left(\mathrm{CH}_{4}^{+\circ} / \mathrm{CD}_{4}\right.$ or $\left.\mathrm{CD}_{4}^{+*} / \mathrm{CH}_{4}\right)$. However, the results were inconsistent such that Sefcik's ${ }^{16}$ and Heck's results ${ }^{18}$ supported the $C_{s}$ model with a localized $3 c 2 e$ 
bond whereas Smith's results ${ }^{17}$ suggested the randomized model (refer to Chapter II for the details).

Because of the difficulties in the indirect characterization of the structure of $\mathrm{CH}_{5}^{+}$, much effort has been given to obtain high resolution infrared (IR) spectra for $\mathrm{CH}_{5}^{+}$, but has achieved little success. One of the difficulties in the high resolution IR study is that $\mathrm{CH}_{5}^{+}$scrambles even at low temperatures, as predicted by the ab initio calculations, causing significant spectral congestion. The spectral congestion would be more extensive for the $\mathrm{CH}_{5}{ }^{+}$ions produced in the conventional ion sources since the ions tend to possess considerable internal energy.

In an attempt to overcome the difficulties of performing IR spectroscopy on $\mathrm{CH}_{5}^{+}$, we have studied the molecular hydrogen solvated carbonium ions, $\mathrm{CH}_{5}^{+}\left(\mathrm{H}_{2}\right)_{\mathrm{n}}(\mathrm{n}=1-6)$ where the $\mathrm{H}_{2}$ molecules are weakly bound to the core ion. The motivation was the notion that the interactions between the core $\mathrm{CH}_{5}{ }^{+}$ions and the $\mathrm{H}_{2}$ molecules are weak enough to cause only a minor perturbation to $\mathrm{CH}_{5}{ }^{+}$, yet strong enough to slow down the scrambling motions. According to Hiraoka and coworkers, the binding energies $\left(\Delta \mathrm{H}_{n-1, n}\right)$ of the $\mathrm{H}_{2}$ molecules to the $\mathrm{CH}_{5}{ }^{+}$core were measured to be less than $2 \mathrm{kcal} /$ mole. ${ }^{15}$ Schaefer and coworkers also calculated the dissociation energy $\left(\mathrm{D}_{0}\right)$ of $\mathrm{CH}_{5}{ }^{+}\left(\mathrm{H}_{2}\right)$ to be $1.46 \mathrm{kcal} / \mathrm{mole}$ at $\mathrm{TZ2P}+\mathrm{d} \operatorname{CCSD}(\mathrm{T}) .^{19}$ The experimental and theoretical dissociation energies and enthalpies for $\mathrm{CH}_{5}{ }^{+}\left(\mathrm{H}_{2}\right)_{n}(\mathrm{n}=1-4)$ are listed in Table I. Experimentally, the weakly bound clusters $\mathrm{CH}_{5}{ }^{+}\left(\mathrm{H}_{2}\right)_{\mathrm{n}}$ have advantages over $\mathrm{CH}_{5}{ }^{+}$in that the cooling of the cluster ions by supersonic expansion is more efficient than the cooling of the $\mathrm{CH}_{5}{ }^{+}$ions, since the low frequency modes involving the core-ligand bonds would play an important 
role in the vibrational energy transfer from initially hot ions to the cold partners. As a preliminary result, the IR spectra for $\mathrm{CH}_{5}{ }^{+}\left(\mathrm{H}_{2}\right)$ have been reported previously ${ }^{20}$

Very recently, we also reported a study on the dynamics of the molecular hydrogen solvated carbonium ions, $\mathrm{CH}_{5}{ }^{+}\left(\mathrm{H}_{2}\right)_{\mathrm{n}}(\mathrm{n}=1,2,3)$ by measuring the IR spectra for the $\mathrm{C}$ - $\mathrm{H}$ stretching modes of $\mathrm{CH}_{5}{ }^{+}\left(\mathrm{H}_{2}\right)_{\mathrm{n}}(\mathrm{n}=1,2,3)$, and performing ab initio molecular dynamics (MD) simulations on $\mathrm{CH}_{5}{ }^{+}\left(\mathrm{H}_{2}\right)_{\mathrm{n}}(\mathrm{n}=0-3){ }^{21}$ The results provided considerable insight into the scrambling motion of $\mathrm{CH}_{5}{ }^{+}$, and revealed the slowdown of the scrambling of the $\mathrm{CH}_{5}{ }^{+}$core by the solvent $\mathrm{H}_{2}$ molecules in $\mathrm{CH}_{5}{ }^{+}\left(\mathrm{H}_{2}\right)_{\mathrm{n}}(\mathrm{n}=1,2,3)$. The complete draft of this study is attached in the Appendix.

In this chapter, we present the complete IR spectra of the molecular hydrogen solvated carbonium ions, $\mathrm{CH}_{5}{ }^{+}\left(\mathrm{H}_{2}\right)_{\mathrm{n}}(\mathrm{n}=1-6)$ including the IR spectra for the $\mathrm{H}-\mathrm{H}$ stretching modes of the solvent $\mathrm{H}_{2}$ molecules, obtained in the frequency range of $2700-4200 \mathrm{~cm}^{-1}$. It will be shown that correlation of the spectral features for the $\mathrm{C}-\mathrm{H}$ stretching modes of the core $\mathrm{CH}_{5}{ }^{+}$with the number of solvent $\mathrm{H}_{2}$ molecules in $\mathrm{CH}_{5}{ }^{+}\left(\mathrm{H}_{2}\right)_{n}$ $(n=1-6)$ can provide information on the structure and dynamics of $\mathrm{CH}_{5}{ }^{+}$. It will also be shown that the vibration-rotation transitions of the $\mathrm{H}-\mathrm{H}$ stretching modes in $\mathrm{CH}_{5}^{+}\left(\mathrm{H}_{2}\right)_{\mathrm{n}}$ $(n=1-6)$ can give additional information on the structure and dynamics of $\mathrm{CH}_{5}^{+}$as well as information about the charge induced dipole interactions between the $\mathrm{CH}_{5}{ }^{+}$core and the solvent $\mathrm{H}_{2}$ molecules. 


\section{EXPERIMENTAL DETAILS}

The experimental apparatus used in this work has been described previously, ${ }^{22-25}$ and also in Chapter I. Briefly, the molecular hydrogen solvated carbonium ions $\mathrm{CH}_{5}^{+}\left(\mathrm{H}_{2}\right)_{n}(\mathrm{n}=1-6)$ were produced from a high pressure corona discharge source and subsequent supersonic expansion through a $75 \mu \mathrm{m}$ nozzle. The corona discharge was maintained in 50-150 tor of gas with ultrahigh purity (UHP) $\mathrm{H}_{2}$ and UHP $\mathrm{CH}_{4}$ in a $3,000,000: 1$ ratio, flowing past a $1.0 \mathrm{kV}$ potential from the discharge tip of the needle to the source body maintained at approximately $350 \mathrm{~V}$ above ground. The discharge current under these conditions was $10 \sim 40 \mu \mathrm{A}$. The source was maintained at the optimum temperature for each kind of cluster ion in order to maximize the ion intensity, by heating up the source body cooled by contact with a liquid nitrogen reservoir. Typical source temperatures for the molecular hydrogen solvated carbonium ions were between $20^{\circ} \mathrm{C}$ and $-70^{\circ} \mathrm{C}$. Pressures in the source chamber were between $1 \times 10^{-5}$ and $1 \times 10^{-4}$ torr during the experiment. To prevent the acceleration of ions in the higher pressure region, which causes internal excitation and dissociation of the ion clusters via collisions with the background gas, the potential of the skimmer was maintained within $1 \mathrm{~V}$ of that of the source body.

After the skimmer, the ion beam entered a second differential pumping region containing collimating and focusing lenses. The pressure in this region was typically an order of magnitude lower than that of the source region. The beam was directed into a $60^{\circ}$ sector magnet mass analyzer through a third differentially pumped region maintained at $10^{-8}$ torr. 
The mass-selected beam was then bent $90^{\circ}$ in a dc quadrupole field, decelerated to less than $0.5 \mathrm{eV}$, and focused into a rf octapole ion trap through an entrance aperture lens. The ions were usually trapped here for $\sim 2 \mathrm{msec}$ before IR irradiation. Usually, $100-500$ ions were trapped per cycle, depending upon the stabilities of the cluster ions. These numbers are too small to allow direct measurement of photon absorption.

The trapped, mass-selected clusters were then vibrationally excited by a pulsed, tunable infrared laser. A Quanta-Ray IR WEX was used as a tunable IR light source. The IR wavelength was produced in a $\mathrm{LiNbO}_{3}$ crystal that generates the difference frequency between a Lambda Physics pulsed dye laser (Model FL3002E) and the $1.06 \mu \mathrm{m}$ fundamental of a Continuum Nd-YAG laser. The IR bandwidth was $0.2 \mathrm{~cm}^{-1}$. The pulse duration was $6 \mathrm{nsec}$ with a $20 \mathrm{~Hz}$ repetition rate, and the laser power was $1-3 \mathrm{~mJ} / \mathrm{pulse}$ in the $2700-4200 \mathrm{~cm}^{-1}$ frequency region scanned in this work.

If the ions absorb one IR photon in the tuning range of $2700-4200 \mathrm{~cm}^{-1}$, the $\mathrm{CH}_{5}^{+}\left(\mathrm{H}_{2}\right)_{\mathrm{n}}(\mathrm{n}=1-6)$ ions vibrationally predissociate into $\mathrm{CH}_{5}^{+}\left(\mathrm{H}_{2}\right)_{\mathrm{x}}+\mathrm{yH} \mathrm{H}_{2}(\mathrm{x}+\mathrm{y}=\mathrm{n})$. Large cluster ions are so weakly bound that the vibrational predissociation of these ions can produce two or more daughter ions which differ by the mass of $\mathrm{H}_{2}$. Roughly $0.5 \mathrm{msec}$ after the laser pulse, the potential on the exit aperture was lowered to extract ions of all masses from the trap. These ions were filtered by a quadrupole mass spectrometer tuned to pass only the daughter ions $\mathrm{CH}_{5}{ }^{+}\left(\mathrm{H}_{2}\right)_{\mathrm{x}}$. The observation of the $\mathrm{CH}_{5}{ }^{+}\left(\mathrm{H}_{2}\right)_{\mathrm{x}}$ signal as a function of laser frequency was a measure of the IR absorption of $\mathrm{CH}_{5}{ }^{+}\left(\mathrm{H}_{2}\right)_{\mathrm{n}}(\mathrm{n}=1-6)$.

Daughter ions were counted with a Daly ion detector ${ }^{26}$ for each laser shot. Background daughter ions resulting from the decay of metastable parent ions in the rf ion 
trap were monitored in a separate cycle with the laser off at each wavelength and subtracted from the laser on signal. The laser power was monitored at each data point, and spectra were normalized for the power of the tunable IR laser assuming a simple linear power dependence. For a typical experiment, signals were averaged for about 500 laser shots for $\mathrm{CH}_{5}^{+}\left(\mathrm{H}_{2}\right)_{\mathrm{n}}(\mathrm{n}=1-6)$ at each wavelength in the $2700-3200 \mathrm{~cm}^{-1}$ and $4000-4150$ $\mathrm{cm}^{-1}$ frequency regions, where the IR absorptions were found for $\mathrm{CH}_{5}{ }^{+}\left(\mathrm{H}_{2}\right)_{\mathrm{n}}(\mathrm{n}=1-6)$.

In this experiment; the composition of ions in the beam was strongly dependent on the $\mathrm{H}_{2} / \mathrm{CH}_{4}$ mixing ratios, source temperatures and source pressures. The experimental conditions used in this work were a $\mathrm{H}_{2}: \mathrm{CH}_{4}$ ratio of $3,000,000: 1$, a source temperature of $-30^{\circ} \mathrm{C}$ and a source pressure of $60-150$ torr. Fig. 2 shows the mass spectrum for $\mathrm{CH}_{5}^{+}\left(\mathrm{H}_{2}\right)_{\mathrm{n}}(\mathrm{n}=1-6)$ obtained under these conditions. The mass spectrum shows a Boltzmann distribution of the $\mathrm{CH}_{5}^{+}\left(\mathrm{H}_{2}\right)_{\mathrm{n}}$ ions with the cluster size ranging from $\mathrm{n}=1$ to $\mathrm{n}=6$. For the cluster ions with $\mathrm{n} \geq 6$, the mass peaks were overlapped with the intense peaks due to $\mathrm{C}_{2} \mathrm{H}_{5}^{+}(\mathrm{m} / \mathrm{e}=29), \mathrm{C}_{2} \mathrm{H}_{7}^{+}(\mathrm{m} / \mathrm{e}=31)$, and $\mathrm{CH}_{5}^{+}\left(\mathrm{CH}_{4}\right)(\mathrm{m} / \mathrm{e}=33)$. In this experiment, the maximum in the distribution of mass peaks was able to be easily shifted between $n=1$ and $n=6$ by changing the source pressures and source temperatures. The maximum ion intensities for large cluster ions were obtained when high source pressures and low source temperatures were used in the discharge.

As reported previously, ${ }^{20}$ the $\mathrm{CH}_{5}{ }^{+}\left(\mathrm{H}_{2}\right)$ ions were also produced using a $\mathrm{H}_{2}: \mathrm{CH}_{4}$ ratio of $2000: 1$, a $-40^{\circ} \mathrm{C}$ source temperature and 150 torr source pressure. But, the IR spectra obtained with these two different conditions were similar to each other. The IR spectra of $\mathrm{CH}_{5}^{+}\left(\mathrm{H}_{2}\right)$ obtained with the latter conditions is presented in this paper, simply 
because of the superior signal-to-noise ratio. 


\section{RESULTS AND ANALYSIS}

\subsection{Internally Cold $\mathrm{CH}_{5}^{+}\left(\mathrm{H}_{2}\right)_{\mathrm{n}}$ Ions}

Since $\mathrm{CH}_{5}{ }^{+}$is expected to scramble extensively even at the moderate temperatures, it is crucial to produce the ions in internally cold forms in order to obtain information about the structure and dynamics of the $\mathrm{CH}_{5}{ }^{+}$cores in the molecular hydrogen solvated carbonium ions, $\mathrm{CH}_{s}^{+}\left(\mathrm{H}_{2}\right)_{\mathrm{n}}(\mathrm{n}=1-6)$. Therefore, it seems appropriate to discuss the conditions of the carbonium ions $\left(\mathrm{CH}_{5}^{+}\right.$and $\left.\mathrm{CH}_{5}{ }^{+}\left(\mathrm{H}_{2}\right)_{n}\right)$ produced in this experiment. As described in detail in the previous section, the carbonium ions were produced in a high pressure and low current corona discharge source and subsequent supersonic expansion. The ionization conditions were kept as soft as possible at the sacrifice of the ion intensity. Nevertheless, the carbonium ions were likely to be vibrationally excited by the discharge process, and were expected to cool down via collisions with the cold wall of the ion source and via collisions with cold neutral species in a small high pressure drift region and during supersonic expansion. It is well known that the collisional cooling strongly depends upon the efficiency of energy transfer from internally hot ions to the cold partners. If the cold partners (e.g. $\mathrm{CH}_{4}$ ) possess similar vibrational frequencies as the internally hot ions, the ions would be cooled much more efficiently by the mechanism of resonant energy transfer. However, this mechanism may not be significant in the cooling process of the ions produced in this work, since the concentration of methane in the gas mixture was kept low in order to avoid the formation of larger hydrocarbon ions. As mentioned previously, large hydrocarbon ions such as $\mathrm{C}_{2} \mathrm{H}_{3}^{+}, \mathrm{C}_{2} \mathrm{H}_{5}^{+}, \mathrm{C}_{3} \mathrm{H}_{7}^{+}$, and $\mathrm{C}_{4} \mathrm{H}_{9}^{+}$, instead of the carbonium ions, were found to be dominant in the mass spectrum when the 
concentration of methane was high. Therefore, the primary mechanism for the cooling of the carbonium ions in this work would be nonresonant energy transfer, efficient only when the molecules possess low frequency vibrational modes.

According to the ab initio calculations on $\mathrm{CH}_{5}{ }^{+}$and $\mathrm{CH}_{5}{ }^{+}\left(\mathrm{H}_{2}\right),{ }^{11,19}$ the lowest vibrational frequency for $\mathrm{e}-\mathrm{C}_{s} \mathrm{CH}_{s}^{+}$was predicted to be quite high $\left(856 \mathrm{~cm}^{-1}\right)$ since the $\mathrm{CH}_{3}-\mathrm{H}_{2}$ torsional mode $\left(145 \mathrm{~cm}^{-1}\right)$ would be a free internal rotation. On the other hand, the molecular hydrogen solvated carbonium ions, $\mathrm{CH}_{5}{ }^{+}\left(\mathrm{H}_{2}\right)_{\mathrm{n}}$ were predicted to possess several low frequency modes involving the core-ligand bonds. As a result, the $\mathrm{CH}_{s}{ }^{+}$ions were expected to possess significant internal energy due to the inefficient cooling whereas the $\mathrm{CH}_{5}^{+}\left(\mathrm{H}_{2}\right)_{\mathrm{n}}(\mathrm{n}=1-6)$ ions were expected to be internally cold.

Small internally cold clusters of $\mathrm{CH}_{5}{ }^{+}\left(\mathrm{H}_{2}\right)_{\mathrm{n}}$ could also be formed during the flight before the mass selection in the magnetic sector, by releasing some $\mathrm{H}_{2}$ molecules from the large clusters of $\mathrm{CH}_{5}{ }^{+}\left(\mathrm{H}_{2}\right)_{n}$. The $\mathrm{CH}_{5}{ }^{+}\left(\mathrm{H}_{2}\right)_{\mathrm{n}}(\mathrm{n}=1-6)$ ions were further cooled down by storing them in an ion trap for $-2 \mathrm{msec}$, during which some radiative cooling took place. Metastable ions, if they exist, would dissociate during the trapping, and their contributions to the observed IR spectra were eliminated by doing a background substraction with the experimental scheme of laser on and off. In this experiment, the background level with laser off was found to be less than $0.1 \%$ of the parent ions, indicating the cold nature of the molecular hydrogen solvated carbonium ions, $\mathrm{CH}_{5}{ }^{+}\left(\mathrm{H}_{2}\right)_{\mathrm{n}}(\mathrm{n}=1-6)$.

\subsection{Infrared Spectra}

Fig. 3 shows the IR spectra for the molecular hydrogen solvated carbonium ions, 
$\mathrm{CH}_{5}{ }^{+}\left(\mathrm{H}_{2}\right)_{\mathrm{n}}(\mathrm{n}=1-5)$ obtained in the frequency range of $2700-3200 \mathrm{~cm}^{-1}$. The spectral features in this frequency region are due to the $\mathrm{C}-\mathrm{H}$ stretching modes of the $\mathrm{CH}_{5}^{+}$cores in $\mathrm{CH}_{5}{ }^{+}\left(\mathrm{H}_{2}\right)_{\mathrm{n}}(\mathrm{n}=1-5)$. Three $\mathrm{C}-\mathrm{H}$ stretching bands were predicted by ab initio calculations in this frequency range, and the solid lines in Fig. 3 are the result of a least squares fit with three gaussian peaks. The positions of the fitted gaussian peaks are listed in Table III.

Fig. 4 shows the IR spectra for the molecular hydrogen solvated carbonium ions $\mathrm{CH}_{5}{ }^{+}\left(\mathrm{H}_{2}\right)_{\mathrm{n}}(\mathrm{n}=1-6)$ obtained in the frequency range of $4050-4150 \mathrm{~cm}^{-1}$. The observed features are due to the $\mathrm{H}-\mathrm{H}$ stretching modes of the solvent $\mathrm{H}_{2}$ molecules in $\mathrm{CH}_{5}^{+}\left(\mathrm{H}_{2}\right)_{\mathrm{n}}$ $(n=1-6)$

In this work, the signal-to-noise ratios of the IR spectra for the large clusters were found to be considerably lower than those for the small clusters, since the absolute number densities of the large clusters were found to be lower than the small clusters due to the weaker binding of the large clusters, and several vibrational predissociation channels available for the large clusters would compete each other, resulting in the smaller number of daughter ions at each channel.

\section{$\mathrm{CH}_{5}^{+}\left(\mathrm{H}_{2}\right)$}

The IR spectra for the $\mathrm{C}-\mathrm{H}$ stretching modes of $\mathrm{CH}_{5}{ }^{+}\left(\mathrm{H}_{2}\right)$, shown in Fig. $3 \mathrm{~A}$ and $3 \mathrm{~B}$, were obtained by monitoring the $\mathrm{CH}_{5}{ }^{+} \operatorname{signal}(\mathrm{m} / \mathrm{e}=17)$. As reported previously, ${ }^{20,21}$ the two IR spectra (Fig. 3A and 3B) were obtained with hot ion conditions and cold ion conditions, respectively (see ref. 10 for the details of the source conditions). One broad 
feature with shoulders, centered at $2964 \mathrm{~cm}^{-1}$, was observed in the IR spectrum with cold ion conditions (Fig. 3B), indicating the floppy nature of $\mathrm{CH}_{5}^{+}$. The shoulder features observed in the cold ion spectrum almost disappeared in the hot ion spectrum (Fig. 3A), revealing increased scrambling of the core $\mathrm{CH}_{5}^{+}$. The lowest frequency peak among three gaussian peaks fitted into the observed IR spectrum with cold ion conditions was quite broad, extending from $2700 \mathrm{~cm}^{-1}$ to $3100 \mathrm{~cm}^{-1}$, centered at $2907 \mathrm{~cm}^{-1}$ (see Table III). According to the recent ab initio calculation on $\mathrm{CH}_{5}{ }^{+}\left(\mathrm{H}_{2}\right),{ }^{19}$, three $\mathrm{C}-\mathrm{H}$ stretching frequencies for $\mathrm{e}-\mathrm{C}_{\mathrm{s}} \mathrm{CH}_{5}{ }^{+}$core, the global minimum energy structure, were predicted to be 2898,2998 , and $3081 \mathrm{~cm}^{-1}$, corresponding to the symmetric $\mathrm{CH}_{3}$ breathing, symmetric $\mathrm{CH}_{3}$ degenerate stretching, and asymmetric $\mathrm{CH}_{3}$ stretching modes, as shown in Table II. These vibrational modes were also predicted to have more or less similar IR intensities. The $\mathrm{C}-\mathrm{H}$ stretching frequencies for the low lying transition state structures such as s- $\mathrm{C}_{s}$ and $\mathrm{C}_{2 \mathrm{v}} \mathrm{CH}_{5}^{+}$were predicted to be 2914,2968 , and $3085 \mathrm{~cm}^{-1}$ for the former, and 2732 , 2987 , and $3094 \mathrm{~cm}^{-1}$ for the latter (Table II). ${ }^{11}$ The two structures were regarded as the transition states along the internal $\mathrm{CH}_{3}$ rotation, and along the in-plane wagging of the $\mathrm{H} 2$ between $\mathrm{Hl}$ and $\mathrm{H} 3$ in the $\mathrm{CH}_{5}{ }^{+}$core, respectively (see Fig. 1). The latter motion will be referred to subsequently as the in-plane wagging motion. It is interesting to notice that the vibrational assignments for the two high $\mathrm{C}-\mathrm{H}$ stretching frequencies of $\mathrm{s}-\mathrm{C}_{\mathrm{s}} \mathrm{CH}_{5}{ }^{+}$core (2968 and $3085 \mathrm{~cm}^{-1}$ ) were the asymmetric $\mathrm{CH}_{3}$ stretching and symmetric $\mathrm{CH}_{3}$ degenerate stretching modes, respectively, which were switched in order, compared to the case for e- $\mathrm{C}_{\mathrm{s}} \mathrm{CH}_{5}^{+}$. This could be the result of the substantial geometrical changes in the $\mathrm{CH}_{3}$ group during the internal rotation, as expected from the differences in the optimized C-H 
bond lengths and angles ${ }^{11,12}$ between $\mathrm{e}-\mathrm{C}_{\mathrm{s}} \mathrm{CH}_{5}{ }^{+}$and $\mathrm{s}-\mathrm{C}_{\mathrm{s}} \mathrm{CH}_{5}{ }^{+}$. The $\mathrm{C}_{2 \mathrm{v}} \mathrm{CH}_{5}^{+}$structure consisted of two strong $\mathrm{C}-\mathrm{H}$ bonds and three weak $\mathrm{C}-\mathrm{H}$ bonds forming a four-center three electron (4c3e) bond: Correspondingly, the three C-H stretching frequencies $(2732,2987$, and $3094 \mathrm{~cm}^{-1}$ ) were assigned to the asymmetric $\mathrm{C}$ - $\mathrm{H}$ stretching mode involving two weak $\mathrm{C}-\mathrm{H}$ bonds, symmetric and asymmetric $\mathrm{C}-\mathrm{H}$ stretching modes involving two strong $\mathrm{C}-\mathrm{H}$ bonds, respectively (Table II)."

The observation of one broad feature with shoulders in the IR spectrum (Fig. 3B) and the result of the broad gaussian peak fitted into the low frequency shoulder suggested that the $\mathrm{CH}_{5}^{+}$core in $\mathrm{CH}_{5}^{+}\left(\mathrm{H}_{2}\right)$ scrambles considerably via large amplitude motions such as the $\mathrm{CH}_{3}$ internal rotation involving the $\mathrm{s}-\mathrm{C}_{\mathrm{s}}$ transition state, and the in-plane wagging motion involving the $\mathrm{C}_{2 \mathrm{v}}$ transition state. Nonetheless, the center of the observed feature at $2965 \mathrm{~cm}^{-1}$ was only $27 \mathrm{~cm}^{-1}$ red-shifted from the average $\mathrm{C}-\mathrm{H}$ stretching frequency of $\mathrm{CH}_{4}\left(2992 \mathrm{~cm}^{-1}\right),{ }^{27}$ reflecting the fact that when a hydrogen atom in $\mathrm{CH}_{5}{ }^{+}$does not participate in the scrambling motions, its corresponding $\mathrm{C}-\mathrm{H}$ bond is similar to the $\mathrm{C}-\mathrm{H}$ bond in $\mathrm{CH}_{4}$.

Fig. 4A shows the IR spectrum for the $\mathrm{H}-\mathrm{H}$ stretching mode of the $\mathrm{H}_{2}$ in $\mathrm{CH}_{5}{ }^{+}\left(\mathrm{H}_{2}\right)$, obtained by monitoring the $\mathrm{CH}_{5}^{+}$signal $(\mathrm{m} / \mathrm{e}=17)$ with $0.2 \mathrm{~cm}^{-1}$ laser resolution. The vibration-rotational spectrum shows clear P-, Q-, and R-branches, indicating the A-type transition of a near symmetric top. The band origin was $4077.4 \mathrm{~cm}^{-1}, 82.6 \mathrm{~cm}^{-1}$ redshifted from free $\mathrm{H}_{2}\left(4160 \mathrm{~cm}^{-1}\right)$, which suggests that the interaction between the $\mathrm{CH}_{5}{ }^{+}$ core and the $\mathrm{H}_{2}$ molecule in $\mathrm{CH}_{5}^{+}\left(\mathrm{H}_{2}\right)$ is dominated by the electrostatic charge induced dipole interaction. The dipole moment of $\mathrm{H}_{2}$ induced by the ion core allowed the $\mathrm{H}-\mathrm{H}$ 
stretching mode to be IR active. The spacing of adjacent rotational lines ranged from 1.4 $\mathrm{cm}^{-1}$ to $1.6 \mathrm{~cm}^{-1}$. The rotational lines were found to possess some fine structures, as shown in Fig. 4A. Two anomalously intense peaks were observed in the R-branch side, as indicated by asterisks in Fig. 4A, and they could be assigned to the Q-branches of two hot band transitions. The rotational progressions of the hot band transitions may contribute to the wide spread of rotational lines with a high background, observed in the R-branch side (see Fig. 4A). The full analysis of the vibration-rotational spectrum will be reported elsewhere.

$\mathrm{CH}_{5}^{+}\left(\mathrm{H}_{2}\right)_{2}$

Fig. $3 \mathrm{C}$ shows the IR spectrum for the $\mathrm{C}-\mathrm{H}$ stretching modes of $\mathrm{CH}_{5}^{+}\left(\mathrm{H}_{2}\right)_{2}$, obtained by monitoring the $\mathrm{CH}_{s}^{+}$signal $(\mathrm{m} / \mathrm{e}=17)$. Two spectral features, centered at 2957 $\mathrm{cm}^{-1}$ and $3078 \mathrm{~cm}^{-1}$, were observed in the frequency range of $2700-3200 \mathrm{~cm}^{-1}$. The broad and intense feature at $2957 \mathrm{~cm}^{-1}$ was fitted with two equal gaussian peaks centered at 2930 and $2983 \mathrm{~cm}^{-1}$, respectively, as shown in Table III, and the narrow feature at 3078 $\mathrm{cm}^{-1}$ was fitted with one gaussian peak. The ab initio $\mathrm{C}-\mathrm{H}$ stretching frequencies for $\mathrm{e}-\mathrm{C}_{\mathrm{s}}$ $\mathrm{CH}_{5}{ }^{+}$in $\mathrm{CH}_{5}{ }^{+}\left(\mathrm{H}_{2}\right)_{2}$, shown in Table II, were more or less similar to those for e- $\mathrm{C}_{\mathrm{s}} \mathrm{CH}_{5}^{+}$ in $\mathrm{CH}_{5}{ }^{+}\left(\mathrm{H}_{2}\right)$ after appropriate scaling. The ab initio $\mathrm{C}-\mathrm{H}$ stretching frequencies for $\mathrm{s}-\mathrm{C}_{\mathrm{s}}$ and $\mathrm{C}_{2 \mathrm{v}} \mathrm{CH}_{5}{ }^{+}$cores in $\mathrm{CH}_{5}^{+}\left(\mathrm{H}_{2}\right)_{2}$ were also expected to be similar to the corresponding frequencies for $\mathrm{CH}_{5}^{+}\left(\mathrm{H}_{2}\right)$.

The low frequency shoulder feature observed in the IR spectrum for $\mathrm{CH}_{5}^{+}\left(\mathrm{H}_{2}\right)$ was not present in the spectrum for $\mathrm{CH}_{5}{ }^{+}\left(\mathrm{H}_{2}\right)_{2}$. This suggested that the scrambling motion 
through the in-plane wagging motion (via $\mathrm{C}_{2 v}$ structure) may be frozen out by the two $\mathrm{H}_{2}$ molecules in $\mathrm{CH}_{5}^{+}\left(\mathrm{H}_{2}\right)_{2}$, unlike the case for $\mathrm{CH}_{5}^{+}\left(\mathrm{H}_{2}\right)$. However, the scrambling of the $\mathrm{CH}_{5}^{+}$core through the $\mathrm{CH}_{3}$ internal rotation was still extensive, indicated by the broad feature at $2957 \mathrm{~cm}^{-1}$, and strong anharmonic couplings for the vibrational modes involving these three $\mathrm{C}-\mathrm{H}$ bonds were also expected.

Fig. 4B shows the IR spectrum of the $\mathrm{H}-\mathrm{H}$ stretching modes for the two $\mathrm{H}_{2}$ molecules in $\mathrm{CH}_{5}^{+}\left(\mathrm{H}_{2}\right)_{2}$, obtained by monitoring the $\mathrm{CH}_{5}^{+}$signal in the frequency range of $4050-4150 \mathrm{~cm}^{-1}$. The IR spectrum was taken with $0.2 \mathrm{~cm}^{-1}$ laser resolution and $1 \mathrm{~cm}^{-1}$ scan step. In spite of the large scan step, the observed spectrum showed clear P-, Q-, and R-branches, indicating the A-type transition of a near symmetric top. The presence of a single rotational progression suggested that the two $\mathrm{H}_{2}$ molecules were bound to the two $\mathrm{H}$ atoms forming a $3 \mathrm{c} 2 \mathrm{e}$ bond, with almost equal strength. In this case, the in-phase $\mathrm{H}-\mathrm{H}$ stretching vibration of the two $\mathrm{H}_{2}$ molecules would be responsible for the observed feature since the change of dipole moment due to the in-phase vibration would be along the Aaxis of $\mathrm{CH}_{5}^{+}\left(\mathrm{H}_{2}\right)_{2}$.

The band origin was $-4088 \mathrm{~cm}^{-1}, 72 \mathrm{~cm}^{-1}$ red-shifted from free $\mathrm{H}_{2}$, but $10 \mathrm{~cm}^{-1}$ blue-shifted from $\mathrm{CH}_{5}^{+}\left(\mathrm{H}_{2}\right)$. This indicated that the interactions between $\mathrm{CH}_{5}^{+}$core and two $\mathrm{H}_{2}$ molecules in $\mathrm{CH}_{s}^{+}\left(\mathrm{H}_{2}\right)_{2}$ were also the charge induced dipole interactions, and the interactions were weaker for $\mathrm{CH}_{5}^{+}\left(\mathrm{H}_{2}\right)_{2}$ since the positive charge of the core $\mathrm{CH}_{5}^{+}$was more delocalized in $\mathrm{CH}_{5}^{+}\left(\mathrm{H}_{2}\right)_{2}$.

\section{$\mathrm{CH}_{5}{ }^{+}\left(\mathrm{H}_{2}\right)_{3}$}


Fig. 3D shows the IR spectrum for the $\mathrm{C}-\mathrm{H}$ stretching modes of $\mathrm{CH}_{5}{ }^{+}\left(\mathrm{H}_{2}\right)_{3}$, obtained by monitoring the $\mathrm{CH}_{s}{ }^{+}$signal in the frequency range of $2800-3100 \mathrm{~cm}^{-1}$. Three partially resolved peaks, centered at 2892,2977 , and $3062 \mathrm{~cm}^{-1}$, were found in the IR spectrum. The presence of the three well-separated peaks suggested that the scrambling motions of the $\mathrm{CH}_{5}{ }^{+}$core were almost frozen out by the three $\mathrm{H}_{2}$ molecules in $\mathrm{CH}_{5}{ }^{+}\left(\mathrm{H}_{2}\right)_{3}$, and the $\mathrm{CH}_{5}^{+}$core could be considered as semi-rigid. It is interesting to notice that the observed frequencies $\left(2892,2977,3062 \cdot \mathrm{cm}^{-1}\right)$ match well with the three ab initio $\mathrm{CH}_{3}$ stretching frequencies for e- $\mathrm{C}_{s} \mathrm{CH}_{5}^{+}\left(2891,2993,3079 \mathrm{~cm}^{-1}\right)$ and e- $\mathrm{C}_{\mathrm{s}} \mathrm{CH}_{5}^{+}\left(\mathrm{H}_{2}\right)(2898$, 2998, $\left.3081 \mathrm{~cm}^{-1}\right)$, calculated at TZ2P (+f) CCSD level, ${ }^{19}$ as shown in Table II. The ab initio $\mathrm{CH}_{3}$ stretching frequencies of e- $\mathrm{C}_{5} \mathrm{CH}_{5}{ }^{+}\left(\mathrm{H}_{2}\right)_{3}$, calculated at MP2/6-311G(D,P) level ${ }^{28}$ also match well with the observed frequencies after appropriate scaling (see Table II). It suggests that the $\mathrm{CH}_{5}{ }^{+}$core in $\mathrm{CH}_{5}{ }^{+}\left(\mathrm{H}_{2}\right)_{3}$ possesses an $\mathrm{e}-\mathrm{C}_{5}$ structure. Since the adiabatic approximations made in the normal mode analysis on the $\mathrm{C}-\mathrm{H}$ stretching frequencies are expected to be valid, due to the semi-rigidity of the $\mathrm{CH}_{5}{ }^{+}$core, the three observed features could be assigned to the symmetric $\mathrm{CH}_{3}$ breathing, symmetric $\mathrm{CH}_{3}$ degenerate stretching, and asymmetric $\mathrm{CH}_{3}$ stretching modes, according to the ab initio normal mode analysis. ${ }^{19}$ Furthermore, the new scaling factors for the anharmonic corrections were calculated by the ratio of $2977 \mathrm{~cm}^{-1}$, one of the observed frequencies, to the corresponding ab initio frequency for the $e-\mathrm{C}_{5} \mathrm{CH}_{5}{ }^{+}$core at the level of theory. The rescaled frequencies are listed in Table II.

Fig. $4 \mathrm{C}$ shows the IR spectrum for the $\mathrm{H}-\mathrm{H}$ stretching modes of the three $\mathrm{H}_{2}$ molecules in $\mathrm{CH}_{5}{ }^{+}\left(\mathrm{H}_{2}\right)_{3}$, obtained by monitoring the $\mathrm{CH}_{5}{ }^{+}$signal in the frequency range 
of 4050-4140 $\mathrm{cm}^{-1}$. Unlike the cases for $\mathrm{CH}_{5}{ }^{+}\left(\mathrm{H}_{2}\right)$ and $\mathrm{CH}_{5}{ }^{+}\left(\mathrm{H}_{2}\right)_{2}$, one broad feature was observed in the spectrum. One of the reasons for the spectral congestion was that the third $\mathrm{H}_{2}$ molecule in $\mathrm{CH}_{5}{ }^{+}\left(\mathrm{H}_{2}\right)_{3}$ was bound to the $\mathrm{CH}_{5}{ }^{+}$core in a different environment . from the first two $\mathrm{H}_{2}$ molecules, indicating the presence of a $3 \mathrm{c} 2 \mathrm{e}$ bond in the $\mathrm{CH}_{5}{ }^{+}$core in $\mathrm{CH}_{5}^{+}\left(\mathrm{H}_{2}\right)_{3}$. The center of the broad feature was located at $\sim 4099 \mathrm{~cm}^{-1}, 61 \mathrm{~cm}^{-1}$ redshifted from free $\mathrm{H}_{2}$, but $11 \mathrm{~cm}^{-1}$ blue-shifted from that of $\mathrm{CH}_{5}^{+}\left(\mathrm{H}_{2}\right)_{2}$. This also suggested that the interactions of the $\mathrm{CH}_{5}^{+}$core with the $\mathrm{H}_{2}$ molecules became weaker due to the increased charge delocalization in $\mathrm{CH}_{5}{ }^{+}\left(\mathrm{H}_{2}\right)_{3}$.

\section{$\mathrm{CH}_{5}{ }^{+}\left(\mathrm{H}_{2}\right)_{4}$}

Fig. $3 \mathrm{E}$ shows the IR spectrum for the $\mathrm{C}-\mathrm{H}$ stretching modes of $\mathrm{CH}_{5}{ }^{+}\left(\mathrm{H}_{2}\right)_{4}$, obtained by monitoring the $\mathrm{CH}_{5}{ }^{+}$signal. Three peaks, centered at 2878, 2977, and 3067 $\mathrm{cm}^{-1}$, were found in the IR spectrum. These three frequencies were similar to those for $\mathrm{CH}_{5}{ }^{+}\left(\mathrm{H}_{2}\right)_{3}\left(2892,2977\right.$, and $\left.3062 \mathrm{~cm}^{-1}\right)$, which were assigned to the symmetric $\mathrm{CH}_{3}$ breathing, symmetric $\mathrm{CH}_{3}$ degenerate stretching, and asymmetric $\mathrm{CH}_{3}$ stretching modes, respectively. This result indicated an e- $\mathrm{C}_{\mathrm{s}}$ structure for the $\mathrm{CH}_{5}{ }^{+}$core in $\mathrm{CH}_{5}{ }^{+}\left(\mathrm{H}_{2}\right)_{4}$, but also no significant solvation effect by the fourth $\mathrm{H}_{2}$ molecule.

Fig. 4D shows the IR spectrum for the $\mathrm{H}-\mathrm{H}$ stretching modes of the $\mathrm{H}_{2}$ molecules in $\mathrm{CH}_{5}{ }^{+}\left(\mathrm{H}_{2}\right)_{4}$. The spectrum was also obtained by monitoring the $\mathrm{CH}_{5}^{+}$signal in the frequency range of $4050-4140 \mathrm{~cm}^{-1}$. One broad feature was again found, centered at $-4106 \mathrm{~cm}^{-1}, 54 \mathrm{~cm}^{-1}$ red-shifted from free $\mathrm{H}_{2}$, but $7 \mathrm{~cm}^{-1}$ blue-shifted from $\mathrm{CH}_{5}{ }^{+}\left(\mathrm{H}_{2}\right)_{3}$, indicating the weaker interaction due to the increased charge delocalization in $\mathrm{CH}_{5}^{+}\left(\mathrm{H}_{2}\right)_{4}$. 
In addition, the slight decrease in the frequency shift from the adjacent smaller cluster ( 7 $\mathrm{cm}^{-1}$ vs $11 \mathrm{~cm}^{-1}$ ) suggested that the solvent effect on the charge induced dipole interaction between the hydrogen molecules and the $\mathrm{CH}_{5}{ }^{+}$core started to decrease at $n=4$, which was consistent with the trend in the $\mathrm{C}-\mathrm{H}$ stretching bands described above.

\section{$\mathrm{CH}_{5}^{+}\left(\mathrm{H}_{2}\right)_{\mathrm{n}}(\mathbf{n}=5,6)$}

Fig. 3F shows the IR spectrum for the $\mathrm{C}-\mathrm{H}$ stretching modes of $\mathrm{CH}_{5}{ }^{+}\left(\mathrm{H}_{2}\right)_{5}$. The IR spectrum was obtained by monitoring the $\mathrm{CH}_{5}{ }^{+}\left(\mathrm{H}_{2}\right)$ signal $(\mathrm{m} / \mathrm{e}=19)$ instead of the $\mathrm{CH}_{5}^{+}$signal, since the $\mathrm{CH}_{5}^{+}\left(\mathrm{H}_{2}\right)$ channel was found to be the major channel for the vibrational predissociation of $\mathrm{CH}_{5}^{+}\left(\mathrm{H}_{2}\right)_{5}$ in the frequency range of $2700-3200 \mathrm{~cm}^{-1}$. Three features, centered at 2879,2972 , and $3043 \mathrm{~cm}^{-1}$, were found in the spectrum, in spite of the low signal-to-noise ratio. These three frequencies are similar to those for $\mathrm{CH}_{5}^{+}\left(\mathrm{H}_{2}\right)_{3}$ and $\mathrm{CH}_{5}{ }^{+}\left(\mathrm{H}_{2}\right)_{4}$, which were assigned to the symmetric $\mathrm{CH}_{3}$ breathing, symmetric $\mathrm{CH}_{3}$ degenerate stretching, and asymmetric $\mathrm{CH}_{3}$ stretching modes of the $\mathrm{e}-\mathrm{C}_{\mathrm{s}} \mathrm{CH}_{5}^{+}$core, respectively. This suggested that the structure of the $\mathrm{CH}_{5}^{+}$core in $\mathrm{CH}_{5}^{+}\left(\mathrm{H}_{2}\right)_{5}$ was not changed by the fifth $\mathrm{H}_{2}$ molecule, but was still an e-C structure.

Fig. $4 \mathrm{E}$ and $4 \mathrm{~F}$ show the IR spectra for the $\mathrm{H}-\mathrm{H}$ stretching modes of $\mathrm{CH}_{5}{ }^{+}\left(\mathrm{H}_{2}\right)_{5}$ and $\mathrm{CH}_{5}{ }^{+}\left(\mathrm{H}_{2}\right)_{6}$, respectively. These IR spectra were obtained by monitoring the $\mathrm{CH}_{5}{ }^{+}$ signal, the major channel in this frequency region, which was different from the case for the $\mathrm{C}-\mathrm{H}$ stretching bands. The additional photon energy in this frequency range was responsible for the complete dissociation. In both spectra, one broad feature was found, centered at 4109 and $4111 \mathrm{~cm}^{-1}, 51$ and $49 \mathrm{~cm}^{-1}$ red-shifted from free $\mathrm{H}_{2}$, respectively. 
These features were only 3 and $2 \mathrm{~cm}^{-1}$ blue-shifted from the adjacent smaller clusters, respectively. This result suggested that the charge induced dipole interactions between the $\mathrm{H}_{2}$ molecules and the $\mathrm{CH}_{5}^{+}$core were almost in saturation for $\mathrm{CH}_{5}^{+}\left(\mathrm{H}_{2}\right)_{5}$ and $\mathrm{CH}_{5}{ }^{+}\left(\mathrm{H}_{2}\right)_{6}$. 


\section{DISCUSSION}

\subsection{Dynamics of $\mathrm{CH}_{5}^{+}$in $\mathrm{CH}_{5}^{+}\left(\mathrm{H}_{2}\right)_{\mathrm{n}}(\mathrm{n}=0-6)$}

Since the IR spectra for $\mathrm{CH}_{5}^{+}\left(\mathrm{H}_{2}\right)_{\mathrm{n}}(\mathrm{n}=1-5)$ provided information about the scrambling motions of $\mathrm{CH}_{5}^{+}$cores, it seems appropriate to discuss the details of the dynamics of $\mathrm{CH}_{5}{ }^{+}$by combining the results of this work and the previous theoretical works. Two crucial theoretical works have been performed previously by Schleyer, Schaefer, and coworkers, and by us in collaboration with Liu and Tse. The first was the high level ab initio calculation at $\mathrm{TZ2P}+\mathrm{f}$ CCSD level, and the second was the ab initio molecular dynamics (MD) simulation. The two theoretical methods seem to be complementary to each other such that the first provides very accurate electronic energies and harmonic frequencies of $\mathrm{CH}_{5}{ }^{+}$, but only for a few optimized nuclear configurations, while the second can simulate all of the classical trajectories of $\mathrm{CH}_{5}{ }^{+}$, allowed at the finite temperatures on the ground electronic potential surface, calculated by the density functional method which may not be as accurate as the first.

Both methods predicted the complete scrambling of $\mathrm{CH}_{5}{ }^{+}$. According to the high level ab initio calculation, ${ }^{11,12}$ the scrambling was predicted to occur through $s-C_{s}$ and $C_{2 v}$ structures, which were regarded as the transition states for the $\mathrm{CH}_{3}$ internal rotation and the in-plane wagging motion. The two internal motions were expected to be strongly coupled to each other such that the $\mathrm{CH}_{3}$ internal rotation would be free only when the $3 \mathrm{c} 2 \mathrm{e}$ bond involved in the in-plane wagging motion is localized, like in the $\mathrm{C}_{\mathrm{s}} \mathrm{CH}_{5}{ }^{+}$ structure. The same high level ab initio calculation on $\mathrm{CH}_{5}{ }^{+}\left(\mathrm{H}_{2}\right)$ predicted almost the same results for the $\mathrm{CH}_{5}{ }^{+}$core in $\mathrm{CH}_{5}{ }^{+}\left(\mathrm{H}_{2}\right)$. At present, no high level ab initio calculation 
has yet been reported on $\mathrm{CH}_{5}{ }^{+}\left(\mathrm{H}_{2}\right)_{\mathrm{n}}(\mathrm{n} \geq 2)$.

Ab initio MD simulations have been performed on $\mathrm{CH}_{s}^{+}\left(\mathrm{H}_{2}\right)_{\mathrm{n}}(\mathrm{n}=0-3)$ as reported previously. During the simulation of $\sim 3$ picoseconds at a temperature of $\sim 100 \mathrm{~K}$, the $3 \mathrm{c} 2 \mathrm{e}$ bond representing a $\mathrm{C}_{\mathrm{s}}$ structure for $\mathrm{CH}_{5}{ }^{+}$could be formed among any pair of $\mathrm{H}$ atoms in $\mathrm{CH}_{5}{ }^{+}$. For $\mathrm{CH}_{5}{ }^{+}\left(\mathrm{H}_{2}\right)$, the $3 \mathrm{c} 2 \mathrm{e}$ bond was more or less localized around the $\mathrm{H}$ atom of the $\mathrm{CH}_{5}{ }^{+}$core which was complexed by the $\mathrm{H}_{2}$ molecule. Scrambling through the two internal motions (via st $\mathrm{C}_{s}$ and $\mathrm{C}_{2 v}$ structures) were still expected to be significant. For $\mathrm{CH}_{5}{ }^{+}\left(\mathrm{H}_{2}\right)_{2}$, the $3 \mathrm{c} 2 \mathrm{e}$ bond was localized to the two $\mathrm{H}$ atoms which were bound by the two $\mathrm{H}_{2}$ molecules. It was explained by the electron deficiency in the $3 \mathrm{c} 2 \mathrm{e}$ bond which attracts the two $\mathrm{H}_{2}$ molecules. Preference for the localized $3 \mathrm{c} 2 \mathrm{e}$ bond was also predicted in the $a b$ initio calculation at MP2/6-31G**, from the decrease in the angle of the $3 c 2 e$ bond ( $\triangle \mathrm{H} 1 \mathrm{CH} 2$ ) from $48.4^{\circ}$ for $\mathrm{CH}_{5}{ }^{+}\left(\mathrm{H}_{2}\right)$ to $47.7^{\circ}$ for $\mathrm{CH}_{5}{ }^{+}\left(\mathrm{H}_{2}\right)_{2}$ (see Fig. 7). ${ }^{15}$ But, the scrambling through the $\mathrm{CH}_{3}$ internal rotation was still extensive. For $\mathrm{CH}_{5}{ }^{+}\left(\mathrm{H}_{2}\right)_{3}$, the $\mathrm{CH}_{5}^{+}$ core was semi-rigid with the $\mathrm{CH}_{3}$ internal rotation considerably hindered, but the in-plane wagging motion unhindered.

In the IR spectrum for the $\mathrm{C}-\mathrm{H}$ stretching modes of $\mathrm{CH}_{5}{ }^{+}\left(\mathrm{H}_{2}\right)$ (Fig. 3B), the center of the observed feature $\left(2965 \mathrm{~cm}^{-1}\right)$ was only 23 and $27 \mathrm{~cm}^{-1}$ red-shifted from the average $\left(2988 \mathrm{~cm}^{-1}\right)$ of the three highest ab initio C-H stretching frequencies of a $\mathrm{C}_{\mathrm{s}} \mathrm{CH}_{s}{ }^{+}\left(\mathrm{e}-\mathrm{C}_{\mathrm{s}}\right.$ and $\left.\mathrm{s}-\mathrm{C}_{\mathrm{s}}\right)$, as shown in Table II, and the average C-H stretching frequency $\left(2992 \mathrm{~cm}^{-1}\right)$ of $\mathrm{CH}_{4}$, respectively. This result suggested that most of the structures possessed by the $\mathrm{CH}_{5}{ }^{+}$ core during the scrambling still contain a $\mathrm{CH}_{3}$ unit with strong $\mathrm{C}-\mathrm{H}$ bonds like those in the optimized $\mathrm{C}_{5} \mathrm{CH}_{5}^{+}$structures or the $\mathrm{C}-\mathrm{H}$ bonds in $\mathrm{CH}_{4}$. The broad low frequency 
shoulder observed in the IR spectrum was suggestive of the scrambling through the inplane wagging motion (via $\mathrm{C}_{2 v}$ structure), which could allow the asymmetric $\mathrm{CH}_{2}$ stretching mode of the $4 \mathrm{c} 3 \mathrm{e}$ bond in $\mathrm{C}_{2 v} \mathrm{CH}_{5}{ }^{+}\left(2732 \mathrm{~cm}^{-1}\right)$ to contribute to the low frequency feature. Therefore, the $\mathrm{CH}_{s}^{+}$core in $\mathrm{CH}_{5}^{+}\left(\mathrm{H}_{2}\right)$ continues to scramble through the $\mathrm{CH}_{3}$ internal rotation and the in-plane wagging motion, but the $\mathrm{C}-\mathrm{H}$ bonds which are not directly involved in the nonclassical bond ( $3 \mathrm{c} 2 \mathrm{e}$ or $4 \mathrm{c} 3 \mathrm{e}$ bond), are expected to be strong like the $\mathrm{C}-\mathrm{H}$ 's in $\mathrm{CH}_{4}$. The A-type vibration-rotational transitions observed in the IR spectrum for the $\mathrm{H}-\mathrm{H}$ stretching mode (Fig. 4A), suggested the structure of $\mathrm{CH}_{5}^{+}\left(\mathrm{H}_{2}\right)$ with the $\mathrm{H}_{2}$ molecule weakly bound to one of the two $\mathrm{H}$ atoms forming the $3 \mathrm{c} 2 \mathrm{e}$ bond, in good agreement with the theoretical predictions. ${ }^{19}$ The anomalously intense peaks and the rotational fine features observed in the spectrum could be due to the scrambling motions involving the $\mathrm{CH}_{3}$ internal rotation and in-plane wagging motion.

For $\mathrm{CH}_{5}{ }^{+}\left(\mathrm{H}_{2}\right)_{2}$, one broad and intense peak at $2957 \mathrm{~cm}^{-1}$ and one narrow peak at $3078 \mathrm{~cm}^{-1}$, were observed while the broad low frequency shoulder observed for $\mathrm{CH}_{5}^{+}\left(\mathrm{H}_{2}\right)$ was no longer present in the IR spectrum (Fig. 3C). This result was consistent with the theoretical prediction that the $\mathrm{CH}_{5}{ }^{+}$core has a $\mathrm{C}_{\mathrm{s}}$ structure with the $3 \mathrm{c} 2 \mathrm{e}$ bond localized. The scrambling through the in-plane wagging motion (via $C_{2 v}$ structure) was expected to be considerably hindered. The broad feature at $2957 \mathrm{~cm}^{-1}$ suggested that the scrambling through the $\mathrm{CH}_{3}$ internal rotation was still significant. Strong anharmonic couplings for the vibrational modes involving the $\mathrm{CH}_{3}$ group were also expected. The broad and intense peak at $2957 \mathrm{~cm}^{-1}$ could be assigned to the two strongly coupled C-H stretching modes, while the narrow feature at $3078 \mathrm{~cm}^{-1}$ could be due to the other less coupled $\mathrm{C}-\mathrm{H}$ 
stretching mode. The A-type vibration-rotational transitions observed in the IR spectrum for the $\mathrm{H}-\mathrm{H}$ stretching modes (Fig. 4B), were suggestive of the $\mathrm{CH}_{5}^{+}\left(\mathrm{H}_{2}\right)_{2}$ structure with the two $\mathrm{H}_{2}$ molecules bound to the two $\mathrm{H}$ atoms forming the $3 \mathrm{c} 2 \mathrm{e}$ bond in the $\mathrm{CH}_{5}{ }^{+}$core. The in-phase vibration of the two $\mathrm{H}-\mathrm{H}$ stretching modes would be exactly along the Aaxis of the ion when the $\mathrm{CH}_{3}$ internal rotation is free.

For $\mathrm{CH}_{5}^{+}\left(\mathrm{H}_{2}\right)_{3}$, three partially resolved features, centered at $2892,2977,3062 \mathrm{~cm}^{-1}$ were observed in the IR spectrum (Fig. 3D), indicating the semi-rigid nature of the $\mathrm{CH}_{5}^{+}$ core. Only scrambling would occur through quantum tunneling, causing the broad bandwidths. It is interesting to notice that the observed frequencies $(2892,2977,3062$ $\left.\mathrm{cm}^{-1}\right)$ match well with the three ab initio $\mathrm{CH}_{3}$ stretching frequencies, for e-C $\mathrm{CH}_{5}{ }^{+}(2891$, $\left.2993,3079 \mathrm{~cm}^{-1}\right)^{11}$ and e- $\mathrm{C}_{s} \mathrm{CH}_{s}{ }^{+}\left(\mathrm{H}_{2}\right)\left(2898,2998,3081 \mathrm{~cm}^{-1}\right) \cdot{ }^{19}$ It suggests that the $\mathrm{CH}_{s}{ }^{+}$ core in $\mathrm{CH}_{5}{ }^{+}\left(\mathrm{H}_{2}\right)_{3}$ possesses an e- $\mathrm{C}_{5}$ structure. Correspondingly, the three $\mathrm{C}-\mathrm{H}$ stretching frequencies could be assigned to the symmetric $\mathrm{CH}_{3}$ breathing, symmetric $\mathrm{CH}_{3}$ degenerate stretching, and asymmetric $\mathrm{CH}_{3}$ stretching modes of e- $\mathrm{C}_{\mathrm{s}} \mathrm{CH}_{5}{ }^{+}$core in $\mathrm{CH}_{5}{ }^{+}\left(\mathrm{H}_{2}\right)_{3}$. The ab initio MD simulation also predicted the semi-rigid nature of the $\mathrm{CH}_{5}^{+}$core, but predicted the scrambling through the in-plane wagging motion, different from the experimental result. The difference was attributed to the underestimation of the potential barrier for the in-plane wagging motion. In addition, other isomers of $\mathrm{CH}_{5}{ }^{+}\left(\mathrm{H}_{2}\right)_{3}$ such as the structure with the third $\mathrm{H}_{2}$ located out of plane to the $3 \mathrm{c} 2 \mathrm{e}$ bond, may contribute to the observed IR spectrum.

For $\mathrm{CH}_{5}{ }^{+}\left(\mathrm{H}_{2}\right)_{4}$, three resolved features, centered at 2878, 2979, and $3067 \mathrm{~cm}^{-1}$, were observed in the IR spectrum (Fig. 3E), similar to the spectral features observed for 
$\mathrm{CH}_{5}{ }^{+}\left(\mathrm{H}_{2}\right)_{3}$ (Fig. 3D). This result suggested that the scrambling of $\mathrm{CH}_{5}{ }^{+}$core was more or less frozen out by the first three $\mathrm{H}_{2}$ molecules, and the addition of the fourth $\mathrm{H}_{2}$ molecule resulted in only a minor change in the structure of the $\mathrm{CH}_{5}{ }^{+}$core. It was consistent with the results of Hiraoka and coworkers' measurements ${ }^{15}$ on $\Delta H_{T}^{\circ}$ 's of the clustering reactions, $\mathrm{CH}_{5}^{+}\left(\mathrm{H}_{2}\right)_{\mathrm{n}-1}+\mathrm{H}_{2}=\mathrm{CH}_{5}{ }^{+}\left(\mathrm{H}_{2}\right)_{\mathrm{n}}$ (see Table I), such that the stabilization of the cluster ions by the fourth $\mathrm{H}_{2}$ molecule was small, compared to the stabilization by the third $\mathrm{H}_{2}(0.17 \mathrm{vs} 0.04 \mathrm{kcal} /$ mole $)$. In the IR spectrum for the $\mathrm{H}-\mathrm{H}$ stretching modes of $\mathrm{CH}_{5}{ }^{+}\left(\mathrm{H}_{2}\right)_{4}$ (Fig. D), the frequency shift of the observed feature from the adjacent smaller cluster decreased from that for $\mathrm{CH}_{5}{ }^{+}\left(\mathrm{H}_{2}\right)_{3}$, which was consistent with the trend for the $\mathrm{C}-\mathrm{H}$ stretching modes as described above.

For $\mathrm{CH}_{5}{ }^{+}\left(\mathrm{H}_{2}\right)_{\mathrm{n}}(\mathrm{n}=5,6)$, the trend of the spectral features observed in the IR spectrum (Fig. 3F, 4E, 4F), were similar to the case for $\mathrm{CH}_{5}{ }^{+}\left(\mathrm{H}_{2}\right)_{4}$. The structures of the $\mathrm{CH}_{5}{ }^{+}$cores were expected to be unchanged by the fifth and sixth $\mathrm{H}_{2}$ molecules.

\subsection{Stabilities and structures of $\mathrm{CH}_{5}{ }^{+}\left(\mathrm{H}_{2}\right)_{\mathrm{n}}(\mathrm{n}=1-6)$}

In this section, the stabilities of the solvated complexes, $\mathrm{CH}_{5}{ }^{+}\left(\mathrm{H}_{2}\right)_{\mathrm{n}}(\mathrm{n}=1-6)$ are discussed from the correlation between the $\mathrm{H}-\mathrm{H}$ stretching frequencies and the strength of the interactions. Possible solvation structures are also presented.

As described previously, the interactions between $\mathrm{CH}_{5}{ }^{+}$core and the $\mathrm{H}_{2}$ molecules are dominated by the electrostatic charge-induced dipole interactions, where the strengths are proportional to the charge densities at the $\mathrm{H}$ atoms of $\mathrm{CH}_{5}{ }^{+}$core, the binding sites for the $\mathrm{H}_{2}$ molecules in $\mathrm{CH}_{5}{ }^{+}\left(\mathrm{H}_{2}\right)_{n}(\mathrm{n}=1-6)$. The effect of the electrostatic interaction on the 
vibrational frequency of the solvent $\mathrm{H}_{2}$ molecule has been addressed previously in the calculation of the Stark shifts of the $\mathrm{H}-\mathrm{H}$ stretching modes as a function of the distance from the charge to $\mathrm{H}_{2}$ molecule by Hunt and Poll. ${ }^{29}$ The frequency shifts of the H-H stretching modes from free $\mathrm{H}_{2}$ could be a measure of the strength of the electrostatic interactions. Fig. 5 shows a plot of the peak positions of the $\mathrm{H}-\mathrm{H}$ stretching modes as a function of the size of the clusters. The frequency shifts from free $\mathrm{H}_{2}\left(4160 \mathrm{~cm}^{-1}\right)$ decreased as the number of $\mathrm{H}_{2}$ molecules increased, and reached a limit at $\mathrm{n}=4$. This result clearly indicated that the positive charge of the $\mathrm{CH}_{s}{ }^{+}$core was gradually delocalized as the size of the clusters increased.

Fig. 6 shows a plot of the correlation between the $\mathrm{H}-\mathrm{H}$ stretching frequencies and the $-\Delta \mathrm{H}_{\mathrm{T}}^{\circ}$ 's of the clustering reactions, $\mathrm{CH}_{5}^{+}\left(\mathrm{H}_{2}\right)_{\mathrm{n}-1}+\mathrm{H}_{2}=\mathrm{CH}_{5}^{+}\left(\mathrm{H}_{2}\right)_{\mathrm{n}}(\mathrm{n}=\mathrm{I}-4)$, measured by Hiraoka and coworkers (see Table I). ${ }^{15}$ The correlation followed the idea of the previous work by Hunt and Poll as described above. A good correlation was found between the $\mathrm{H}-\mathrm{H}$ stretching frequencies and the $-\Delta \mathrm{H}^{\circ}{ }_{\mathrm{T}}$ 's of the clustering reactions, as shown in Fig. 6. From the correlation, the $-\Delta \mathrm{H}_{\mathrm{T}}^{\circ}$ 's for the formation of $\mathrm{CH}_{5}^{+}\left(\mathrm{H}_{2}\right)_{5}$ and $\mathrm{CH}_{5}{ }^{+}\left(\mathrm{H}_{2}\right)_{6}$, which were not measured in the previous work by Hiraoka and coworkers, were calculated to be 1.52 and $1.49 \mathrm{kcal} / \mathrm{mole}$, respectively. Furthermore, one could correlate the $\mathrm{H}-\mathrm{H}$ stretching frequencies with the theoretical binding energies to test the consistency of the calculations.

Finally, it is appropriate to address the possible structures of the solvated complexes, $\mathrm{CH}_{5}{ }^{+}\left(\mathrm{H}_{2}\right)_{n}$ (n=1-6) by combining the results of this work and the results of the theoretical work. Fig. 7 shows the possible structures of $\mathrm{CH}_{5}^{+}\left(\mathrm{H}_{2}\right)_{\mathrm{n}}(\mathrm{n}=1-6)$. Both 
experimental and theoretical results ${ }^{15,19}$ consistently suggested the structures shown in Fig. 7A and 7B for $\mathrm{CH}_{5}^{+}\left(\mathrm{H}_{2}\right)$ and $\mathrm{CH}_{5}^{+}\left(\mathrm{H}_{2}\right)_{2}$, where the $\mathrm{H}_{2}$ molecules were bound to the $\mathrm{H}$ atoms forming the $3 \mathrm{c} 2 \mathrm{e}$ bond in the $\mathrm{CH}_{5}{ }^{+}$core. For $\mathrm{CH}_{5}{ }^{+}\left(\mathrm{H}_{2}\right)_{3}$, the most stable structure was predicted to be the structure shown in Fig. $7 \mathrm{C}$, but other structures such as the structure shown in Fig. 7D, where the third $\mathrm{H}_{2}$ was located out of plane to the $3 \mathrm{c} 2 \mathrm{e}$ bond, could be formed in internally hot ions. Due to the weak interactions between the $\mathrm{CH}_{5}{ }^{+}$ core and the $\mathrm{H}_{2}$ molecules in $\mathrm{CH}_{5}^{+}\left(\mathrm{H}_{2}\right)_{\mathrm{n}} \cdot(\mathrm{n} \geq 4)$; the structures of the ions are better described as the mixture of several structures undergoing rapid isomerizations on the very shallow potential energy surfaces. But, it is still instructive to consider the local minimum structures for $\mathrm{CH}_{5}^{+}\left(\mathrm{H}_{2}\right)_{\mathrm{n}}(\mathrm{n} \geq 4)$. For $\mathrm{CH}_{5}^{+}\left(\mathrm{H}_{2}\right)_{4}$, the fourth $\mathrm{H}_{2}$ could bind to either the $\mathrm{H} 4$ (or $\mathrm{H} 5$ ) of the $\mathrm{CH}_{5}{ }^{+}$core (Fig. 7E) or the 3c2e bond in the out-of-plane fashion (Fig. 7F). For $\mathrm{CH}_{5}^{+}\left(\mathrm{H}_{2}\right)_{s}$, the fifth $\mathrm{H}_{2}$ molecule could bind to the $\mathrm{H} 5$ (or $\mathrm{H} 4$ ) of the $\mathrm{CH}_{5}^{+}$core, completing the first solvation shell around the $\mathrm{CH}_{5}^{+}$core (Fig. $7 \mathrm{G}$ ). In addition, the $\mathrm{CH}_{5}^{+}\left(\mathrm{H}_{2}\right)_{5}$ ions could form the structures with one or two $\mathrm{H}_{2}$ molecules binding to the $3 \mathrm{c} 2 \mathrm{e}$ bond in the out-of-plane fashion (Fig. $7 \mathrm{H}$ ). For $\mathrm{CH}_{5}{ }^{+}\left(\mathrm{H}_{2}\right)_{6}$, the sixth $\mathrm{H}_{2}$ molecule can bind to the $3 \mathrm{c} 2 \mathrm{e}$ bond of the $\mathrm{CH}_{5}{ }^{+}$core in the out-of-plane fashion (Fig. 7I) after the first solvation shell is complete at $n=5$. Other structures involving the isomers of $\mathrm{CH}_{5}{ }^{+}\left(\mathrm{H}_{2}\right)_{4}$ and $\mathrm{CH}_{5}{ }^{+}\left(\mathrm{H}_{2}\right)_{5}$ are also possible for $\mathrm{CH}_{5}{ }^{+}\left(\mathrm{H}_{2}\right)_{6}$. 


\section{SUMMARY}

The infrared spectra for the molecular hydrogen-solvated carbonium ions, $\mathrm{CH}_{5}{ }^{+}\left(\mathrm{H}_{2}\right)_{\mathrm{n}}(\mathrm{n}=1-6)$ have been presented. Spectroscopic evidence has been presented in support of the scrambling of $\mathrm{CH}_{5}^{+}$through the large amplitude motions such as the $\mathrm{CH}_{3}$ internal rotation and the in-plane wagging motion. More importantly, the scrambling motions of $\mathrm{CH}_{s}^{+}$cores were slowed down by attaching the solvent $\mathrm{H}_{2}$ molecules to the core ion. The complete freezing of the scrambling motions was found when the first three $\mathrm{H}_{2}$ molecules were bound to the $\mathrm{CH}_{5}{ }^{+}$core. A good agreement between the experimental results and the theoretical predictions was found in the dynamics of $\mathrm{CH}_{5}{ }^{+}$.

A clear extension of this work would be to improve the resolution of the IR spectra for the $\mathrm{H}-\mathrm{H}$ stretching modes of $\mathrm{CH}_{5}{ }^{+}\left(\mathrm{H}_{2}\right)$ and $\mathrm{CH}_{5}{ }^{+}\left(\mathrm{H}_{2}\right)_{2}$, which would provide additional information on the structures and the rotational and tunneling dynamics of both the $\mathrm{CH}_{5}{ }^{+}$cores and the entire clusters. High order overtone transitions of free $\mathrm{CH}_{5}{ }^{+}$can be measured by improving the schemes for vibrational excitation and probe with the use

of high power IR and $\mathrm{CO}_{2}$ lasers. In addition, significant efforts for the generation of internally cold $\mathrm{CH}_{5}{ }^{+}$ions should be made, so that the IR spectra are not smeared out due to spectral congestion by the scrambling of $\mathrm{CH}_{5}{ }^{+}$. 


\section{REFERENCES}

1. G.A. Olah, G.K.S. Prakash, and J. Sommer, Superacids (Wiley-Interscience, New York, 1985).

2. G.A. Olah, Carbocations and Electrophilic Reactions (Verlag Chemie, Weinheim, 1973).

3. F.H. Field, Acc. Chem. Res., v.1, 42 (1968); F.H. Field, and M.S.B. Munson, J. Am. Chem. Soc., v. 87, 3289 (1965).

4. G.A. Olah, G. Klopman, and R.H. Schlosberg, J. Am. Chem. Soc., v.91, 3261 (1969);

G.A. Olah and R.H. Schlosberg, J. Am. Chem. Soc., v.90, 2726 (1968).

5. D.P. Stevenson and D.O. Schissler, J. Chem. Phys., v.23, 1353 (1955).

6. A. Dalgano, in Molecular Astrophysics; edited by G.H.F. Dierchsen et al (D. Reidel Publishing Company, 1985) pp 3-22.

7. V. Dyczmons, V. Staemmler, and W. Kutzelnigg, Chem. Phys. Lett., v.5, 361 (1970).

8. W.A. Lathan, W.J. Hehre, L.A. Curtiss, and J.A. Pople, J. Am. Chem. Soc., v.93, 6377 (1971); K. Ragavachari, R.A. Whiteside, J.A. Pople, and P.v.R. Schleyer, J. Am. Chem. Soc., v.103, 5649 (1981).

9. K. Hirao and S. Yamabe, Chem Phys., v.89, 237 (1984).

10. W. Klopper and W. Kutzelnigg, J. Phys. Chem., v.94, 5625 (1990).

11. P.R. Schreiner, S.J. Kim, H.F. Schaefer, and P.v.R. Schleyer, J. Chem. Phys., v.99, 3716 (1993).

12. P.v.R. Schleyer and J.W.M. Carneiro, J. Comput. Chem., v.13, 997 (1992). 
13. G.E. Scuseria, Nature, v.366, 512 (1993).

14. K. Hiraoka and T. Mori, Chem. Phys. Lett., v.161, 111 (1989); K. Hiraoka and P. Kebarle, J. Am. Chem. Soc., v.97, 4179 (1975).

15. K. Hiraoka, I. Kudaka, and S. Yamabe, Chem. Phys. Lett., v.184, 271 (1991).

16. M.D. Sefcik, J.M.S. Henis, and P.P. Gasper, J. Chem. Phys., v.61, 4321 (1974).

17. R.D. Smith and J.H. Futrell, Chem. Phys. Lett., v.36, 545 (1975).

18. A.J.R. Heck, L.J. de Koning, and N.M.M. Nibbering, J. Am. Soc. Mass Spectrom., v.2, $453(1991)$.

19. S.J. Kim, P.R. Schreiner, P.v.R. Schleyer, and H.F. Schaefer, J. Phys. Chem., v.97, 12232 (1993).

20. D.W. Boo and Y.T. Lee, Chem. Phys. Lett., v.211, 358 (1993).

21. D.W. Boo, Z.F. Liu, J.T. Tse, Y.T. Lee, and A.G. Suits, submitted to Science (1995).

22. S.W. Bustamente, Ph.D. Thesis, University of California at Berkeley (1983).

23. M. Okumura, Ph.D. Thesis, University of California at Berkeley (1986).

24. L.I.-C. Yeh, Ph.D. Thesis, University of California at Berkeley (1988).

25. J.M. Price, Ph.D. Thesis, University of California at Berkeley (1991).

26. R.N. Daly, Rev. Sci. Instr., v.31, 264 (1960).

27. G. Herzberg, Molecular Spectra and Molecular Structure, v.II Infrared and Raman Spectra of Polyatomic Molecules (Krieger Publishing Company, Florida, 1991).

28. J.T. Tse, unpublished results.

29. J.L. Hunt and J.D. Poll, Can. J. Chem., v.63, 84 (1985). 
TABLE I. Experimental and theoretical dissociation energies and enthalpies for $\mathrm{CH}_{5}{ }^{+}\left(\mathrm{H}_{2}\right)_{\mathrm{n}}$ (Units are $\mathrm{kcal} / \mathrm{mole}$ )

\begin{tabular}{|c|c|c|c|c|c|}
\hline reference & \multicolumn{2}{|c|}{$\mathrm{n}=1$} & 2 & 3 & 4 \\
\hline Hiraoka et al. & $-\Delta \mathrm{H}^{\circ}{ }_{T}$ & $1.88 \pm 0.10$ & $1.78 \pm 0.10$ & $1.61 \pm 0.10$ & $1.57 \pm 0.10$ \\
\hline Hiraoka et al. & $D_{c}$ & 2.02 & 1.76 & 0.91 & 0.64 \\
\hline \multicolumn{3}{|c|}{ MP2/6-31G } & & & \\
\hline Schaefer et al. & $\begin{array}{r}D_{e}\left(D_{0}\right. \\
T Z 2 P+d\end{array}$ & $\begin{array}{l}3.48(1.46) \\
S D(T)\end{array}$ & $\because \quad i$ & & \\
\hline \multirow[t]{2}{*}{ This work } & $\begin{array}{c}D_{c} \\
D M O L(J\end{array}$ & $\begin{array}{l}2.96 \\
V+B 88)\end{array}$ & 2.05 & & \\
\hline & $\begin{array}{c}\mathrm{D}_{\mathrm{c}} \\
\text { DMOL(I }\end{array}$ & $\begin{array}{c}4.30 \\
+B 88)\end{array}$ & 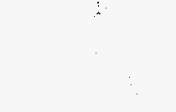 & & \\
\hline
\end{tabular}


TABLE II. Vibrational frequencies ${ }^{2}$ of the $\mathrm{C}-\mathrm{H}$ and $\mathrm{H}-\mathrm{H}$ stretching modes for $\mathrm{CH}_{5}^{+}\left(\mathrm{H}_{2}\right)_{\mathrm{n}}(\mathrm{n}=1-3)$ predicted by the ab initio calculations. Units are in $\mathrm{cm}^{-1}$.

\begin{tabular}{|c|c|c|c|c|}
\hline & $\begin{array}{l}\text { Asym } \mathrm{CH}_{3} \\
\text { stretch }\end{array}$ & $\begin{array}{l}\text { Sym } \mathrm{CH}_{3} \text { deg } \\
\text { stretch }\end{array}$ & $\begin{array}{l}\text { Sym } \mathrm{CH}_{3} \\
\text { breath }\end{array}$ & $\mathrm{H}_{2}$ stretch \\
\hline $\begin{array}{r}\mathrm{CH}_{5}^{+}, \mathrm{e}-\mathrm{C}_{3} \\
\mathrm{TZ} 2 \mathrm{P}+\mathrm{f}^{\mathrm{b}} \\
\mathrm{CCSD}\end{array}$ & $3079(3063)$ & $2993(2977)$ & $2898(2883)$ & - \\
\hline $\begin{array}{r}\mathrm{CH}_{s}^{+}, \mathrm{s}-\mathrm{C}_{\mathrm{s}} \\
\mathrm{TZ2P}+\mathrm{f}^{+} \\
\mathrm{CCSD}\end{array}$ & $2968(2952)$ & $3085(3069)$ & $2914(2898)$ & - \\
\hline $\begin{array}{r}\mathrm{CH}_{s}^{+}, \mathrm{C}_{2 \mathrm{r}} \\
\mathrm{TZ} 2 \mathrm{P}+\mathrm{f}^{\dagger+} \\
\mathrm{CCSD}\end{array}$ & $3094(3077)$ & $2987(2971)$ & $2732(2717)$ & - \\
\hline $\begin{array}{l}\mathrm{CH}_{s}^{+}\left(\mathrm{H}_{2}\right) \\
\mathrm{e}-\mathrm{C}_{s} \mathrm{CH}_{s}^{+} \\
\mathrm{TZ2P} \mathrm{CCSD}\end{array}$ & $3081(3059)$ & $2998(2977)$ & $2898(2878)$ & $4107(4078)$ \\
\hline $\begin{array}{l}\mathrm{CH}_{s}^{+}\left(\mathrm{H}_{2}\right) \\
\mathrm{C}_{2 v} \mathrm{CH}_{s}^{+} \\
\quad \mathrm{TZ2P} \mathrm{SCF}{ }^{\mathrm{ct}}\end{array}$ & $3079(3063)$ & $2972(2956)$ & $2706(2692)$ & $4104(4082)$ \\
\hline $\begin{array}{l}\mathrm{CH}_{5}{ }^{+}\left(\mathrm{H}_{2}\right)_{2} \\
\mathrm{e}-\mathrm{C}_{5} \mathrm{CH}_{5}{ }^{+} \\
\mathrm{MP}^{2} / 6- \\
311 \mathrm{G}(\mathrm{D}, \mathrm{P})^{\mathrm{d}}\end{array}$ & $3278(3069)$ & $3183(2980)$ & $3068(2872)$ & $\begin{array}{l}4446(4162) \\
4463(4178)\end{array}$ \\
\hline $\begin{array}{c}\mathrm{CH}_{s}{ }^{+}\left(\mathrm{H}_{2}\right)_{3} \\
\mathrm{e}-\mathrm{C}_{s} \mathrm{CH}_{s}^{+} \\
\mathrm{MP} 2 / 6- \\
311 \mathrm{G}(\mathrm{D}, \mathrm{P})^{\mathrm{d}}\end{array}$ & $3280(3071)$ & $3180(2977)$ & $3043(2849)$ & $\begin{array}{l}4448(4164) \\
4459(4174) \\
4493(4206)\end{array}$ \\
\hline
\end{tabular}

The numbers in parenthesis are the frequencies scaled by the ratio of $2977 \mathrm{~cm}^{-1}$, one of the observed peaks for $\mathrm{CH}_{5}{ }^{+}\left(\mathrm{H}_{2}\right)_{3}$, and the corresponding ab initio C-H stretching frequency for the eclipsed $\mathrm{C}_{s} \mathrm{CH}_{s}{ }^{+}$core at the level of theory. For example, the ratio was $2977 / 2993=.995$ at TZ2P+f CCSD; $2977 / 2998=.993$ at TZ2P CCSD; 2977/2993=.995 at TZ2P SCF; 2977/3180 $=.936$ at MP2/6-311G(D,P).

${ }^{b}$ Ref. 11. ${ }^{c}$ Ref. 19. ${ }^{\mathrm{d}}$ Ref. 28

Note that the vibrational assignments for $\mathrm{C}_{2 \gamma} \mathrm{CH}_{3}^{+}$should be changed to the $\mathrm{CH}_{2}$ asymmetric, $\mathrm{CH}_{2}$ symmetric, and $\mathrm{CH}_{2}{ }^{\circ}$ asymmetric stretching modes, respectively $\left(\mathrm{CH}_{2}{ }^{\circ}\right.$ indicates the two of three $\mathrm{C}-\mathrm{H}$ bonds forming the $4 \mathrm{c} 3 \mathrm{c}$ bond). 
TABLE III. Vibrational frequencies of the molecular hydrogen solvated carbonium ions. Units are in $\mathrm{cm}^{-1}$.

\begin{tabular}{|l|l|l|}
\hline Ions & C-H Stretching Modes ${ }^{\mathrm{a}}$ & $\begin{array}{l}\text { Band Origins of H-H } \\
\text { Stretching Modes }\end{array}$ \\
\hline \hline $\mathrm{CH}_{5}{ }^{+}\left(\mathrm{H}_{2}\right)$ & $2964(2907,2965,3070)^{\mathrm{b}}$ & $4077.4^{\mathrm{c}}$ \\
\hline $\mathrm{CH}_{5}{ }^{+}\left(\mathrm{H}_{2}\right)_{2}$ & $2957(2930,2983){ }^{\mathrm{b}} 3078$ & $4088.2^{\mathrm{c}}$ \\
\hline $\mathrm{CH}_{5}{ }^{+}\left(\mathrm{H}_{2}\right)_{3}$ & $2892,2977,3062$ & $4099^{d}$ \\
\hline $\mathrm{CH}_{5}{ }^{+}\left(\mathrm{H}_{2}\right)_{4}$ & $2878,2979,3067$ & $4106^{\mathrm{d}}$ \\
\hline $\mathrm{CH}_{5}{ }^{+}\left(\mathrm{H}_{2}\right)_{5}$ & $2879,2972,3043$ & $4109^{\mathrm{d}}$ \\
\hline $\mathrm{CH}_{5}{ }^{+}\left(\mathrm{H}_{2}\right)_{6}$ & & $4111^{\mathrm{d}}$ \\
\hline
\end{tabular}

${ }^{3}$ These $\mathrm{C}-\mathrm{H}$ stretching frequencies were determined by the nonlinear least square fit with three gaussian peaks.

${ }^{b} T$ These frequencies in paranthesis were not resolved in the observed spectra. The frequencies for $n=2$ were obtained by fitting with two equal gaussian peaks.

'These frequencies were measured at the maximum of the Q-branches.

${ }^{\mathrm{T}}$ These frequencies were measured at the center of the observed features.

Not Observed. 


\section{FIGURE CAPTIONS}

Fig. $1 \mathrm{Ab}$ initio structures of $\mathrm{CH}_{5}^{+}$

Fig. 2 Mass spectrum showing the carbonium ion $\mathrm{CH}_{5}{ }^{+}$and the molecular hydrogen solvated carbonium ions $\mathrm{CH}_{5}^{+}\left(\mathrm{H}_{2}\right)_{\mathrm{n}}(\mathrm{n}=1-6)$. The mixing ratio of $\mathrm{CH}_{4}: \mathrm{H}_{2}$ was 1:3,000,000, and the source temperature and the discharge current were $-30^{\circ} \mathrm{C}$ and $20 \mu \mathrm{A}$, respectively.

Fig. 3 IR spectra for the $\mathrm{C}-\mathrm{H}$ stretching modes of the $\mathrm{CH}_{5}{ }^{+}$cores: $(\mathrm{A}) \mathrm{CH}_{5}{ }^{+}\left(\mathrm{H}_{2}\right)$, under hot ion conditions; (B) $\mathrm{CH}_{5}{ }^{+}\left(\mathrm{H}_{2}\right)$, under cold ion conditions; (C) $\mathrm{CH}_{5}{ }^{+}\left(\mathrm{H}_{2}\right)_{2} ;(\mathrm{D}) \mathrm{CH}_{5}{ }^{+}\left(\mathrm{H}_{2}\right)_{3}$; (E) $\mathrm{CH}_{5}^{+}\left(\mathrm{H}_{2}\right)_{4}$; (F) $\mathrm{CH}_{5}^{+}\left(\mathrm{H}_{2}\right)_{s}$.

Fig. 4 IR spectra for the $\mathrm{H}-\mathrm{H}$ stretching modes of the solvent $\mathrm{H}_{2}$ molecules: (A) $\mathrm{CH}_{5}^{+}\left(\mathrm{H}_{2}\right) ;(\mathrm{B}) \mathrm{CH}_{5}^{+}\left(\mathrm{H}_{2}\right)_{2} ;(\mathrm{C}) \mathrm{CH}_{5}^{+}\left(\mathrm{H}_{2}\right)_{3} ;$ (D) $\mathrm{CH}_{5}{ }^{+}\left(\mathrm{H}_{2}\right)_{4} ;(\mathrm{E}) \mathrm{CH}_{5}^{+}\left(\mathrm{H}_{2}\right)_{5}$; (F) $\mathrm{CH}_{5}^{+}\left(\mathrm{H}_{2}\right)_{6}$.

Fig. 5 Plot of the $\mathrm{H}-\mathrm{H}$ stretching frequencies as a function of the size of the clusters $\mathrm{CH}_{5}^{+}\left(\mathrm{H}_{2}\right)_{\mathrm{n}}(\mathrm{n}=1-6)$.

Fig. 6 Plot of correlation between the $\mathrm{H}-\mathrm{H}$ stretching frequencies and the $-\Delta \mathrm{H}_{\mathrm{T}}^{\circ}$ 's of the clustering reactions, $\mathrm{CH}_{5}{ }^{+}\left(\mathrm{H}_{2}\right)_{\mathrm{n}-1}+\mathrm{H}_{2}=\mathrm{CH}_{5}{ }^{+}\left(\mathrm{H}_{2}\right)_{\mathrm{n}}(\mathrm{n}=1-4)$.

Fig. 7 Possible structures of the molecular hydrogen solvated carbonium ions, $\mathrm{CH}_{5}{ }^{+}\left(\mathrm{H}_{2}\right)_{\mathrm{n}}$ 
$(n=1-6)$ 

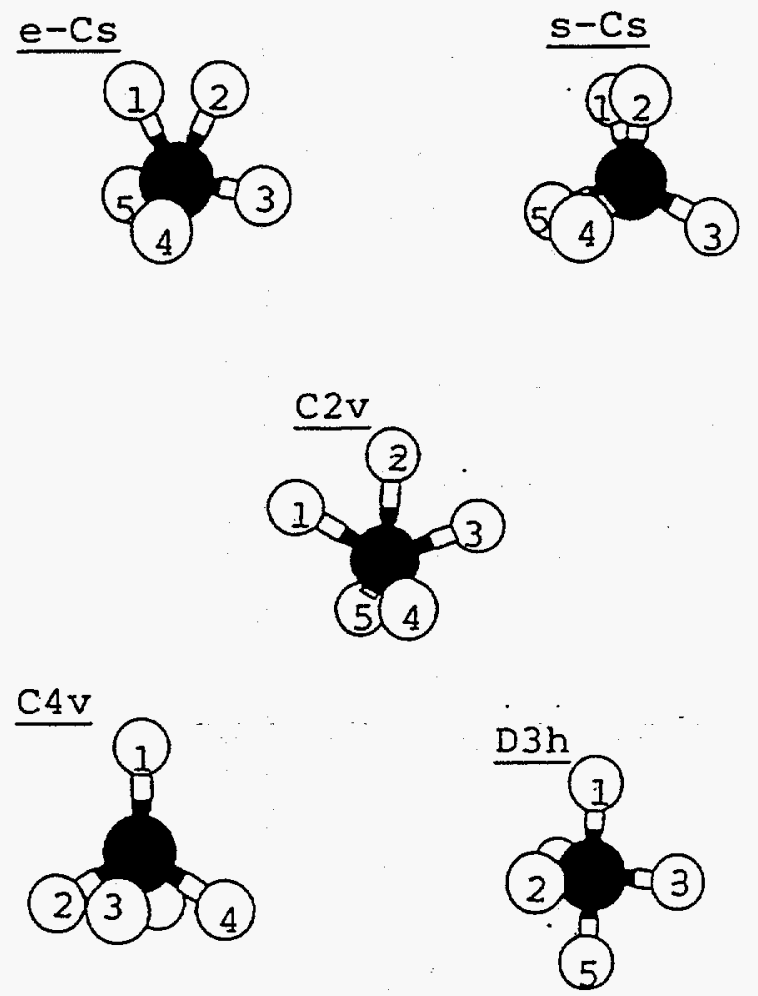

Fig. 1 


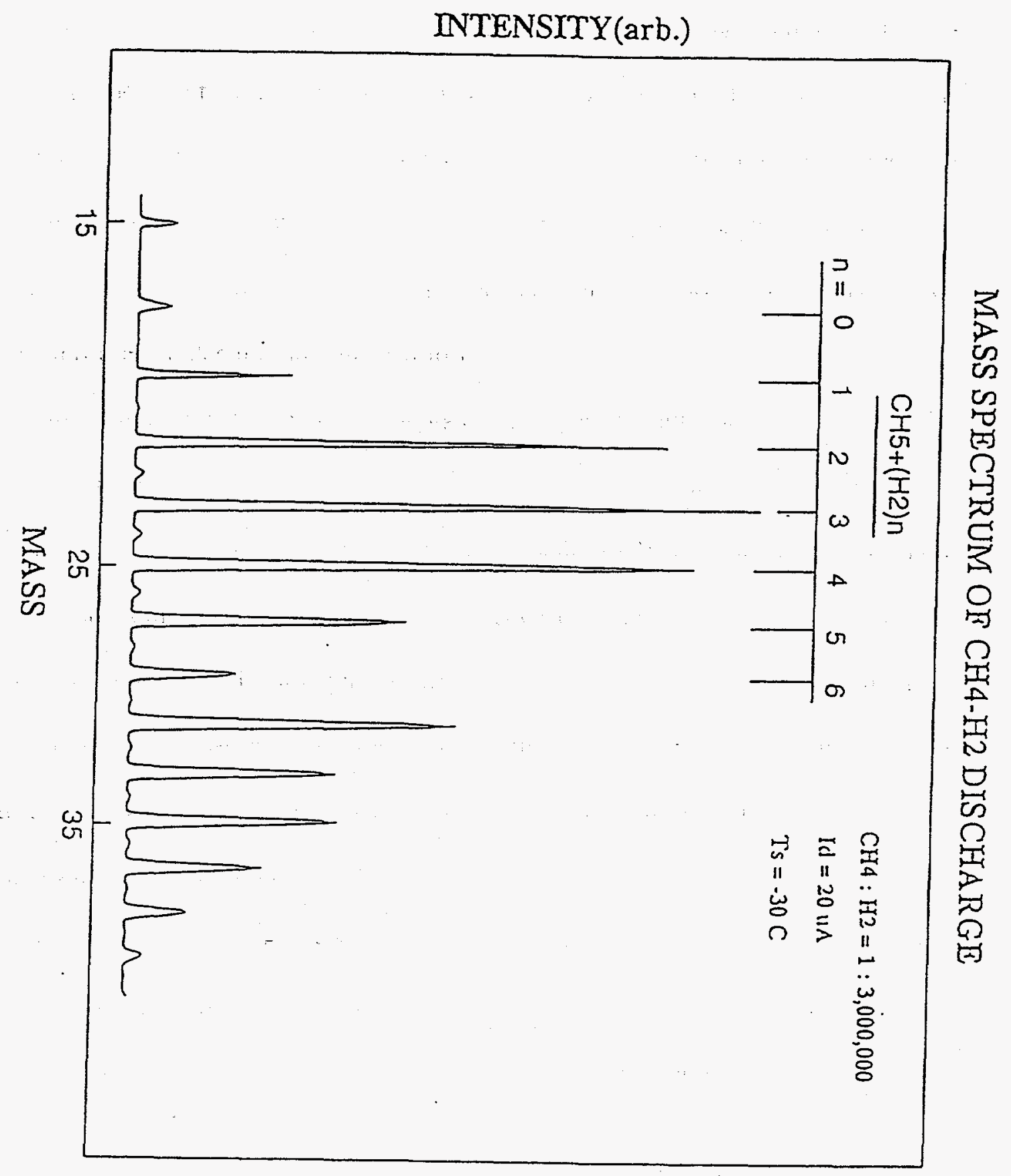

Fig. 2 


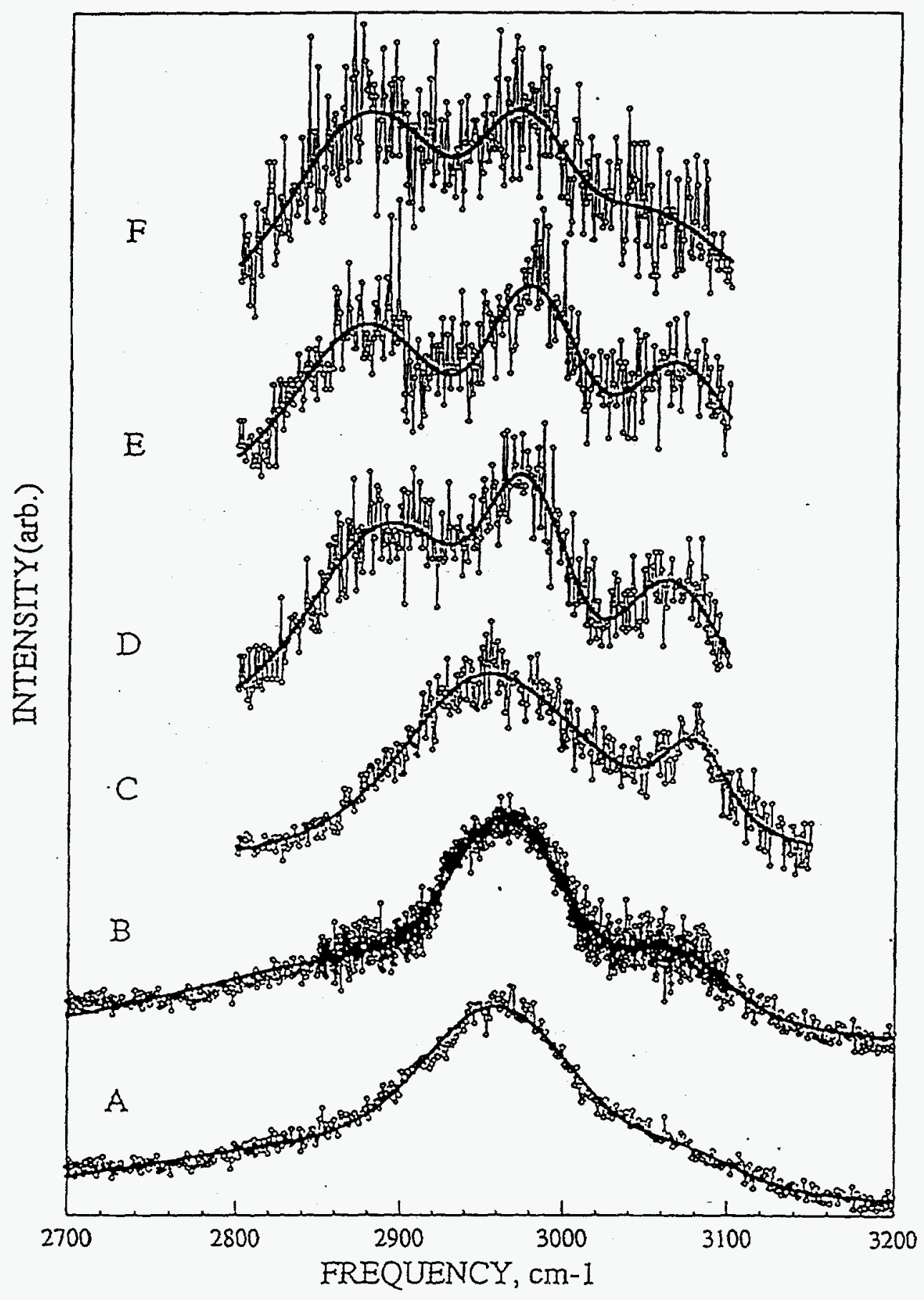

Fig. 3 


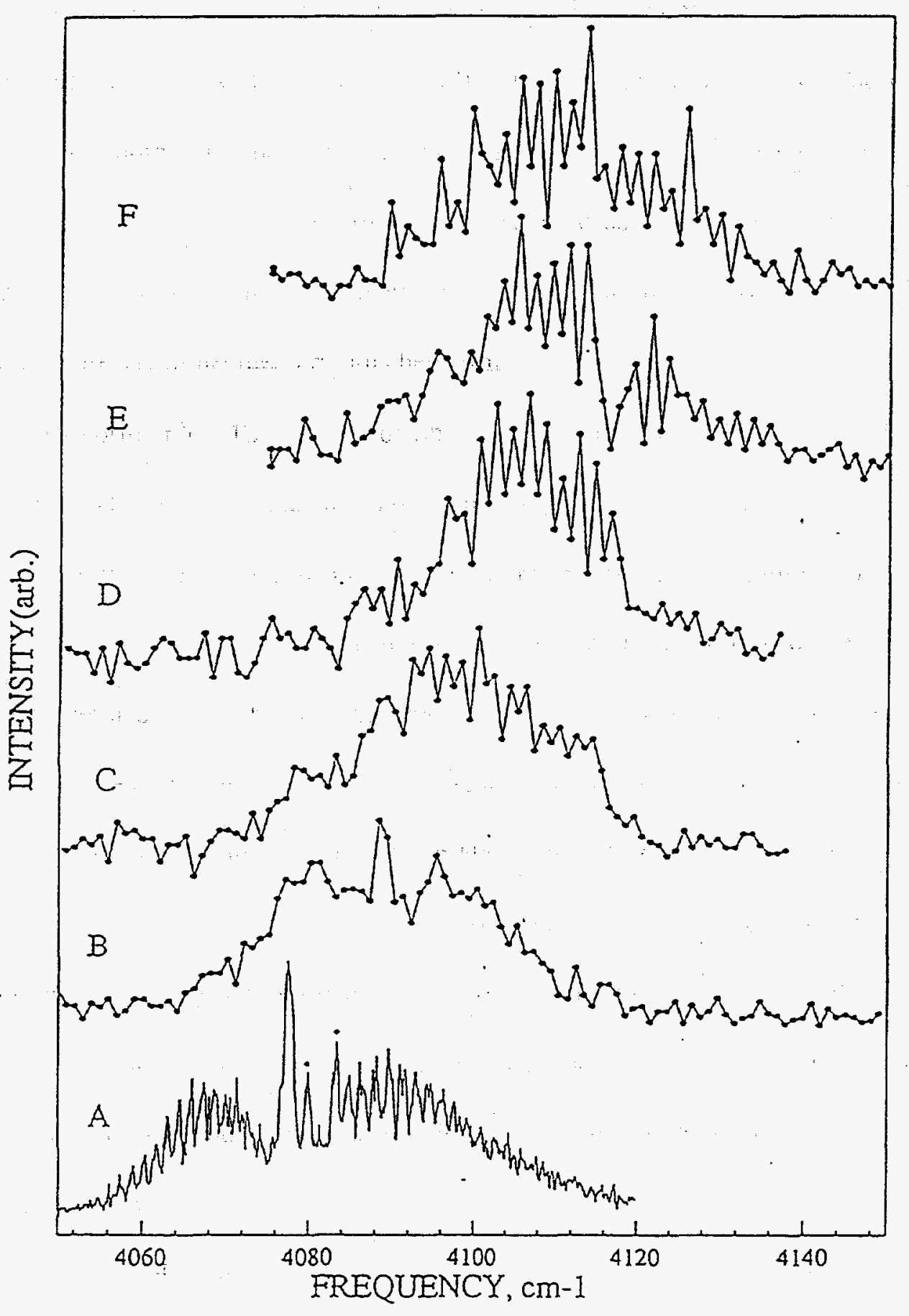

Fig. 4 


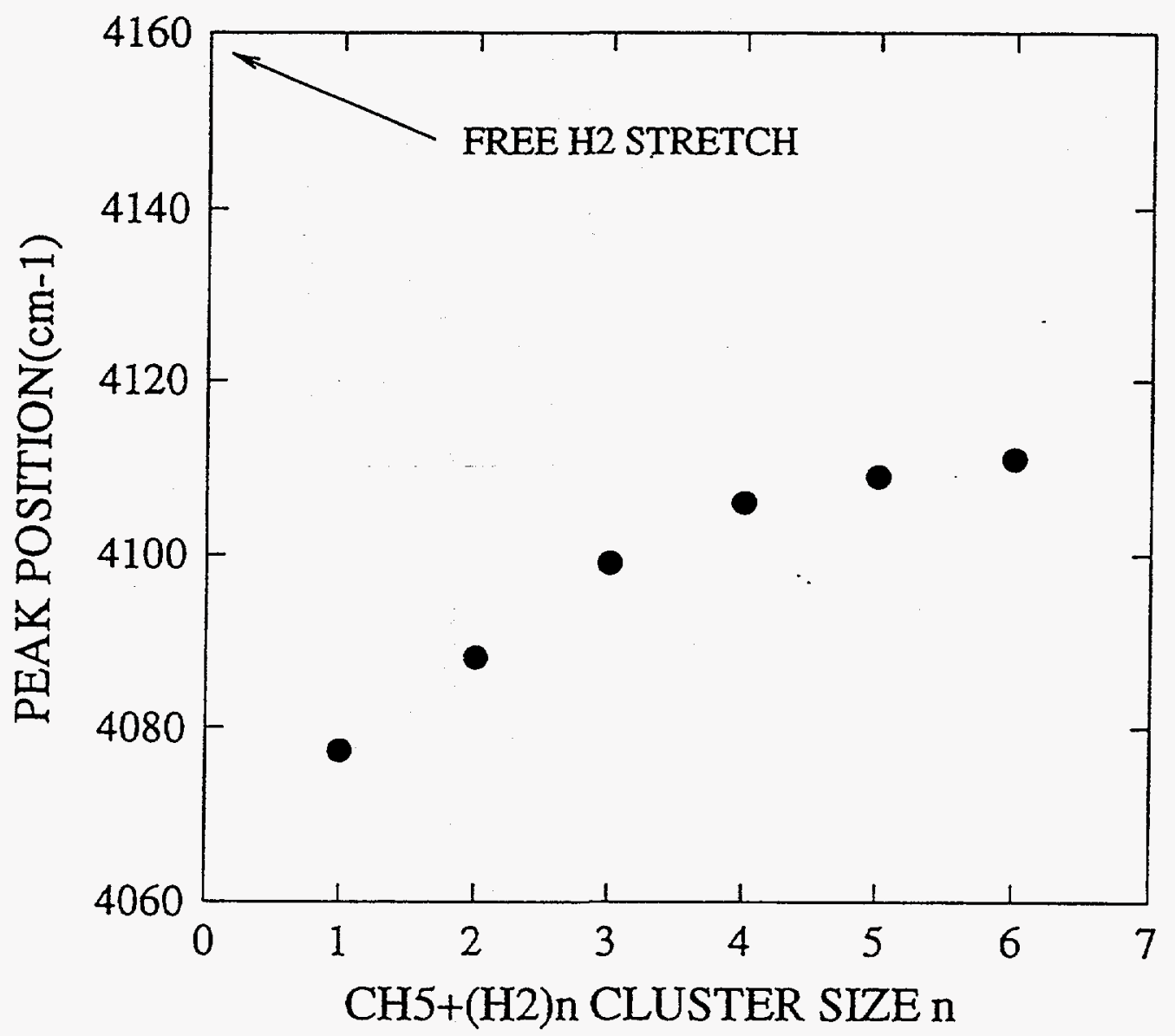

Fig. 5 


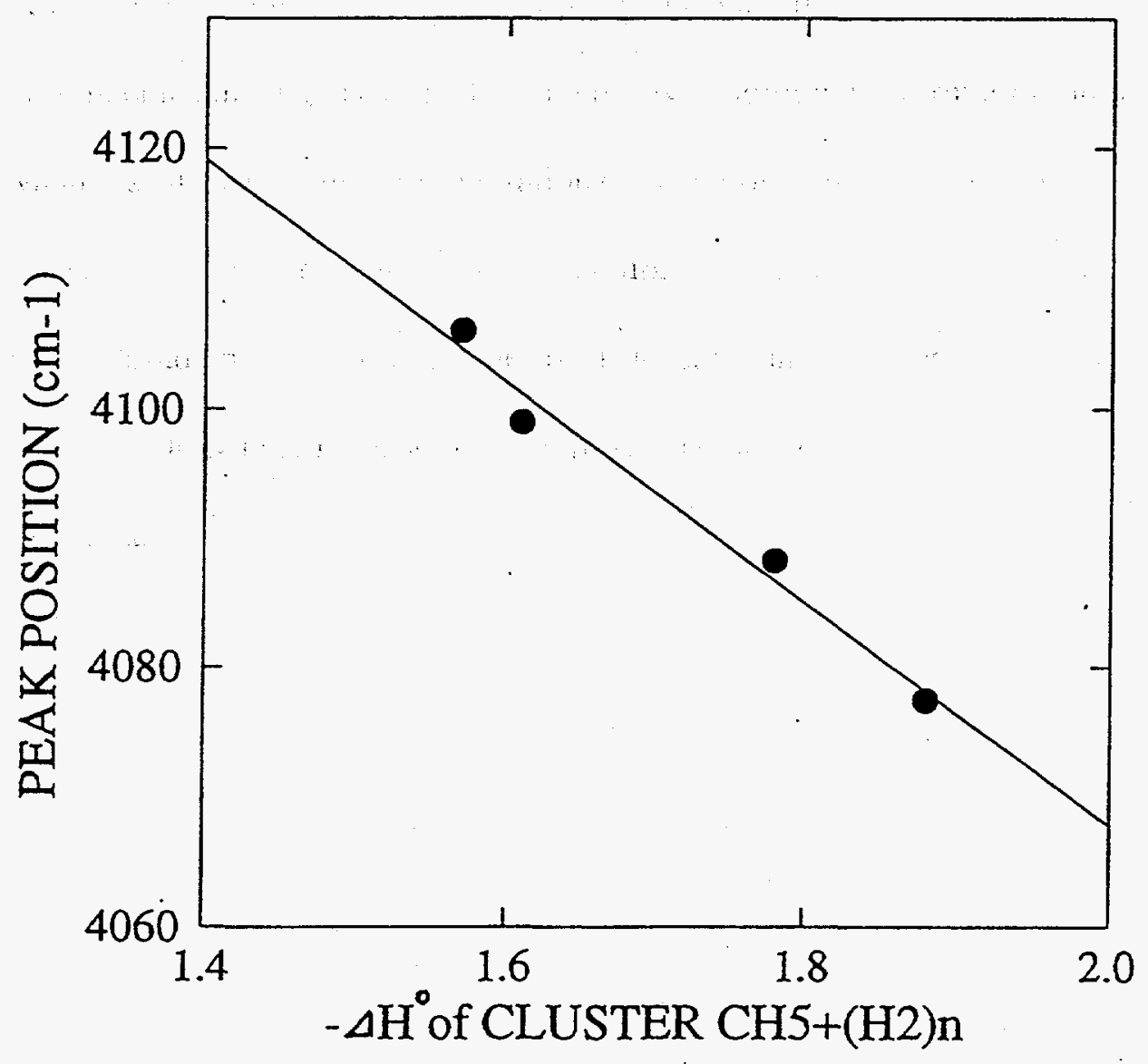

Fig. 6 
A.

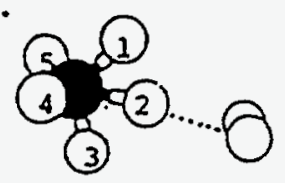

D.

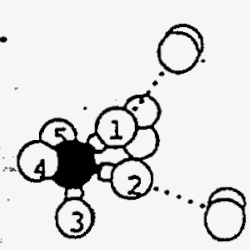

G.

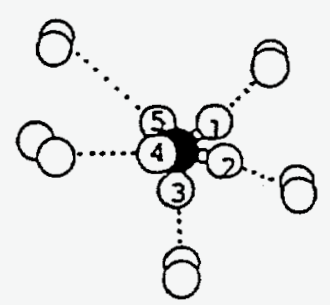

B.

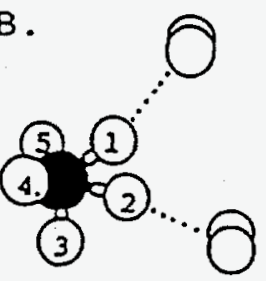

O.

$\mathrm{H}$.

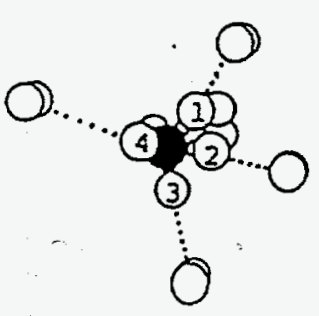

Fig. 7 c.

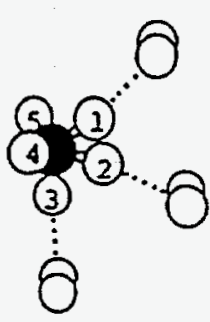

F.

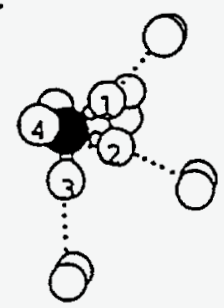

I.

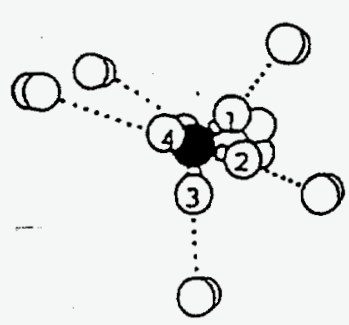




\section{APPENDIX}

\section{Dynamics of Molecular Hydrogen Solvated Carbonium Ions $\mathrm{CH}_{5}^{+}\left(\mathrm{H}_{2}\right)_{\mathrm{n}}(\mathrm{n}=1,2,3)$}

Protonated alkanes are highly reactive intermediates in the acid-catalyzed transformations of hydrocarbons pioneered by Olah and coworkers. ${ }^{1}$ These carbonium ions are known to form a three-center two-electron $(3 \mathrm{c} 2 \mathrm{e})$ bond, having pentacoordinated carbon atoms and bridged hydrogens. ${ }^{2} \mathrm{CH}_{5}^{+}$, being the simplest one, has attracted considerable attention from both experimentalists and theoreticians over the last two decades. ${ }^{3,4}$ Recent ab initio calculations at the most sophisticated level, performed by Schleyer, Schaefer, and coworkers, ${ }^{5}$ predicted the eclipsed $C_{s}\left(e-C_{s}\right)$ symmetry to be the global minimum energy structure. However, the calculated energy differences between the $e-C_{s}$ structure and others such as the staggered $C_{s}$ or $C_{2 v}$ structures were very small and became negligible when corrected for zero point vibrational energies. As emphasized by Scuseria in a recent Nature editorial, ${ }^{6}$ these results "clearly indicated that for all practical purposes $\mathrm{CH}_{5}^{+}$does not have a unique, stable equilibrium structure. The Hydrogen atoms are predicted to scramble almost freely among multiple equivalent minima."

Studying the dynamics of such internal motion is quite challenging. Experimentally, Fourier Transform Ion Cyclotron Resonance Mass Spectrometry was used to characterize indirectly the structure of $\mathrm{CH}_{5}^{+}$, but the results were inconclusive. ${ }^{3}$ Much effort has been made to obtain high resolution infrared (IR) spectra for $\mathrm{CH}_{5}^{+}$, with little 
success, probably due to the scrambling of $\mathrm{CH}_{5}{ }^{+}$, even at low temperatures, which caused significant spectral congestion. Theoretically, elucidation of the scrambling motion in $\mathrm{CH}_{5}{ }^{+}$requires us to go beyond conventional quantum chemistry methods which essentially treat a molecular or ionic system as a static entity. Molecular dynamics (MD) method ${ }^{7}$ would be ideal for such a floppy system, but unfortunately construction of a potential surface for such an ion with strong and complex chemical interactions is an impossible task.

We report an attempt to overcome these difficulties by a combination of state-of-the art experimental and theoretical techniques. These have been directed to a study on the dynamics of the scrambling motion of core $\mathrm{CH}_{5}{ }^{+}$in molecular hydrogen solvated carbonium ions $\mathrm{CH}_{5}{ }^{+}\left(\mathrm{H}_{2}\right)_{\mathrm{n}}(\mathrm{n}=1,2,3)$. The motivation was the notion that the interactions between the core $\mathrm{CH}_{5}{ }^{+}$ions and the $\mathrm{H}_{2}$ molecules are weak enough to cause only a-minor perturbation to $\mathrm{CH}_{5}{ }^{+}$, yet strong enough to slow down the scrambling motions. Preliminary experimental results on $\mathrm{CH}_{5}{ }^{+}\left(\mathrm{H}_{2}\right)$ were reported very recently. ${ }^{8}$ Ion trap vibrational predissociation spectroscopy was used to measure the IR absorption of $\mathrm{CH}_{5}{ }^{+}\left(\mathrm{H}_{2}\right)_{\mathrm{n}}(\mathrm{n}=1,2,3)$. The experimental setup has been described in detail previously. ${ }^{9}$ Briefly, internally cold ions $\mathrm{CH}_{5}{ }^{+}\left(\mathrm{H}_{2}\right)_{\mathrm{n}}(\mathrm{n}=1,2,3)$ were produced from a high pressure and low current corona discharge source and subsequent supersonic expansion. The ion source was maintained at the optimum temperature for each kind of cluster ion to maximize the ion intensity. After several stages of ion optics to shape the beam, the ions were mass-selected by a $60^{\circ}$ magnet sector analyzer, decelerated to less than $0.5 \mathrm{eV}$ translation energy, and focused into a radio frequency octapole ion trap. They were 
trapped there for $\sim 2 \mathrm{msec}$. This was a very important step during which metastable ions decomposed and radiative cooling took place for internally hot ions. The trapped, mass-selected ions were then vibrationally excited with a pulsed, tunable IR laser in the frequency region of $2600-3200 \mathrm{~cm}^{-1}$. When such an IR photon was absorbed, $\mathrm{CH}_{5}^{+}\left(\mathrm{H}_{2}\right)_{\mathrm{n}}$ $(\mathrm{n}=1,2,3)$ vibrationally predissociated into $\mathrm{CH}_{5}{ }^{+}$and $\mathrm{nH}_{2}$. The ions were then extracted and filtered by a quadrupole mass spectrometer tuned to pass only the daughter ions $\mathrm{CH}_{5}{ }^{+}$ which were then detected by a Daly ion detector. ${ }^{10}$ The intensity of the $\mathrm{CH}_{5}{ }^{+}$signal as a function of laser frequency was a measure of the IR absorption of $\mathrm{CH}_{5}{ }^{+}\left(\mathrm{H}_{2}\right)_{\mathrm{n}}(\mathrm{n}=1,2,3)$. Such a combination of a cold ion source and an ion trap made it possible for the direct spectroscopic measurement on internally cold $\mathrm{CH}_{5}{ }^{+}\left(\mathrm{H}_{2}\right)_{\mathrm{n}}(\mathrm{n}=1,2,3)$ ions exclusively.

In theoretical calculations, we used the first-principle MD method to simulate $\mathrm{CH}_{5}{ }^{+}\left(\mathrm{H}_{2}\right)_{\mathrm{n}}(\mathrm{n}=1,2,3)$ dynamics at finite temperatures. Pioneered by Car and Parrinello, this method calculates the potential energy and forces on atoms, within the framework of local density functional theory, at each point along the classical Newtonian trajectory." Very recently this method was successfully applied to floppy ions such as $\mathrm{CH}_{s}{ }^{+}$and $\mathrm{C}_{2} \mathrm{H}_{3}{ }^{+}$. In our calculations, a cluster ion was seated in a fcc lattice cell with a lattice parameter of 30 a.u., so that a plane wave basis set can be used while the interaction between ions in adjacent sites is negligible. The cutoff energy of the plane wave basis set was 20.0 Rydberg. Vanderbilt type pseudopotentials were used for both $\mathrm{C}$ and $\mathrm{H}$ atoms. Direct simulation of the internal motion for $\mathrm{CH}_{5}{ }^{+}\left(\mathrm{H}_{2}\right)_{\mathrm{n}}(\mathrm{n}=1,2,3)$ gave considerable insights into the solvation effects of $\mathrm{H}_{2}$ for $\mathrm{CH}_{5}^{+}$.

The experimental IR spectra for $\mathrm{CH}_{5}^{+}\left(\mathrm{H}_{2}\right)_{n}(\mathrm{n}=1,2,3)$ are shown in Fig. 1. These 
spectral features are due to $\mathrm{C}-\mathrm{H}$ stretching modes in the core $\mathrm{CH}_{5}^{+}$. Three stretching bands were predicted by $a b$ initio calculations ${ }^{13}$ in this frequency range, and the solid lines in Fig. 1 are the results of a least squares fit with three gaussian peaks. These peaks are fairly broad, indicating spectral congestion due to the scrambling motions of the core $\mathrm{CH}_{5}{ }^{+}$. However, as the number of solvent $\mathrm{H}_{2}$ increases, the IR spectra become better resolved. The trend seems to indicate that the scrambling motion in core $\mathrm{CH}_{5}{ }^{+}$slows down as more $\mathrm{H}_{2}$ molecules are attached to it.

First-principle MD results corroborate the experimentally observed trend. The evolution of $\mathrm{H}-\mathrm{H}$ distance during 40,000 time steps (a total of $-3 \mathrm{psec}$ ) of simulation for $\mathrm{CH}_{5}{ }^{+}\left(\mathrm{H}_{2}\right)_{\mathrm{n}}(\mathrm{n}=0-3)$ is shown in Fig. 2: The temperature of these simulations was about $100 \mathrm{~K}$ corresponding to an average internal energy of $0.3 \mathrm{kcal} / \mathrm{mol}$, calculated from $\mathrm{ab}$ initio frequencies. ${ }^{5,13,14}$ The structure shown in Column A of Fig. 2 is an e-C $C_{s}$ structure, and can be used as a reference for discussion, although $\mathrm{CH}_{5}{ }^{+}$was not restricted to this structure. The three $\mathrm{H}$ atoms, $\mathrm{Hl}, \mathrm{H} 2$ and $\mathrm{H} 4$, formed three strong $\mathrm{C}-\mathrm{H}$ bonds, while $\mathrm{H} 3$ and $\mathrm{H} 5$ formed a $3 \mathrm{c} 2 \mathrm{e}$ bond with the $\mathrm{C}$ atom. This electron deficient $3 \mathrm{c} 2 \mathrm{e}$ bond was characterized by a short $\mathrm{H}-\mathrm{H}$ distance $(<1.5 \AA)$. During the entire simulation, all $\mathrm{H}-\mathrm{H}$ distances fluctuated between $1.0-2.2 \AA$, and the $3 \mathrm{c} 2 \mathrm{e}$ bond could be formed among any pair of $\mathrm{H}$ atoms, in agreement with the previous theoretical predictions that $\mathrm{CH}_{5}{ }^{+}$does not have a stable structure.

For $\mathrm{CH}_{5}{ }^{+}\left(\mathrm{H}_{2}\right)$, shown in Column B of Fig. 2, the $\mathrm{CH}_{5}{ }^{+}$core remains floppy. For example, both $\mathrm{H} 3-\mathrm{H} 4$ and $\mathrm{H} 3-\mathrm{H} 1$ distances showed considerable fluctuations similar to those observed for $\mathrm{CH}_{5}{ }^{+}$. However, the $\mathrm{H}_{2}$ molecule was always bound to the $\mathrm{H} 3$ atom 
during the entire simulation. Moreover, when $\mathrm{Min}(\mathrm{H} 3-\mathrm{Hn})$, which is the minimum value of the distances between $\mathrm{H} 3$ and any one of the other $\mathrm{H}$ atoms in the $\mathrm{CH}_{5}^{+}$core, was compared with the corresponding Min( $\mathrm{H} 1-\mathrm{Hn})$, the former fluctuated much less and had a smaller average value than the latter. This is an indication that the $3 \mathrm{c} 2 \mathrm{e}$ bond is more or less localized around $\mathrm{H} 3$, a slight yet interesting change in the scrambling motion of $\mathrm{CH}_{5}^{+}$core.

For $\mathrm{CH}_{5}{ }^{+}\left(\mathrm{H}_{2}\right)_{2}$, shown in Column $\mathrm{C}$ of Fig. 2, the stabilization effect of two weakly bound $\mathrm{H}_{2}$ becomes more prominent. The two $\mathrm{H}_{2}$ molecules were always bound to $\mathrm{H} 1$ and $\mathrm{H} 2$ of the core $\mathrm{CH}_{5}{ }^{+}$respectively, and the $\mathrm{H} 1-\mathrm{H} 2$ distance stayed around $1.2 \AA$ with remarkably small fluctuation. This suggests that the $3 \mathrm{c} 2 \mathrm{e}$ bond is localized to the carbon atom and the two $\mathrm{H}$ atoms weakly bonded to the two solvent $\mathrm{H}_{2}$ molecules. It could be explained by the electron deficiency in the $3 \mathrm{c} 2 \mathrm{e}$ bond which attracts the two solvent $\mathrm{H}_{2}$ molecules. In contrast, the other three $\mathrm{H}$ atoms continued to go through large amplitude motions such as $\mathrm{CH}_{3}$ internal rotation, as indicated by the large fluctuations in H1-Hn distance in Column C of Fig. 2.

For $\mathrm{CH}_{5}{ }^{+}\left(\mathrm{H}_{2}\right)_{3}$, shown in Column D of Figure 3 , the $\mathrm{CH}_{5}{ }^{+}$core becomes semi-rigid. Three $\mathrm{H}_{2}$ molecules were bound to $\mathrm{H} 1, \mathrm{H} 2$ and $\mathrm{H} 3$ in the $\mathrm{CH}_{5}^{+}$core, respectively, during the entire simulation. The in-plane wagging motion of $\mathrm{H} 2$ between $\mathrm{H} 1$ and $\mathrm{H} 3$ contributed to the slightly larger fluctuations in the $\mathrm{H} 1-\mathrm{H} 2$ and $\mathrm{H} 2-\mathrm{H} 3$ distances than in the $\mathrm{H} 1-\mathrm{H} 2$ distance for $\mathrm{CH}_{5}{ }^{+}\left(\mathrm{H}_{2}\right)_{2}$. However, the fluctuations in the $\mathrm{H} 1-\mathrm{H} 4$ and $\mathrm{H} 2-\mathrm{H} 4$ distances were only $0.4 \AA$, indicating a considerable slowdown in the $\mathrm{CH}_{5}{ }^{+}$scrambling motion, and in agreement with the experimentally observed trend. 
A better understanding of the IR spectra shown in Fig. 1 was facilitated by the insight into the dynamics of the scrambling motion as discussed above and by comparison of the experimental spectra with the power spectra for $\mathrm{CH}_{5}^{+}\left(\mathrm{H}_{2}\right)_{\mathrm{n}}(\mathrm{n}=1,2,3)$. The power spectra, obtained from the first-principle MD simulation, are plotted in Fig. 3 with the vibrational density of states (DOS) as a function of frequency. Anharmonic coupling, which is very important for the floppy $\mathrm{CH}_{5}^{+}$yet difficult to account for in ab initio calculations, is naturally included in a power spectrum calculated by the Fourier transform of the velocity correlation function. ${ }^{7}$ For $\mathrm{CH}_{5}{ }^{+}\left(\mathrm{H}_{2}\right)$, in spite of the stabilization effect of $\mathrm{H}_{2}$, the $\mathrm{CH}_{5}{ }^{+}$remained very floppy, and strong anharmonic couplings among vibrational modes were expected. Nonetheless, the center of the experimental spectrum at $2965 \mathrm{~cm}^{-1}$ was only $27 \mathrm{~cm}^{-1}$ red-shifted from the average $\mathrm{C}-\mathrm{H}$ stretching frequency of $\mathrm{CH}_{4}$ $\left(2992 \mathrm{~cm}^{-1}\right)$, reflecting the fact that when a hydrogen atom in $\mathrm{CH}_{5}{ }^{+}$does not participate in the $3 \mathrm{c} 2 \mathrm{e}$ bond, its corresponding $\mathrm{C}-\mathrm{H}$ bond is similar to the $\mathrm{C}-\mathrm{H}$ bond in $\mathrm{CH}_{4}$. The three features in the power spectrum, shown in Fig. 3B, could be correlated with the broad feature with two shoulders in the experimental spectrum (Fig. 1B). The calculated frequencies were around $10 \%$ lower than the experiment. Such discrepancy was likely due to slight imperfection in the pseudopotential. Mismatch in the intensities could be due to the fact that the plot shown in Fig. 3 is for DOS, rather than for IR intensity.

For $\mathrm{CH}_{5}^{+}\left(\mathrm{H}_{2}\right)_{2}$, the $3 \mathrm{c} 2 \mathrm{e}$ bond was localized to $\mathrm{H} 1-\mathrm{C}-\mathrm{H} 2$, which slowed down the scrambling of the $\mathrm{CH}_{5}{ }^{+}$core considerably. However, the scrambling of the other three $\mathrm{C}-\mathrm{H}$ bonds was still extensive, and strong anharmonic couplings for the vibrational modes involving these three bonds were again expected. Two features were observed in the IR 
spectrum of $\mathrm{CH}_{5}^{+}\left(\mathrm{H}_{2}\right)_{2}$ (Fig. 1C), and the low frequency shoulder observed for $\mathrm{CH}_{5}^{+}\left(\mathrm{H}_{2}\right)$ was no longer present. The broad and intense feature, centered at $2957 \mathrm{~cm}^{-1}$, could be due to two strongly coupled $\mathrm{C}-\mathrm{H}$ stretching modes, while the narrow feature, centered at $3078 \mathrm{~cm}^{-1}$, could be due to another less coupled $\mathrm{C}-\mathrm{H}$ stretching mode. The power spectrum for $\mathrm{CH}_{5}{ }^{+}\left(\mathrm{H}_{2}\right)_{2}$ (Fig. 3C) was in remarkably good agreement with experiment (Fig. 1C).

For $\mathrm{CH}_{5}{ }^{+}\left(\mathrm{H}_{2}\right)_{3}$, the $\mathrm{CH}_{5}{ }^{+}$core was semi-rigid with internal scrambling considerably hindered. The presence of three partially resolved features in the experimental IR spectrum (Fig. 1D) is also suggestive of the semi-rigid nature of the $\mathrm{CH}_{s}^{+}$core in $\mathrm{CH}_{5}^{+}\left(\mathrm{H}_{2}\right)_{3}$. It is interesting to notice that the observed frequencies $\left(2892,2977,3062 \mathrm{~cm}^{-1}\right)$ match well with the three ab initio $\mathrm{CH}_{3}$ stretching frequencies, for e- $\mathrm{C}_{\mathrm{s}} \mathrm{CH}_{5}^{+}(2891,2993$, $\left.3079 \mathrm{~cm}^{-1}\right)^{5}$ and $\mathrm{e}-\mathrm{C}_{\mathrm{s}} \mathrm{CH}_{5}{ }^{+}\left(\mathrm{H}_{2}\right)\left(2898,2998,3081 \mathrm{~cm}^{-1}\right)^{13}$. It suggests that the $\mathrm{CH}_{5}{ }^{+}$core in $\mathrm{CH}_{5}{ }^{+}\left(\mathrm{H}_{2}\right)_{3}$ possesses an e- $\mathrm{C}_{5}$ structure. The power spectrum for $\mathrm{CH}_{5}{ }^{+}\left(\mathrm{H}_{2}\right)_{3}$ in Fig. 3D shows one sharp feature around $2800 \mathrm{~cm}^{-1}$ and two sharp features around $2500 \mathrm{~cm}^{-1}$. The discrepancy is probably due to the underestimation of the potential barrier for the in-plane wagging motion of $\mathrm{H} 2$ between $\mathrm{H} 1$ and $\mathrm{H} 3$ (see Fig. 2D) and as a consequence the $3 \mathrm{c} 2 \mathrm{e}$ bond was quite delocalized in our simulation. Preference for the delocalized 3c2e bond in $\mathrm{CH}_{5}{ }^{+}$has also been observed in our previous density functional quantum chemistry calculations. $^{14}$

Finally, the general feature of the IR spectrum for $\mathrm{CH}_{5}{ }^{+}$could be inferred from the results discussed above. Although the scrambling motion in $\mathrm{CH}_{5}{ }^{+}$was slightly more extensive than that in the $\mathrm{CH}_{5}{ }^{+}$core of $\mathrm{CH}_{5}^{+}\left(\mathrm{H}_{2}\right)$, as predicted by first-principle MD 
simulation, their power spectra were more or less similar to each other. This suggests that the IR spectrum of $\mathrm{CH}_{5}^{+}$will be close to the spectrum of $\mathrm{CH}_{5}{ }^{+}\left(\mathrm{H}_{2}\right)$ under hot ion conditions, shown in Fig. 1A. The two shoulders observed for $\mathrm{CH}_{5}{ }^{+}\left(\mathrm{H}_{2}\right)$ under cold ion conditions (Fig. 1B) were smeared out in the hot ion spectrum of $\mathrm{CH}_{5}^{+}\left(\mathrm{H}_{2}\right)$, revealing increased scrambling of the core $\mathrm{CH}_{5}^{+}$(Fig. 1A). This work clearly can be extended in two ways. First, a high resolution study on the vibration-rotational transitions of the solvent molecules in $\mathrm{CH}_{5}{ }^{+}\left(\mathrm{H}_{2}\right)_{\mathrm{n}}(\mathrm{n}=1,2,3)$ will give additional information on the structure and dynamics of $\mathrm{CH}_{5}{ }^{+}$, since the vibrational transitions are not strongly coupled to the floppy $\mathrm{CH}_{5}{ }^{+}$core, but still sample the structural parameters of the core ion. Secondly, inclusion of gradient correction in the local density functional calculation embedded in the first-principle MD simulation may improve the accuracy of the potential energy and of the simulation results. 


\section{REFERENCES}

1. G.A. Olah, G.K.S. Prakash, and J. Sommer, Superacids (Wiley-Interscience, New York, 1985).

2. G.A. Olah, Carbocations and Electrophilic Reactions (Verlag Chemie, Weinheim, 1973).

3. M.D. Sefcik, J.M.S. Henis, and P.P. Gasper, J. Chem. Phys., v.61; 4321 (1974); R.D. Smith and J.H. Futrell, Chem. Phys. Lett., v.36, 545 (1975); A.J.R. Heck, L.J. de Koning, and N.M.M. Nibbering, J. Am. Soc. Mass Spectrom., v.2, 453 (1991).

4. V. Dyczmons, V. Staemmler, and W. Kutzelnigg, Chem. Phys. Lett., v.5, 361 (1970); W.A. Lathan, W.J. Hehre, L.A. Curtiss, and J.A. Pople, J. Am. Chem. Soc., v.93, 6377 (1971); K. Ragavachari, R.A. Whiteside, J.A. Pople, and P.v.R. Schleyer, J. Am. Chem. Soc., v.103, 5649 (1981); K. Hirao and S. Yamabe, Chem Phys., v.89, 237 (1984); W. Klopper and W. Kutzelnigg, J. Phys. 'Chem., v.94, 5625 (1990).

5. P.R. Schreiner, S.J. Kim, H.F. Schaefer, and P.v.R. Schleyer, J. Chem. Phys., v.99, 3716 (1993); P.v.R. Schleyer and J.W.M. Cameiro, J. Comput. Chem., v.13, 997 (1992).

6. G.E. Scuseria, Nature, v.366, 512 (1993).

7. M.P. Allen, and D.J. Tildesley, Computer Simulation of Liquids (Oxford University Press, Oxford, 1987).

8. D.W. Boo and Y.T. Lee, Chem. Phys. Lett., v.211, 358 (1993).

9. S.W. Bustamente, Ph.D. Thesis, University of California at Berkeley (1983).

10. R.N. Daly, Rev. Sci. Instr., v.31, 264 (1960). 
11. R. Car and M. Parrinello, Phys. Rev. Lett., v.55, 2471 (1985); D.K. Remler and P.A. Madden, Mol. Phys., v.70, 921 (1990).

12. J.S. Tse, D.D. Klug, and K. Lassonen, Phys. Rev. Lett., in print.

13. S.J. Kim, P.R. Schreiner, P.v.R. Schleyer, and H.F. Schaefer, J. Phys. Chem., v.97, 12232 (1993).

14. D.W. Boo and J.S. Tse, unpublished results. 


\section{FIGURE CAPTIONS}

Figure 1. Experimental IR spectra of $\mathrm{CH}_{5}^{+}\left(\mathrm{H}_{2}\right)_{n}(\mathrm{n}=1,2,3)$ for the $\mathrm{C}-\mathrm{H}$ stretching modes: (A) $\mathrm{CH}_{5}{ }^{+}\left(\mathrm{H}_{2}\right)$, under hot ion conditions; (B) $\mathrm{CH}_{5}{ }^{+}\left(\mathrm{H}_{2}\right)$, under cold ion conditions; (C) $\mathrm{CH}_{5}^{+}\left(\mathrm{H}_{2}\right)_{2} ;$ (D) $\mathrm{CH}_{5}^{+}\left(\mathrm{H}_{2}\right)_{3}$.

Figure 2. Evolution of the $\mathrm{H}-\mathrm{H}$ distances in the $\mathrm{CH}_{5}^{+}$core during the first principle $\mathrm{MD}$ simulation: (A) $\mathrm{CH}_{5}^{+}$; (B) $\mathrm{CH}_{5}^{+}\left(\mathrm{H}_{2}\right)$; (C) $\mathrm{CH}_{5}^{+}\left(\mathrm{H}_{2}\right)_{2} ;$ (D) $\mathrm{CH}_{5}^{+}\left(\mathrm{H}_{2}\right)_{3}$.

Figure 3. Power spectra obtained from first principle $\mathrm{MD}$ simulation: (A) $\mathrm{CH}_{5}^{+}$; (B) $\mathrm{CH}_{5}^{+}\left(\mathrm{H}_{2}\right) ;(\mathrm{C}) \mathrm{CH}_{5}^{+}\left(\mathrm{H}_{2}\right)_{2} ;(\mathrm{D}) \mathrm{CH}_{5}^{+}\left(\mathrm{H}_{2}\right)_{3}$. 


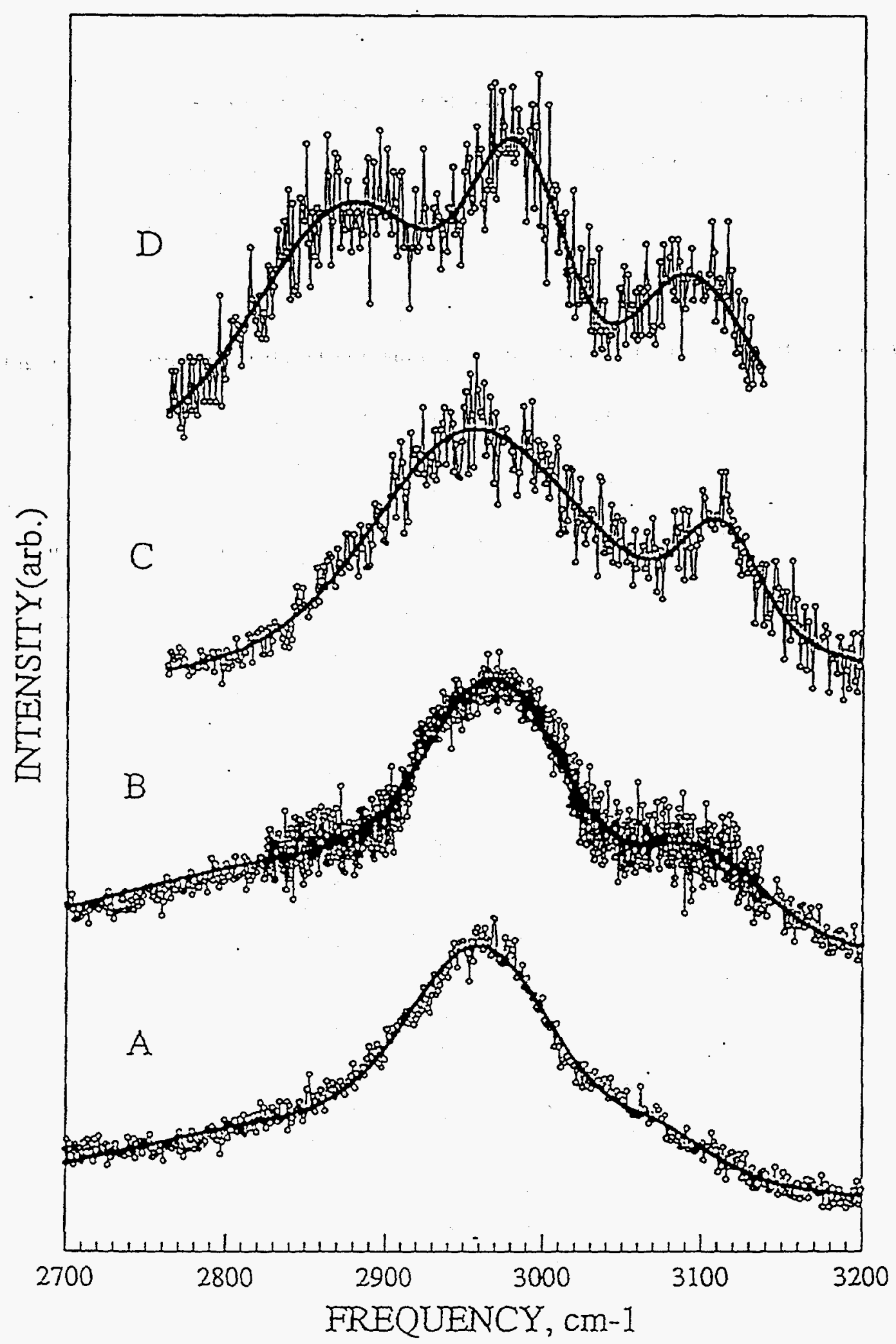

Fig. 1 


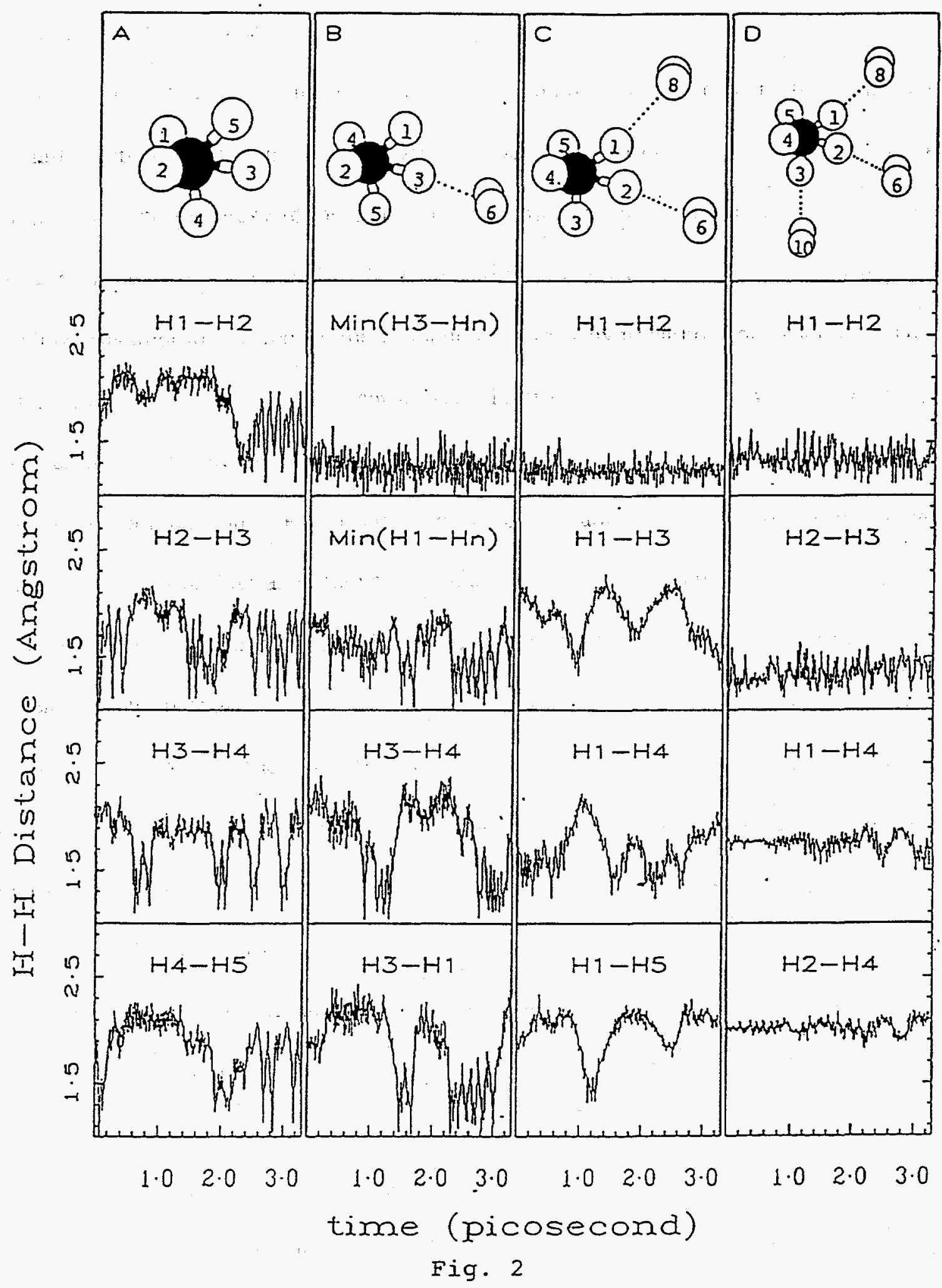




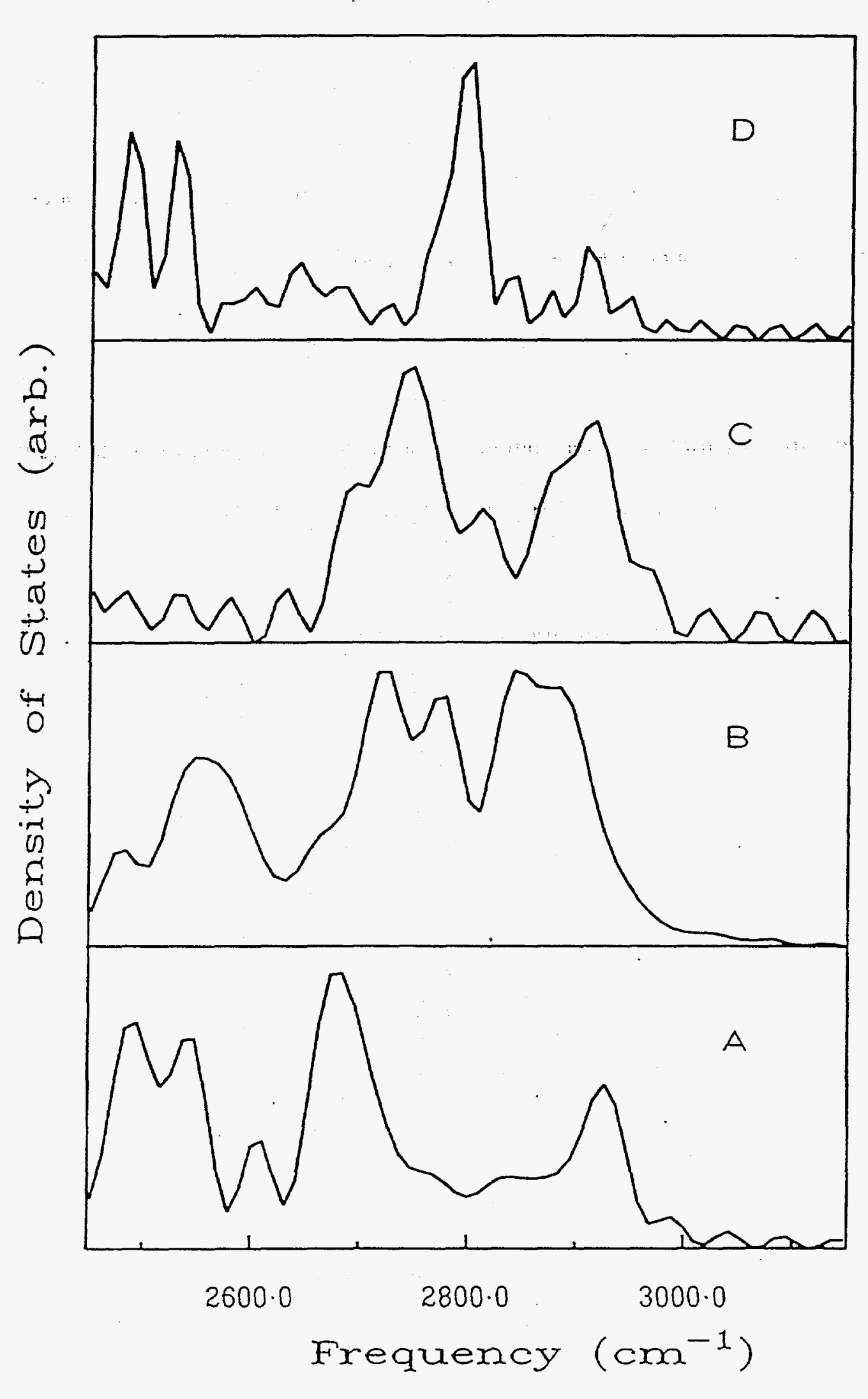

92

Fig. 3 


\section{CHAPTER IV}

\section{Infrared Spectroscopy of the Solvated Carbonium Ions, $\mathrm{CH}_{5}^{+}(\mathrm{A})_{\mathrm{x}}(\mathrm{B})_{\mathrm{y}}\left(\mathrm{A}, \mathrm{B}=\mathrm{H}_{2}, \mathrm{Ar}, \mathrm{N}_{2}, \mathrm{CH}_{4} ; \mathrm{x}, \mathrm{y}=0-5\right)$}

\section{INTRODUCTION}

The introduction on $\mathrm{CH}_{5}{ }^{+}$has been described in Chapter II and III. As mentioned previously, the high level theoretical calculations predicted that $\mathrm{CH}_{5}{ }^{+}$scrambles constantly through the low lying transition states $\left(s-C_{s}\right.$ and $\left.C_{2 v}\right)$, without possessing a definite equilibrium geometry. ${ }^{1-9}$

Some experiments have been performed previously to characterize indirectly the structure of $\mathrm{CH}_{5}^{+}$using mass spectrometry, as mentioned in Chapter II and III. ${ }^{10-15}$ Hiraoka and coworkers measured $-\Delta \mathrm{H}_{\mathrm{n}-1, \mathrm{n}}^{\mathrm{o}}$ and $-\Delta \mathrm{S}_{\mathrm{n}-1, \mathrm{n}}^{\mathrm{n}}$ for the formation of the solvated $\mathrm{CH}_{5}{ }^{+}$clusters, $\mathrm{CH}_{5}{ }^{+}\left(\mathrm{H}_{2}\right)_{\mathrm{n}}(\mathrm{n}=1-4)^{10}$ and $\mathrm{CH}_{5}{ }^{+}\left(\mathrm{CH}_{4}\right)_{\mathrm{n}}(\mathrm{n}=1-9)^{11.12}$ using pulsed electron beam high pressure mass spectrometry. For the weakly bound clusters $\mathrm{CH}_{5}{ }^{+}\left(\mathrm{H}_{2}\right)_{\mathrm{n}}$, the positive charge of the $\mathrm{CH}_{5}^{+}$core was found to be more or less delocalized, indicated by the gradual decrease observed in $-\Delta \mathrm{H}_{\mathrm{n}-1, \mathrm{n}}^{\mathrm{o}}$ with increasing $\mathrm{n}$. In contrast, irregular decreases in the value $-\Delta \mathrm{H}_{n-1, n}^{\circ}$ and $-\Delta \mathrm{S}_{\mathrm{n}-1, \mathrm{n}}^{\circ}$ for $\mathrm{CH}_{5}{ }^{+}\left(\mathrm{CH}_{4}\right)_{\mathrm{n}}$ were observed between $\mathrm{n}=2$ and 3 , and $\mathrm{n}=7$ and 8 , as shown in Table 1, suggesting a $\mathrm{C}_{\mathrm{s}}$ symmetry structure for the $\mathrm{CH}_{5}{ }^{+}$core in $\mathrm{CH}_{5}{ }^{+}\left(\mathrm{CH}_{4}\right)_{n}$, and the formation of a complete solvation shell at $\mathrm{n}=7$, respectively. These results suggested that the structure and dynamics of $\mathrm{CH}_{5}{ }^{+}$could be significantly changed by the stabilization effects of the solvents in the solvated carbonium ions. 
Experiments using Fourier Transform Ion Cyclotron Resonance (FTICR) mass spectrometry ${ }^{13-15}$ have also been performed to address the structure of $\mathrm{CH}_{5}{ }^{+}$indirectly by studying the collisionally induced intramolecular randomization of hydrogen and deuterium atoms in $\mathrm{CH}_{4} \mathrm{D}^{+}$and $\mathrm{CD}_{4} \mathrm{H}^{+}$, but the results were inconsistent, probably due to unusual isotope effects and uncertainties in the internal energies of the carbonium ions produced in these studies. Because of difficulties in the indirect characterization of the $\mathrm{CH}_{5}{ }^{+}$structures, much effort has been made to obtain high resolution IR spectra for $\mathrm{CH}_{5}^{+}$, but has achieved little success.

In an attempt to overcome the difficulties of performing spectroscopy on $\mathrm{CH}_{5}^{+}$, and to determine the structure and dynamics of $\mathrm{CH}_{5}{ }^{+}$directly, we have measured the IR spectra for molecular hydrogen solvated carbonium ions $\mathrm{CH}_{5}{ }^{+}\left(\mathrm{H}_{2}\right)_{\mathrm{n}}(\mathrm{n}=1-6) \cdot{ }^{16-18}$ As reported previously, $\mathrm{CH}_{5}{ }^{+}$was expected to scramble extensively via large amplitude motions, and the scrambling slowed down gradually with increasing number of $\mathrm{H}_{2}$ molecules in the clusters. The scrambling of $\mathrm{CH}_{5}{ }^{+}$core was almost frozen out for $\mathrm{CH}_{5}{ }^{+}\left(\mathrm{H}_{2}\right)_{\mathrm{n}}$ with $\mathrm{n} \geq 3$.

In this chapter, we report a systematic study of the solvent effects on the structure and dynamics of $\mathrm{CH}_{5}{ }^{+}$by using different solvent molecules such as $\mathrm{H}_{2}, \mathrm{Ar}, \mathrm{N}_{2}$, and $\mathrm{CH}_{4}$, and by changing the number of solvent molecules in the clusters. In addition, it will be shown that the structures of the solvated carbonium ions can be accurately determined from the changes in the IR spectra of the solvated carbonium ions, improving the early predictions on the structures of $\mathrm{CH}_{5}{ }^{+}\left(\mathrm{CH}_{4}\right)_{\mathrm{n}}(\mathrm{n}=1-9) .^{11,12}$ It will be also shown that the proton transfer in the proton-bound $\mathrm{CH}_{4}$ dimer, $\mathrm{CH}_{5}{ }^{+}\left(\mathrm{CH}_{4}\right)$ can be probed 
spectroscopically by measuring the vibrational predissociation IR spectra for the single ${ }^{13} \mathrm{C}$ exchanged dimers, ${ }^{13} \mathrm{CH}_{5}{ }^{+}\left(\mathrm{CH}_{4}\right)$ and $\mathrm{CH}_{5}{ }^{+}\left({ }^{13} \mathrm{CH}_{4}\right)$. 


\section{EXPERIMENTAL DETAILS}

The experimental apparatus used in this work has been described previously ${ }^{19-22}$ and also in Chapter I. Briefly, the solvated carbonium ions, $\mathrm{CH}_{5}^{+}(\mathrm{A})_{\mathrm{x}}(\mathrm{B})_{\mathrm{y}}$ $\left(\mathrm{A}, \mathrm{B}=\mathrm{H}_{2}, \mathrm{Ar}, \mathrm{N}_{2}, \mathrm{CH}_{4} ; \mathrm{x}, \mathrm{y}=0-5\right)$ were produced from a high pressure corona discharge source and subsequent supersonic expansion through a $75 \mu \mathrm{m}$ nozzle. The corona discharge was maintained in 60-300 torr of a gas mixture with ultrahigh purity (UHP) $\mathrm{H}_{2}$ and $\mathrm{UHP} \mathrm{CH}_{4}$, and with the addition of UHP Ar and $\mathrm{N}_{2}$ for the corresponding clusters, flowing past a $1.0 \mathrm{kV}$ potential from the discharge tip of the needle to the source body maintained at 350 $\mathrm{V}$ above ground. The discharge currents under these conditions were $20-40 \mu \mathrm{A}$. The temperature of the source body was maintained between -20 and $-70{ }^{\circ} \mathrm{C}$ by heating the source body in contact with a liquid nitrogen trap. Typical pressures in the source chamber were $2 \times 10^{-5}-4 \times 10^{-5}$ torr during the experiment. To prevent the acceleration of ions in the higher pressure region which causes internal excitation and dissociation of the ion clusters via collisions with the background gas, the potential of the skimmer was maintained within $1 \mathrm{~V}$ of that of the source body.

After the skimmer, the ion beam entered a second differential pumping region containing collimating and focusing lenses. The pressure in this region was typically an order of magnitude lower than that of the source region. The beam was directed into a $60^{\circ}$ sector magnet mass analyzer through a third differentially pumped region maintained at $2 \times 10^{-8}$ torr.

The mass-selected beam was then bent $90^{\circ}$ in a dc quadrupole field, decelerated to less than $0.5 \mathrm{eV}$, and focused into a rf octapole ion trap through an entrance aperture 
lens. The ions were usually trapped here for $-2 \mathrm{msec}$ before IR irradiation. The trapped, mass-selected clusters were then vibrationally excited by a pulsed, tunable infrared (IR) laser. A Quanta-Ray IR WEX was used as a tunable IR light source. The IR wavelength was generated in a $\mathrm{LiNbO}_{3}$ crystal that takes the difference frequency between a Lambda Physics pulsed dye laser (Model FL3002E) and the $1.06 \mu \mathrm{m}$ fundamental of a Continuum Nd-YAG laser. The IR resolution was $0.2 \mathrm{~cm}^{-1}$. The pulse duration was $6 \mathrm{nsec}$ with a $20 \mathrm{~Hz}$ repetition rate, and the laser power was $0.5-2 \mathrm{~mJ} /$ pulse in the $2500-3200 \mathrm{~cm}^{-1}$ region scanned in this work.

If the ions absorb one or more IR photon(s) in the usual tuning range of 2500$3200 \mathrm{~cm}^{-1}$, the $\mathrm{CH}_{5}^{+}(\mathrm{A})_{x}(\mathrm{~B})_{y}$ ions vibrationally predissociate into the daughter ions $\mathrm{CH}_{5}{ }^{+}(\mathrm{A})_{\mathrm{x}-\mathrm{m}}(\mathrm{B})_{y-\mathrm{n}}$ and the solvent molecules $\mathrm{mA}+\mathrm{nB}(\mathrm{m}, \mathrm{n}=0,1,2, . .$, but $\leq \mathrm{x}, \mathrm{y})$. Roughly 0.5 msec after the laser pulse, the potential on the exit aperture was lowered to extract ions of all masses from the trap. These ions were filtered by a quadrupole mass spectrometer tuned to pass only one of the $\mathrm{CH}_{5}{ }^{+}(\mathrm{A})_{\mathrm{x}-\mathrm{m}}(\mathrm{B})_{\mathrm{y}-\mathrm{n}}$ daughter ions. In this work, the quadrupole mass filter was fixed at the mass of a specific daughter ion which gave the maximum intensity among the $\mathrm{CH}_{5}^{+}(\mathrm{A})_{x-\mathrm{m}}(\mathrm{B})_{y-n}$ daughter ions. The observation of the daughter ion signal as a function of laser frequency was a measure of the infrared absorption of the parent ion, $\mathrm{CH}_{5}^{+}(\mathrm{A})_{\mathrm{x}}(\mathrm{B})_{\mathrm{y}}\left(\mathrm{A}, \mathrm{B}=\mathrm{H}_{2}, \mathrm{Ar}, \mathrm{N}_{2}, \mathrm{CH}_{4}, \mathrm{x}, \mathrm{y}=0-5\right)$.

Daughter ions were counted with a Daly ion detector $^{23}$ for each laser shot. Background daughter ions resulting from the decay of metastable parent ions in the rf ion trap were monitored in a separate cycle with the laser off at each wavelength and subtracted from the laser on signal. The laser power was monitored at each data point, 
and spectra were normalized for the power of the tunable infrared laser assuming a simple linear power dependence.

In this experiment, it was seen that the composition of ions in the beam was strongly dependent on the mixing ratio of gases, the discharge current, the source temperature and the pressure inside the source. Practical rules used in the discharge for the carbonium ion clusters are as following: First, the concentration of $\mathrm{CH}_{4}$ in the gas mixture was kept low to reduce the formation of larger hydrocarbon ions such as $\mathrm{C}_{2} \mathrm{H}_{3}{ }^{+}$, $\mathrm{C}_{2} \mathrm{H}_{5}{ }_{5}, \mathrm{C}_{3} \mathrm{H}_{7}{ }^{+}$, etc, via $\mathrm{CH}_{3}{ }^{+}$precursor ions, as discussed in Chapter I. When these larger hydrocarbon ions were present as the major ions in the mass spectra, the intensities of the solvated carbonium ions were observed to be considerably low. Second, the discharge current was kept as low as possible to reduce the internal excitation of the ions at the scrafice of the ion intensities. A slight increase of the discharge current resulted in an increase in the background level. The source temperatures and source pressures were optimized to maximize the intensity of each cluster ion, but they were preferred to set at the low and high values, respectively as long as no significant decrease in the ion intensity was observed, in order to produce the ions as cold as possible.

For $\mathrm{CH}_{5}{ }^{+}\left(\mathrm{CH}_{4}\right)_{n}(\mathrm{n}=1-5)$, the $\mathrm{CH}_{4} / \mathrm{H}_{2}$ mixing ratio of $1: 10,000$ was found to be an optimum ratio in the discharge. Usually, 750 ions for $\mathrm{CH}_{5}{ }^{+}\left(\mathrm{CH}_{4}\right)_{\mathrm{n}}$ with $\mathrm{n}=1$ and 2 , and 300 ions for $\mathrm{CH}_{5}{ }^{+}\left(\mathrm{CH}_{4}\right)_{n}$ with $\mathrm{n}=3,4$, and 5 were trapped per cycle, which are not enough to allow direct measurement of photon absorption. For a typical experiment, signals were averaged for about 500 laser shots at each wavelength in the range of $2500-3200 \mathrm{~cm}^{-1}$. In order to study the vibrational predissociation dynamics of $\mathrm{CH}_{5}{ }^{+}\left(\mathrm{CH}_{4}\right)$ as well as to 
improve the vibrational assignment for the IR spectra, the isotope of methane, ${ }^{13} \mathrm{CH}_{4}$ was also used in the discharge with the equal ${ }^{12} \mathrm{CH}_{4}{ }^{13} \mathrm{CH}_{4}$ ratio. Fig. 1 shows the mass spectrum obtained with a 200 torr source pressure, $-50^{\circ} \mathrm{C}$ source temperature and $40 \mu \mathrm{A}$ discharge current with a gas mixture of $\mathrm{CH}_{4}: \mathrm{H}_{2}=1: 10,000$. As shown in Fig. 1, the $\mathrm{CH}_{5}{ }^{+}\left(\mathrm{CH}_{4}\right)_{x}\left(\mathrm{H}_{2}\right)_{y}(\mathrm{x}, \mathrm{y}=0,1,2, \ldots)$ ions were observed in the mass spectrum, and also studied in this work.

For $\mathrm{CH}_{5}{ }^{+}(\mathrm{Ar})_{\mathrm{x}}\left(\mathrm{CH}_{4}\right)_{y}(\mathrm{x}=1,2 ; \mathrm{y}=0,1)$, the Ar gas was mixed with the $\mathrm{CH}_{4} / \mathrm{H}_{2}$ mixture with the ratio of $\mathrm{CH}_{4}: \mathrm{Ar}: \mathrm{H}_{2}=1: 1,000: 10,000$. Typically, 200 ions were trapped per cycle, and the signals were averaged for about 500 shots at each wavelength in the $2500-3200$ $\mathrm{cm}^{-1}$ region.

For $\mathrm{CH}_{5}{ }^{+}\left(\mathrm{N}_{2}\right)$, the $\mathrm{CH}_{4} / \mathrm{H}_{2}$ mixture was used in the discharge with an impurity amount of $\mathrm{N}_{2}$ which was originally introduced by a small leak in the gas inlet line. The discharge of the gas mixture with UHP $\mathrm{N}_{2}$ in an exact ratio identified the mass peak at $\mathrm{m} / \mathrm{e}=45$ to be $\mathrm{CH}_{5}{ }^{+}\left(\mathrm{N}_{2}\right)$. Since $\mathrm{C}_{3} \mathrm{H}_{9}{ }^{+}$has the same mass-to-charge ratio $(\mathrm{m} / \mathrm{e}=45)$, the isotope of methane, ${ }^{13} \mathrm{CH}_{4}$ was used in the gas mixture to identify the $\mathrm{CH}_{5}{ }^{+}\left(\mathrm{N}_{2}\right)$ by observing the mass peak shifting from $\mathrm{m} / \mathrm{e}=45$ to $\mathrm{m} / \mathrm{e}=46$. 


\section{RESULTS AND ANALYSIS}

\subsection{Mono-solvated carbonium ions, $\mathrm{CH}_{5}^{+}(\mathrm{A})$}

Fig. 2 shows IR spectra for the mono-solvated carbonium ions, $\mathrm{CH}_{5}{ }^{+}(\mathrm{A})\left(\mathrm{A}=\mathrm{H}_{2}\right.$, $\mathrm{Ar}, \mathrm{N}_{2}, \mathrm{CH}_{4}$ ), obtained by monitoring the $\mathrm{CH}_{5}^{+}$signal (m/e=17) in the frequency region of $2700-3200 \mathrm{~cm}^{-1}$. The IR features in this frequency region were attributed to the $\mathrm{C}-\mathrm{H}$ stretching modes of the core ion $\mathrm{CH}_{5}^{+}$and the solvent $\mathrm{CH}_{4}$ molecules. ${ }^{7.16-18,24}$ The frequencies of the observed features are listed in Table II. As discussed in Chapter III, three $\mathrm{C}-\mathrm{H}$ stretching modes of the $\mathrm{CH}_{5}{ }^{+}$core were predicted in this frequency range by the ab initio calculation, ${ }^{7}$ and they were expected to be strongly coupled to each other via large amplitude motions such as the $\mathrm{CH}_{3}$ internal rotation involving a s- $\mathrm{C}_{\mathrm{s}}$ transition state, and the in-plane wagging motion of the $3 \mathrm{c} 2 \mathrm{e}$ bond involving a $\mathrm{C}_{2 \mathrm{v}}$ transition state.17,18 The two motions were also suggested to be strongly coupled such that the $\mathrm{CH}_{3}$ internal rotation would be free only when the in-plane wagging motion was not excited, i.e. the $3 \mathrm{c} 2 \mathrm{e}$ bond was localized like in $\mathrm{C}_{5} \mathrm{CH}_{5}^{+}$structure. The scrambling of the $\mathrm{CH}_{5}^{+}$core via the $\mathrm{CH}_{3}$ internal rotation would result in spectral congestion of the three $\mathrm{C}-\mathrm{H}$ stretching modes on the high frequency side, since the three $\mathrm{C}-\mathrm{H}$ stretching modes were predicted to be localized in the $\mathrm{CH}_{3}$ unit of $\mathrm{CH}_{5}{ }^{+}$core, not strongly perturbed by the electron deficient $3 \mathrm{c} 2 \mathrm{e}$ bond (subsequently referred to as the $\mathrm{CH}_{3}$ stretching modes of $\mathrm{CH}_{5}{ }^{+}$core). In contrast, the scrambling via the in-plane wagging motion involving a $\mathrm{C}_{2 \mathrm{v}}$ transition state could result in a broad feature on the low frequency side since one of the $\mathrm{C}-\mathrm{H}$ stretching modes of the $\mathrm{C}_{2 v} \mathrm{CH}_{5}{ }^{+}$structure (asymmetric $\mathrm{CH}_{2}$ stretching mode of a fourcenter three-electron bond) $)^{7,25}$ was predicted to occur on the low frequency side. 


\section{$\mathrm{CH}_{5}^{+}\left(\mathbf{H}_{2}\right)$}

The IR spectrum for $\mathrm{CH}_{5}^{+}\left(\mathrm{H}_{2}\right)$, shown in Fig. 2A, has been described in detail previously. ${ }^{16-18}$ Briefly, one broad feature with shoulders, centered at $2964 \mathrm{~cm}^{-1}$, was observed in the IR spectrum with cold ion conditions. The result indicated that the $\mathrm{CH}_{s}{ }^{+}$ core in $\mathrm{CH}_{5}^{+}\left(\mathrm{H}_{2}\right)$ scrambles considerably via large amplitude motions such as the $\mathrm{CH}_{3}$ internal rotation and the in-plane wagging motion (see Chapter III for the details).

\section{$\mathrm{CH}_{s}^{+}(\mathrm{Ar})$}

Fig. 2B shows the IR spectrum for $\mathrm{CH}_{5}^{+}(\mathrm{Ar})$ obtained in the frequency range of $2820-3120 \mathrm{~cm}^{-1}$. Two features, centered at 2974 and $3081 \mathrm{~cm}^{-1}$, were observed in the IR spectrum along with the broad feature on the low frequency side (see Fig. 2B). These two features were assigned to the two strongly coupled $\mathrm{CH}_{3}$ stretching modes, and one less coupled $\mathrm{CH}_{3}$ stretching mode of the $\mathrm{CH}_{5}{ }^{+}$core, respectively. The 2974 and 3081 $\mathrm{cm}^{-1}$ features were found to be much narrower than those for $\mathrm{CH}_{5}^{+}\left(\mathrm{H}_{2}\right)$, indicating the decreased scrambling of the $\mathrm{CH}_{5}{ }^{+}$core, due to the increased charge-induced dipole interaction in $\mathrm{CH}_{5}{ }^{+}(\mathrm{Ar})$, as expected from the difference in the electric dipole polarizabilities of $\mathrm{Ar}$ and $\mathrm{H}_{2}\left(1.64 \times 10^{-24} \mathrm{vs} 0.80 \times 10^{-24} \mathrm{~cm}^{3}\right){ }^{26}$ The low intensity of the broad feature on the low frequency side, compared to the case for $\mathrm{CH}_{5}{ }^{+}\left(\mathrm{H}_{2}\right)$, suggested the slowdown of the scrambling via the in-plane wagging motion. The presence of the small rotational constants for $\mathrm{CH}_{5}{ }^{+}(\mathrm{Ar})$ also suggested less spectral congestion from the overlap of the vibrational bands. 


\section{$\mathrm{CH}_{5}^{+}\left(\mathrm{N}_{2}\right)$}

The IR spectrum for $\mathrm{CH}_{s}^{+}\left(\mathrm{N}_{2}\right)$ shown in Fig. $2 \mathrm{C}$ was obtained by monitoring the $\mathrm{CH}_{s}^{+}$signal $(\mathrm{m} / \mathrm{e}=17)$ in the frequency range of $2800-3200 \mathrm{~cm}^{-1}$. Since the mass-tocharge ratio of $\mathrm{CH}_{5}^{+}\left(\mathrm{N}_{2}\right)(\mathrm{m} / \mathrm{e}=45)$ was the same as that of $\mathrm{C}_{3} \mathrm{H}_{9}^{+}$(consisting of $\mathrm{C}_{2} \mathrm{H}_{5}^{+}$and $\mathrm{CH}_{4}$, a probable ion species which could be formed in a discharge of methane and hydrogen gases), another experiment using the isotope of methane $\left({ }^{13} \mathrm{CH}_{4}\right)$ was performed to confirm the mass assignment. The mass peak at $\mathrm{m} / \mathrm{e}=45$ was shifted to $\mathrm{m} / \mathrm{e}=46$ when the ${ }^{13} \mathrm{CH}_{4}$ was used in the discharge, and the IR spectrum for the $\mathrm{m} / \mathrm{e}=46$ ions was similar to the IR spectrum for the $\mathrm{m} / \mathrm{e}=45$ ions, except for the slight frequency shifts due to the isotope effects, confirming the assignment of the $\mathrm{m} / \mathrm{e}=45$ peak to $\mathrm{CH}_{5}{ }^{+}\left(\mathrm{N}_{2}\right)$.

Two features with a low frequency shoulder, centered at 2983 and $3077 \mathrm{~cm}^{-1}$, respectively, were observed in the IR spectrum (Fig. 2C). The observed features at 2983 and $3077 \mathrm{~cm}^{-1}$, assigned to the two strongly coupled $\mathrm{CH}_{3}$ stretching modes, and one less coupled $\mathrm{CH}_{3}$ stretching mode of the $\mathrm{CH}_{5}{ }^{+}$core, were slightly narrower than those for $\mathrm{CH}_{5}{ }^{+}(\mathrm{Ar})$, in spite of the larger rotational constants due to the smaller mass of $\mathrm{N}_{2}$. This result suggested that the stronger charge-induced dipole interaction in $\mathrm{CH}_{5}\left(\mathrm{~N}_{2}\right)$ due to the slightly larger polarizability of $\mathrm{N}_{2}$ than $\operatorname{Ar}\left(1.74 \times 10^{-24} \mathrm{vs} 1.64 \times 10^{-24} \mathrm{~cm}^{3}\right)^{26}$ could freeze slightly more the scrambling motions which are responsible for the spectral broadening.

Another vibrational band, centered at $2623 \mathrm{~cm}^{-1}$, was found in the IR spectrum obtained in the frequency region of $2500-2700 \mathrm{~cm}^{-1}$ as shown in Fig. 6A. This peak was attributed to the $\mathrm{H}-\mathrm{H}$ stretching mode of the $3 \mathrm{c} 2 \mathrm{e}$ bond in the core $\mathrm{CH}_{5}{ }^{+}$, since the peak 
position was similar to the ab initio $\mathrm{H}-\mathrm{H}$ stretching frequency of the $3 \mathrm{c} 2 \mathrm{e}$ bond in $\mathrm{e}-\mathrm{C}_{\mathrm{s}}$ $\mathrm{CH}_{5}^{+}\left(2633 \mathrm{~cm}^{-1}\right)$, calculated at TZ2P+f CCSD level. ${ }^{7}$. It will be further discussed later.

\section{$\mathrm{CH}_{5}^{+}\left(\mathrm{CH}_{4}\right)$}

Fig. 2D shows the IR spectrum of $\mathrm{CH}_{5}^{+}\left(\mathrm{CH}_{4}\right)$ obtained in the frequency range of $2800-3100 \mathrm{~cm}^{-1}$. Three features were found, centered at 2869,2982 , and $3063 \mathrm{~cm}^{-1}$ in the IR spectrum. The $2869 \mathrm{~cm}^{-1}$ peak was attributed to the $\mathrm{C}-\mathrm{H}$ stretching mode of the solvent $\mathrm{CH}_{4}$ molecule in $\mathrm{CH}_{5}^{+}\left(\mathrm{CH}_{4}\right)$ since this peak was not observed in the IR spectra for the other mono-solvated carbonium ions, $\mathrm{CH}_{5}^{+}(\mathrm{A})\left(\mathrm{A}=\mathrm{H}_{2}, \mathrm{Ar}, \mathrm{N}_{2}\right)$. It was $45 \mathrm{~cm}^{-1}$ redshifted from the totally symmetric $v_{1} \mathrm{C}-\mathrm{H}$ stretching mode of free $\mathrm{CH}_{4}\left(2914 \mathrm{~cm}^{-1}\right){ }^{24}$ indicating the weakening of the $\mathrm{C}-\mathrm{H}$ bonds directly involved in the coordination of the solvent $\mathrm{CH}_{4}$ to the core $\mathrm{CH}_{5}{ }^{+}$. The coordination of $\mathrm{CH}_{4}$ to the $\mathrm{CH}_{5}^{+}$core, as predicted by the ab initio calculations, ${ }^{27}$ was expected to occur via the 3 -fold face of $\mathrm{CH}_{4}$, and as a result, the normal mode would be more or less localized in the three bound $\mathrm{C}-\mathrm{H}$ bonds.

The two features at 2982 and $3063 \mathrm{~cm}^{-1}$ were assigned to the two strongly coupled $\mathrm{CH}_{3}$ stretching modes, and one less coupled $\mathrm{CH}_{3}$ stretching mode of the $\mathrm{CH}_{5}{ }^{+}$core, from the similarities of the spectral features to those for $\mathrm{CH}_{5}{ }^{+}(\mathrm{Ar})$ and $\mathrm{CH}_{5}{ }^{+}\left(\mathrm{N}_{2}\right)$. The 2982 and $3063 \mathrm{~cm}^{-1}$ peaks were narrower than those for $\left.\mathrm{CH}_{5}{ }^{+} \mathrm{Ar}\right)$ and $\mathrm{CH}_{5}{ }^{+}\left(\mathrm{N}_{2}\right)$, indicating the strong interaction between $\mathrm{CH}_{5}^{+}$core and the solvent $\mathrm{CH}_{4}$ molecule $\left(\Delta \mathrm{H}^{\circ} \mathrm{T}=6.87\right.$ $\mathrm{kcal} / \mathrm{mole}$ ). It is interesting to notice that the $2982 \mathrm{~cm}^{-1}$ peak possesses a high frequency shoulder, centered at $3010 \mathrm{~cm}^{-1}$, determined from a least squares fit, as shown in Fig. 3 . This shoulder feature could be assigned to the $\mathrm{C}-\mathrm{H}$ stretching mode localized in the $\mathrm{C}-\mathrm{H}$ 
bonds of $\mathrm{CH}_{4}$ not directly involved in the coordination since it was only $-10 \mathrm{~cm}^{-1}$ redshifted from the triply degenerate $\mathrm{V}_{3} \mathrm{C}-\mathrm{H}$ stretching modes of free $\mathrm{CH}_{4}\left(3020 \mathrm{~cm}^{-1}\right)$. The two $\mathrm{C}-\mathrm{H}$ stretching bands for the solvent $\mathrm{CH}_{4}\left(2869,3010 \mathrm{~cm}^{-1}\right)$ were different in pattern from those for free $\mathrm{CH}_{4}$ where the $\mathrm{v}_{1} \mathrm{C}-\mathrm{H}$ stretching mode is IR inactive while the $v_{3}$ mode is IR active. ${ }^{24}$ The difference was attributed to the different symmetry of the ion complex as well as the localization of the normal modes, which resulted in the high IR intensity for the bound $\mathrm{C}-\mathrm{H}$ stretching mode $\left(2869 \mathrm{~cm}^{-1}\right)$. Similar frequency shifts and intensity patterns have been observed previously in the IR spectra for the $\mathrm{CH}_{4}$ molecules adsorbed on $\mathrm{NaCl}$ film ${ }^{28}$ as well as the $\mathrm{CH}_{4}$ molecules adsorbed on cationic forms of high-silica zeolites. ${ }^{29}$ As in the case for $\mathrm{CH}_{5}{ }^{+}\left(\mathrm{N}_{2}\right)$, another vibrational band, centered at $2608 \mathrm{~cm}^{-1}$, was observed in the IR spectrum obtained in the frequency region of 2500 $2700 \mathrm{~cm}^{-1}$, as shown in Fig. $6 \mathrm{~B}$. Similarly, this feature was attributed to the $\mathrm{H}-\mathrm{H}$ stretching mode of the $3 \mathrm{c} 2 \mathrm{e}$ bond in $\mathrm{CH}_{5}{ }^{+}$core.

Since $\mathrm{CH}_{5}{ }^{+}\left(\mathrm{CH}_{4}\right)$ is a proton bound symmetric dimer, the proton transfer between two $\mathrm{CH}_{4}$ molecules would occur in a double well potential surface, similar to the cases for $\mathrm{H}_{3} \mathrm{O}^{+}\left(\mathrm{H}_{2} \mathrm{O}\right)^{21}$ and $\mathrm{NH}_{4}^{+}\left(\mathrm{NH}_{3}\right),{ }^{22}$ but probably with a different potential barrier. The details of the dynamics of the proton transfer will be addressed later.

\subsection{Di-solvated carbonium ions, $\mathrm{CH}_{5}^{+}(\mathrm{A})(\mathrm{B})$}

Fig. 4 shows the IR spectra for the di-solvated carbonium ions, $\mathrm{CH}_{5}^{+}(\mathrm{A})(\mathrm{B})$ $\left(\mathrm{A}, \mathrm{B}=\mathrm{H}_{2}, \mathrm{Ar}, \mathrm{CH}_{4}\right)$ obtained in the frequency region of $2700-3200 \mathrm{~cm}^{-1}$. The spectral features in this frequency region were due to the $\mathrm{C}-\mathrm{H}$ stretching modes of the core $\mathrm{CH}_{5}{ }^{+}$ 
and the solvent $\mathrm{CH}_{4}$. The frequencies of the observed features are listed in Table II.

\section{$\mathrm{CH}_{5}^{+}\left(\mathrm{H}_{2}\right)_{2}$}

As described in Chapter 3, the IR spectrum of $\mathrm{CH}_{5}{ }^{+}\left(\mathrm{H}_{2}\right)_{2}$ (Fig. 4A) was obtained by monitoring the $\mathrm{CH}_{5}^{+}$signal in the frequency region of $2800-3150 \mathrm{~cm}^{-1}$. In the IR spectrum, two spectral features were found, centered at 2957 and $3078 \mathrm{~cm}^{-1}$. The 2957 $\mathrm{cm}^{-1}$ peak was attributed to the two strongly coupled $\mathrm{CH}_{3}$ stretching modes of the $\mathrm{CH}_{5}^{+}$ core (via $\mathrm{CH}_{3}$ internal rotation), while the $3078 \mathrm{~cm}^{-1}$ peak was assigned to the other less coupled $\mathrm{CH}_{3}$ stretching mode. The absence of the broad low frequency shoulder observed in the IR spectrum of $\mathrm{CH}_{5}{ }^{+}\left(\mathrm{H}_{2}\right)$, suggested the slowdown of the scrambling motion via the in-plane wagging motion, by the two $\mathrm{H}_{2}$ molecules:

$\mathrm{CH}_{5}^{+}(\mathrm{Ar})_{2}$

The IR spectrum shown in Fig. 4B was obtained by monitoring the $\mathrm{CH}_{5}{ }^{+}$signal in the frequency range of $2820-3120 \mathrm{~cm}^{-1}$. One broad and one sharp feature, centered at 2957 and $3072 \mathrm{~cm}^{-1}$, respectively, were observed in the IR spectrum and were again assigned to the two strongly coupled $\mathrm{CH}_{3}$ stretching modes, and one less coupled $\mathrm{CH}_{3}$ stretching mode of the $\mathrm{CH}_{5}^{+}$core. The $2957 \mathrm{~cm}^{-1}$ peak was observed to be slightly more intense on the low frequency side, and the $3072 \mathrm{~cm}^{-1}$ was sharper and more intense, compared to the corresponding peaks for $\mathrm{CH}_{5}{ }^{+}\left(\mathrm{H}_{2}\right)_{2}$, respectively (see Fig. 4A and 4B). The difference could be explained by the fact that the increased charge-induced dipole interactions in $\mathrm{CH}_{5}^{+}(\mathrm{Ar})_{2}$ due to the larger electric polarizability of $\mathrm{Ar}$, slowed down 
slightly the scrambling of the $\mathrm{CH}_{5}^{+}$core (via the $\mathrm{CH}_{3}$ internal rotation), and as a result, the three $\mathrm{CH}_{3}$ stretching modes could be less coupled. The scrambling of the $\mathrm{CH}_{5}^{+}$core via the in-plane wagging motion, was more or less frozen out, indicated by the absence of the low frequency shoulder observed for $\mathrm{CH}_{5}{ }^{+}\left(\mathrm{H}_{2}\right)$.

\section{$\mathrm{CH}_{5}^{+}(\mathrm{Ar})\left(\mathrm{CH}_{4}\right)$}

The IR spectrum for $\mathrm{CH}_{5}^{+}(\mathrm{Ar})\left(\mathrm{CH}_{4}\right)$, as shown in Fig. $4 \mathrm{C}$, was observed by monitoring the $\mathrm{CH}_{5}^{+}\left(\mathrm{CH}_{4}\right)$ signal $(\mathrm{m} / \mathrm{e}=33)$ in the frequency region of $2800-3100 \mathrm{~cm}^{-1}$. In the spectrum, three features, centered at 2874,2974 , and $3072 \mathrm{~cm}^{-1}$, were found along with the broad feature around $2900 \mathrm{~cm}^{-1}$ and a shoulder feature at $~ 3000 \mathrm{~cm}^{-1}$ (Fig. 4C). The $2874 \mathrm{~cm}^{-1}$ peak was assigned to the bound $\mathrm{C}-\mathrm{H}$ stretching mode of the solvent $\mathrm{CH}_{4}$, and it was $5 \mathrm{~cm}^{-1}$ blue-shifted from the corresponding peak of $\mathrm{CH}_{5}{ }^{+}\left(\mathrm{CH}_{4}\right)$, indicating the weakening of the interaction between the core ion and the $\mathrm{CH}_{4}$ molecule due to the slight delocalization of the positive charge of the core ion by the solvent Ar. Of the features for the $\mathrm{C}-\mathrm{H}$ stretching modes of the core $\mathrm{CH}_{5}^{+}$, the $2974 \mathrm{~cm}^{-1}$ peak and the broad feature around $2900 \mathrm{~cm}^{-1}$ were correlated with the $2957 \mathrm{~cm}^{-1}$ peak of $\mathrm{CH}_{5}^{+}(\mathrm{Ar})_{2}$, assigned to the two strongly coupled $\mathrm{CH}_{3}$ stretching modes, respectively, and the $3072 \mathrm{~cm}^{-1}$ peak was assigned to the less coupled $\mathrm{CH}_{3}$ stretching mode, as in the case of $\mathrm{CH}_{5}{ }^{+}(\mathrm{Ar})_{2}$. The separation of the two strongly coupled $\mathrm{CH}_{3}$ stretching modes for $\mathrm{CH}_{5}{ }^{+}(\mathrm{Ar})\left(\mathrm{CH}_{4}\right)(2974$ and $-2900 \mathrm{~cm}^{-1}$ features) suggested that the stronger interaction of the $\mathrm{CH}_{5}{ }^{+}$core with $\mathrm{CH}_{4}$ vs. Ar decoupled the two vibrational modes. On the other hand, the $3072 \mathrm{~cm}^{-1}$ peak assigned to the less coupled $\mathrm{C}-\mathrm{H}$ stretching mode was not shifted from the corresponding 
peak of $\mathrm{CH}_{5}{ }^{+}(\mathrm{Ar})_{2}$. The high frequency shoulder of the $2974 \mathrm{~cm}^{-1}$ peak was attributed to the free $\mathrm{C}-\mathrm{H}$ stretching mode of the solvent $\mathrm{CH}_{4}$ in $\mathrm{CH}_{5}{ }^{+}(\mathrm{Ar})\left(\mathrm{CH}_{4}\right)$, similar to the 3010 $\mathrm{cm}^{-1}$ shoulder of $\mathrm{CH}_{5}^{+}\left(\mathrm{CH}_{4}\right)$ (Fig. 3).

\section{$\mathrm{CH}_{5}^{+}\left(\mathrm{CH}_{4}\right)_{2}$}

The IR spectrum for $\mathrm{CH}_{5}{ }^{+}\left(\mathrm{CH}_{4}\right)_{2}$ shown in Fig. $4 \mathrm{D}$, was obtained by monitoring the $\mathrm{CH}_{5}^{+}\left(\mathrm{CH}_{4}\right)$ signal $(\mathrm{m} / \mathrm{e}=33)$ in the frequency range of $2700-3150 \mathrm{~cm}^{-1}$. Three features, centered at 2879,2974 , and $3082 \mathrm{~cm}^{-1}$, were found in the spectrum along with the broad feature around $2900 \mathrm{~cm}^{-1}$ and a shoulder feature at $~ 3000 \mathrm{~cm}^{-1}$. The $2879 \mathrm{~cm}^{-1}$ peak and the shoulder at $\sim 3000 \mathrm{~cm}^{-1}$ were assigned to the bound $\mathrm{C}-\mathrm{H}$ stretching and free $\mathrm{C}-\mathrm{H}$ stretching modes, respectively, of the solvent $\mathrm{CH}_{4}$ molecules in $\mathrm{CH}_{5}^{+}\left(\mathrm{CH}_{4}\right)_{2}$, as in the cases for $\mathrm{CH}_{5}^{+}\left(\mathrm{CH}_{4}\right)$ and $\mathrm{CH}_{5}^{+}(\mathrm{Ar})\left(\mathrm{CH}_{4}\right)$. The single feature at $2879 \mathrm{~cm}^{-1}$ for the bound $\mathrm{C}$ - $\mathrm{H}$ stretching modes of $\mathrm{CH}_{5}{ }^{+}\left(\mathrm{CH}_{4}\right)_{2}$ suggested that the two $\mathrm{CH}_{4}$ molecules were bound to the core $\mathrm{CH}_{5}^{+}$with equal strength, indicating the presence of a $3 \mathrm{c} 2 \mathrm{e}$ bond containing two equivalent acidic $\mathrm{H}$ atoms in the $\mathrm{CH}_{5}{ }^{+}$core. In addition, the blue-shifts (10 and 5 $\left.\mathrm{cm}^{-1}\right)$ of the $2879 \mathrm{~cm}^{-1}$ peak from the corresponding peaks for $\mathrm{CH}_{5}^{+}\left(\mathrm{CH}_{4}\right)$ and $\mathrm{CH}_{5}{ }^{+}(\mathrm{Ar})\left(\mathrm{CH}_{4}\right)$, respectively, suggested that the interaction between the core $\mathrm{CH}_{5}{ }^{+}$and the individual $\mathrm{CH}_{4}$ molecule in $\mathrm{CH}_{5}^{+}\left(\mathrm{CH}_{4}\right)_{2}$ was weaker than those in $\mathrm{CH}_{5}^{+}\left(\mathrm{CH}_{4}\right)$ and $\mathrm{CH}_{5}{ }^{+}(\mathrm{Ar})\left(\mathrm{CH}_{4}\right)$, due to the equal partitioning of the charge densities of the core ion for the two solvent $\mathrm{CH}_{4}$ molecules.

On the other hand, the $2974 \mathrm{~cm}^{-1}$ peak and the broad feature around $2900 \mathrm{~cm}^{-1}$ were assigned to the two strongly coupled $\mathrm{CH}_{3}$ stretching modes of the $\mathrm{CH}_{5}^{+}$core, 
respectively, as in the case of $\mathrm{CH}_{5}^{+}(\mathrm{Ar})\left(\mathrm{CH}_{4}\right)$. The $3082 \mathrm{~cm}^{-1}$ peak observed for $\mathrm{CH}_{5}{ }^{+}\left(\mathrm{CH}_{4}\right)_{2}$ was narrower than, and $10 \mathrm{~cm}^{-1}$ blue-shifted, from the corresponding peaks for $\mathrm{CH}_{5}^{+}(\mathrm{Ar})\left(\mathrm{CH}_{4}\right)$ and $\mathrm{CH}_{5}^{+}(\mathrm{Ar})_{2}\left(3072 \mathrm{~cm}^{-1}\right)$, which were assigned to the less coupled $\mathrm{C}-\mathrm{H}$ stretching mode of $\mathrm{CH}_{5}{ }^{+}$core. This result suggested that the formation of the tightly bound cluster, $\mathrm{CH}_{5}{ }^{+}\left(\mathrm{CH}_{4}\right)_{2}$ could involve a slight geometrical change in the $\mathrm{CH}_{5}{ }^{+}$ core in order to accommodate two $\mathrm{CH}_{4}$ molecules close to the $\mathrm{CH}_{5}^{+}$core.

Fig. 6C shows the IR spectrum for $\mathrm{CH}_{5}^{+}\left(\mathrm{CH}_{4}\right)_{2}$ obtained in the frequency region of $2500-2700 \mathrm{~cm}^{-1}$. One broad feature, centered at $2577 \mathrm{~cm}^{-1}$, was found in the spectrum, and was attributed to the $\mathrm{H}-\mathrm{H}$ stretching mode of the $3 \mathrm{c} 2 \mathrm{e}$ bond in $\mathrm{CH}_{5}{ }^{+}$core, as seen for $\mathrm{CH}_{5}^{+}\left(\mathrm{N}_{2}\right)$ and $\mathrm{CH}_{5}^{+}\left(\mathrm{CH}_{4}\right)$.

\subsection{Tri-solvated carbonium ions, $\mathrm{CH}_{5}^{+}(\mathrm{A})(\mathrm{B})(\mathrm{C})$}

Fig. 5 shows the IR spectra for the tri-solvated carbonium ions, $\mathrm{CH}_{5}{ }^{+}(\mathrm{A})(\mathrm{B})(\mathrm{C})$ $\left(\mathrm{A}, \mathrm{B}, \mathrm{C}=\mathrm{H}_{2}, \mathrm{Ar}, \mathrm{CH}_{4}\right)$, obtained in the frequency region of $2700-3200 \mathrm{~cm}^{-1}$. The spectral features in this frequency region were due to the $\mathrm{C}-\mathrm{H}$ stretching modes of the core $\mathrm{CH}_{s}{ }^{+}$ and the solvent $\mathrm{CH}_{4}$ molecules. The frequencies of the observed features are listed in Table II.

\section{$\mathrm{CH}_{5}^{+}\left(\mathrm{H}_{2}\right)_{3}$}

Three partially resolved features, centered at 2892,2977 , and $3062 \mathrm{~cm}^{-1}$, were found in the IR spectrum as shown in Fig. 5A (also see ref. 17,18). As reported previously, the three features were attributed to the three $\mathrm{CH}_{3}$ stretching modes of the 
core $\mathrm{CH}_{5}{ }^{+}$, the symmetric $\mathrm{CH}_{3}$ breathing, symmetric $\mathrm{CH}_{3}$ degenerate stretching, and asymmetric $\mathrm{CH}_{3}$ stretching modes, respectively. The scrambling of the $\mathrm{CH}_{5}{ }^{+}$core via the $\mathrm{CH}_{3}$ internal rotation and in-plane wagging motion were more or less frozen out by the stabilization effects of the three $\mathrm{H}_{2}$ molecules in $\mathrm{CH}_{5}^{+}\left(\mathrm{H}_{2}\right)_{3}$.

\section{$\mathrm{CH}_{5}^{+}(\mathrm{Ar})_{2}\left(\mathrm{CH}_{4}\right)$}

The IR spectrum shown in Fig. 5B, was obtained by monitoring the $\mathrm{CH}_{5}{ }^{+}\left(\mathrm{CH}_{4}\right)$ signal $(\mathrm{m} / \mathrm{e}=33)$ in the frequency range of $2800-3100 \mathrm{~cm}^{-1}$. Three features, centered at 2877,2980 , and $3070 \mathrm{~cm}^{-1}$, were found in the IR spectrum along with the broad feature around $2900 \mathrm{~cm}^{-1}$. The $2877 \mathrm{~cm}^{-1}$ peak was assigned to the bound $\mathrm{C}-\mathrm{H}$ stretching mode of the solvent $\mathrm{CH}_{4}$ molecule. It was $3 \mathrm{~cm}^{-1}$ blue-shifted, but $2 \mathrm{~cm}^{-1}$ red-shifted from the corresponding peaks for $\left.\mathrm{CH}_{5}{ }^{+} \mathrm{Ar}\right)\left(\mathrm{CH}_{4}\right)$ and $\mathrm{CH}_{5}{ }^{+}\left(\mathrm{CH}_{4}\right)_{2}$, respectively, indicating the increased delocalization of the positive charge by the additional Ar, and the stronger interaction of the core ion with $\mathrm{CH}_{4}$ than $\mathrm{Ar}$, respectively. The $2980 \mathrm{~cm}^{-1}$ peak and the broad feature around $2900 \mathrm{~cm}^{-1}$ were attributed to two coupled $\mathrm{CH}_{3}$ stretching modes of the $\mathrm{CH}_{5}{ }^{+}$core, respectively, and the $3070 \mathrm{~cm}^{-1}$ peak was assigned to the other less coupled $\mathrm{CH}_{3}$ stretching mode.

\section{$\mathrm{CH}_{5}^{+}(\mathrm{Ar})\left(\mathrm{CH}_{4}\right)_{2}$}

The IR spectrum shown in Fig. $5 \mathrm{C}$ was obtained by monitoring the $\mathrm{CH}_{5}^{+}\left(\mathrm{CH}_{4}\right)$ signal $(\mathrm{m} / \mathrm{e}=33)$ in the frequency range of $2800-3100 \mathrm{~cm}^{-1}$. Three features, centered at 2881,2978 , and $3079 \mathrm{~cm}^{-1}$, were found along with the broad feature around $2900 \mathrm{~cm}^{-1}$ 
in the IR spectrum. As in the case for $\mathrm{CH}_{5}{ }^{+}(\mathrm{Ar})_{2}\left(\mathrm{CH}_{4}\right)$, the $2881 \mathrm{~cm}^{-1}$ peak was assigned to the bound $\mathrm{C}-\mathrm{H}$ stretching mode of the solvent $\mathrm{CH}_{4}$ molecule. It was 4 and $2 \mathrm{~cm}^{-1}$ blueshifted from the bound $\mathrm{C}-\mathrm{H}$ stretching modes for $\mathrm{CH}_{5}{ }^{+}(\mathrm{Ar})_{2}\left(\mathrm{CH}_{4}\right)\left(2877 \mathrm{~cm}^{-1}\right)$ and $\mathrm{CH}_{5}^{+}\left(\mathrm{CH}_{4}\right)_{2}\left(2879 \mathrm{~cm}^{-1}\right)$, respectively, indicating the similar solvent effects on the interaction between the core $\mathrm{CH}_{5}^{+}$and $\mathrm{CH}_{4}$ molecules as described previously. Furthermore, the single feature for the bound C-H stretching modes $\left(2881 \mathrm{~cm}^{-1}\right)$ suggested that the equal interactions between the core $\mathrm{CH}_{5}{ }^{+}$and two $\mathrm{CH}_{4}$ molecules observed for $\mathrm{CH}_{5}{ }^{+}\left(\mathrm{CH}_{4}\right)_{2}$ were not perturbed by the third solvent Ar. The $2978 \mathrm{~cm}^{-1}$ peak and the broad feature around $2900 \mathrm{~cm}^{-1}$ were again attributed to the two $\mathrm{CH}_{3}$ stretching modes, and the $3079 \mathrm{~cm}^{-1}$ peak was assigned to the less coupled $\mathrm{CH}_{3}$ stretching mode of the $\mathrm{CH}_{5}^{+}$ core.

\section{$\mathrm{CH}_{5}^{+}\left(\mathrm{CH}_{4}\right)_{3}$}

Fig. 5D shows the IR spectrum of $\mathrm{CH}_{5}{ }^{+}\left(\mathrm{CH}_{4}\right)_{3}$ obtained by measuring the $\mathrm{CH}_{5}{ }^{+}\left(\mathrm{CH}_{4}\right)_{2}$ signal $(\mathrm{m} / \mathrm{e}=49)$ in the frequency range of $2700-3100 \mathrm{~cm}^{-1}$. Significant spectral changes were observed in the IR spectrum (Fig. 5D), compared to those for other tri-solvated carbonium ions (Fig. 5A,B,C). First, one broad and intense feature, centered at $2823 \mathrm{~cm}^{-1}$, was found in the spectrum while the broad feature around $2900 \mathrm{~cm}^{-1}$ observed in the IR spectra for $\mathrm{CH}_{5}^{+}\left(\mathrm{CH}_{4}\right)_{2}, \mathrm{CH}_{5}{ }^{+}(\mathrm{Ar})\left(\mathrm{CH}_{4}\right)_{2}$, and $\mathrm{CH}_{5}^{+}(\mathrm{Ar})_{2}\left(\mathrm{CH}_{4}\right)$ was no longer present. Second, the bound $\mathrm{C}-\mathrm{H}$ stretching modes of the solvent $\mathrm{CH}_{4}$ molecules were splitted into two peaks, centered at 2880 and $2890 \mathrm{~cm}^{-1}$ in the spectrum (Fig. 5D). Third, two features at 2989 and $3077 \mathrm{~cm}^{-1}$, were observed to be much sharper than the 
corresponding features for the other solvated carbonium ions. Finally, the fine structures around $3010 \mathrm{~cm}^{-1}$ were observed in the IR spectrum, along with the two sharp features at 3002 and $3022 \mathrm{~cm}^{-1}$.

The spectral features at 2823,2989 , and $3077 \mathrm{~cm}^{-1}$ were attributed to the three $\mathrm{CH}_{3}$ stretching modes of the $\mathrm{CH}_{5}^{+}$core, respectively. Since the third $\mathrm{CH}_{4}$ in $\mathrm{CH}_{5}^{+}\left(\mathrm{CH}_{4}\right)_{3}$ would be bound to one of the three $\mathrm{C}-\mathrm{H}$ bonds in the $\mathrm{CH}_{3}$ group, as predicted in the previous theoretical work, ${ }^{27}$ strong perturbations on one of the three $\mathrm{C}-\mathrm{H}$ stretching modes were expected. Therefore, the feature at $2823 \mathrm{~cm}^{-1}$, considerably red-shifted and broadened from the other vibrational modes, could be assigned to the bound $\mathrm{C}-\mathrm{H}$ stretching mode of the $\mathrm{CH}_{3}$ group in the $\mathrm{CH}_{5}^{+}$core, with the normal mode more or less localized in the $\mathrm{C}-\mathrm{H}$ bond bound to the third $\mathrm{CH}_{4}$. The sharp features at 2989 and 3077 $\mathrm{cm}^{-1}$ could be assigned to the symmetric and asymmetric $\mathrm{CH}_{2}$ stretching modes involving the two free $\mathrm{C}-\mathrm{H}$ bonds in the $\mathrm{CH}_{3}$ group, respectively.

The 2880 and $2890 \mathrm{~cm}^{-1}$ peaks were attributed to the bound $\mathrm{C}-\mathrm{H}$ stretching modes of the solvent $\mathrm{CH}_{4}$ molecules, as in the other tri-solvated carbonium ions. Since the 2880 $\mathrm{cm}^{-1}$ peak was only $1 \mathrm{~cm}^{-1}$ blue-shifted from the corresponding peak of $\mathrm{CH}_{5}{ }^{+}\left(\mathrm{CH}_{4}\right)_{2}$, and the $2890 \mathrm{~cm}^{-1}$ peak was not present in the IR spectra for other tri-solvated carbonium ions possessing no third $\mathrm{CH}_{4}$, such as $\mathrm{CH}_{5}^{+}(\mathrm{Ar})\left(\mathrm{CH}_{4}\right)_{2}$ and $\mathrm{CH}_{5}{ }^{+}(\mathrm{Ar})_{2}\left(\mathrm{CH}_{4}\right)$. (Fig. 5B,C), these two peaks were assigned to the bound $\mathrm{C}-\mathrm{H}$ stretching modes of the first two $\mathrm{CH}_{4}$ molecules, and the third $\mathrm{CH}_{4}$ molecule in $\mathrm{CH}_{5}{ }^{+}\left(\mathrm{CH}_{4}\right)_{3}$, respectively. The fine features around $3010 \mathrm{~cm}^{-1}$ including the 3002 and $3022 \mathrm{~cm}^{-1}$ peaks were attributed to the free $\mathrm{C}-\mathrm{H}$ stretching modes of the solvent $\mathrm{CH}_{4}$ molecules like the other $\mathrm{CH}_{4}$ solvated carbonium 
ions.

Fig. 6D shows the IR spectrum obtained in the frequency range of $2525-2675 \mathrm{~cm}^{-1}$. The broad feature, centered at $2578 \mathrm{~cm}^{-1}$ in the spectrum, was again attributed to the $\mathrm{H}-\mathrm{H}$ stretching mode of the $3 \mathrm{c} 2 \mathrm{e}$ bond in the $\mathrm{CH}_{5}{ }^{+}$core. The center of the feature was only slightly shifted from the corresponding feature of $\mathrm{CH}_{5}{ }^{+}\left(\mathrm{CH}_{4}\right)_{2}\left(2577 \mathrm{~cm}^{-1}\right)$, indicating small or no perturbation to the $3 \mathrm{c} 2 \mathrm{e}$ bond by the third $\mathrm{CH}_{4}$ molecule.

\subsection{Tetra- and penta-solvated carbonium ions, $\mathrm{CH}_{5}^{+}(\mathrm{A})_{4,5}\left(\mathrm{~A}=\mathrm{CH}_{4}\right)$}

Fig. 7A shows the IR spectrum for $\mathrm{CH}_{5}{ }^{+}\left(\mathrm{CH}_{4}\right)_{4}$, obtained by monitoring the $\mathrm{CH}_{5}{ }^{+}\left(\mathrm{CH}_{4}\right)_{2}(\mathrm{~m} / \mathrm{e}=49)$ in the frequency range of $2700-3100 \mathrm{~cm}^{-1}$. The observed features were similar to those for $\mathrm{CH}_{5}^{+}\left(\mathrm{CH}_{4}\right)_{3}$ (Fig. 5D), with the exception of the single feature at $2890 \mathrm{~cm}^{-1}$ (see Fig. 7A). The broad feature at $\sim 2823 \mathrm{~cm}^{-1}$, and two peaks at 2989 and $3079 \mathrm{~cm}^{-1}$ observed in the IR spectrum (Fig. 7A), were attributed to the bound $\mathrm{C}-\mathrm{H}$ stretching mode, and the symmetric and asymmetric free $\mathrm{CH}_{2}$ stretching modes of the $\mathrm{CH}_{3}$ group in the $\mathrm{CH}_{5}^{+}$core, respectively, as in the case of $\mathrm{CH}_{5}^{+}\left(\mathrm{CH}_{4}\right)_{3}$. It is interesting to notice that these frequencies were very close to the corresponding frequencies for $\mathrm{CH}_{5}^{+}\left(\mathrm{CH}_{4}\right)_{3}\left(2823,2989,3077 \mathrm{~cm}^{-1}\right)$. The $2890 \mathrm{~cm}^{-1}$ peak and the fine structures around $3000 \mathrm{~cm}^{-1}$ were attributed to the bound $\mathrm{C}-\mathrm{H}$ stretching modes and free $\mathrm{C}-\mathrm{H}$ stretching modes of the solvent $\mathrm{CH}_{4}$ molecules in $\mathrm{CH}_{5}^{+}\left(\mathrm{CH}_{4}\right)_{4}$, respectively.

Fig. 7B shows the IR spectrum for $\mathrm{CH}_{5}{ }^{+}\left(\mathrm{CH}_{4}\right)_{5}$, obtained by monitoring the $\mathrm{CH}_{5}^{+}\left(\mathrm{CH}_{4}\right)_{3}(\mathrm{~m} / \mathrm{e}=65)$ in the frequency range of $2850-2950 \mathrm{~cm}^{-1}$. Three sharp features at 2886, 2892, and $2896 \mathrm{~cm}^{-1}$, observed in the IR spectrum (Fig. 7B), were attributed to the 
bound $\mathrm{C}-\mathrm{H}$ stretching modes of the solvent $\mathrm{CH}_{4}$ molecules in $\mathrm{CH}_{5}^{+}\left(\mathrm{CH}_{4}\right)_{5}$. Notice that these multiple features were somewhat different from the cases for $\mathrm{CH}_{5}{ }^{+}\left(\mathrm{CH}_{4}\right)_{3}$ and $\mathrm{CH}_{5}^{+}\left(\mathrm{CH}_{4}\right)_{4}$. 


\section{DISCUSSION}

\subsection{Vibrational assignment of the feature in $2500-2700 \mathrm{~cm}^{-1}$}

As mentioned previously, one vibrational feature was observed in the IR spectra for $\mathrm{CH}_{5}{ }^{+}\left(\mathrm{N}_{2}\right)$ and $\mathrm{CH}_{5}{ }^{+}\left(\mathrm{CH}_{4}\right)_{\mathrm{n}}(\mathrm{n}=1,2,3)$, obtained in the frequency region of $2500-2700$ $\mathrm{cm}^{-1}$ (see Fig. 6). Since the intensity of the IR laser in this frequency region was about three times lower than that for the normal scan range $\left(2800-3200 \mathrm{~cm}^{-1}\right)$, and the absorption cross section of the feature was found to be small, it was necessary to accumulate the spectra for over several scans in order to have a reasonable signal-to-noise ratio. In the IR spectra (Fig. 6), the frequencies of the observed features were 2623, 2608, 2577, and $2578 \mathrm{~cm}^{-1}$ for $\mathrm{CH}_{5}^{+}\left(\mathrm{N}_{2}\right)$ and $\mathrm{CH}_{5}{ }^{+}\left(\mathrm{CH}_{4}\right)_{\mathrm{n}}(\mathrm{n}=1,2,3)$, respectively. According to the vibrational analysis on $\mathrm{CH}_{5}{ }^{+}$performed at the sophisticated level of theory $(\mathrm{TZ2} 2 \mathrm{P}+\mathrm{f} \mathrm{CCSD}),{ }^{7}$ the $\mathrm{H}-\mathrm{H}$ stretching frequencies of the $3 \mathrm{c} 2 \mathrm{e}$ bond in $\mathrm{e}-\mathrm{C}_{\mathrm{s}}$ and $\mathrm{s}-\mathrm{C}_{\mathrm{s}}$ $\mathrm{CH}_{5}^{+}$were predicted to be 2633 and $2650 \mathrm{~cm}^{-1}$, respectively, after appropriate corrections for the anharmonicities. These frequencies were expected to decrease slightly in the cases of the solvated carbonium ions, since the solvent molecules would prefer to bind to the $\mathrm{H}$ atoms forming the electron deficient $3 \mathrm{c} 2 \mathrm{e}$ bond, and as a result, the force constants of the vibrational modes would decrease, besides the increase in its effective reduced mass. In fact, the $\mathrm{H}-\mathrm{H}$ stretching frequency of e- $\mathrm{C}_{\mathrm{s}} \mathrm{CH}_{5}{ }^{+}$core in $\mathrm{CH}_{5}{ }^{+}\left(\mathrm{H}_{2}\right)$, where the $\mathrm{H}_{2}$ was bound to one of the two $3 \mathrm{c} 2 \mathrm{e} \mathrm{H}$ atoms, predicted at TZ2P CCSD level, ${ }^{25}$ was $2600 \mathrm{~cm}^{-1}$, $33 \mathrm{~cm}^{-1}$ red-shifted from the corresponding frequency of e- $\mathrm{C}_{\mathrm{s}} \mathrm{CH}_{\mathrm{s}}^{+}\left(2633 \mathrm{~cm}^{-1}\right)$.

As reported previously on $\mathrm{CH}_{5}{ }^{+}\left(\mathrm{H}_{2}\right)_{\mathrm{n}}(\mathrm{n}=1-6)$, the $\mathrm{CH}_{5}{ }^{+}$core could scramble considerably without possessing a definite $3 \mathrm{c} 2 \mathrm{e}$ bond, and the vibrational analysis for the 
static $\mathrm{CH}_{s}{ }^{+}$structures would be no longer valid. In this case, the features observed in this frequency range could be due to the overtone or combination bands of the low frequency modes in the $\mathrm{CH}_{5}^{+}$core. On the other hand, the solvent $\mathrm{N}_{2}$ and $\mathrm{CH}_{4}$ molecules could stabilize the $\mathrm{CH}_{5}{ }^{+}$core from scrambling, with the $3 \mathrm{c} 2 \mathrm{e}$ bond being localized, and as a result, the $\mathrm{H}-\mathrm{H}$ stretching mode of the $3 \mathrm{c} 2 \mathrm{e}$ bond would appear in the frequency range of $2500-2700 \mathrm{~cm}^{-1}$, with some frequency shifts due to the solvent molecules.

In the IR spectrum shown in Fig. 6 , the observed feature for $\mathrm{CH}_{5}{ }^{+}\left(\mathrm{CH}_{4}\right)$ (Fig. 6B) was centered at $2608 \mathrm{~cm}^{-1}, 15 \mathrm{~cm}^{-1}$ red-shifted from the corresponding feature at 2623 $\mathrm{cm}^{-1}$ for $\mathrm{CH}_{5}^{+}\left(\mathrm{N}_{2}\right)$ (Fig. 6A). This indicates the strong solvent effect of $\mathrm{CH}_{4}$ due to the large binding energy of $\mathrm{CH}_{5}{ }^{+}\left(\mathrm{CH}_{4}\right)\left(\Delta \mathrm{H}^{\circ}{ }_{\mathrm{T}}=6.87 \mathrm{kcal} / \mathrm{mole}\right),{ }^{11}$ consistent with the predicted structure of $\mathrm{CH}_{5}{ }^{+}\left(\mathrm{CH}_{4}\right)$, where the $\mathrm{CH}_{4}$ molecule was bound to one of the two $\mathrm{H}$ atoms forming the $3 \mathrm{c} 2 \mathrm{e}$ bond. ${ }^{11,12}$. The observed feature for $\mathrm{CH}_{5}{ }^{+}\left(\mathrm{CH}_{4}\right)_{2}$ (Fig. 6C) was considerably red-shifted $\left(46 \mathrm{~cm}^{-1}\right)$ from the $2623 \mathrm{~cm}^{-1}$ peak, also consistent with the predicted structure of $\mathrm{CH}_{5}{ }^{+}\left(\mathrm{CH}_{4}\right)_{2}$ where the two $\mathrm{CH}_{4}$ molecules are bound to the two acidic $\mathrm{H}$ atoms of the $3 \mathrm{c} 2 \mathrm{e}$ bond, respectively. In case of $\mathrm{CH}_{5}{ }^{+}\left(\mathrm{CH}_{4}\right)_{3}$, no or small frequency shifts were expected for the $\mathrm{H}-\mathrm{H}$ stretching mode of the $3 \mathrm{c} 2 \mathrm{e}$ bond, since the two $\mathrm{H}$ atoms of the $3 \mathrm{c} 2 \mathrm{e}$ bond would be no longer used for the coordination of the third $\mathrm{CH}_{4}$ molecule. Indeed, the feature observed in the IR spectrum for $\mathrm{CH}_{5}{ }^{+}\left(\mathrm{CH}_{4}\right)_{3}$ (Fig. 6D) was centered at $2578 \mathrm{~cm}^{-1}$, only $1 \mathrm{~cm}^{-1}$ red-shifted from the feature for $\mathrm{CH}_{5}^{+}\left(\mathrm{CH}_{4}\right)_{2}$, indicating only a minor perturbation to the $\mathrm{H}-\mathrm{H}$ stretching mode of the $3 \mathrm{c} 2 \mathrm{e}$ bond by the third $\mathrm{CH}_{4}$ molecule. It is interesting to notice that the observed feature for $\mathrm{CH}_{5}^{+}\left(\mathrm{CH}_{4}\right)_{3}$ was considerably broad, suggesting some inhomogeneous broadening due to the shallow 
potential surface formed between the $\mathrm{CH}_{5}^{+}$core and the third $\mathrm{CH}_{4}$ molecule. In conclusion, the consistent frequency shifts of these IR features suggested that the 2623 , 2608, 2577, $2578 \mathrm{~cm}^{-1}$ features observed in the IR spectra for $\left.\mathrm{CH}_{5}{ }^{+} \mathrm{N}_{2}\right)$ and $\mathrm{CH}_{5}{ }^{+}\left(\mathrm{CH}_{4}\right)_{\mathrm{n}}$ $(n=1,2,3)$, respectively, would be assigned to the $\mathrm{H}-\mathrm{H}$ stretching mode of the $3 \mathrm{c} 2 \mathrm{e}$ bond in the $\mathrm{CH}_{s}^{+}$core, rather than to the overtone or combination bands of the low frequency modes of the $\mathrm{CH}_{s}{ }^{+}$core.

\subsection{Dynamics of $\mathrm{CH}_{5}^{+}$cores in $\mathrm{CH}_{5}^{+}(\mathrm{A})_{\mathrm{x}}(\mathrm{B})_{\mathrm{y}}\left(\mathrm{A}, \mathrm{B}=\mathrm{H}_{2}, \mathrm{Ar}, \mathrm{N}_{2}, \mathrm{CH}_{4} ; \mathrm{x}, \mathrm{y}=0-5\right)$}

The experimentally measured $-\Delta \mathrm{H}_{\mathrm{T}}^{\circ}$ 's of the clustering reactions $\mathrm{CH}_{5}^{+}\left(\mathrm{H}_{2}\right)_{\mathrm{n}-1}+\mathrm{H}_{2}$ $=\mathrm{CH}_{5}{ }^{+}\left(\mathrm{H}_{2}\right)_{\mathrm{n}}(\mathrm{n}=1-4)$ were $1.88,1.78,1.61$, and $1.57 \mathrm{kcal} / \mathrm{mole}$, and the theoretically calculated dissociation energies $\left(D_{c}\right)$ were $2.02,1.76,0.91$, and $0.64 \mathrm{kcal} / \mathrm{mole}$, respectively, ${ }^{10}$ suggesting weak charge-induced dipole interactions between the core $\mathrm{CH}_{5}{ }^{+}$ and the $\mathrm{H}_{2}$ molecules. On the other hand, the measured $-\Delta \mathrm{H}_{\mathrm{T}}^{\circ}$ 's of the clustering reactions $\mathrm{CH}_{5}{ }^{+}\left(\mathrm{CH}_{4}\right)_{\mathrm{n}-\mathrm{l}}+\mathrm{CH}_{4}=\mathrm{CH}_{5}^{+}\left(\mathrm{CH}_{4}\right)_{\mathrm{n}}(\mathrm{n}=1-5)$, were $6.87,5.34,3.14,3.02$, and $2.79 \mathrm{kcal} / \mathrm{mole}$, respectively, ${ }^{11}$ and some covalent bonding between the spatially extended LUMO (5a') of $\mathrm{CH}_{5}{ }^{+}$and the HOMO $\left(3 \mathrm{t}_{2}\right)$ of $\mathrm{CH}_{4}$ was predicted by the ab initio MO calculations. ${ }^{30}$ For $\mathrm{CH}_{5}{ }^{+}\left(\mathrm{CH}_{4}\right)$, the contribution from the covalent interaction was predicted to be comparable to that from the charge-induced dipole interaction between the core $\mathrm{CH}_{5}{ }^{+}$and the $\mathrm{CH}_{4}$ molecule (mentioned as "polarization energy in $\mathrm{CH}_{4}{ }^{\text {" in their paper }}{ }^{30}$ ). In any case, strong solvent effects of the $\mathrm{CH}_{4}$ molecules on the dynamics of $\mathrm{CH}_{5}{ }^{+}$core were expected for $\mathrm{CH}_{5}^{+}\left(\mathrm{CH}_{4}\right)_{\mathrm{n}}$, unlike in the case of $\mathrm{CH}_{5}^{+}\left(\mathrm{H}_{2}\right)_{\mathrm{n}}$. For $\mathrm{CH}_{5}^{+}(\mathrm{Ar})_{\mathrm{n}}$ and $\mathrm{CH}_{5}^{+}\left(\mathrm{N}_{2}\right)_{\mathrm{m}}$, the solvent effects of $\mathrm{Ar}$ and $\mathrm{N}_{2}$ on the dynamics of $\mathrm{CH}_{5}{ }^{+}$core were expected to be intermediate 
between those for $\mathrm{CH}_{4}$ and $\mathrm{H}_{2}$, since the electric dipole polarizabilities of $\mathrm{Ar}\left(1.64 \times 10^{-24}\right.$ $\left.\mathrm{cm}^{3}\right)$ and $\mathrm{N}_{2}\left(1.74 \times 10^{-24} \mathrm{~cm}^{3}\right)$, which determine the strengths of charge-induced dipole interactions, are larger than $\mathrm{H}_{2}\left(0.80 \times 10^{-24} \mathrm{~cm}^{3}\right)$, but smaller than $\mathrm{CH}_{4}\left(2.59 \times 10^{-24} \mathrm{~cm}^{3}\right){ }^{26}$ Furthermore, such solvent effects were expected to be more significant with increasing the number of solvent molecules in the clusters.

In the IR spectra for the mono-solvated carbonium ions, $\mathrm{CH}_{5}{ }^{+}(\mathrm{A})$ $\left(\mathrm{A}=\mathrm{H}_{2}, \mathrm{Ar}, \mathrm{N}_{2}, \mathrm{CH}_{4}\right)$, as shown in Fig. 2, the observed features for the $\mathrm{C}-\mathrm{H}$ stretching modes of the $\mathrm{CH}_{5}^{+}$core, centered at 2964 and $\sim 3070 \mathrm{~cm}^{-1}$ for $\mathrm{CH}_{5}^{+}\left(\mathrm{H}_{2}\right)$ in the spectrum, respectively, became narrower and better resolved with changing the solvent molecules from $\mathrm{H}_{2}$ to $\mathrm{Ar}, \mathrm{N}_{2}$, and $\mathrm{CH}_{4}$. In addition, the broad feature around $2900 \mathrm{~cm}^{-1}$ observed for $\mathrm{CH}_{5}{ }^{+}\left(\mathrm{H}_{2}\right)$ were less significant for $\mathrm{CH}_{5}^{+}(\mathrm{Ar})$ and $\mathrm{CH}_{5}{ }^{+}\left(\mathrm{N}_{2}\right)$ (Fig. 2B,C), and it was no longer present in the IR spectrum for $\mathrm{CH}_{5}^{+}\left(\mathrm{CH}_{4}\right)$ (Fig. 2D). As reported previously and also mentioned in the previous section, the broad feature was due to the scrambling of $\mathrm{CH}_{5}{ }^{+}$core via the in-plane wagging motion of the $3 \mathrm{c} 2 \mathrm{e}$ bond involving a $\mathrm{C}_{2 v}$ transition state. ${ }^{17,18}$ The less significant appearance of this feature in the IR spectra for $\mathrm{CH}_{5}{ }^{+}(\mathrm{Ar})$ and $\mathrm{CH}_{5}{ }^{+}\left(\mathrm{N}_{2}\right)$ suggested a considerable slowdown of this scrambling motion by the increased solvent effects of $\mathrm{Ar}$ and $\mathrm{N}_{2}$. For $\mathrm{CH}_{5}{ }^{+}\left(\mathrm{CH}_{4}\right)$, this scrambling motion would be almost frozen out, indicated by the absence of the broad feature in the spectrum (Fig. 2D).

On the other hand, the presence of two features for the $\mathrm{C}-\mathrm{H}$ stretching modes of the $\mathrm{CH}_{5}{ }^{+}$core in this frequency range, instead of the three distinct $\mathrm{C}-\mathrm{H}$ stretching modes $\left(2891,2993,3079 \mathrm{~cm}^{-1}\right)$ predicted by the ab initio calculations ${ }^{7}$ on e- $\mathrm{C}_{\mathrm{s}} \mathrm{CH}_{5}^{+}$, suggested that the scrambling of $\mathrm{CH}_{5}{ }^{+}$core via the $\mathrm{CH}_{3}$ internal rotation were still extensive, and 
as a result, two among the three vibrational modes could be accidentally degenerate or spectrally congested. The candidates for the coupled modes would be the 2964,2974 , 2983 , and $2982 \mathrm{~cm}^{-1}$ peaks for $\mathrm{CH}_{5}^{+}(\mathrm{A})\left(\mathrm{A}=\mathrm{H}_{2}, \mathrm{Ar}, \mathrm{N}_{2}, \mathrm{CH}_{4}\right)$, respectively.

For the di-solvated carbonium ions, $\mathrm{CH}_{5}^{+}(\mathrm{A})(\mathrm{B})\left(\mathrm{A}, \mathrm{B}=\mathrm{H}_{2}, \mathrm{Ar}, \mathrm{CH}_{4}\right)$, the solvent effects on the scrambling of $\mathrm{CH}_{5}{ }^{+}$core were expected to be more prominent, compared to those for the mono-solvated carbonium ions. In the IR spectra for the di-solvated carbonium ions shown in Fig. 4, the coupled modes observed for the mono-solvated carbonium ions $\left(2982 \mathrm{~cm}^{-1}\right.$ for $\mathrm{CH}_{5}^{+}\left(\mathrm{CH}_{4}\right)$ ) started to decouple by showing the broad feature near $2900 \mathrm{~cm}^{-1}$ and a feature at $2974 \mathrm{~cm}^{-1}$ for both $\mathrm{CH}_{5}^{+}(\mathrm{Ar})\left(\mathrm{CH}_{4}\right)$ and $\mathrm{CH}_{5}{ }^{+}\left(\mathrm{CH}_{4}\right)_{2}$ cases (Fig. $4 \mathrm{C}, \mathrm{D}$ ). The single broad feature at $2957 \mathrm{~cm}^{-1}$ for $\mathrm{CH}_{5}^{+}\left(\mathrm{H}_{2}\right)_{2}$ and $\mathrm{CH}_{5}{ }^{+}(\mathrm{Ar})_{2}$ suggested that this coupling was still significant for these weakly bound clusters, but it was observed to be much less than the cases for the mono-solvated carbonium ions, indicated by the broad feature which was red-shifted $\left(7\right.$ and $17 \mathrm{~cm}^{-1}$, respectively) from the corresponding features for the mono-solvated carbonium ions. In addition, the 3078 $\mathrm{cm}^{-1}$ peak of $\mathrm{CH}_{5}^{+}\left(\mathrm{H}_{2}\right)_{2}$ was better resolved from the broad feature $\left(2957 \mathrm{~cm}^{-1}\right)$ than in the case for $\mathrm{CH}_{5}{ }^{+}\left(\mathrm{H}_{2}\right)$, consistent with the increased solvent effects in the di-solvated carbonium ions. These solvent effects were observed to be more significant in the IR spectra for the solvated carbonium ions with $\mathrm{Ar}$ and $\mathrm{CH}_{4}$ molecules, as shown in Fig. $4 \mathrm{~B}$, $\mathrm{C}$, and D. Furthermore, the scrambling through the in-plane wagging motion involving a $\mathrm{C}_{2 v}$ transition state was expected to be frozen out in the di-solvated carbonium ions.

For the tri-solvated carbonium ions, $\mathrm{CH}_{5}^{+}(\mathrm{A})(\mathrm{B})(\mathrm{C})\left(\mathrm{A}, \mathrm{B}, \mathrm{C}=\mathrm{H}_{2}, \mathrm{Ar}, \mathrm{CH}_{4}\right)$, one congested feature for the two coupled $\mathrm{CH}_{3}$ stretching modes observed in the IR spectrum 
for $\mathrm{CH}_{5}{ }^{+}\left(\mathrm{H}_{2}\right)_{2}\left(2957 \mathrm{~cm}^{-1}\right)$ was separated into two features, centered at 2892 and 2977 $\mathrm{cm}^{-1}$, in the IR spectrum for $\mathrm{CH}_{5}^{+}\left(\mathrm{H}_{2}\right)_{3}$ (Fig. 5A), indicating the freezing of the scrambling of $\mathrm{CH}_{5}^{+}$core via the $\mathrm{CH}_{3}$ internal rotation. In the IR spectra for $\mathrm{CH}_{5}{ }^{+}(\mathrm{Ar})_{2}\left(\mathrm{CH}_{4}\right)$ and $\mathrm{CH}_{5}^{+}(\mathrm{Ar})\left(\mathrm{CH}_{4}\right)_{2}$, the corresponding features of $\mathrm{CH}_{5}{ }^{+}$core were observed to be broad and less intense while the peaks due to the bound $\mathrm{C}-\mathrm{H}$ stretching modes of the solvent $\mathrm{CH}_{4}$ molecules were very intense. This indicates a substantial change in the oscillator strength of the clusters favoring for the bound $\mathrm{C}-\mathrm{H}$ stretching modes of the solvent $\mathrm{CH}_{4}$ molecules, due in part to the changes in the symmetries of the clusters. Strong solvent effects of the three solvent molecules $\left(\mathrm{Ar}, \mathrm{CH}_{4}\right)$ were also expected in these clusters, and as a result, the scrambling motions of the $\mathrm{CH}_{5}{ }^{+}$core could be frozen out in $\mathrm{CH}_{5}{ }^{+}(\mathrm{Ar})_{2}\left(\mathrm{CH}_{4}\right)$ and $\mathrm{CH}_{5}{ }^{+}(\mathrm{Ar})\left(\mathrm{CH}_{4}\right)_{2}$. In the IR spectrum for $\mathrm{CH}_{5}{ }^{+}\left(\mathrm{CH}_{4}\right)_{3}$ shown in Fig. 5D, the solvent effects were observed to be so strong that the $\mathrm{CH}_{5}{ }^{+}$core could be regarded as a rigid system, indicated by the appearance of the three distinct $\mathrm{C}-\mathrm{H}$ stretching bands $\left(2823,2989,3077 \mathrm{~cm}^{-1}\right)$. In $\mathrm{CH}_{5}{ }^{+}\left(\mathrm{CH}_{4}\right)_{3}$, the $\mathrm{CH}_{3}$ group in the $\mathrm{CH}_{5}{ }^{+}$core no longer possessed the three similar strong $\mathrm{C}-\mathrm{H}$ bonds, but it was consisted of one $\mathrm{CH}_{2}$ group with two strong $\mathrm{C}-\mathrm{H}$ bonds and one weak $\mathrm{C}-\mathrm{H}$ bond bound by the third $\mathrm{CH}_{4}$ molecule. As mentioned previously, the sharp features at 2989 and $3077 \mathrm{~cm}^{-1}$ were assigned to the symmetric and asymmetric $\mathrm{CH}_{2}$ stretching modes, respectively, and the broad and intense feature at $\sim 2823 \mathrm{~cm}$ was assigned to the bound $\mathrm{C}-\mathrm{H}$ stretching mode of the $\mathrm{CH}_{5}^{+}$core.

For $\mathrm{CH}_{5}{ }^{+}\left(\mathrm{CH}_{4}\right)_{4}$ and $\mathrm{CH}_{5}{ }^{+}\left(\mathrm{CH}_{4}\right)_{5}$, the $\mathrm{CH}_{5}{ }^{+}$core was also regarded as a rigid one, as in $\mathrm{CH}_{5}^{+}\left(\mathrm{CH}_{4}\right)_{3}$. The three $\mathrm{C}-\mathrm{H}$ stretching frequencies for $\mathrm{CH}_{5}^{+}\left(\mathrm{CH}_{4}\right)_{4}$ (Fig. 7A) were 
observed to be almost the same as those for $\mathrm{CH}_{5}{ }^{+}\left(\mathrm{CH}_{4}\right)_{3}$ (Fig. 5D).

\subsection{Structures of $\mathrm{CH}_{5}^{+}(\mathrm{A})_{\mathrm{x}}(\mathrm{B})_{\mathrm{y}}\left(\mathrm{A}, \mathrm{B}=\mathrm{H}_{2}, \mathrm{Ar}, \mathrm{N}_{2}, \mathrm{CH}_{4} ; \mathrm{x}, \mathrm{y}=0-5\right)$}

For the mono-solvated carbonium ions, $\mathrm{CH}_{5}^{+}(\mathrm{A})\left(\mathrm{A}=\mathrm{H}_{2}, \mathrm{Ar}, \mathrm{N}_{2}, \mathrm{CH}_{4}\right)$, the solvent molecules would prefer to bind to one of the two $\mathrm{H}$ atoms forming the electron deficient $3 \mathrm{c} 2 \mathrm{e}$ bond, as predicted by the previous experimental ${ }^{10-12,16-18}$ and theoretical works $s^{10,25,27,30}$ on $\mathrm{CH}_{5}^{+}\left(\mathrm{H}_{2}\right)_{\mathrm{n}}(\mathrm{n}=1-4)$ and $\mathrm{CH}_{5}^{+}\left(\mathrm{CH}_{4}\right)_{\mathrm{n}}(\mathrm{n}=1-9)$. The two $\mathrm{H}$ atoms of the $3 \mathrm{c} 2 \mathrm{e}$ bond would be almost equivalent via the $\mathrm{CH}_{3}$ internal rotation of the $\mathrm{CH}_{5}{ }^{+}$core. The probable structures for the mono-solvated carbonium ions are sketched in Fig. 8A. In the structure of $\mathrm{CH}_{5}{ }^{+}\left(\mathrm{CH}_{4}\right)$ shown in Fig. 8A, the $\mathrm{CH}_{4}$ molecule is attached to the other $\mathrm{H}$ atom of the $3 \mathrm{c} 2 \mathrm{e}$ bond in order to be consistent with the previous predictions, but the two $\mathrm{H}$ atoms were expected to be indistinguishable via the $\mathrm{CH}_{3}$ internal rotation.

For the di-solvated carbonium ions, $\mathrm{CH}_{5}{ }^{+}(\mathrm{A})(\mathrm{B})\left(\mathrm{A}, \mathrm{B}=\mathrm{H}_{2}, \mathrm{Ar}, \mathrm{CH}_{4}\right)$, the two solvent molecules would prefer to bind to the two $\mathrm{H}$ atoms of the $3 \mathrm{c} 2 \mathrm{e}$ bond, respectively. The single feature for the bound $\mathrm{C}-\mathrm{H}$ stretching modes of the solvent $\mathrm{CH}_{4}$ molecules in $\mathrm{CH}_{5}{ }^{+}\left(\mathrm{CH}_{4}\right)_{2}$ (Fig. 4D), suggested the equal strength of bonding for the two $\mathrm{CH}_{4}$ molecules, consistent with the above prediction. For the mixed cluster $\mathrm{CH}_{5}^{+}(\mathrm{Ar})\left(\mathrm{CH}_{4}\right)$, the $\mathrm{CH}_{4}$ molecule would bind first to one of the two $\mathrm{H}$ atoms of the $3 \mathrm{c} 2 \mathrm{e}$ bond by slightly deforming the structure of $\mathrm{CH}_{5}{ }^{+}$core, then the Ar molecule would bind weakly to the other $\mathrm{H}$ atom, since $\mathrm{CH}_{4}$ has higher binding affinity to the charge center than Ar. The structures of the di-solvated carbonium ions are sketched in Fig. 8B.

For the tri-solvated carbonium ions, $\mathrm{CH}_{5}{ }^{+}(\mathrm{A})(\mathrm{B})(\mathrm{C})\left(\mathrm{A}, \mathrm{B}, \mathrm{C}=\mathrm{H}_{2}, \mathrm{Ar}, \mathrm{CH}_{4}\right)$, the first 
two solvent molecules would bind to the two acidic $H$ atoms of the $3 \mathrm{c} 2 \mathrm{e}$ bond, then the third solvent molecule binds to the $\mathrm{H}$ atom of $e-\mathrm{C}_{s} \mathrm{CH}_{5}{ }^{+}$core, which is in plane with the $3 \mathrm{c} 2 \mathrm{e}$ bond (will be referred to as in-plane $\mathrm{H}$ atom), as shown in Fig. 8C. For the mixed clusters, the solvent molecules with higher binding affinities $\left(\mathrm{CH}_{4}, \mathrm{Ar}, \mathrm{H}_{2}\right.$, in order $)$ would be preferred to bind first to the acidic $\mathrm{H}$ atoms, as in the case for the di-solvated carbonium ions. For $\mathrm{CH}_{5}{ }^{+}(\mathrm{Ar})_{2}\left(\mathrm{CH}_{4}\right)$, the $\mathrm{CH}_{4}$ molecule would bind first to one of the two acidic $\mathrm{H}$ atoms, then two $\mathrm{Ar}$ molecules would bind to the other acidic $\mathrm{H}$ atom and the in-plane $\mathrm{H}$ atom of the $\mathrm{CH}_{5}{ }^{+}$core, respectively. This prediction was supported by the slight blue-shift of the bound $\mathrm{C}-\mathrm{H}$ stretching mode of $\mathrm{CH}_{4}$ in $\mathrm{CH}_{5}{ }^{+}(\mathrm{Ar})_{2}\left(\mathrm{CH}_{4}\right)\left(2877 \mathrm{~cm}^{-1}\right)$ from the corresponding feature of $\mathrm{CH}_{5}{ }^{+}(\mathrm{Ar})\left(\mathrm{CH}_{4}\right)\left(2874 \mathrm{~cm}^{-1}\right)$, as shown in Table II. For $\mathrm{CH}_{5}{ }^{+}(\mathrm{Ar})\left(\mathrm{CH}_{4}\right)_{2}$, the two $\mathrm{CH}_{4}$ molecules would bind to the two acidic $\mathrm{H}$ atoms of the $3 \mathrm{c} 2 \mathrm{e}$ bond, respectively and the Ar molecule would bind to the in-plane $\mathrm{H}$ atom, indicated by the slight blue-shift of the bound $\mathrm{C}-\mathrm{H}$ stretching mode of the $\mathrm{CH}_{4}$ molecules in $\mathrm{CH}_{5}{ }^{+}(\mathrm{Ar})\left(\mathrm{CH}_{4}\right)_{2}\left(2881 \mathrm{~cm}^{-1}\right)$ from the corresponding frequency for $\mathrm{CH}_{5}{ }^{+}\left(\mathrm{CH}_{4}\right)_{2}$ (2879 $\mathrm{cm}^{-1}$.

For $\mathrm{CH}_{5}{ }^{+}\left(\mathrm{CH}_{4}\right)_{3}$, the IR spectrum (Fig. 5D) showed clear evidence for the above predicted structures for the tri-solvated carbonium ions as following. First, the two bound $\mathrm{C}-\mathrm{H}$ stretching bands at 2880 and $2890 \mathrm{~cm}^{-1}$, were assigned to the two equivalent $\mathrm{CH}_{4}$ molecules and the third $\mathrm{CH}_{4}$ molecule, respectively. The $2880 \mathrm{~cm}^{-1}$ peak was almost not shifted from the bound $\mathrm{C}-\mathrm{H}$ stretching frequency of $\mathrm{CH}_{5}^{+}(\mathrm{Ar})\left(\mathrm{CH}_{4}\right)_{2}\left(2881 \mathrm{~cm}^{-1}\right)$, indicating only a minor perturbation to the coordination of the first two $\mathrm{CH}_{4}$ molecules by the third $\mathrm{CH}_{4}$ molecule. Second, the broad and intense peak at $-2823 \mathrm{~cm}^{-1}$ was assigned 
to the $\mathrm{C}-\mathrm{H}$ stretching mode of the $\mathrm{C}-\mathrm{H}$ bond in-plane to the $3 \mathrm{c} 2 \mathrm{e}$ bond of $\mathrm{CH}_{5}^{+}$core, and also bound by the third $\mathrm{CH}_{4}$ molecule (simply, the bound in-plane $\mathrm{C}-\mathrm{H}$ stretching mode of $\mathrm{CH}_{5}^{+}$core), as discussed in the previous section. These results were consistent with the above predicted structure for $\mathrm{CH}_{5}^{+}\left(\mathrm{CH}_{4}\right)_{3}$, where the first two $\mathrm{CH}_{4}$ molecules bind to the two $\mathrm{H}$ atoms of the $3 \mathrm{c} 2 \mathrm{e}$ bond, and the third $\mathrm{CH}_{4}$ molecule binds to the in-plane $\mathrm{H}$ atom of the $\mathrm{CH}_{5}{ }^{+}$core. Therefore, the $\mathrm{CH}_{5}{ }^{+}\left(\mathrm{CH}_{4}\right)_{3}$ structure predicted by Hiraoka and coworkers, ${ }^{11}$ where the third $\mathrm{CH}_{4}$ molecule located out-of-plane to the $3 \mathrm{c} 2 \mathrm{e}$ bond, should be reconsidered.

For $\mathrm{CH}_{5}{ }^{+}\left(\mathrm{CH}_{4}\right)_{4}$, the fourth $\mathrm{CH}_{4}$ molecule could bind to either one of the two free $\mathrm{C}-\mathrm{H}$ bonds of $\mathrm{CH}_{s}{ }^{+}$core, predicted by the ab initio calculations, ${ }^{27}$ or the $3 \mathrm{c} 2 \mathrm{e}$ bond in the out-of-plane fashion, as predicted by Hiraoka and coworkers ${ }^{11}$ for the third and fourth $\mathrm{CH}_{4}$ molecules in $\mathrm{CH}_{5}^{+}\left(\mathrm{CH}_{4}\right)_{\mathrm{n}}(\mathrm{n}=1-9)$. The third possibility, predicted by Kebarle and coworkers ${ }^{12}$ for the third and fourth $\mathrm{CH}_{4}$ molecules in $\mathrm{CH}_{5}{ }^{+}\left(\mathrm{CH}_{4}\right)_{\mathrm{n}}(\mathrm{n}=1-5)$, would be the structure where the fourth $\mathrm{CH}_{4}$ molecule binds to one of the $\mathrm{CH}_{4}$ molecules already bound to the acidic $\mathrm{H}$ atoms of $\mathrm{CH}_{5}{ }^{+}$core. In this picture, the acidic $\mathrm{H}$ atoms of the $3 \mathrm{c} 2 \mathrm{e}$ bond interact with the electron pair of $\mathrm{C}-\mathrm{H}$ bonds in the first two $\mathrm{CH}_{4}$ molecules, forming another $3 \mathrm{c} 2 \mathrm{e}$ bond in the $\mathrm{CH}_{4}$ molecule, and the resulting acidic $\mathrm{H}$ atom is responsible for bonding with the next $\mathrm{CH}_{4}$ molecule.

In the IR spectrum shown in Fig. 7A, the observed features were similar to those for $\mathrm{CH}_{5}^{+}\left(\mathrm{CH}_{4}\right)_{3}$, with the exception of the single feature for the bound $\mathrm{C}-\mathrm{H}$ stretching modes of the solvent $\mathrm{CH}_{4}$ molecules. The position of the feature was the same as that for the third $\mathrm{CH}_{4}$ molecule in $\mathrm{CH}_{5}^{+}\left(\mathrm{CH}_{4}\right)_{3}\left(2890 \mathrm{~cm}^{-1}\right)$. This result excluded the third 
possibility since more than two bound $\mathrm{C}-\mathrm{H}$ stretching bands for the $\mathrm{CH}_{4}$ molecules would be expected due to the presence of four inequivalent $\mathrm{CH}_{4}$ molecules in this structure. In the spectrum (Fig. 7A), the symmetric and asymmetric $\mathrm{CH}_{2}$ stretching bands of the $\mathrm{CH}_{5}^{+}$ core $\left(2989,3079 \mathrm{~cm}^{-1}\right)$ were not much shifted from the corresponding frequencies of $\mathrm{CH}_{5}^{+}\left(\mathrm{CH}_{4}\right)_{3}\left(2989,3077 \mathrm{~cm}^{-1}\right)$, indicating little or no perturbation to the $\mathrm{CH}_{2}$ group of $\mathrm{CH}_{5}^{+}$ core by the fourth $\mathrm{CH}_{4}$ molecule. This result excluded the first possibility, the structure with the fourth $\mathrm{CH}_{4}$ molecule bound to the $\mathrm{CH}_{2}$ group. The remaining is the second possibility, the structure with the fourth $\mathrm{CH}_{4}$ molecule bound to the $3 \mathrm{c} 2 \mathrm{e}$ bond in the outof-plane fashion. The question is how this structure can explain the single feature for the bound $\mathrm{C}-\mathrm{H}$ stretching modes of the $\mathrm{CH}_{4}$ molecules in $\mathrm{CH}_{5}{ }^{+}\left(\mathrm{CH}_{4}\right)_{4}$. A close examination of the feature reveals that it possesses a low frequency shoulder at the frequency similar to the bound $\mathrm{C}-\mathrm{H}$ stretching frequency for the first two $\mathrm{CH}_{4}$ molecules in $\mathrm{CH}_{5}{ }^{+}\left(\mathrm{CH}_{4}\right)_{3}$. It is also interesting to notice that the bandwidth of the observed feature increased to slightly less than twice the bandwidth of the corresponding feature for $\mathrm{CH}_{5}{ }^{+}\left(\mathrm{CH}_{4}\right)_{3}$. Based upon the above observations, it is believed that slight geometrical changes of the $\mathrm{CH}_{5}{ }^{+}$ core were accompanied by the coordination of the fourth $\mathrm{CH}_{4}$ molecule to the $3 \mathrm{c} 2 \mathrm{e}$ bond in the out-of-plane fashion. This could result in a decrease in the IR intensity for the bound $\mathrm{C}-\mathrm{H}$ stretching modes for the first and second $\mathrm{CH}_{4}$ molecules, due in part to changes in the symmetry of the ion complex. Ab initio calculations on this structure would be helpful for a better understanding of the spectral changes in the IR spectrum of $\mathrm{CH}_{5}{ }^{+}\left(\mathrm{CH}_{4}\right)_{4}$. The predicted structure for $\mathrm{CH}_{5}{ }^{+}\left(\mathrm{CH}_{4}\right)_{4}$ is sketched in Fig. 8D.

For $\mathrm{CH}_{5}{ }^{+}\left(\mathrm{CH}_{4}\right)_{5}$, the fifth $\mathrm{CH}_{4}$ molecule would bind to the other out-of-plane side 
of the 3c2e bond, forming a structure of similar symmetry to that for $\mathrm{CH}_{5}^{+}\left(\mathrm{CH}_{4}\right)_{3}$, with the two additional $\mathrm{CH}_{4}$ molecules located out-of-plane to the $3 \mathrm{c} 2 \mathrm{e}$ bond. Three features for the bound $\mathrm{C}-\mathrm{H}$ stretching modes of the $\mathrm{CH}_{4}$ molecules were observed, centered at 2886, 2892, and $2896 \mathrm{~cm}^{-1}$, respectively, in the IR spectrum, as shown in Fig. 7B. The $2886 \mathrm{~cm}^{-1}$ peak was $4 \mathrm{~cm}^{-1}$ red-shifted from the $2890 \mathrm{~cm}^{-1}$ peak of $\mathrm{CH}_{5}{ }^{+}\left(\mathrm{CH}_{4}\right)_{4}$, but $6 \mathrm{~cm}^{-1}$ blue-shifted from the bound $\mathrm{C}-\mathrm{H}$ stretching modes for $\mathrm{CH}_{5}{ }^{+}\left(\mathrm{CH}_{4}\right)_{3}$. Since the bound $\mathrm{C}-\mathrm{H}$ stretching frequencies of the $\mathrm{CH}_{4}$ molecules were expected to become close to the $v_{1}$ frequency of free $\mathrm{CH}_{4}\left(2916 \mathrm{~cm}^{-1}\right)^{24}$ with increasing the cluster size, the $2886 \mathrm{~cm}^{-1}$ feature, which was observed to be weak in intensity in the IR spectrum for $\mathrm{CH}_{5}{ }^{+}\left(\mathrm{CH}_{4}\right)_{4}$ (Fig. 7A), could be assigned to the bound $\mathrm{C}-\mathrm{H}$ stretching modes for the first two $\mathrm{CH}_{4}$ molecules. Correspondingly, the 2892 and $2896 \mathrm{~cm}^{-1}$ peaks could be assigned to the bound $\mathrm{C}-\mathrm{H}$ stretching modes of the third $\mathrm{CH}_{4}$ molecule bound to the in-plane $\mathrm{H}$ atom of $\mathrm{CH}_{5}^{+}$core, and the fourth and fifth $\mathrm{CH}_{4}$ molecules located out-of-plane to the $3 \mathrm{c} 2 \mathrm{e}$ bond, respectively. This result also supported the above prediction on the structure for $\mathrm{CH}_{5}{ }^{+}\left(\mathrm{CH}_{4}\right)_{4}$. The predicted structure for $\mathrm{CH}_{5}{ }^{+}\left(\mathrm{CH}_{4}\right)_{5}$ is sketched in Fig. 8E.

\subsection{Proton transfer in $\mathrm{CH}_{5}^{+}\left(\mathrm{CH}_{4}\right)$}

The proton transfer in the proton-bound dimers such as $\mathrm{H}_{3} \mathrm{O}^{+}\left(\mathrm{H}_{2} \mathrm{O}\right)^{21}$ and $\mathrm{NH}_{4}{ }^{+}\left(\mathrm{NH}_{3}\right)^{22}$ has been of considerable interest in understanding the dynamics of proton transfer in chemical and biological systems. ${ }^{31,32}$ Much theoretical work ${ }^{33}$ has been performed to determine the potential surface for the proton transfer, and surprisingly, the potential surfaces of the minimum energy pathways for $\mathrm{H}_{3} \mathrm{O}^{+}\left(\mathrm{H}_{2} \mathrm{O}\right)$ and $\mathrm{NH}_{4}^{+}\left(\mathrm{NH}_{3}\right)$ were 
predicted to be almost flat at the most sophisticated level of theory. In the calculation, the potential energy surfaces for proton transfer were found to be mostly determined by the distances of the two $\mathrm{O}, \mathrm{N}$ atoms in $\mathrm{H}_{3} \mathrm{O}^{+}\left(\mathrm{H}_{2} \mathrm{O}\right)$ and $\mathrm{NH}_{4}{ }^{+}\left(\mathrm{NH}_{3}\right)$, not by the locations of the central protons, probably due to the heavy atom effects of $\mathrm{O}$ and $\mathrm{N}$ atoms.

On the other hand, the proton-bound $\mathrm{CH}_{4}$ dimer, $\mathrm{CH}_{5}^{+}\left(\mathrm{CH}_{4}\right)$, which is the isoelectronic with, but lighter than $\mathrm{H}_{3} \mathrm{O}^{+}\left(\mathrm{H}_{2} \mathrm{O}\right)$ and $\mathrm{NH}_{4}{ }^{+}\left(\mathrm{NH}_{3}\right)$, has not received much attention, probably due to the unusual bonding in $\mathrm{CH}_{5}{ }^{+}$and the experimental difficulties. To our knowledge, one ab initio calculation on the potential barrier of the proton transfer, ${ }^{27}$ and one study on the kinetic model for the proton motion within the deuteriumexchanged $\mathrm{CH}_{5}{ }^{+}\left(\mathrm{CH}_{4}\right){ }^{34}$ has been performed previously. Simonetta and coworkers ${ }^{27}$ predicted the potential barrier for the proton transfer between two $\mathrm{CH}_{4}$ groups in $\mathrm{CH}_{5}{ }^{+}\left(\mathrm{CH}_{4}\right)$ to be $14.6,24.04$, and $1.55 \mathrm{kcal} / \mathrm{mole}$ at $\mathrm{HF} / 3-21 \mathrm{G}, \mathrm{HF} / 6-31 \mathrm{G}^{* *} / / 3-21 \mathrm{G}$, and CNDO level, respectively. The predicted potential barriers strongly depended upon the theoretical methods used in the calculation. It is also surprising to notice that the potential barrier was predicted to be larger when a larger basis set was used (3-21G vs 6-31G**). Henchman and coworkers ${ }^{34}$ reported a kinetic model for the proton (deuteron) transfer in $\mathrm{CH}_{5}{ }^{+}\left(\mathrm{CD}_{4}\right)$ and $\mathrm{CD}_{5}{ }^{+}\left(\mathrm{CH}_{4}\right)$, where the average number of proton/deuteron jumps during the lifetime of the clusters was calculated as a function of temperature by fitting with the kinetic data and estimating the lifetimes of the clusters at the temperature.

In this work, we attempted to observe spectroscopically the proton transfer in ${ }^{13} \mathrm{CH}_{5}{ }^{+}\left({ }^{12} \mathrm{CH}_{4}\right)$ or ${ }^{12} \mathrm{CH}_{5}{ }^{+}\left({ }^{13} \mathrm{CH}_{4}\right)(\mathrm{m} / \mathrm{e}=34)$, one ${ }^{13} \mathrm{C}$-exchanged cluster of $\mathrm{CH}_{5}{ }^{+}\left(\mathrm{CH}_{4}\right)$. The motivation of this study was the notion that the isotope effects of ${ }^{13} \mathrm{C}$ in $\mathrm{CH}_{5}{ }^{+}\left(\mathrm{CH}_{4}\right)$ are 
small, due to the small changes in the reduced masses of $\mathrm{C}-\mathrm{H}$ bonds, and the product ions $\left(\mathrm{CH}_{5}{ }^{+}{ }^{13} \mathrm{CH}_{5}{ }^{+}\right)$vibrationally predissociated from the dimers after IR absorption, can be separately detected. If the ${ }^{13} \mathrm{CH}_{5}{ }^{+}\left(\mathrm{CH}_{4}\right)$ or $\mathrm{CH}_{5}{ }^{+}\left({ }^{13} \mathrm{CH}_{4}\right)$ ions undergo rapid proton transfer after vibrational excitation, the IR spectra obtained by detecting $\mathrm{CH}_{5}{ }^{+}(\mathrm{m} / \mathrm{e}=17)$ and ${ }^{13} \mathrm{CH}_{5}{ }^{+}(\mathrm{m} / \mathrm{e}=18)$, respectively, would be equivalent. On the other hand, if the clusters do not undergo the proton transfer after vibrational excitation, the IR spectra monitored at $\mathrm{m} / \mathrm{e}=17$ and 18 , respectively; would be different from each other, but be the same as the IR spectra of $\mathrm{CH}_{5}{ }^{+}\left(\mathrm{CH}_{4}\right)(\mathrm{m} / \mathrm{e}=33)$ and $\left.{ }^{13} \mathrm{CH}_{5}{ }^{+}{ }^{13} \mathrm{CH}_{4}\right)(\mathrm{m} / \mathrm{e}=35)$, respectively, when the vibrational modes of $\mathrm{CH}_{5}{ }^{+}$core are excited. They would be the same as the IR spectra of ${ }^{13} \mathrm{CH}_{5}{ }^{+}\left({ }^{13} \mathrm{CH}_{4}\right)$ and $\mathrm{CH}_{5}{ }^{+}\left(\mathrm{CH}_{4}\right)$, respectively, when the vibrational modes of the solvent $\mathrm{CH}_{4}$ are excited.

Fig. 9 shows the IR spectra of the $m / e=34$ ions, consisting of almost equal numbers of ${ }^{13} \mathrm{CH}_{5}{ }^{+}\left(\mathrm{CH}_{4}\right)$ and $\mathrm{CH}_{5}{ }^{+}\left({ }^{13} \mathrm{CH}_{4}\right)$ due to the small isotope effects, along with the IR spectra of $\mathrm{CH}_{5}{ }^{+}\left(\mathrm{CH}_{4}\right)(\mathrm{m} / \mathrm{e}=33)$ and ${ }^{13} \mathrm{CH}_{5}{ }^{+}\left({ }^{13} \mathrm{CH}_{4}\right)(\mathrm{m} / \mathrm{e}=35)$ as references. As discussed previously, three resolved features $\left(2869,2982,3063 \mathrm{~cm}^{-1}\right)$ were observed in the IR spectrum of $\mathrm{CH}_{5}{ }^{+}\left(\mathrm{CH}_{4}\right)$ (Fig. 2D), and were assigned to the bound $\mathrm{C}-\mathrm{H}$ stretching mode of the solvent $\mathrm{CH}_{4}$, the coupled $\mathrm{CH}_{3}$ stretching and less coupled $\mathrm{CH}_{3}$ stretching modes of $\mathrm{CH}_{5}^{+}$core, respectively. The bound $\mathrm{C}-\mathrm{H}$ stretching feature for the solvent molecule in ${ }^{13} \mathrm{CH}_{5}{ }^{+}\left(\mathrm{CH}_{4}\right)$ and $\mathrm{CH}_{5}{ }^{+}\left({ }^{13} \mathrm{CH}_{4}\right)$ is shown in the upper part of Fig. $9 \mathrm{~A}$, and the corresponding features for $\mathrm{CH}_{5}{ }^{+}\left(\mathrm{CH}_{4}\right)$ and ${ }^{13} \mathrm{CH}_{5}{ }^{+}\left({ }^{13} \mathrm{CH}_{4}\right)$ are shown in the lower part of Fig. 9A. The IR feature for ${ }^{13} \mathrm{CH}_{5}^{+}\left({ }^{13} \mathrm{CH}_{4}\right)$ was $-5 \mathrm{~cm}^{-1}$ red-shifted from the corresponding feature for $\mathrm{CH}_{5}^{+}\left(\mathrm{CH}_{4}\right)$, as expected from the isotope shifts. However, the features for the 
$\mathrm{m} / \mathrm{e}=34$ ions detected at $\mathrm{m} / \mathrm{e}=17$ and 18 , were found to be equivalent in both intensities and frequencies, suggesting rapid proton transfer at the IR photon energy $(-8 \mathrm{kcal} / \mathrm{mole})$.

Fig. 9B shows the IR features of the coupled $\mathrm{CH}_{3}$ stretching modes of the $\mathrm{CH}_{5}^{+}$ core for the $\mathrm{m} / \mathrm{e}=34$ ions, detected at $\mathrm{m} / \mathrm{e}=17$ and 18 , respectively, in the upper part, and the corresponding features for $\mathrm{CH}_{5}{ }^{+}\left(\mathrm{CH}_{4}\right)$ and ${ }^{13} \mathrm{CH}_{5}{ }^{+}\left({ }^{13} \mathrm{CH}_{4}\right)$ in the lower part. The IR feature for ${ }^{13} \mathrm{CH}_{5}^{+}\left({ }^{13} \mathrm{CH}_{4}\right)$ was $\sim 6 \mathrm{~cm}^{-1}$ red-shifted from the corresponding feature for $\mathrm{CH}_{5}{ }^{+}\left(\mathrm{CH}_{4}\right)$, due to the isotope effects. The features for the $\mathrm{m} / \mathrm{e}=34$ ions detected at $\mathrm{m} / \mathrm{e}=17$ and 18 , respectively, were again equivalent in both intensities and frequencies, indicating the rapid proton transfers. The same results were also obtained for the less coupled $\mathrm{CH}_{3}$ stretching mode of the $\mathrm{CH}_{5}{ }^{+}$core, as shown in Fig. 9C. Therefore, the proton transfer in $\mathrm{CH}_{5}^{+}\left(\mathrm{CH}_{4}\right)$ was very rapid when the ions were vibrationally excited in the frequency range of $2840-3100 \mathrm{~cm}^{-1}$, and no mode specific proton transfer was observed. It would be interesting to study the proton transfer in $\mathrm{CH}_{5}{ }^{+}\left(\mathrm{CH}_{4}\right)$ by exciting its low frequency vibrational modes.

This result suggested that the potential barrier for the proton transfer in $\mathrm{CH}_{5}{ }^{+}\left(\mathrm{CH}_{4}\right)$ should be lower than $\sim 8 \mathrm{kcal} / \mathrm{mole}$, the lower limit of the frequency range scanned in this work, assuming no quantum tunneling effects. Since the early $a b$ initio calculation ${ }^{27}$ predicted a large potential barrier for the proton transfer $(24 \mathrm{kcal} / \mathrm{mole}$ at $\mathrm{HF} / 6-31 \mathrm{G} * * / / 3$ $21 \mathrm{G})$, inconsistent with the above experimental result, it was necessary to reconsider the theoretical predictions. In their calculation, the predicted transition state for proton transfer had a $C_{s}$ symmetry, close to $D_{3 h}$ symmetry, where the C-C distance $(2.92 \AA)$ was significantly shorter than that in the ground state $(3.60 \AA)$, resulting in the large potential 
barrier for the proton transfer.

In this work, a density functional method, known as DMol, ${ }^{35}$ was used to calculate the energies of the ground state and a transition state structure for the proton transfer in $\mathrm{CH}_{5}{ }^{+}\left(\mathrm{CH}_{4}\right)$. Instead of the $\mathrm{C}_{\mathrm{s}}$ symmetry transition state predicted by Simonetta and coworkers, the structure of a $\mathrm{C}_{2 \mathrm{~h}}$ symmetry shown in Fig. 10, where no significant change in the C-C distance was found $(\leq 0.2 \AA)$, was used as a transition state for the proton transfer in this calculation. The calculated potential barriers at the JMW+B88 and $\mathrm{LYP}+\mathrm{B} 88$ levels ${ }^{36}$ were 4.47 and $3.42 \mathrm{kcal} / \mathrm{mole}$, respectively, consistent with the above experimental result. It is also interesting to notice that the predicted potential barrier tended to decrease at the higher level of theory (LYP+B88), like the trend observed in the previous ab initio calculations on $\mathrm{H}_{3} \mathrm{O}^{+}\left(\mathrm{H}_{2} \mathrm{O}\right)$ and $\mathrm{NH}_{4}{ }^{+}\left(\mathrm{NH}_{3}\right){ }^{33}$ 


\section{SUMMARY}

In this chapter, the infrared (IR) spectra for the solvated carbonium ions, $\mathrm{CH}_{5}{ }^{+}(\mathrm{A})_{\mathrm{x}}(\mathrm{B})_{\mathrm{y}}\left(\mathrm{A}, \mathrm{B}=\mathrm{H}_{2}, \mathrm{Ar}, \mathrm{N}_{2}, \mathrm{CH}_{4} ; \mathrm{x}, \mathrm{y}=0,1,2, ..\right)$, have been presented, along with the IR spectra for the ${ }^{13} \mathrm{C}$ isotope-exchanged $\mathrm{CH}_{5}{ }^{+}\left(\mathrm{CH}_{4}\right)$. These IR spectra provided the first systematic study of the solvation effects on the dynamics of $\mathrm{CH}_{5}^{+}$. The scrambling motions of the $\mathrm{CH}_{5}^{+}$core were observed to slow down substantially with increasing binding affinities of the solvent molecules from $\mathrm{H}_{2}$ to $\mathrm{Ar}, \mathrm{N}_{2}, \mathrm{CH}_{4}$, and with increasing number of solvent molecules. The complete freezing of the scrambling motions was found when three solvent molecules were bound to the core $\mathrm{CH}_{5}{ }^{+}$, and the $\mathrm{CH}_{5}{ }^{+}$cores in $\mathrm{CH}_{5}{ }^{+}\left(\mathrm{CH}_{4}\right)_{\mathrm{n}}(\mathrm{n} \geq 3)$ were regarded as rigid.

These IR spectra also provided information about the structures of the solvated carbonium ions, with which the previous predicted structures were corrected. In general, the first two solvent molecules were bound to the two $\mathrm{H}$ atoms forming the $3 \mathrm{c} 2 \mathrm{e}$ bond of the $\mathrm{CH}_{s}{ }^{+}$core, in the order of decreasing binding affinities of the solvent molecules in the case of mixed clusters. The third solvent was bound to the $\mathrm{H}$ atom, in plane with the $3 c 2 e$ bond, and the fourth and fifth solvent molecules were predicted to bind out-of-plane to the $3 \mathrm{c} 2 \mathrm{e}$ bond of $\mathrm{CH}_{5}^{+}$core.

For $\mathrm{CH}_{5}^{+}\left(\mathrm{CH}_{4}\right)$, a proton bound $\mathrm{CH}_{4}$ dimer, evidence for rapid proton transfer between the two $\mathrm{CH}_{4}$ molecules when the ions were vibrationally excited was found in the IR spectra for the single ${ }^{13} \mathrm{C}$ isotope-exchanged dimer, ${ }^{13} \mathrm{CH}_{5}^{+}\left(\mathrm{CH}_{4}\right)$ or $\mathrm{CH}_{5}{ }^{+}\left({ }^{13} \mathrm{CH}_{4}\right)$. The upper limit of the potential barrier for the proton transfer was determined to be $\sim 8$ $\mathrm{kcal} / \mathrm{mole}$, and compared with the potential barriers predicted by the density functional 
ab initio calculations.

As a future study, first, it will be interesting to study the larger solvated carbonium ions to find evidence for the complete formation of a solvation shell at $n=7$, predicted by previous pulsed electron beam high pressure mass spectrometry. Second, it is important to study the dynamics of the proton transfer in $\mathrm{CH}_{5}{ }^{+}\left(\mathrm{CH}_{4}\right)$ by vibrationally exciting the low frequency modes of the proton bound dimer, comparable in energy with the predicted potential barrier. 


\section{REFERENCES}

1. G.A. Olah, G.K.S. Prakash, and J. Sommer, Superacids (Wiley-Interscience, New York, 1985).

2. G.A. Olah, Carbocations and Electrophilic Reactions (Verlag Chemie, Weinheim, 1973).

3. V. Dyczmons, V. Staemmler, and W. Kutzelnigg, Chem. Phys. Lett., v.5, 361 (1970).

4. W.A. Lathan, W.J. Hehre, L.A: Curtiss, and J.A. Pople, J. Am. Chem. Soc., v.93, 6377 (1971); K. Ragavachari, R.A. Whiteside, J.A. Pople, and P.v.R. Schleyer, J. Am. Chem. Soc., v.103, 5649 (1981).

5. K. Hirao and S. Yamabe, Chem Phys., v.89, 237 (1984).

6. W. Klopper and W. Kutzelnigg, J. Phys. Chem., v.94, 5625 (1990).

7. P.R. Schreiner, S.J. Kim, H.F. Schaefer, and P.v.R. Schleyer, J. Chem. Phys., v.99, 3716 (1993).

8. P.v.R. Schleyer and J.W.M. Carneiro, J. Comput. Chem., v.13, 997 (1992).

9. G.E. Scuseria, Nature, v.366, 512 (1993).

10. K. Hiraoka, I. Kudaka, and S. Yamabe, Chem. Phys. Lett., v.184, 271 (1991).

11. K. Hiraoka and T. Mori, Chem. Phys. Lett., v.161, 111 (1989).

12. K. Hiraoka and P. Kebarle, J. Am. Chem. Soc., v.97, 4179 (1975).

13. M.D. Sefcik, J.M.S. Henis, and P.P. Gasper, J. Chem. Phys., v.61, 4321 (1974).

14. R.D. Smith and J.H. Futrell, Chem. Phys. Lett., v.36, 545 (1975).

15. A.J.R. Heck, L.J. de Koning, and N.M.M. Nibbering, J. Am. Soc. Mass Spectrom., 
v.2, $453(1991)$.

16. D.W. Boo and Y.T. Lee, Chem. Phys. Lett., v.211, 358 (1993).

17. D.W. Boo, Z.F. Liu, J.T. Tse, Y.T. Lee, and A.G. Suits, submitted to Science (1995).

18. D.W. Boo and Y.T. Lee, in preparation (1994).

19. S.W. Bustamente, Ph.D. Thesis, University of California at Berkeley (1983).

20. M. Okumura, Ph.D. Thesis, University of California at Berkeley (1986).

21. L.I.-C. Yeh, Ph.D. Thesis, University of California at Berkeley (1988).

22. J.M. Price, Ph.D. Thesis, University of California at Berkeley (1991).

23. R.N. Daly, Rev. Sci. Instr., v.31, 264 (1960).

24. G. Herzberg, Molecular Spectra and Molecular Structure, v.II Infrared and Raman Spectra of Polyatomic Molecules (Krieger Publishing Company, Florida, 1991).

25. S.J. Kim, P.R. Schreiner, P.v.R. Schleyer, and H.F. Schaefer, J. Phys. Chem., v.97, 12232 (1993).

26. D.R. Lide, eds. CRC Handbook of Chemistry and Physics, 74th edition (CRC Press, 1993-1994).

27. E. Fois, A. Gamba, and M. Simonetta, Can. J. Chem., v.63, 1468 (1985).

28. J.A. Edling, H.H. Richardson, and G.E. Ewing, J. Mol. Struct., v.157, 167 (1987).

29. A.Y. Khodakov, L.M. Kustov, V.B. Kazansky, and C. Williams, J. Chem. Soc. Faraday Trans., v.89, 1393 (1993).

30. S. Yamabe, Y. Osamura, and T. Minato, J. Am. Chem. Soc., v.102, 2268 (1980).

31. G.A. Jeffrey and W. Saenger, Hydrogen Bonding in Biological Structures (SpringerVerlag, Berlin, 1991). 
32. R.P. Bell, The Proton in Chemistry, 2nd ed. (Chapman and Hall, London, 1973). 33. Y. Xie, R.B. Remington, and H.F. Schaefer, J. Chem. Phys., v.101, 4878 (1994); F.R. Tortonda, J.-L. P.-Ahuir, E. Silla, and I. Tunon, J. Phys. Chem., v.97, 11087 (1993); K. Luth and S. Scheiner, J. Chem. Phys., v.97, 7507, 7519 (1992); T. Komatsuzaki and I. Ohmine, Chem. Phys., v.180, 239 (1994).

34. M. Henchman, D. Smith, and N.G. Adams, Int. J. Mass Spectrom. Ion Proc., v.109, 105 (1991).

35. First-principles quantum chemistry software package based on density functional theory, version 2.3 (Biosym Technologies, 1993).

36. JMW+B88 means the use of the Hedin-Lundqvist/Janak-Morruzi-Williams local correlation functionals, and Becke's 1988 version of a gradient-corrected exchange functional. LYP+B88 means the use of the Lee-Yang-Parr correlation functional and the Becke's functional. 
TABLE I. Experimental and theoretical dissociation energies and enthalpies for $\mathrm{CH}_{5}^{+}\left(\mathrm{CH}_{4}\right)_{\mathrm{n}}$. Units are in $\mathrm{kcal} / \mathrm{mole}$.

\begin{tabular}{|c|c|c|c|c|c|c|c|c|c|}
\hline Reference & $=1$ & 2 & 3 & 4 & 5 & 6 & 7 & 8 & 9 \\
\hline $\begin{array}{l}\text { Hiraoka } \\
\text { and Mori } \quad \Delta H_{T}^{\circ}\end{array}$ & 6.87 & 5.34 & 3.14 & 3.02 & 2.79 & 2.71 & 2.67 & 2.04 & 1.54 \\
\hline $\begin{array}{l}\text { Hiraoka } \\
\text { and Kebarle }{ }^{b} \Delta \mathrm{H}^{\circ} \mathrm{T}\end{array}$ & 7.4 & 5.9 & 4.1 & 3.9 & & & & & \\
\hline $\begin{array}{l}\text { Simonetta } D_{c} \\
\text { et al. }{ }^{c} H F / 6-31 G^{\circ}\end{array}$ & 3.27 & 2.95 & & & & & & & \\
\hline $\mathrm{HF} / 3-21 \mathrm{G}$ & 3.48 & 3.01 & 1.56 & 1.31 & & & & & \\
\hline $\mathrm{CNDO} / 2$ & 11.95 & 3.9 & 7.0 & 4.7 & & & & & \\
\hline $\begin{array}{l}\text { Yamabe } \quad D_{c} \\
\text { et al }{ }^{d} \text { HF/4-31G }\end{array}$ & 3.1 & 2.9 & 1.2 & & & & & & \\
\hline
\end{tabular}

Error is $\pm 0.3 \mathrm{kcal} / \mathrm{mole}$ for $\mathrm{n}=1-2$ and $\pm 0.2 \mathrm{kcal} / \mathrm{mole}$ for $\mathrm{n}=3-8$ (ref. 11 ).

'Error is $\pm 0.1 \mathrm{kcal} /$ mole (ref. 12). ' Ref. 27. ' Ref. 30. 
TABLE II. Observed vibrational frequencies and assignments for the solvated carbonium ions. Units are $\mathrm{cm}^{-1}$.

\begin{tabular}{|c|c|c|}
\hline \multicolumn{3}{|c|}{ Mono-solvated carbonium ions, $\mathrm{CH}_{s}{ }^{+}(\mathrm{A})$} \\
\hline Ions & Frequencies & Vibrational Assignment \\
\hline $\mathrm{CH}_{5}^{+}\left(\mathrm{H}_{2}\right)$ & $\begin{array}{l}-2907(\mathrm{~b}, \mathrm{sh})^{\dagger} \\
2964 \\
-3070(\mathrm{sh})^{\dagger} \\
4077.4\end{array}$ & $\begin{array}{l}\text { Coupled } \mathrm{CH}_{3} \text { stretches, } \mathrm{CH}_{5}^{+} \\
" \text { " } \\
\mathrm{H}-\mathrm{H} \text { stretch, } \mathrm{H}_{2}\end{array}$ \\
\hline $\mathrm{CH}_{s}^{+}(\mathrm{Ar})$ & $\begin{array}{l}-2900(b, s h)^{\dagger} \\
2974 \\
3081\end{array}$ & $\begin{array}{l}\text { Coupled } \mathrm{CH}_{3} \text { stretches, } \mathrm{CH}_{5}^{+} \\
\text {Less coupled } \mathrm{CH}_{3} \text { stretch, } \mathrm{CH}_{5}^{+}\end{array}$ \\
\hline $\mathrm{CH}_{5}^{+}\left(\mathrm{N}_{2}\right)$ & $\begin{array}{l}2623 \\
-2900(b, s h)^{\dagger} \\
2983 \\
3077\end{array}$ & $\begin{array}{l}\mathrm{H}-\mathrm{H} \text { stretch, } 3 \mathrm{c} 2 \mathrm{e} \text { bond, } \mathrm{CH}_{5}^{+} \\
\text {Coupled } \mathrm{CH}_{3} \text { stretches, } \mathrm{CH}_{5}^{+} \\
\text {Less coupled } \mathrm{CH}_{3} \text { stretch, } \mathrm{CH}_{5}^{+}\end{array}$ \\
\hline $\mathrm{CH}_{5}^{+}\left(\mathrm{CH}_{4}\right)$ & $\begin{array}{l}2608 \\
2869 \\
2982 \\
3010 \\
3063 \\
\end{array}$ & $\begin{array}{l}\mathrm{H}-\mathrm{H} \text { stretch, } 3 \mathrm{c} 2 \mathrm{e} \text { bond, } \mathrm{CH}_{5}{ }^{+} \\
\text {Bound } \mathrm{C}-\mathrm{H} \text { stretch, } \mathrm{CH}_{4} \\
\text { Coupled } \mathrm{CH}_{3} \text { stretches, } \mathrm{CH}_{5}{ }^{+} \\
\text {Free } \mathrm{C}-\mathrm{H} \text { stretch, } \mathrm{CH}_{4} \\
\text { Less coupled } \mathrm{CH}_{3} \text { stretch, } \mathrm{CH}_{5}\end{array}$ \\
\hline
\end{tabular}

\begin{tabular}{|c|c|c|}
\hline \multicolumn{3}{|c|}{ Di-solvated carbonium ions, $\mathrm{CH}_{5}{ }^{+}(\mathrm{A})(\mathrm{B})$} \\
\hline $\mathrm{CH}_{5}^{+}\left(\mathrm{H}_{2}\right)_{2}$ & $\begin{array}{l}2957 \\
3078 \\
4088.2\end{array}$ & $\begin{array}{l}\text { Coupled } \mathrm{CH}_{3} \text { stretches, } \mathrm{CH}_{5}^{+} \\
\text {Less coupled } \mathrm{CH}_{3} \text { stretch, } \mathrm{CH}_{5}{ }^{+} \\
\mathrm{H}-\mathrm{H} \text { stretch, } \mathrm{H}_{2}\end{array}$ \\
\hline $\mathrm{CH}_{5}^{+}(\mathrm{Ar})_{2}$ & $\begin{array}{l}2957 \\
3072 \\
\end{array}$ & $\begin{array}{l}\text { Coupled } \mathrm{CH}_{3} \text { stretches, } \mathrm{CH}_{5}{ }^{+} \\
\text {Less coupled } \mathrm{CH}_{3} \text { stretch, } \mathrm{CH}_{5}{ }^{+}\end{array}$ \\
\hline $\mathrm{CH}_{5}{ }^{+}\left(\mathrm{CH}_{4}\right)\left(\mathrm{H}_{2}\right)$ & $\begin{array}{l}2873 \\
2975 \\
3075\end{array}$ & $\begin{array}{l}\text { Bound } \mathrm{C}-\mathrm{H} \text { stretch, } \mathrm{CH}_{4} \\
\text { Coupled } \mathrm{CH}_{3} \text { stretches, } \mathrm{CH}_{5}^{+} \\
\text {Less coupled } \mathrm{CH}_{3} \text { stretch, } \mathrm{CH}_{5}^{+}\end{array}$ \\
\hline $\mathrm{CH}_{5}{ }^{+}\left(\mathrm{CH}_{4}\right)(\mathrm{Ar})$ & $\begin{array}{l}2874 \\
-2900(b) \\
2974 \\
3072\end{array}$ & $\begin{array}{l}\text { Bound } \mathrm{C}-\mathrm{H} \text { stretch, } \mathrm{CH}_{4} \\
\text { Coupled } \mathrm{CH}_{3} \text { stretches, } \mathrm{CH}_{5}{ }^{+} \\
\text {Less coupled } \mathrm{CH}_{3} \text { stretch, } \mathrm{CH}_{5}{ }^{+}\end{array}$ \\
\hline
\end{tabular}




\begin{tabular}{|l|l|l|}
\hline $\mathrm{CH}_{5}^{+}\left(\mathrm{CH}_{4}\right)_{2}$ & 2577 & $\mathrm{H}-\mathrm{H}$ stretch, 3c2e bond, $\mathrm{CH}_{5}^{+}$ \\
& 2879 & Bound $\mathrm{C}-\mathrm{H}$ stretch, $\mathrm{CH}_{4}$ \\
& $-2900(\mathrm{~b})^{\dagger}$ & Coupled $\mathrm{CH}$ stretches, $\mathrm{CH}_{5}^{+}$ \\
& 2974 & " \\
& 3082 & Less coupled $\mathrm{CH}_{3}$ stretch, $\mathrm{CH}_{5}^{+}$ \\
\hline
\end{tabular}

\begin{tabular}{|c|c|c|}
\hline \multicolumn{3}{|c|}{ Tri-solvated carbonium ions, $\mathrm{CH}_{5}^{+}(\mathrm{A})(\mathrm{B})(\mathrm{C})$} \\
\hline $\mathrm{CH}_{5}^{+}\left(\mathrm{H}_{2}\right)_{3}$ & $\begin{array}{l}2892 \\
2977 \\
3062 \\
4099\end{array}$ & $\begin{array}{l}\text { Sym. } \mathrm{CH}_{3} \text { breathing, } \mathrm{CH}_{5}^{+} \\
\text {Sym. } \mathrm{CH}_{3} \text { deg. stretch, } \mathrm{CH}_{5}^{+} \\
\text {Asym. } \mathrm{CH}_{3} \text { stretch, } \mathrm{CH}_{5}^{+} \\
\mathrm{H}-\mathrm{H} \text { stretches, } \mathrm{H}_{2}\end{array}$ \\
\hline $\mathrm{CH}_{5}^{+}\left(\mathrm{CH}_{4}\right)\left(\mathrm{H}_{2}\right)_{2}$ & $\begin{array}{l}2874 \\
2984 \\
3070\end{array}$ & $\begin{array}{l}\text { Bound } \mathrm{C}-\mathrm{H} \text { stretch, } \mathrm{CH}_{4} \\
\text { Coupled } \mathrm{CH}_{3} \text { stretches, } \mathrm{CH}_{5}^{+} \\
\text {Less coupled } \mathrm{CH}_{3} \text { stretch, } \mathrm{CH}_{5}^{+}\end{array}$ \\
\hline $\mathrm{CH}_{5}^{+}\left(\mathrm{CH}_{4}\right)(\mathrm{Ar})_{2}$ & $\begin{array}{l}2877 \\
-2900(b)^{\dagger} \\
2980 \\
3066\end{array}$ & $\begin{array}{l}\text { Bound } \mathrm{C}-\mathrm{H} \text { stretch, } \mathrm{CH}_{4} \\
\text { Coupled } \mathrm{CH}_{3} \text { stretches, } \mathrm{CH}_{5}{ }^{+} \\
\text {Less coupled } \mathrm{CH}_{3} \text { stretch, } \mathrm{CH}_{5}^{+}\end{array}$ \\
\hline $\mathrm{CH}_{5}^{+}\left(\mathrm{CH}_{4}\right)_{2}(\mathrm{Ar})$ & $\begin{array}{l}2881 \\
-2900(\mathrm{~b})^{\dagger} \\
2978 \\
3079\end{array}$ & $\begin{array}{l}\text { Bound } \mathrm{C}-\mathrm{H} \text { stretch, } \mathrm{CH}_{4} \\
\text { Coupled } \mathrm{CH}_{3} \text { stretches, } \mathrm{CH}_{5}^{+} \\
\text {Less coupled } \mathrm{CH}_{3} \text { stretch, } \mathrm{CH}_{5}^{+}\end{array}$ \\
\hline $\mathrm{CH}_{5}{ }^{+}\left(\mathrm{CH}_{4}\right)_{3}$ & $\begin{array}{l}2578 \\
2823(\mathrm{~b})^{\dagger} \\
2880 \\
2890 \\
2989 \\
3002 \\
\\
3022 \\
3077\end{array}$ & $\begin{array}{l}\mathrm{H}-\mathrm{H} \text { stretch, } 3 \mathrm{c} 2 \mathrm{e} \text { bond, } \mathrm{CH}_{5}^{+} \\
\text {Bound } \mathrm{C}-\mathrm{H} \text { stretch, } \mathrm{CH}_{5}^{+} \\
\text {Bound } \mathrm{C}-\mathrm{H} \text { stretches, } \mathrm{CH}_{4}(1,2) \\
\text { Bound } \mathrm{C}-\mathrm{H} \text { stretch, } \mathrm{CH}_{4}(3) \\
\text { Sym. free } \mathrm{CH}_{2} \text { stretch, } \mathrm{CH}_{5}^{+} \\
\text {Free } \mathrm{C}-\mathrm{H} \text { stretches, } \mathrm{CH}_{4}^{\prime} \text { s } \\
\text { Asym. free } \mathrm{CH}_{2} \text { stretch, } \mathrm{CH}_{5}^{+}\end{array}$ \\
\hline
\end{tabular}




\begin{tabular}{|l|l|l||}
\hline \multicolumn{2}{|l|}{ Tetra-solvated carbonium ions, $\mathrm{CH}_{5}{ }^{+}(\mathrm{A})_{4}$} \\
\hline \hline $\mathrm{CH}_{5}{ }^{+}\left(\mathrm{CH}_{4}\right)_{4}$ & $2823(\mathrm{~b})^{+}$ & Bound $\mathrm{C}-\mathrm{H}$ stretch, $\mathrm{CH}_{5}{ }^{+}$ \\
& 2890 & Bound $\mathrm{C}-\mathrm{H}$ stretches, $\mathrm{CH}_{4}$ \\
& 2989 & Sym. $\mathrm{CH}$ stretch, $\mathrm{CH}_{5}{ }^{+}$ \\
& 3002 & \\
& 3021 & Free C-H stretches, $\mathrm{CH}_{4}$ \\
& 3079 & Asym $\mathrm{CH}_{2}$ stretch, $\mathrm{CH}_{5}{ }^{+}$ \\
\hline
\end{tabular}

\begin{tabular}{|l|l|l|}
\hline \multicolumn{2}{|l|}{ Penta-solvated carbonium ions, $\mathrm{CH}_{5}{ }^{+}(\mathrm{A})_{5}$} \\
\hline \hline $\mathrm{CH}_{5}{ }^{+}\left(\mathrm{CH}_{4}\right)_{5}$ & 2886 & Bound $\mathrm{C}-\mathrm{H}$ stretches, $\mathrm{CH}_{4}$ \\
& 2892 & $"$ \\
& 2896 & $"$ \\
\hline
\end{tabular}

The features denoted by "b"and/or "sh" indicated the "broad" and/or "shoulder" features, respectively. 


\section{FIGURE CAPTIONS}

Fig. 1 Mass spectrum showing the methane and hydrogen solvated carbonium ions, $\mathrm{CH}_{5}{ }^{+}\left(\mathrm{CH}_{4}\right)_{x}\left(\mathrm{H}_{2}\right)_{y}(\mathrm{x}, \mathrm{y}=0,1,2, \ldots)$. The mixing ratio $\mathrm{CH}_{4}: \mathrm{H}_{2}$ was $1: 10,000$, and source pressure, the source temperature, and the discharge current were 200 torr, $-50^{\circ} \mathrm{C}$, and 40 $\mu \mathrm{A}$, respectively.

Fig. 2 IR spectra for the mono-solvated carbonium ions: (A) $\mathrm{CH}_{5}{ }^{+}\left(\mathrm{H}_{2}\right)$; (B) $\mathrm{CH}_{5}{ }^{+}(\mathrm{Ar}) ;(\mathrm{C})$ $\mathrm{CH}_{5}^{+}\left(\mathrm{N}_{2}\right) ;(\mathrm{D}) \mathrm{CH}_{5}^{+}\left(\mathrm{CH}_{4}\right)$.

Fig. 3 Deconvolution of the $2982 \mathrm{~cm}^{-1}$ peak of $\mathrm{CH}_{5}^{+}\left(\mathrm{CH}_{4}\right)$ into two gaussian peaks representing the coupled $\mathrm{CH}_{3}$ stretching bands of the core $\mathrm{CH}_{5}^{+}\left(2982 \mathrm{~cm}^{-1}\right)$, and one free $\mathrm{C}-\mathrm{H}$ stretching band of the solvent $\mathrm{CH}_{4}\left(3010 \mathrm{~cm}^{-1}\right)$.

Fig. 4 IR spectra for the di-solvated carbonium ions: (A) $\mathrm{CH}_{5}{ }^{+}\left(\mathrm{H}_{2}\right)_{2}$; (B) $\mathrm{CH}_{5}{ }^{+}(\mathrm{Ar})_{2} ;(\mathrm{C})$ $\mathrm{CH}_{5}^{+}(\mathrm{Ar})\left(\mathrm{CH}_{4}\right)$; (D) $\mathrm{CH}_{5}^{+}\left(\mathrm{CH}_{4}\right)_{2}$.

Fig. 5 IR spectra for the tri-solvated carbonium ions: $(A) \mathrm{CH}_{5}{ }^{+}\left(\mathrm{H}_{2}\right)_{3}$; (B) $\mathrm{CH}_{5}{ }^{+}(\mathrm{Ar})_{2}\left(\mathrm{CH}_{4}\right)$; (C) $\mathrm{CH}_{5}{ }^{+}(\mathrm{Ar})\left(\mathrm{CH}_{4}\right)_{2} ;(\mathrm{D}) \mathrm{CH}_{5}{ }^{+}\left(\mathrm{CH}_{4}\right)_{3}$.

Fig. 6 IR spectra for the $\mathrm{H}-\mathrm{H}$ stretching mode of the $3 \mathrm{c} 2 \mathrm{e}$ bond in the $\mathrm{CH}_{5}{ }^{+}$core of $(\mathrm{A})$ $\mathrm{CH}_{5}^{+}\left(\mathrm{N}_{2}\right)$; (B) $\mathrm{CH}_{5}^{+}\left(\mathrm{CH}_{4}\right) ;(\mathrm{C}) \mathrm{CH}_{5}^{+}\left(\mathrm{CH}_{4}\right)_{2} ;(\mathrm{D}) \mathrm{CH}_{5}^{+}\left(\mathrm{CH}_{4}\right)_{3}$. 
Fig. 7 IR spectra for the tetra- and penta-solvated carbonium ions: (A) $\mathrm{CH}_{5}{ }^{+}\left(\mathrm{CH}_{4}\right)_{4}$; (B) $\mathrm{CH}_{5}^{+}\left(\mathrm{CH}_{4}\right)_{5}$.

Fig. 8 Possible structures of (A) mono-solvated carbonium ions, $\mathrm{CH}_{5}{ }^{+}(\mathrm{A})\left(\mathrm{A}=\mathrm{H}_{2}, \mathrm{Ar}, \mathrm{N}_{2}\right.$, $\left.\mathrm{CH}_{4}\right)$; (B) di-solvated carbonium ions, $\mathrm{CH}_{5}^{+}(\mathrm{A})(\mathrm{B})\left(\mathrm{A}, \mathrm{B}=\mathrm{H}_{2}, \mathrm{Ar}, \mathrm{CH}_{4}\right)$; (C) tri-solvated carbonium ions, $\mathrm{CH}_{5}^{+}(\mathrm{A})(\mathrm{B})(\mathrm{C})\left(\mathrm{A}, \mathrm{B}, \mathrm{C}=\mathrm{H}_{2}, \mathrm{Ar}, \mathrm{CH}_{4}\right) ;(\mathrm{D})$ tetra- and penta-solvated carbonium ions, $\mathrm{CH}_{5}^{+}(\mathrm{A})_{4}$ and $\mathrm{CH}_{5}{ }^{+}(\mathrm{A})_{5}:\left(\mathrm{A}=\mathrm{CH}_{4}\right)$.

Fig. 9 IR spectra for the single methane solvated carbonium ions with different isotopes, $\mathrm{CH}_{5}{ }^{+}\left(\mathrm{CH}_{4}\right) \quad(\mathrm{m} / \mathrm{e}=33),{ }^{13} \mathrm{CH}_{5}^{+}\left(\mathrm{CH}_{4}\right)$ (or $\left.\mathrm{CH}_{5}{ }^{+}\left({ }^{13} \mathrm{CH}_{4}\right)\right) \quad(\mathrm{m} / \mathrm{e}=34)$, and ${ }^{13} \mathrm{CH}_{5}{ }^{+}\left({ }^{13} \mathrm{CH}_{4}\right)$ ( $\mathrm{m} / \mathrm{e}=35$ ), obtained in the frequency range of (A) $2840-2890 \mathrm{~cm}^{-1}$ for the bound $\mathrm{C}-\mathrm{H}$ stretching mode of the solvent $\mathrm{CH}_{4}$; (B) $2950-3000 \mathrm{~cm}^{-1}$ for the coupled $\mathrm{CH}_{3}$ stretching modes of the $\mathrm{CH}_{5}^{+}$core; (C) $3000-3100 \mathrm{~cm}^{-1}$ for the less coupled $\mathrm{CH}_{3}$ stretching mode of the $\mathrm{CH}_{5}{ }^{+}$core. The results show the rapid proton transfer between two $\mathrm{CH}_{4}$ molecules, when the ions are vibrationally excited.

Fig. 10 Structures of $\mathrm{CH}_{5}{ }^{+}\left(\mathrm{CH}_{4}\right)$ along the proton transfer coordinate. 


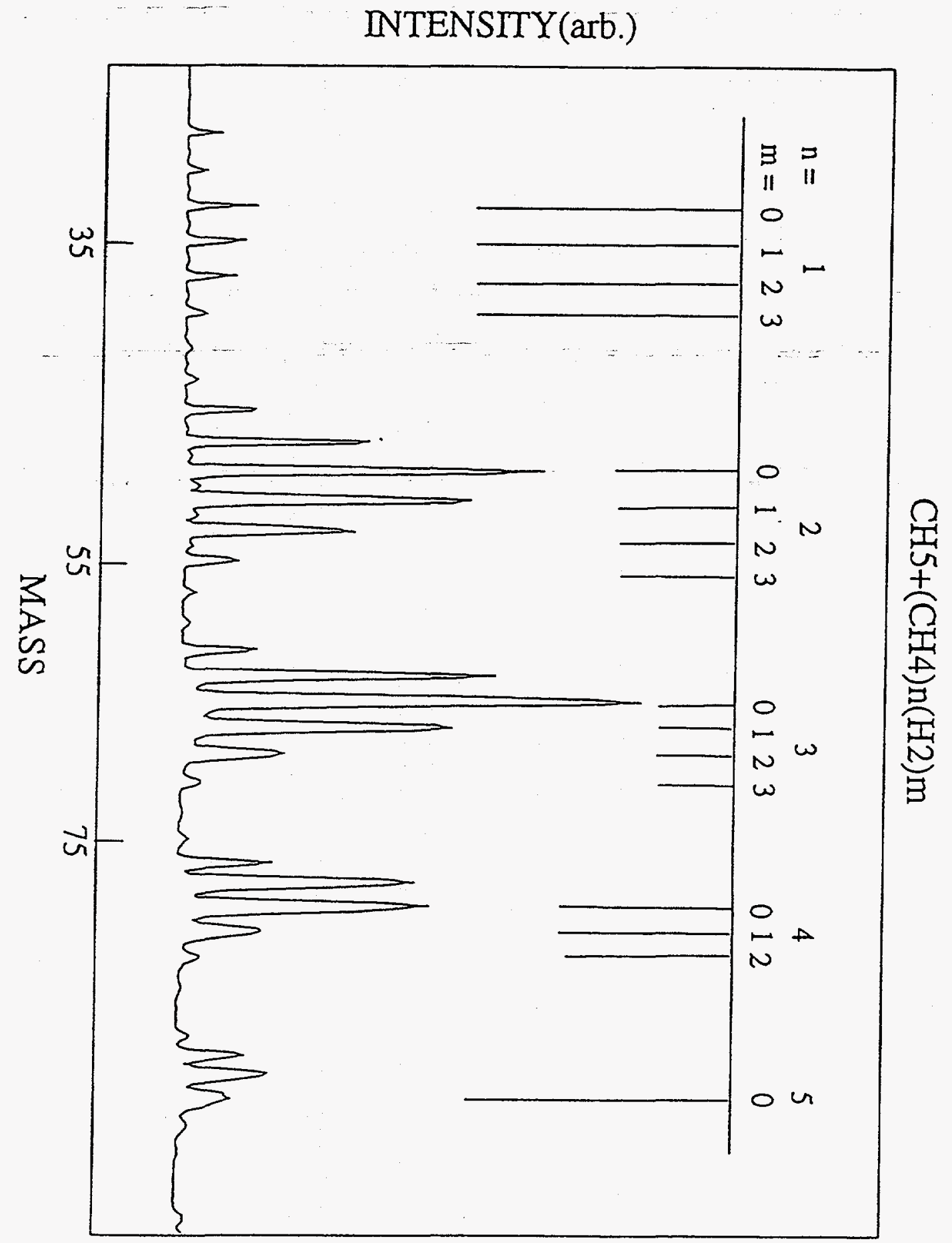

Fig. 1 


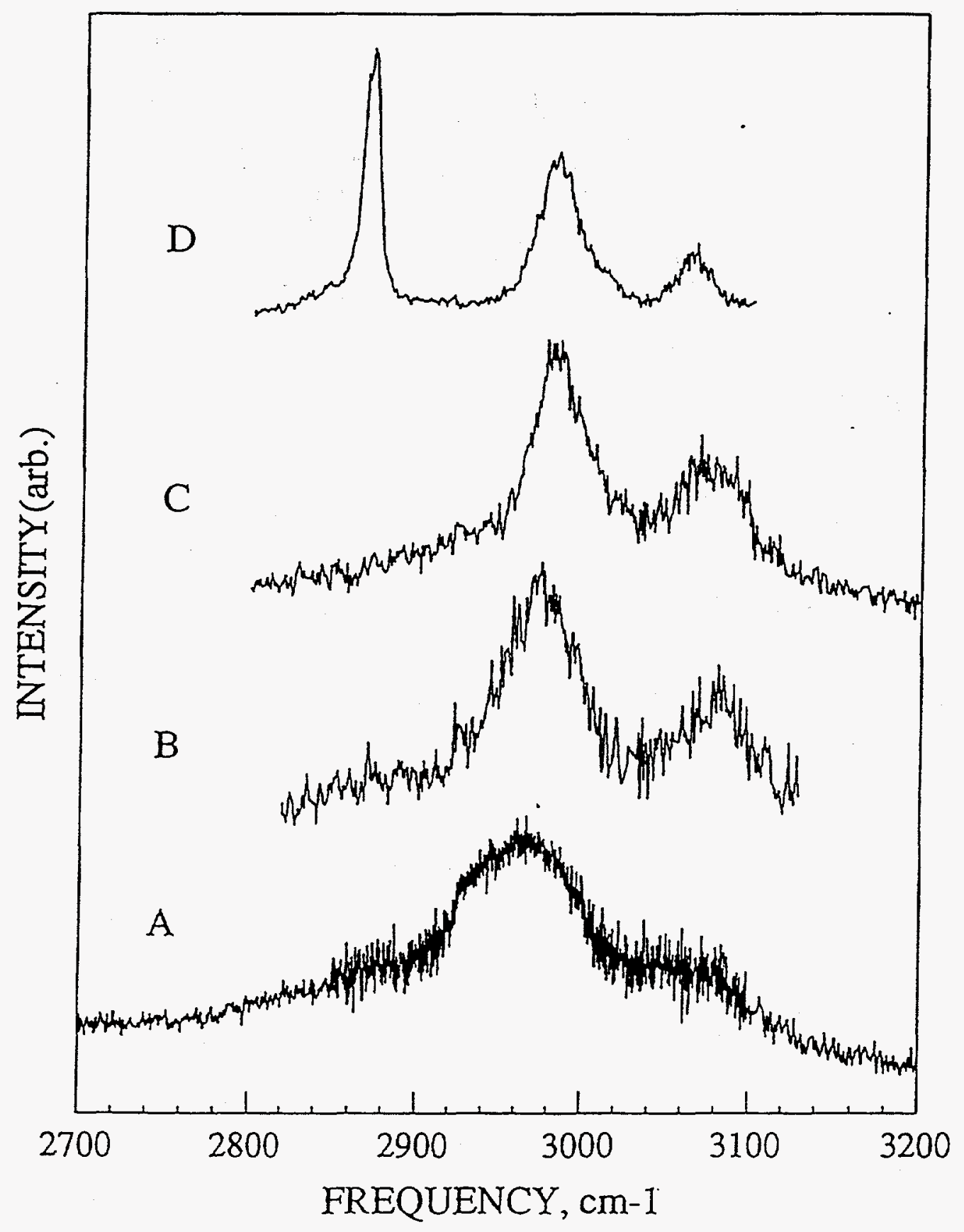

Fig. 2 


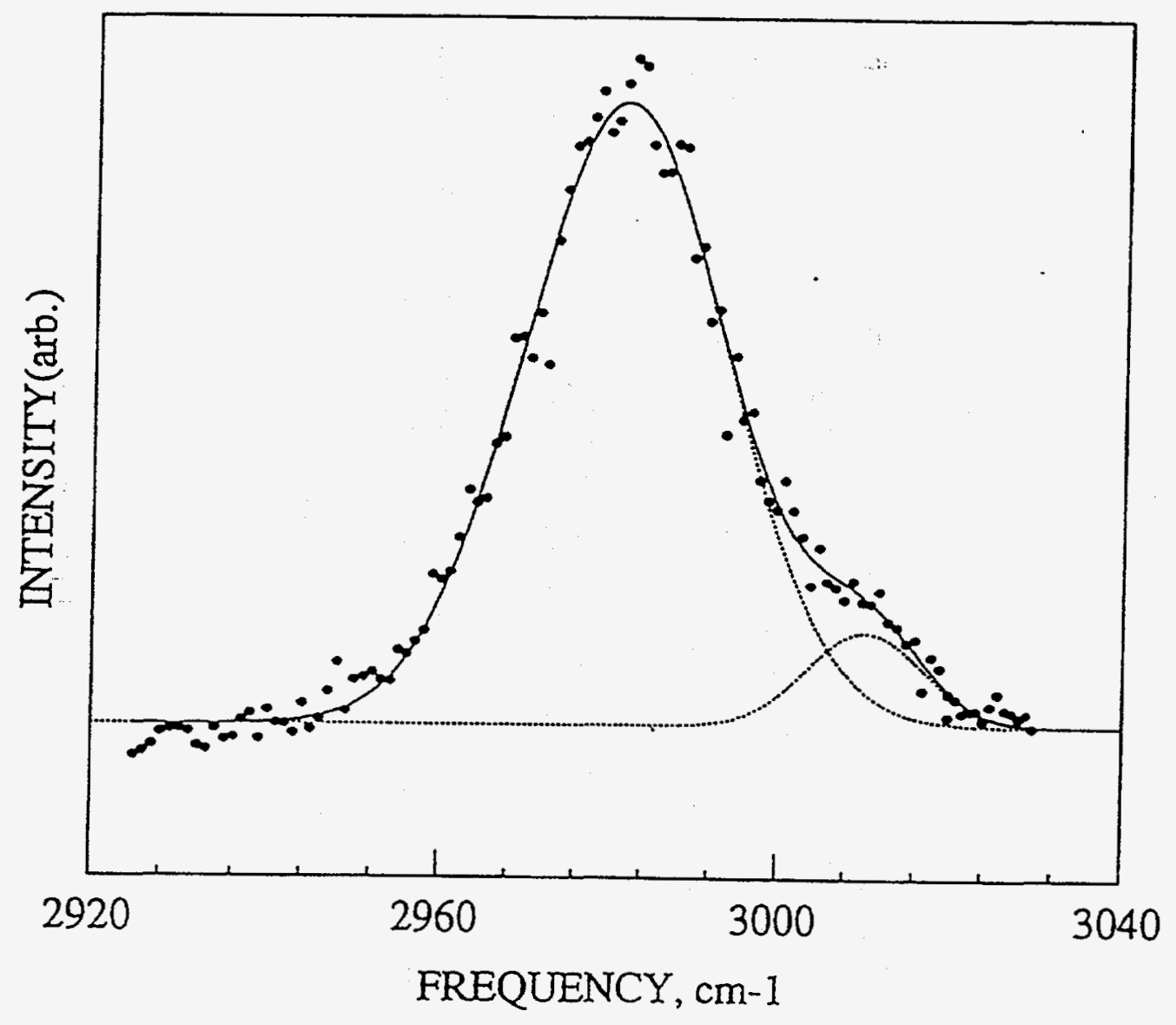

Fig. 3 


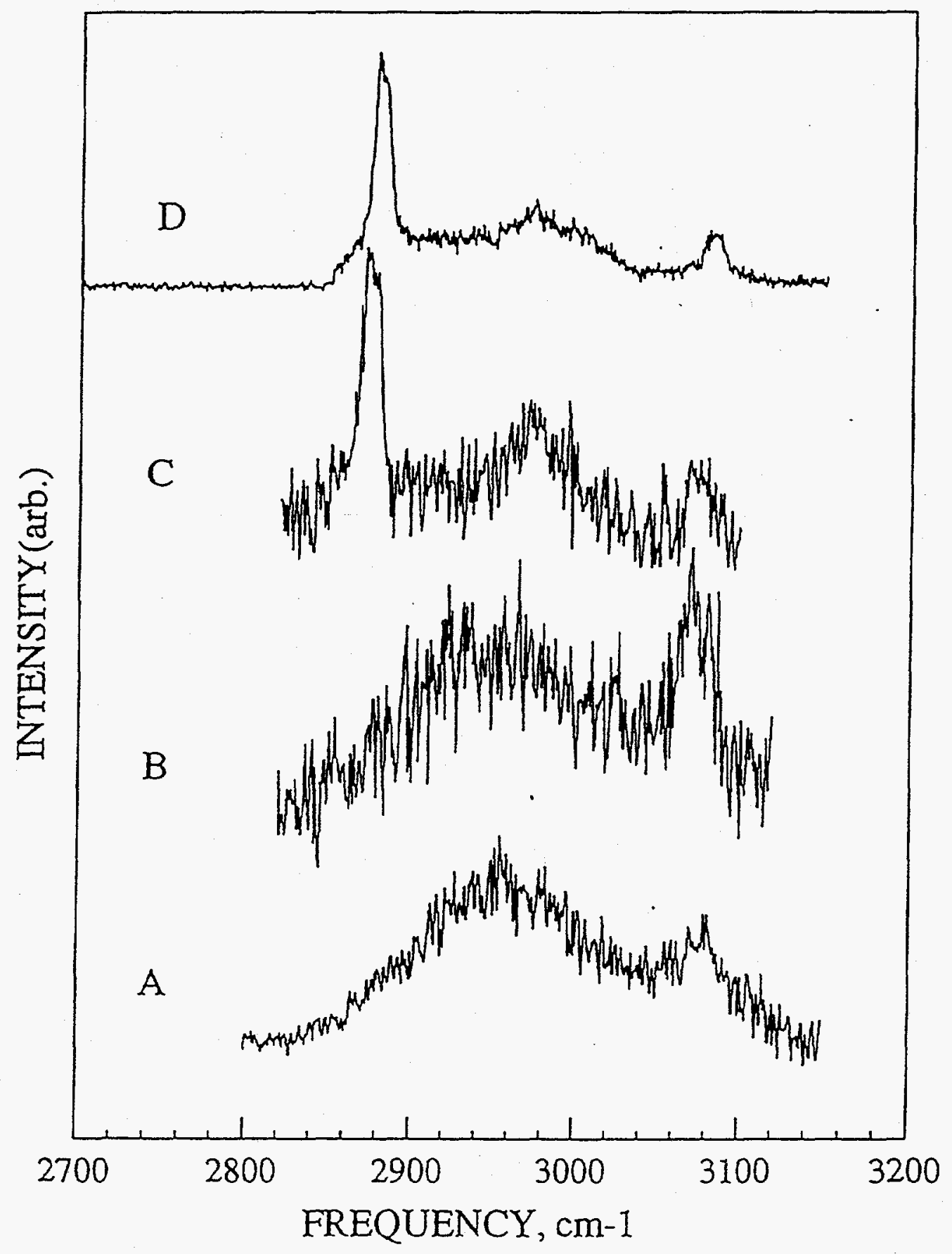

Fig. 4 


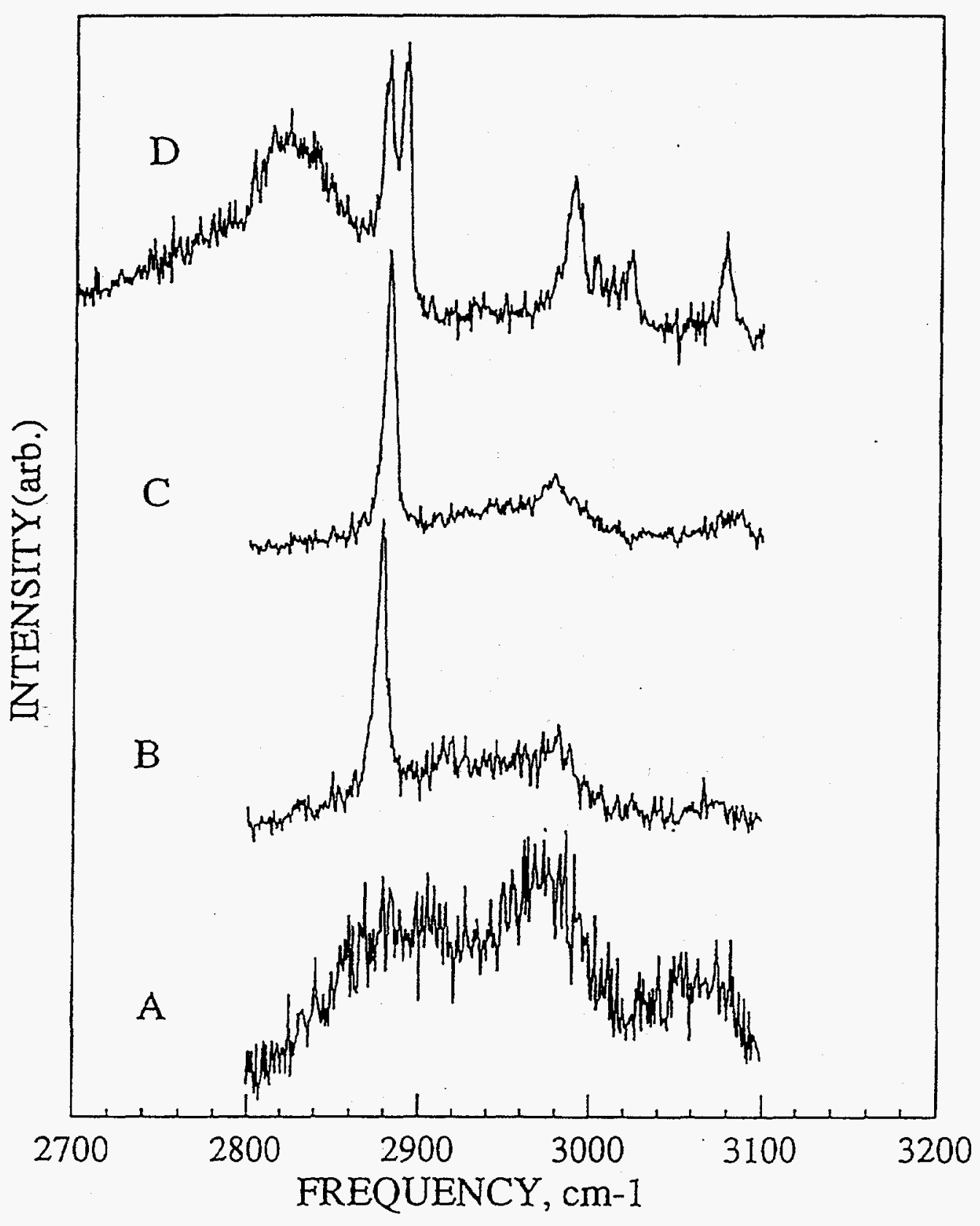

Fig. 5 


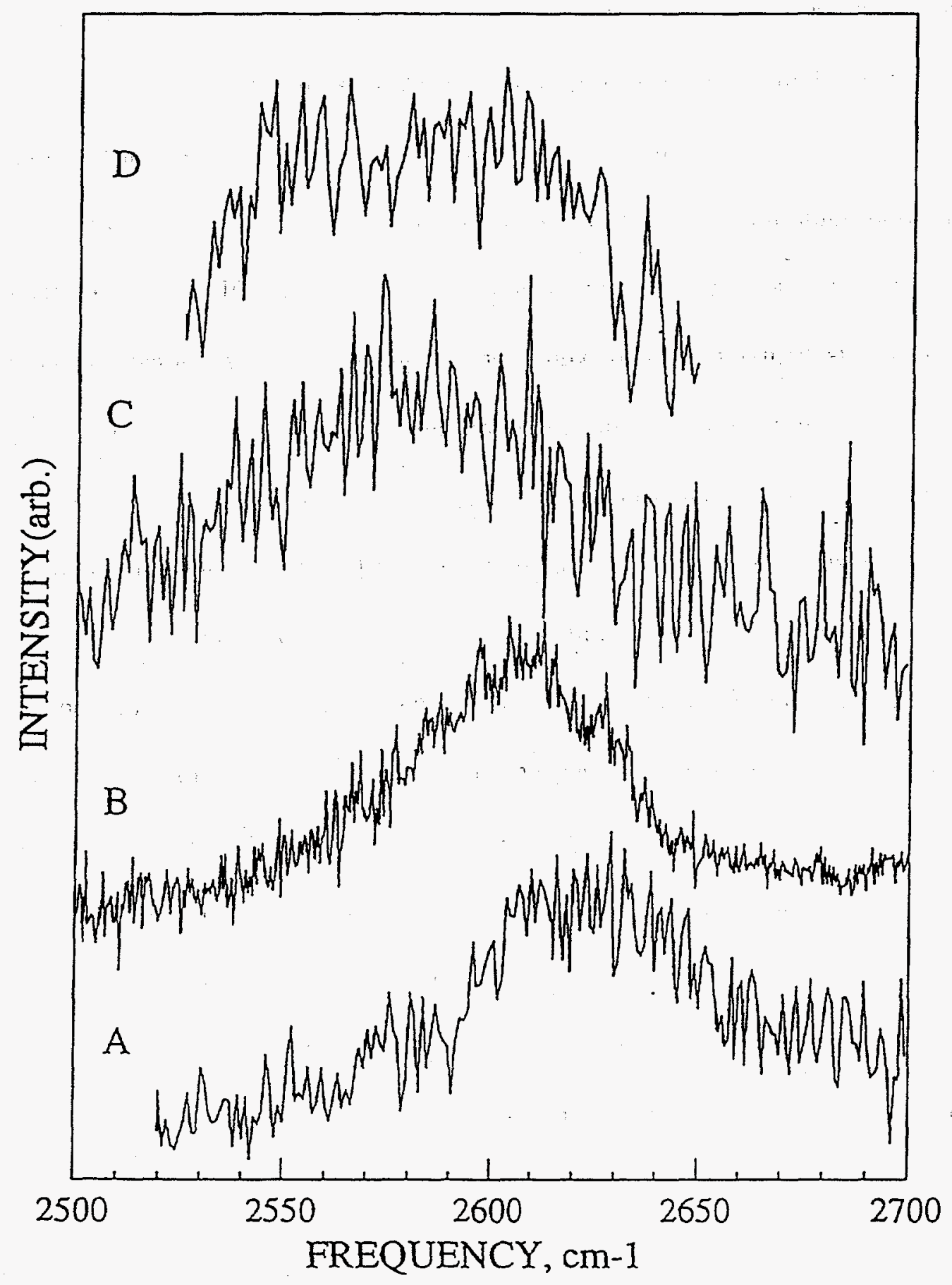

Fig. 6 


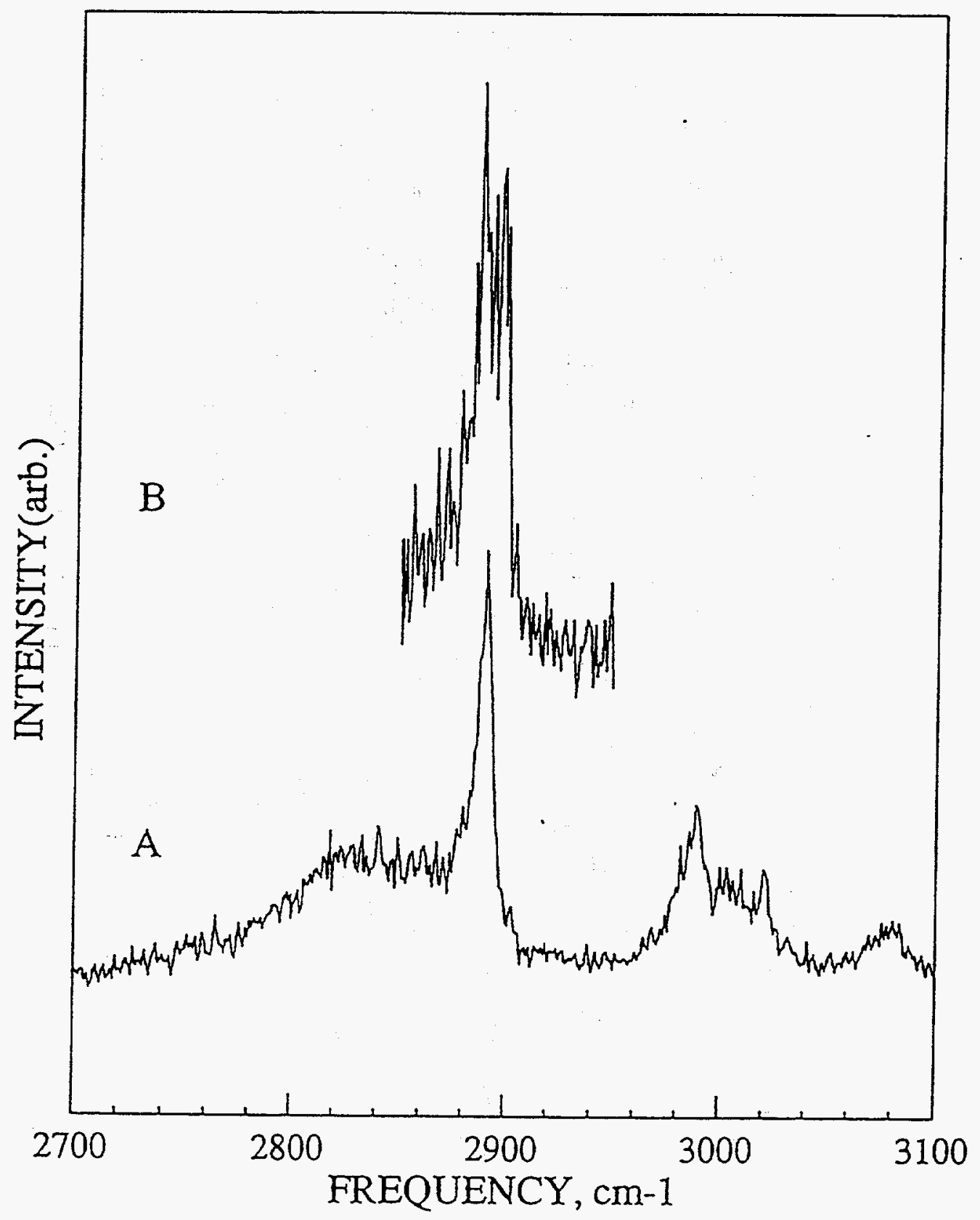

Fig. 7 


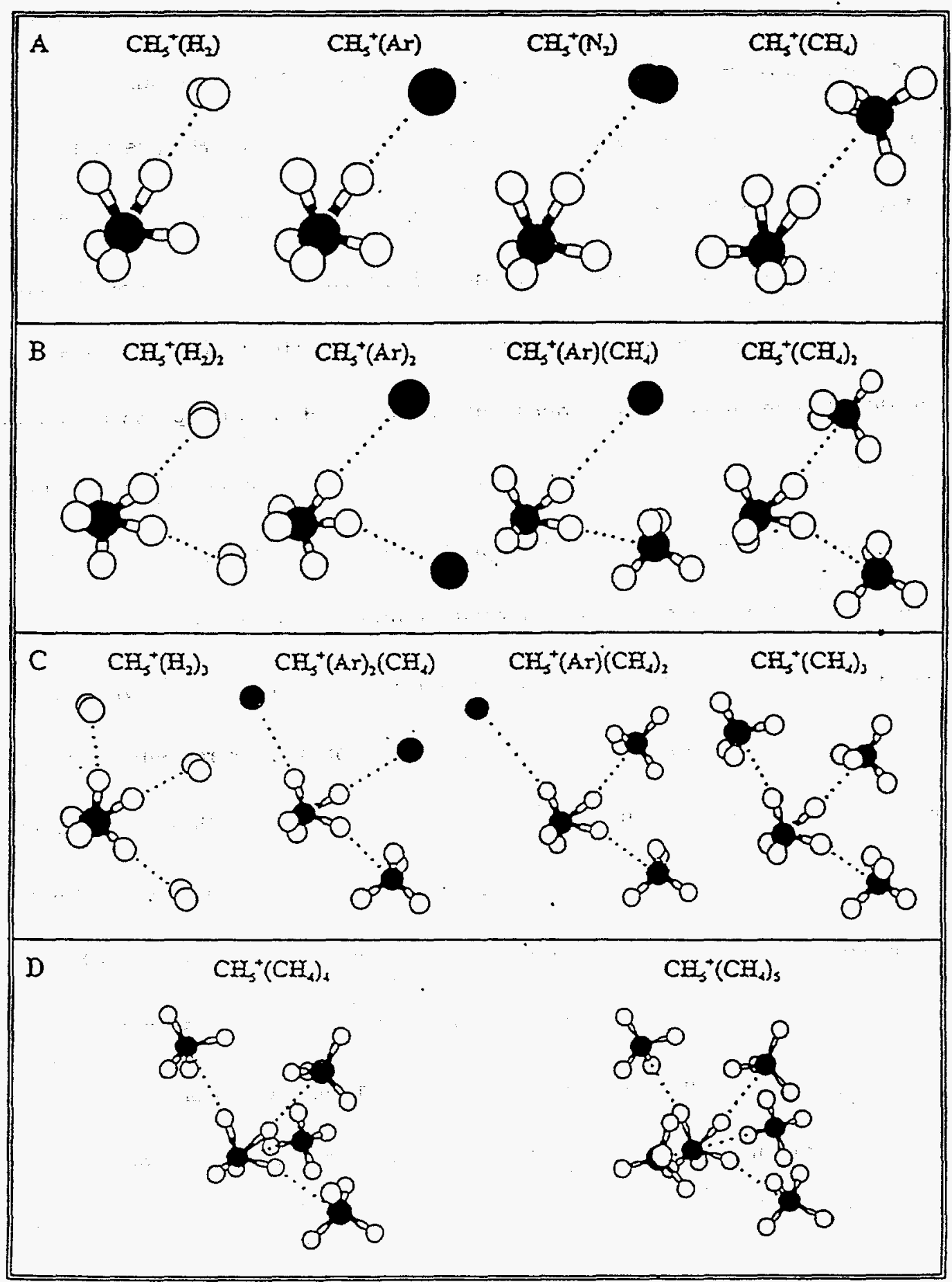

Fig. 8 


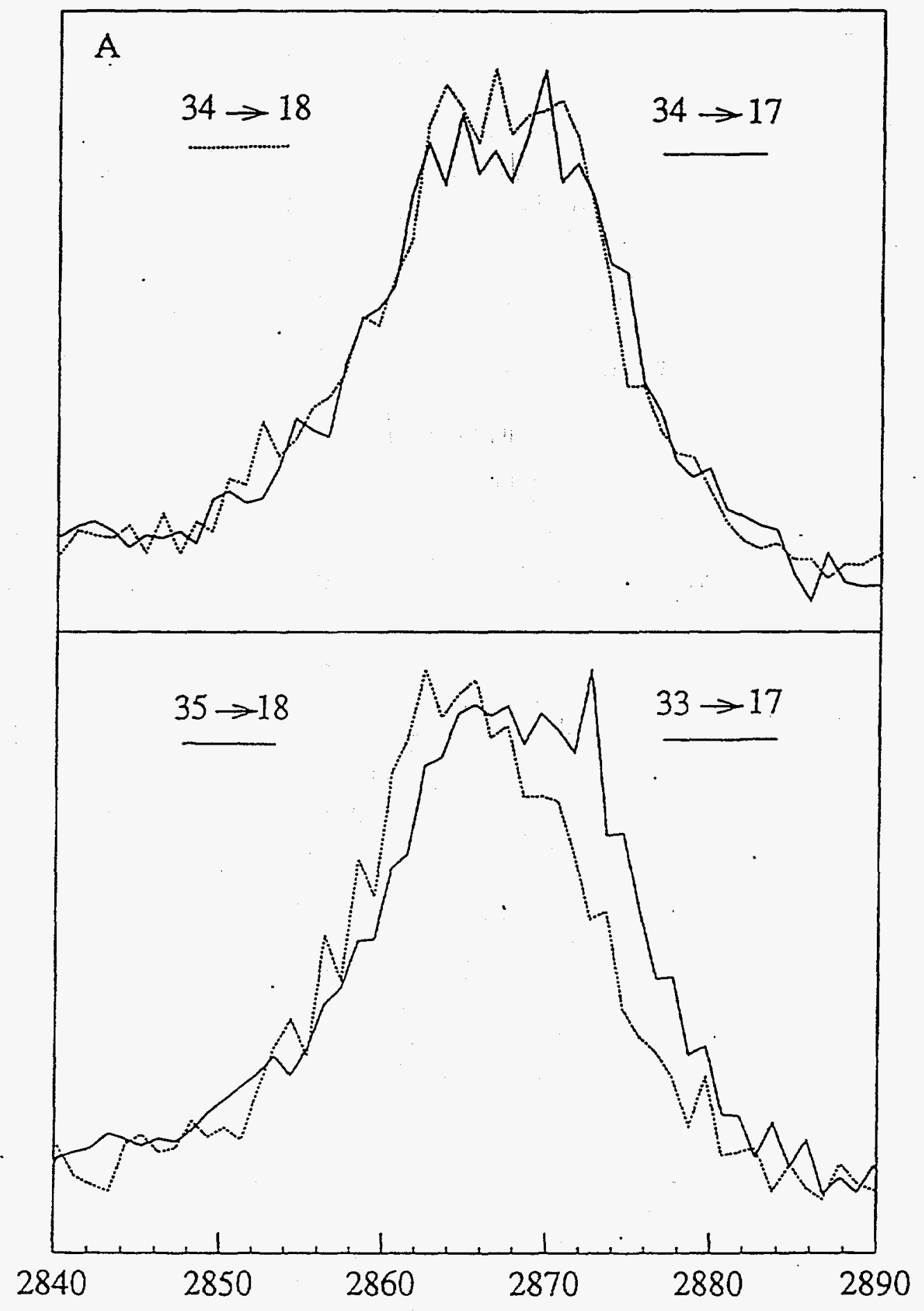

Fig. 9 


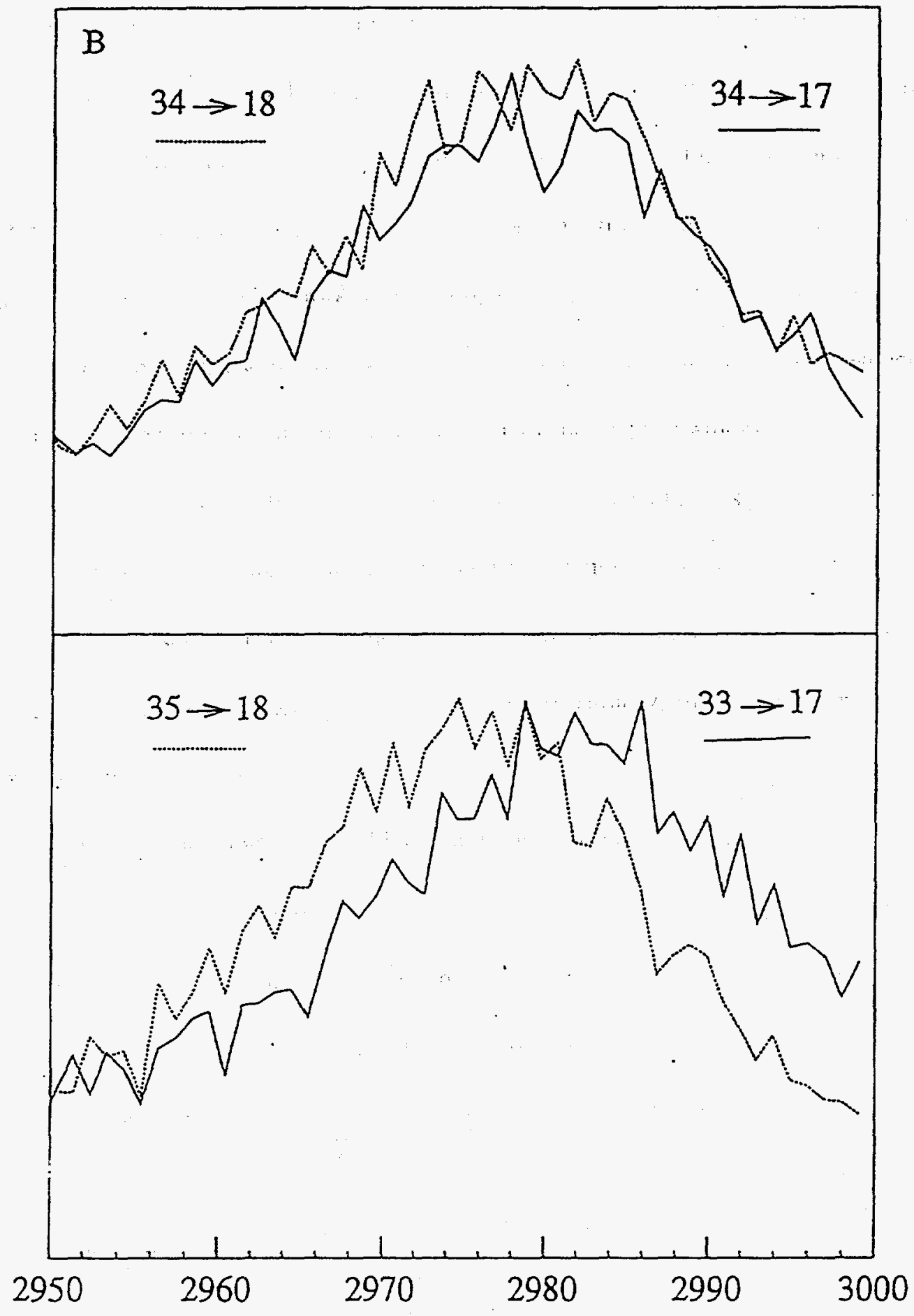

Fig. 9 


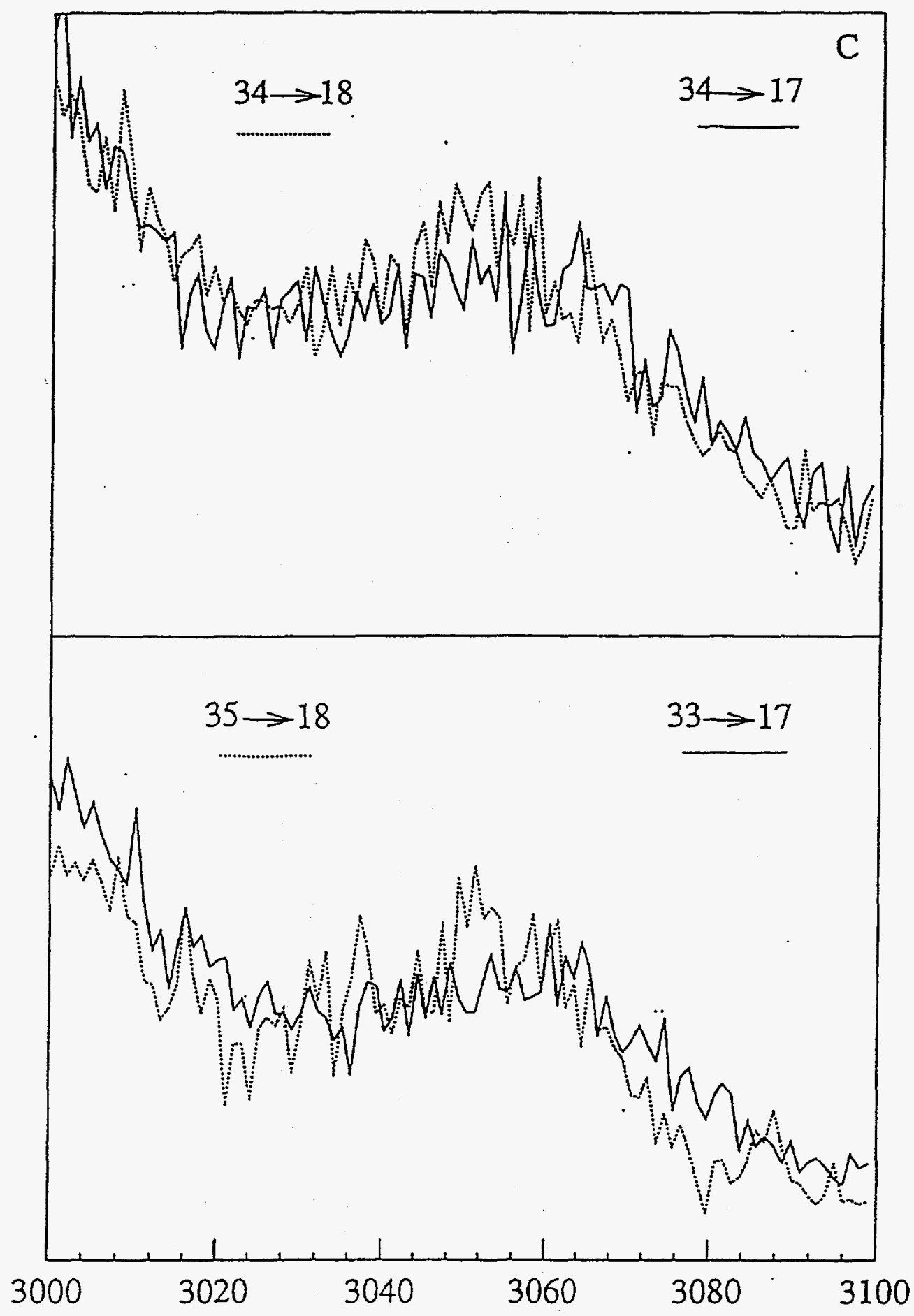

Fig. 9 


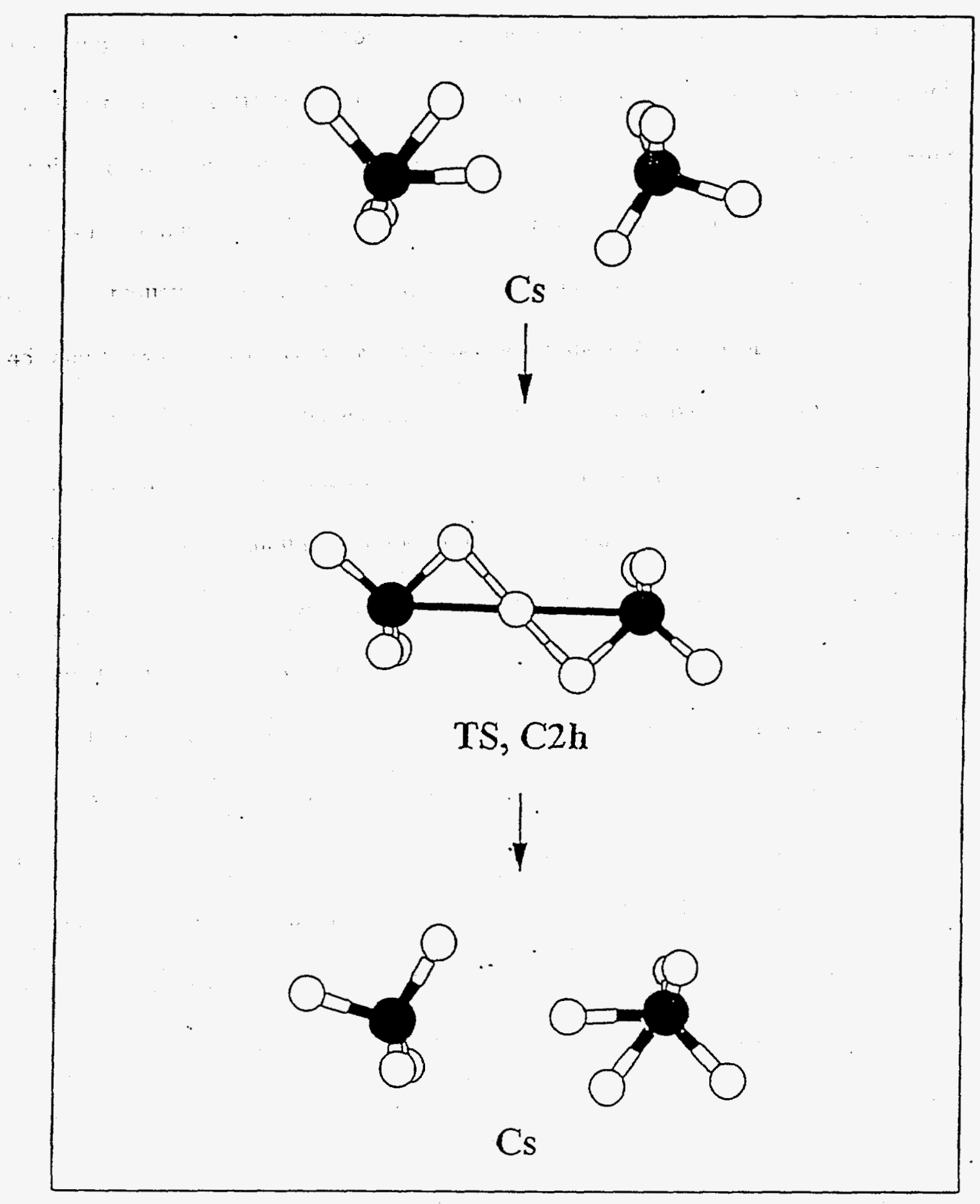

Fig. 10 


\section{CHAPTER V}

\section{Infrared Spectroscopy of the Silanium Ion, $\mathrm{SiH}_{5}^{+}$}

\section{INTRODUCTION}

The silanium ion $\mathrm{SiH}_{5}{ }^{+}$, an analogue of the carbonium ion $\mathrm{CH}_{5}^{+}$, is of considerable interest in understanding the nature of nonclassical bonding. Nonclassical bonding is characterized by a three-center two-electron bond ( $3 \mathrm{c} 2 \mathrm{e}$ ) having a pentacoordinated central atom and bridged hydrogens. ${ }^{1}$ Theoretical calculations ${ }^{2-5}$ suggested that the minimum energy structure for $\mathrm{SiH}_{5}^{+}$is composed of $\mathrm{SiH}_{3}{ }^{+}$and $\mathrm{H}_{2}$ groups, and the $\mathrm{H}_{2}$ group is predicted to rotate freely around the $\mathrm{C}_{3 \mathrm{v}}$ axis of $\mathrm{SiH}_{3}^{+}$. Unlike $\mathrm{CH}_{5}^{+}$, the scrambling motion involving a $C_{2 v}$ transition state structure was predicted to possess a high barrier $(26.8 \mathrm{kcal} / \mathrm{mole}) .^{2}$ Therefore, the structure and dynamics of $\mathrm{SiH}_{5}{ }^{+}$are expected to be analogous to, but distinct from those for $\mathrm{CH}_{5}{ }^{+}$.

Recently, Okumura and coworkers ${ }^{6}$ reported the infrared spectrum on $\mathrm{SiH}_{7}^{+}$ obtained by employing the vibrational predissociation spectroscopy with a newly designed pulsed reflectron time-of flight mass spectrometer. They concluded that the structure of $\mathrm{SiH}_{7}{ }^{+}$may be regarded as a symmetric complex between $\mathrm{SiH}_{3}{ }^{+}$and two $\mathrm{H}_{2}$ molecules, different from the structure of $\mathrm{CH}_{7}^{+}$proposed as $\mathrm{CH}_{5}^{+}\left(\mathrm{H}_{2}\right)$ in our previous work. ${ }^{7}$ This is also suggestive of the difference in nonclassical bonding between $\mathrm{SiH}_{5}{ }^{+}$and $\mathrm{CH}_{5}{ }^{+}$.

In this chapter we present the first infrared spectrum for $\mathrm{SiH}_{5}{ }^{+}$from 3650 to 3740 $\mathrm{cm}^{-1}$ obtained by using ion trap vibrational predissociation spectroscopy. Of the 
interesting features observed in the spectrum are rotation-vibration transitions of the $\mathrm{H}-\mathrm{H}$ stretching mode in $\mathrm{SiH}_{s}^{+}$. 


\section{EXPERIMENTAL DETAILS}

The experimental apparatus used in this work has been described previously ${ }^{8}$ and also in Chapter I. Briefly, the silanium ions were produced from a high pressure corona discharge source and subsequent supersonic expansion through a $75 \mu \mathrm{m}$ nozzle. The corona discharge was maintained in 200 torr of gas mixture with ultrahigh purity (UHP) $\mathrm{H}_{2}$, UHP He, and UHP $\mathrm{SiH}_{4}$ in a $50,000: 5,000: 1$ ratio, flowing past a $1.0 \mathrm{kV}$ potential from the discharge tip of the needle to the source body maintained at $350 \mathrm{~V}$ above ground. The discharge currents under these conditions were around $30 \mu \mathrm{A}$. The temperature of the source body was maintained at approximately $-10^{\circ} \mathrm{C}$ by heating the source body in contact with a liquid nitrogen trap. Typical pressures in the source chamber were around $2 \times 10^{-5}$ torr during the experiment. To prevent the acceleration of ions in the higher pressure region which causes internal excitation and dissociation of the ion clusters via collisions with the background gas, the potential of the skimmer was maintained within $0.3 \mathrm{~V}$ of that of the source body.

After the skimmer, the ion beam entered a second differential pumping region containing collimating and focusing lenses. The pressure in this region was typically an order of magnitude lower than that of the source region. The beam was directed into a $60^{\circ}$ sector magnet mass analyzer through a third differentially pumped region maintained at $2 \times 10^{-8}$ torr.

The mass-selected beam was then bent $90^{\circ}$ in a dc quadrupole field, decelerated to less than $0.5 \mathrm{eV}$, and focused into a rf octapole ion trap through an entrance aperture lens. The ions were usually trapped here for $18 \mathrm{msec}$ per cycle for the interaction with 
the IR lasers. Usually 1,000 ions were trapped per cycle, which is not enough to allow direct measurement of photon absorption.

The trapped, mass-selected clusters were then vibrationally excited by a pulsed, tunable infrared laser. A Quanta-Ray IR WEX was used as a tunable infrared light source. The infrared wavelength was generated in a $\mathrm{LiNbO}_{3}$ crystal that takes the difference frequency between a Lambda Physics pulsed dye laser (Model FL3002E) and the $1.06 \mu \mathrm{m}$ fundamental of a Continuum Nd-YAG laser. The IR resolution was $0.2 \mathrm{~cm}^{-1}$, the pulse duration was $6 \mathrm{nsec}$ with a $20 \mathrm{~Hz}$ repetition rate, and the laser power was 2-3 $\mathrm{mJ} /$ pulse in the $3300-4200 \mathrm{~cm}^{-1}$ region.

Because of the large binding energy of $\mathrm{SiH}_{5}^{+}(17.8 \mathrm{kcal} / \mathrm{mole}),{ }^{6,9}$ the absorption of one photon from the tunable IR laser could not cause the vibrational predissociation of $\mathrm{SiH}_{5}{ }^{+}$. In this case, a line tunable cw CO $\mathrm{CO}_{2}$ laser (MPB Technologies, 5W @10.6 $\mu \mathrm{m}$ ) was used to drive the $\mathrm{SiH}_{5}{ }^{+}$ions excited by the tunable IR laser over the dissociation threshold through the absorption of multiple $\mathrm{CO}_{2}$ laser photons, as the schematic is shown in Fig. 1. Typical irradiation time of the $\mathrm{CO}_{2}$ laser at $10.6 \mu \mathrm{m}$ and $5 \mathrm{~W}$ was about 16 msec after the tunable IR pulse. After the $\mathrm{CO}_{2}$ laser irradiation, the potential on the exit aperture was lowered to extract ions of all masses from the trap. These ions were filtered by a quadrupole mass spectrometer tuned to pass only the $\mathrm{SiH}_{3}{ }^{+}$daughter ions for the $\mathrm{SiH}_{5}^{+}$parent ions. In this work, the observation of the $\mathrm{SiH}_{3}{ }^{+}$signal as a function of laser frequency was a measure of the infrared absorption of $\mathrm{SiH}_{s}{ }^{+}$.

Daughter ions were counted with a Daly ion detector $^{10}$ for each laser shot. Background daughter ions resulting from both the multiphoton dissociation (MPD) by the 
$\mathrm{CO}_{2}$ laser irradiation alone and the decay of metastable parent ions in the rf ion trap were monitored in a separate cycle with the tunable IR laser off at each wavelength and subtracted from the laser on signal. The laser power was monitored at each data point, and spectra were normalized for the power of the tunable infrared laser assuming a simple linear power dependence. For a typical experiment, signals were averaged for about 2,000 laser shots at each wavelength from 3650 to $3750 \mathrm{~cm}^{-1}$, where only infrared absorption of $\mathrm{SiH}_{5}{ }^{+}$was found in the frequency range of $3300-4200 \mathrm{~cm}^{-1}$ scanned in this work.

In this experiment, it was seen that the composition of ions in the beam was strongly dependent on the $\mathrm{H}_{2} / \mathrm{He} / \mathrm{SiH}_{4}$ mixing ratio, the discharge current, the source temperature and the source pressure. The ratio of $\mathrm{SiH}_{4}: \mathrm{He}_{2} \mathrm{H}_{2}$ used in this work was 1:5,000:50,000. An increase of the concentration of $\mathrm{SiH}_{4}$ in the gas mixture resulted in an increase in the formation of the larger silanium ions, namely $\mathrm{Si}_{x} \mathrm{H}_{y}{ }^{+}(x \geq 2)$. The discharge current was kept as low as possible to reduce the internal excitation of the ions. In the mass spectra under these source conditions, the $\mathrm{SiH}_{5}{ }^{+}$ions $(\mathrm{m} / \mathrm{e}=33)$ showed a maximum intensity among the several mass peaks observed. Fig. 2 shows the mass spectrum obtained with the 200 torr source pressure, $-10^{\circ} \mathrm{C}$ source temperature and $30 \mu \mathrm{A}$ discharge current for a gas mixture of $\mathrm{SiH}_{4}: \mathrm{He}_{2} \mathrm{H}_{2}=1: 5,000: 50,000$. 


\section{GROUP THEORETICAL TREATMENT ${ }^{11,12}$}

$\mathrm{Ab}$ initio calculation ${ }^{2}$ predicted that the silanium ion, $\mathrm{SiH}_{5}{ }^{+}$, has a free internal rotation of $\mathrm{H}_{2}$ around the A-axis, as shown in Fig. 3. In order to treat this problem, it is required to use the complete nuclear permutation inversion (CNPI) group theory, instead of the point group theory. We label the $\mathrm{H}$ atoms 1 through 5 as shown in Fig. 3. The size of the CNPI group is $5 ! \times 2=240$ for the permutations and inversions of the five $\mathrm{H}$ atoms in $\mathrm{SiH}_{5}{ }^{+}$. Since the scrambling of the $\mathrm{H}$ atoms via the in-plane wagging of the $3 \mathrm{c} 2 \mathrm{e}$ bond observed for $\mathrm{CH}_{5}{ }^{+}$, responsible for the total scrambling of the five $\mathrm{H}$ atoms, was predicted to be strongly hindered in $\mathrm{SiH}_{s}{ }^{+}(\Delta \mathrm{E}=26.8 \mathrm{kcal} / \mathrm{mole}){ }^{2}$ the size of the feasible permutation inversion operations, i.e the size of the molecular symmetry (MS) group, is reduced to $3 \times 2 \times 2=12, \mathrm{G}_{12}$ group, consisted of the exchanges of $\mathrm{H} 1, \mathrm{H} 2$, and $\mathrm{H} 3$ atoms, and $\mathrm{H} 4$ and $\mathrm{H} 5$ atoms, respectively, and the inversions through the origin of the molecule-fixed axes. The elements of the $G_{12}$ MS group, isomorphic with the $D_{3 h}$ point group, are listed in the character table shown in Table 1. In the character table, the equivalent rotations for the $G_{12}$ symmetry operations are also listed in the bottom of Table 1 , following the Bunker's idea. ${ }^{12}$ The $R_{\alpha}{ }^{\beta}$ means the rotation by the angle $\beta$ around the $\alpha$ axis. The $(\theta, \phi, \chi)$, shown in Table 1 , are Euler angles to define the molecule-fixed coordinates $(x, y, z)$ with respect to the space-fixed coordinates $(X, Y, Z)$, and their transformation properties under $G_{12}$ group are also listed in the table. In addition, the transformation properties of $\rho$, the torsional angle for the internal rotation of $\mathrm{H}_{2}$, are listed in Table 1. In the Table, the primes and double primes indicate the character with respect to the element (45). 
According to the exclusion principle, if a symmetry element has the sole effect of permuting the positions and spins of identical particles, then it must multiply the wavefunction by the factor $\Pi(-1)^{p}$, where the product is over all sets of identical particles of half-odd spin and $\mathrm{p}$ denotes the parity of the permutation which the symmetry element induces in a typical set. Therefore, the overall wavefunction of $\mathrm{SiH}_{5}{ }^{+}$must belong to one or other irreducible representations $A_{1}$ " or $A_{2}{ }^{\prime \prime}$, which are asymmetric with respect to the (45) and (123)(45), and symmetric with respect to the (123) elements.

Table 2. shows the characters of the reducible representations generated by the five proton spin functions consisted of the $\mathrm{SiH}_{3}$ and $\mathrm{H}_{2}$ groups, resulted from the free internal rotation, but no scrambling via the in-plane wagging motion. As the irreducible representations are also shown in the last column of Table 2, the possible spin states are the direct products of $\left(4 A_{1}^{\prime}, 2 E^{\prime}\right)$ and $\left(3 A_{1}^{\prime}, 1 A_{1}^{\prime \prime}\right)$.

Turning to the rotational problem, $\mathrm{SiH}_{5}{ }^{+}$is predicted to be a near prolate top with the $a b$ initio rotational constants $A=2.522 \mathrm{~cm}^{-1}, B=1.691 \mathrm{~cm}^{-1}$, and $C=1.644 \mathrm{~cm}^{-1}$ for the global minimum energy structure, as shown in Fig. 3. The zero order rotational Hamiltonian of $\mathrm{SiH}_{s}{ }^{+}$is that of an asymmetric top, and the asymmetric rotor species can be deduced from the equivalent rotations given in Table 1. The results, as shown in Table 3., are $A_{1}^{\prime}, A_{2}{ }^{\prime}, A_{1}{ }^{\prime \prime}$ and $A_{2}{ }^{\prime \prime}$ for $K_{2} K_{c}=e e$, eo, oe, and oo, respectively, where $K_{a}$ and $\mathrm{K}_{\mathrm{c}}$ indicate the prolate and oblate levels, respectively with which the level correlates $\left(K_{\mathrm{a}}=\left|\mathrm{k}_{\mathrm{a}}\right|\right.$ and $\left.\mathrm{K}_{\mathrm{c}}=\left|\mathrm{k}_{\mathrm{c}}\right|\right)$, and $\mathrm{e}$ and $\mathrm{o}$ means even and odd numbers, respectively. For the free internal rotation, the eigenfunctions and eigenvalues are given by

$$
\Phi_{\text {tor }}=\exp \left(\mathrm{ik}_{\mathrm{i}} \rho\right)
$$


and

$$
\mathrm{E}_{\mathrm{tor}}=\mathrm{Dk}_{\mathrm{i}}^{2}
$$

where $\mathrm{k}_{\mathrm{i}}=0, \pm 1, \pm 2, \ldots$ and $\mathrm{D}$ is the internal rotational constant of the $\mathrm{H}_{2}-\mathrm{SiH}_{3}$ about the A-axis $\left(D_{a b}=58.5 \mathrm{~cm}^{-1}\right)$. The symmetry species of the torsional wavefunctions is shown in Table 4.

Now we are in a position to calculate the nuclear spin statistical weights of the rotational states in any vibration and internal rotation states. For the ground vibrational and internal rotational states of the totally symmetric $A_{1}{ }^{\prime}$ symmetry, the direct product of the proton spin symmetry species of $\mathrm{SiH}_{3}$ and $\mathrm{H}_{2}$, and the rotational symmetry species, must belong to $A_{1} "$ or $A_{2} "$ symmetries, i.e.

$$
\left(4 A_{1}^{\prime}, 2 E^{\prime}\right) \times\left(3 A_{1}^{\prime}, 1 A_{1}^{\prime \prime}\right) \times\left(A_{1}^{\prime}, A_{2}^{\prime \prime}, E^{\prime}, E^{\prime \prime}\right) \supseteq A_{1}^{\prime \prime} \text { or } A_{2}^{\prime \prime}
$$

As a result, the nuclear spin statistical weights of the rotational states of $\mathrm{SiH}_{5}{ }^{+}$are shown in the parentheses of Table 3, i.e.

$$
A_{1}^{\prime}(4) \quad A_{1}{ }^{\prime \prime}(12) \quad A_{2}^{\prime}(4) \quad A_{2}^{\prime \prime}(12) \text {. }
$$

The same procedure can be used to determine the nuclear spin statistical weights of the rotational states in the excited vibration and internal rotation states, by incorporating their symmetry species into the direct product described above. 


\section{RESULTS AND ANALYSIS}

Fig. 4A shows the infrared spectrum of the silanium ion $\mathrm{SiH}_{5}^{+}$, taken with $0.2 \mathrm{~cm}^{-1}$ resolution from 3650 to $3740 \mathrm{~cm}^{-1}$. In the spectrum, clear $\mathrm{P}, \mathrm{Q}$, and $\mathrm{R}$-rotational branches were observed, indicating the A-type transition of an asymmetric top. The average spacing of the adjacent rotational lines in the $\mathrm{P}$ and $\mathrm{R}$-branches was $\sim 3.3 \mathrm{~cm}^{-1}$, very close to the $(\mathrm{B}+\mathrm{C})\left(=3.335 \mathrm{~cm}^{-1}\right)$ for the minimum energy structure of $\mathrm{SiH}_{5}{ }^{+}$predicted by the ab initio calculation $\left(A=2.522, B=1.691, C=1.644 \mathrm{~cm}^{-1}\right)^{2}$

Since the rotational lines are clearly resolved in the spectrum, they were able to fit with the A-type rotational transitions of an asymmetric top using the Watson S-type asymmetric top rotational hamiltonian. ${ }^{13}$ In the fit, each $J, K_{a}, K_{c}$ rotational transition was represented by a Lorentzian function with certain bandwidth, and its center and height were determined by calculating the frequencies and intensities for the A-type transitions from the individual $J, K_{a}, K_{c}$ states, with the Boltzmann factors and the nuclear spin statistical weights for $G_{12} M S$ group, $A_{1}^{\prime}(4), A_{1}^{\prime \prime}(12), A_{2}^{\prime}(4)$, and $A_{2}{ }^{\prime \prime}(12)$, taken into account. The resulting Lorentzian functions for each $J$ value were added to give the final line shape, and the frequency at the maximum was compared with the observed frequency for each J quantum number. As a preliminary fit, the ground state A rotational constant was fixed at $2.519 \mathrm{~cm}^{-1}$, the effective A rotational constant which was calculated from the ab intio structures of $\mathrm{SiH}_{5}{ }^{+}$, with the free internal rotation of $\mathrm{H}_{2}-\mathrm{SiH}_{3}{ }^{+}$taken into account. In addition, the centrifugal distortion terms were entirely ignored in the fit since the number of rotational lines resolved in the spectrum (16 lines) were not enough to determine those terms. Therefore, the six parameters, i.e. ground state $B, C$, excited state 
A, B, C constants, and the band origin were used to fit the 16 lines. As a result, the ground state $\mathrm{B}, \mathrm{C}$ constants were $1.689(0.003), 1.639(0.003) \mathrm{cm}^{-1}$, the excited state $\mathrm{A}$, B, C constants were $2.537(0.008), 1.692(0.002), 1.636(0.004) \mathrm{cm}^{-1}$, respectively, and the band origin was $3693.97(0.06) \mathrm{cm}^{-1}$, as shown in Table 5. Note that the numbers in parentheses are single standard deviations calculated from the fit. The observed and calculated frequencies for the $\mathrm{J}$ rotational quantum numbers are listed in Table 6, along with the differences of the two frequencies.

A complete agreement was found between the experimental results and the theoretical predictions for the ground state $\mathrm{B}$ and $\mathrm{C}$ rotational constants. This result strongly suggests that $\mathrm{SiH}_{5}{ }^{+}$can be described as a complex of $\mathrm{SiH}_{3}{ }^{+}$and $\mathrm{H}_{2}$, and the internal rotation of $\mathrm{H}_{2}-\mathrm{SiH}_{3}{ }^{+}$is likely to be free. Unlike $\mathrm{CH}_{5}{ }^{+}$, the scrambling through the $\mathrm{C}_{2 \mathrm{v}}$ transition state does not occur in $\mathrm{SiH}_{5}{ }^{+}$.

Fig. $4 \mathrm{~B}$ shows a simulated spectrum obtained with the rotational constants determined from the fit, the Lorentzian bandwidth of $0.15 \mathrm{~cm}^{-1}$, and the rotational temperature at $90^{\circ} \mathrm{K}$. The intensity distribution in the $\mathrm{P}$ and R-branches of the simulated spectrum was different from that of the observed spectrum, as shown in Fig. 4A and 4B. A close examination of the observed spectrum reveals that the intensity distribution of the observed spectrum is well correlated with the upper state J's, rather than the lower state $\mathrm{J}$ 's. For example, both the $\mathrm{P}$ and $\mathrm{R}$-branches of the observed spectrum have maximum intensities at the upper state $J=6$, and then decrease slowly in intensity as the upper state $\mathrm{J}$ increases, as shown Fig. 4A. In addition, the intensity alternation for the upper state $\mathrm{J} \leq 5$ is similar for both $\mathrm{P}$ and $\mathrm{R}$-branches. This result indicates that the multiphoton 
process induced by the $\mathrm{CO}_{2}$ laser (Fig. 1), which drives the vib-rotationally excited $\mathrm{SiH}_{5}{ }^{+}$ ions over the dissociation threshold, could modify the vibrational predissociation spectrum. Since the density of states for $\mathrm{SiH}_{5}{ }^{+}$at the energy of one IR photon from the tunable laser $\left(-3700 \mathrm{~cm}^{-1}\right)$, as shown in Table 7 , was calculated to be far below the quasicontinuum threshold, multiphoton processes are likely to occur in the discrete states, rather than in the quasicontinuum states. Previously, the multiphoton process in the discrete states was known to depend strongly upon the intermediate vibration-rotational states involved in the process. ${ }^{14}$

In spite of the errors involved in determining the frequencies used in the fit from neglecting both the multiphoton process and the high order terms such as centrifugal distortions, the results of the preliminary fit would be still valid within the accuracy of the observed rotational line width since the observed lines are sharply resolved. Therefore, we conclude that the silanium ion $\mathrm{SiH}_{5}{ }^{+}$possesses the structure predicted by the ab initio calculation, which can be described as a complex between $\mathrm{SiH}_{3}{ }^{+}$and a freely internally rotating $\mathrm{H}_{2}$ groups. Unlike the carbonium ion $\mathrm{CH}_{5}{ }^{+}$, the silanium ion $\mathrm{SiH}_{5}{ }^{+}$ does not scramble through the $\mathrm{C}_{2 v}$ transition state, and the $3 \mathrm{c} 2 \mathrm{e}$ bond is highly localized. A complete analysis of the observed IR spectrum with the multiphoton process taken into account is now on progress. 


\section{REFERENCES}

1. G.A. Olah, Carbocations and electrophilic reactions (Verlag Chemie, Weinheim, 1973).

2. Ching-Han Hu, Mingzuo Shen and Henry F. Schaefer III, Chem. Phys. Lett., v.190, 543 (1992).

3. P.v.R. Schleyer, Y. Apeloig, D. Arad, Brian T. Luke, and John A. Pople, Chem. Phys. Lett., v.95 (477).

4. Ruifeng Liu and Xuefeng Zhou, J. Phys. Chem., v.97, 9555 (1993).

5. Ching-Han Hu, Peter R. Schreiner, P.v.R. Schleyer, and Henry F. Schaefer III, J. Phys. Chem., v.98, 5040 (1994).

6. Yibin Cao, Jong-Ho Choi, Bernd-Michael Haas, Mathew S. Johnson, and Michio Okumura, J. Phys. Chem., v.97, 5215 (1993).

7. Doo Wan Boo and Yuan T. Lee, Chem. Phys. Lett., v.211, 358 (1993).

8. S.W. Bustamente, Ph.D. Thesis, University of California at Berkeley (1983).

9. Bong Hyun Boo and P.B. Armentrout, J. Am. Chem. Soc., v.109, 3549 (1987).

10. R.N Daly, Rev. Sci. Instr., v.31, 264 (1960).

11. H.C. Longuet-Higgins, Mol. Phys., 445 (1962).

12. P.R. Bunker, "Molecular Symmetry and Spectroscopy," Academic Press, New York, 1979.

13. J.K.G. Watson, in "Vibrational Spectra and Structure" (J.R. Durig, ed.), v.6, 1-89, Elsevier, Amsterdam, 1977.

14. P.A. Schultz, Ph.D. Thesis, University of California at Berkeley (1979). See the 
references thereafter. 
Table 1. Character table of the $\mathrm{G}_{12}$ group for $\mathrm{SiH}_{5}^{+}$

\begin{tabular}{|c|c|c|c|c|c|c|}
\hline $\mathrm{G}_{12}$ & $\mathrm{E}$ & $\begin{array}{l}(123) \\
(132) \\
\end{array}$ & $\begin{array}{l}(23)^{*} \\
(31)^{*} \\
(12)^{*}\end{array}$ & (45) & $\begin{array}{l}(123)(45) \\
(132)(45) \\
\end{array}$ & $\begin{array}{l}(23)(45)^{*} \\
(31)(45)^{*} \\
(12)(45)^{*}\end{array}$ \\
\hline$A_{1}^{\prime}$ & 1 & 1 & 1 & 1 & 1 & 1 \\
\hline$A_{2}^{\prime}$ & 1 & 1 & -1 & 1 & 1 & -1 \\
\hline$E^{\prime}$ & 2 & -1 & 0 & 2 & -1 & 0 \\
\hline$A_{1}{ }^{\prime \prime}$ & 1 & 1 & 1 & -1 & -1 & -1 \\
\hline$A_{2}{ }^{\prime \prime}$ & 1 & 1 & -1 & -1 & -1 & 1 \\
\hline$E^{\prime \prime}$ & 2 & -1 & 0 & -2 & 1 & 0 \\
\hline $\begin{array}{l}\text { Equiv. } \\
\text { Rotation }\end{array}$ & $\mathrm{R}^{0}$ & $\mathrm{R}^{0}$ & $\mathrm{R}_{\mathrm{c}}{ }^{\pi}$ & $\mathrm{R}_{\mathrm{a}}{ }^{\pi}$ & $\mathrm{R}_{\mathrm{a}}{ }^{\pi}$ & $\mathrm{R}_{\mathrm{b}}{ }^{\pi}$ \\
\hline$\theta, \phi, \chi^{\mathrm{a}}$ & $\theta, \phi, \chi$ & $\theta, \phi, \chi$ & $\pi-\theta, \pi+\phi, \pi-\chi$ & $\theta, \phi, \pi+\chi$ & $\theta, \phi, \pi+\chi$ & $\pi-\theta, \pi+\phi, 2 \pi-\chi$ \\
\hline$\rho^{b}$ & $\rho$ & $\rho-2 \pi / 3$ & $2 \pi-\rho$ & $\rho+\pi$ & $\rho+\pi / 3$ & $\pi-\rho$ \\
\hline
\end{tabular}

${ }^{\mathrm{a}} \theta, \phi, \chi$ are the Euler angles to define the molecule-fixed coordinates $(x, y, z)$ with respect to the space-fixed coordinates $(\mathrm{X}, \mathrm{Y}, \mathrm{Z})$.

${ }^{b} \rho$ defines the torsional angle for the internal rotation of $\mathrm{H}_{2}--\mathrm{SiH}_{3}{ }^{+}$. 


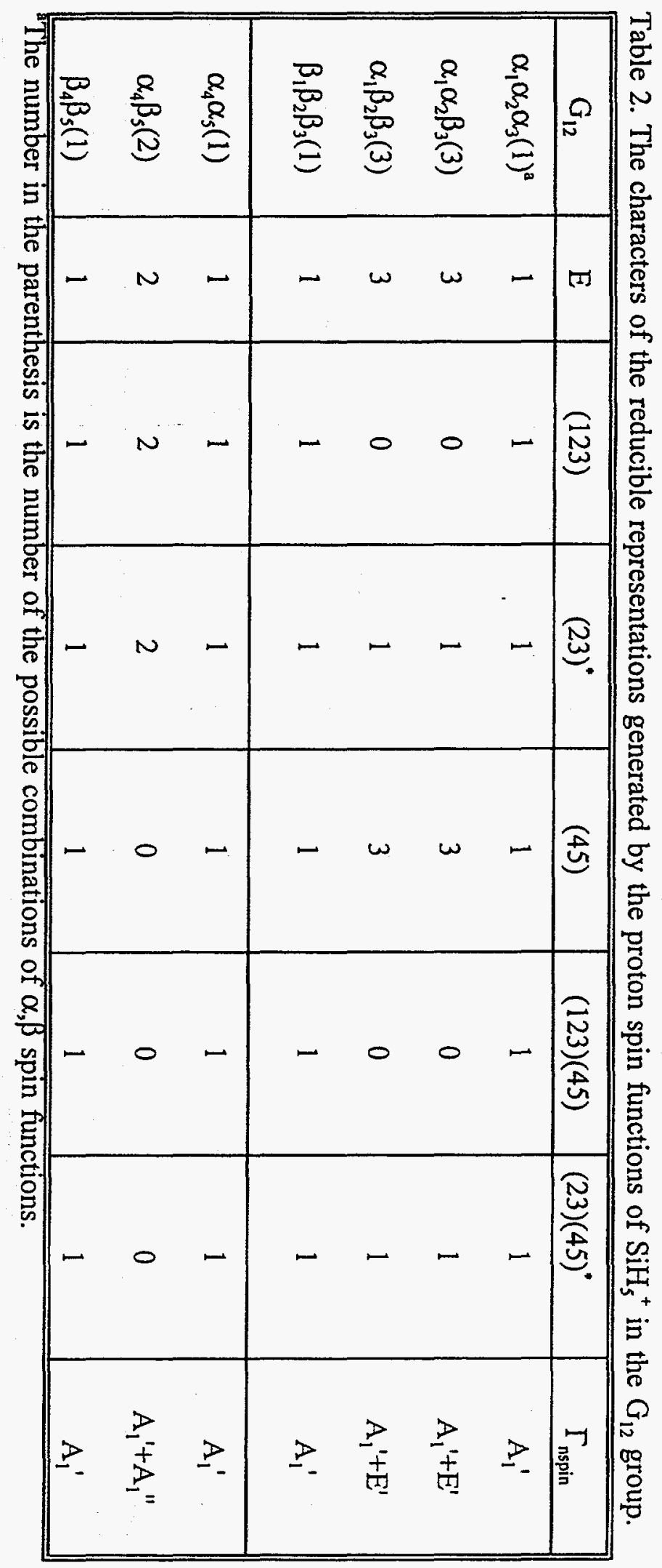


Table 3. Symmetry species of asymmetric top rotational wavefunctions of $\mathrm{SiH}_{5}^{+}$in the group $\mathrm{G}_{12}$.

\begin{tabular}{|c|c|}
\hline $\mathrm{K}_{\mathrm{a}} \mathrm{K}_{\mathrm{c}}$ & $\Gamma_{\mathrm{rot}}{ }^{\mathrm{a}}$ \\
\hline ee & $\mathrm{A}_{1}{ }^{\prime}(4)$ \\
eo & $\mathrm{A}_{2}{ }^{\prime}(4)$ \\
oe & $\mathrm{A}_{1}{ }^{\prime \prime}(12)$ \\
oo & $\mathrm{A}_{2}{ }^{\prime \prime}(12)$ \\
\hline
\end{tabular}

The numbers in parentheses are the nuclear spin statistical weights for the ground vibrational and torsional states.

Table 4. Symmetry species of torsional wavefunctions, $\exp \left(\mathrm{ik}_{\mathrm{i}} \rho\right)$, of $\mathrm{SiH}_{s}{ }^{+}$in the $\mathrm{G}_{12}$ group.

\begin{tabular}{|c|c|}
\hline \hline $\mathrm{K}_{\mathrm{i}}^{\mathrm{a}}$ & $\Gamma_{\text {lor }}$ \\
\hline 0 & $\mathrm{~A}_{1}{ }^{\prime}$ \\
$6 \mathrm{~m}+1$ & $\mathrm{E}^{\prime \prime}$ \\
$6 \mathrm{~m}+2$ & $\mathrm{E}^{\prime}$ \\
$6 \mathrm{~m}+3$ & $\mathrm{~A}_{1}{ }^{\prime \prime}+\mathrm{A}_{2}{ }^{\prime \prime}$ \\
$6 \mathrm{~m}+6$ & $\mathrm{~A}_{1}{ }^{\prime}+\mathrm{A}_{2}{ }^{\prime}$ \\
\hline
\end{tabular}

${ }^{2} K_{i}=\left|k_{i}\right|>0$, and $m$ is a nonnegative integer. 
Table 5. Parameters for the ground and excited states of the $\mathrm{H}-\mathrm{H}$ stretching mode in $\mathrm{SiH}_{5}{ }^{+}$, derived from a nolinear least square fit to 16 lines. Single standard deviations are given in parenthesis. Units are in $\mathrm{cm}^{-1}$.

\begin{tabular}{|c|ll||}
\hline \hline & & \\
Parameter & Ground & Excited \\
& & \\
\hline A & $2.519^{\mathrm{a}}$ & $2.537(0.008)$ \\
$\mathrm{B}$ & $1.689(0.003)$ & $1.692(0.002)$ \\
$\mathrm{C}$ & $1.639(0.003)$ & $1.636(0.004)$ \\
& & \\
Band origin & & $3693.97(0.06)$ \\
\hline
\end{tabular}

${ }^{2}$ The ground $\mathrm{A}$ constant was determined from $\mathrm{ab}$ initio results for $\mathrm{SiH}_{s}{ }^{+}$with a free internal rotation, and was fixed in the fit. 
Table 6. Observed and calculated rotational transitions in the $\mathrm{H}-\mathrm{H}$ stretching mode of $\mathrm{SiH}_{5}^{+}$. Units are in $\mathrm{cm}^{-1}$.

\begin{tabular}{||c|c|c|c|c||}
\hline Lower J & Upper J & Obs. $^{\mathrm{a}}$ & Calc. $^{\mathrm{b}}$ & Obs.- Calc. \\
\hline 11 & 10 & 3657.60 & 3657.49 & 0.11 \\
10 & 9 & 3660.85 & 3660.82 & 0.03 \\
9 & 8 & 3664.05 & 3664.12 & -0.07 \\
8 & 7 & 3667.48 & 3667.50 & -0.02 \\
7 & 6 & 3670.70 & 3670.79 & -0.09 \\
6 & 5 & 3673.95 & 3674.10 & -0.15 \\
5 & 4 & - & 3677.42 & - \\
4 & 3 & 3680.60 & 3680.71 & -0.11 \\
3 & 2 & - & 3684.05 & - \\
2 & 1 & - & 3687.34 & - \\
1 & 0 & - & 3690.63 & - \\
Q-branch & Q-branch & 3694.25 & 3694.19 & 0.06 \\
0 & 1 & - & 3697.31 & - \\
1 & 2 & 3700.70 & 3700.64 & 0.06 \\
2 & 3 & 3704.15 & 3703.98 & 0.17 \\
3 & 4 & - & 3707.36 & - \\
4 & 5 & 3710.65 & 3710.74 & -0.09 \\
5 & 6 & 3714.23 & 3714.12 & 0.11 \\
6 & 7 & 3717.45 & 3717.50 & -0.05 \\
7 & 8 & 3720.85 & 3720.84 & 0.01 \\
8 & 9 & 3724.15 & 3724.18 & -0.03 \\
9 & 10 & 3727.45 & 3727.55 & -0.10 \\
10 & 11 & - & 3730.89 & - \\
\hline
\end{tabular}

${ }^{2}$ The transitions marked by "-" were not resolved in the spectrum.

${ }^{b} T$ These frequecnies were determined at the maximum of the rotational band contour, constructed from the transitions of all the $K_{a}, K_{c}$ quantum numbers for each $J$. Each $J$, $\mathrm{K}_{\mathrm{a}}, \mathrm{K}_{\mathrm{c}}$ transition was represented by a Lorentzian line shape function with $0.15 \mathrm{~cm}^{-1}$ FWHM. 
Table 7. Density of states for $\mathrm{SiH}_{5}{ }^{+}$calculated as a function of internal energy using the Witten-Rabinovich equation. The torsional mode was considered as a free internal rotation, and was not included in this calculation.

$$
\text { (E) per } \mathrm{cm}^{-1}
$$

\begin{tabular}{|l|l|l|l|}
\hline Energy & $3500 \mathrm{~cm}^{-1}$ & $5000 \mathrm{~cm}^{-1}$ & $7000 \mathrm{~cm}^{-1}$ \\
\hline$\rho(E)$ & 0.40 & 2.03 & 11.6 \\
\hline
\end{tabular}

The vibrational frequencies used in this calculation were obtained by scaling the ab initio harmonic frequencies at TZ2P CCSD (ref. 2), by the ratio of the observed and calculated $\mathrm{H}-\mathrm{H}$ stretching frequencies. The results are $3694,2201,2194,937,874,867,822,666$, 604 , and $588 \mathrm{~cm}^{-1}$. 


\section{FIGURE CAPTIONS}

Fig. 1 Schematic of the two color IR multiphoton process used in this experiment. The $\mathrm{H}-\mathrm{H}$ stretching mode of $\mathrm{SiH}_{s}^{+}$was excited first by the pulsed and tunable IR laser, then the $\mathrm{cw} \mathrm{CO}_{2}$ laser pumped the vibrationally excited ions over the dissociation threshold.

Fig. 2 Mass spectrum showing the silanium ions, $\mathrm{SiH}_{5}{ }^{+}$and $\mathrm{SiH}_{7}{ }^{+}$. The mixing ratio $\mathrm{SiH}_{4}: \mathrm{He}: \mathrm{H}_{2}$ was 1:5,000:50,000, and source pressure, the source temperature, and the discharge current were 200 torr, $-10^{\circ} \mathrm{C}$, and $30 \mu \mathrm{A}$, respectively.

Fig. 3 Structure of $\mathrm{SiH}_{5}^{+}$, predicted by ab initio calculation (ref. 2).

Fig. 4 (A) Infrared spectrum of the $\mathrm{H}-\mathrm{H}$ stretching mode in $\mathrm{SiH}_{5}^{+}$, showing clear features for the A-type vibration-rotation transitions. (B) Simulated spectrum of the A-type transitions with the rotational constants determined from the fit, a Lorentzian line width of $0.15 \mathrm{~cm}^{-1}$, and the rotational temperature at $90^{\circ} \mathrm{K}$. Note the assignments of $\mathrm{J}$ quantum numbers for the lower and upper states. 


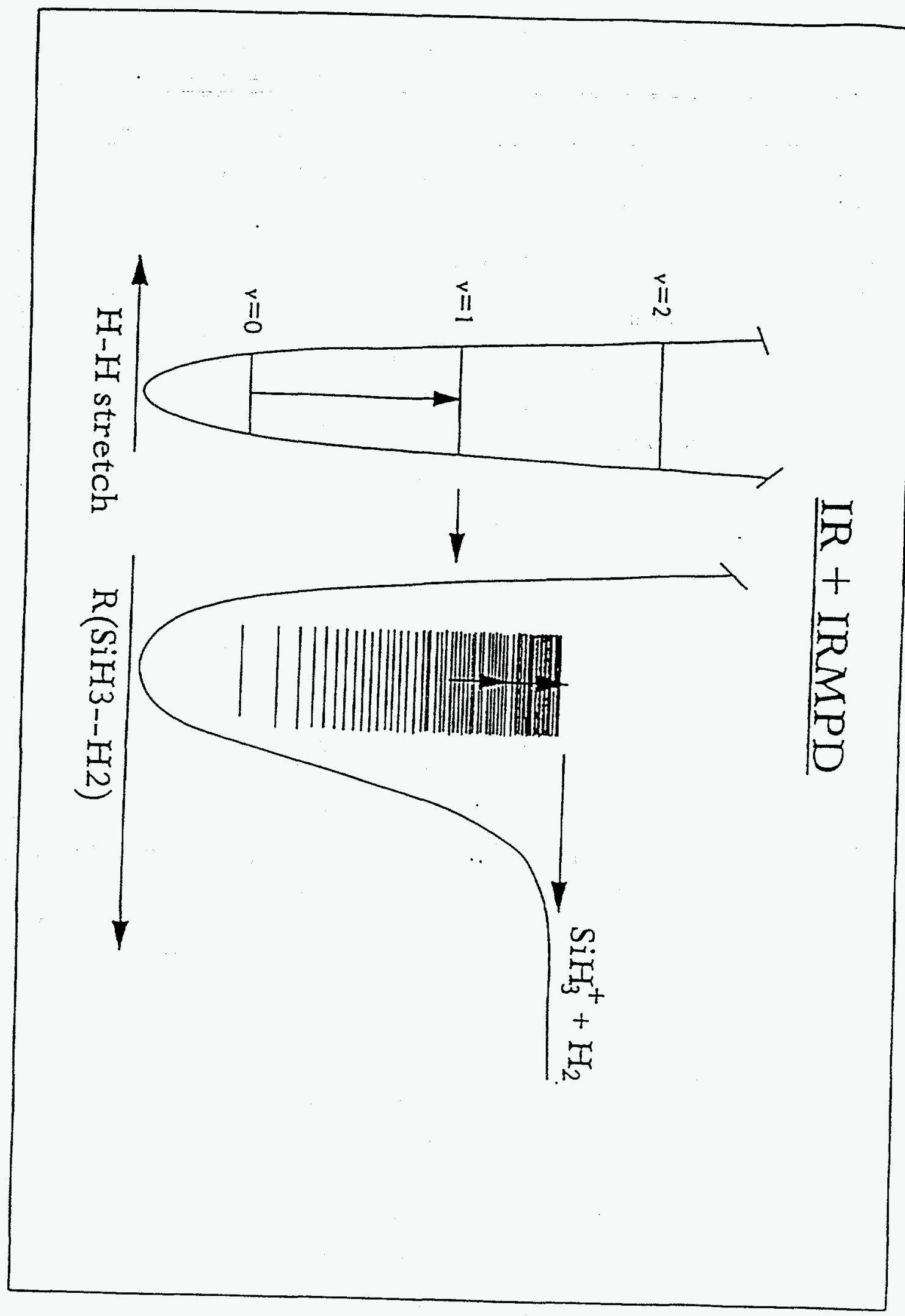

Fig. 1 
INTENSITY(arb.)

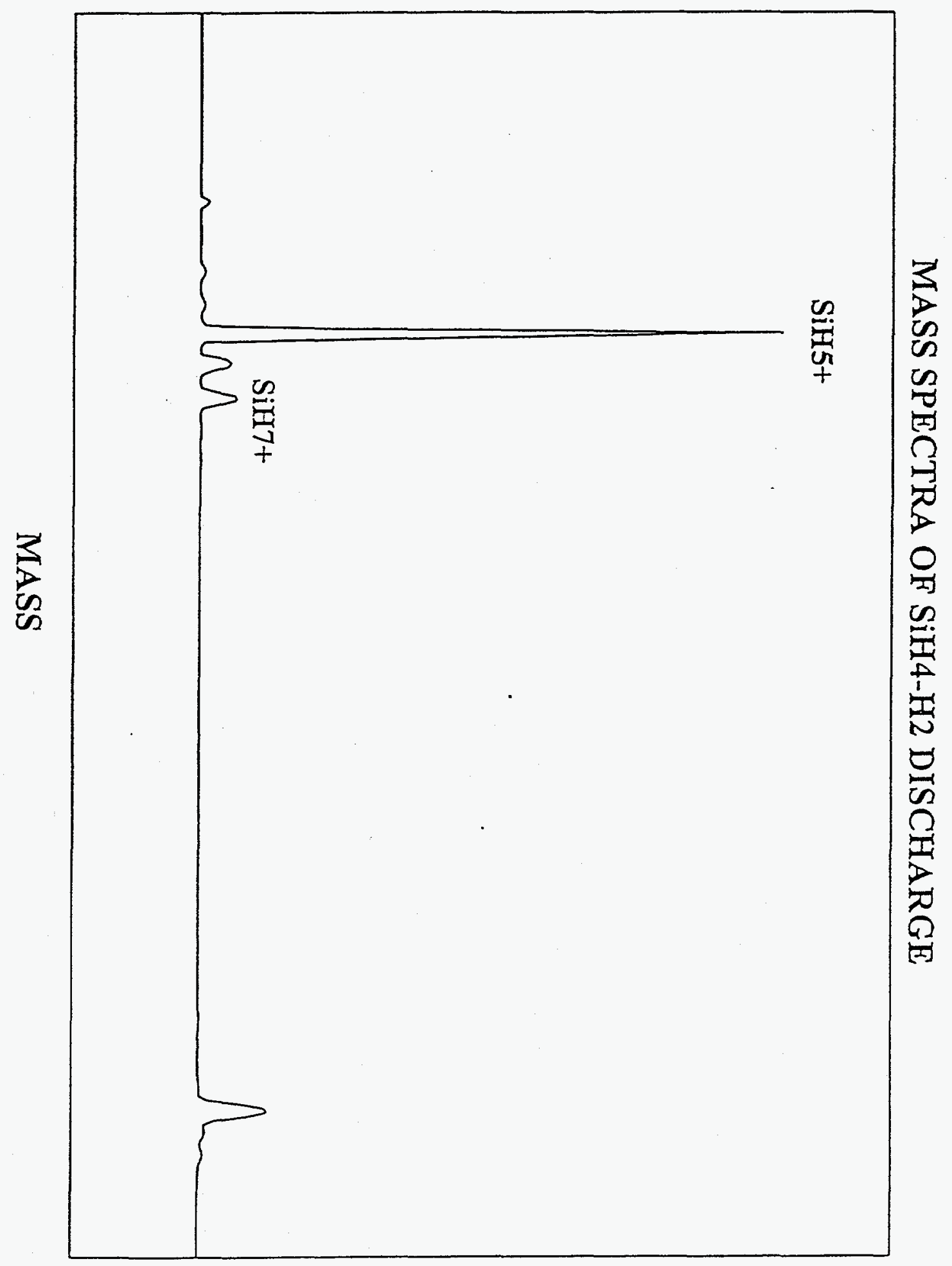

Fig. 2 


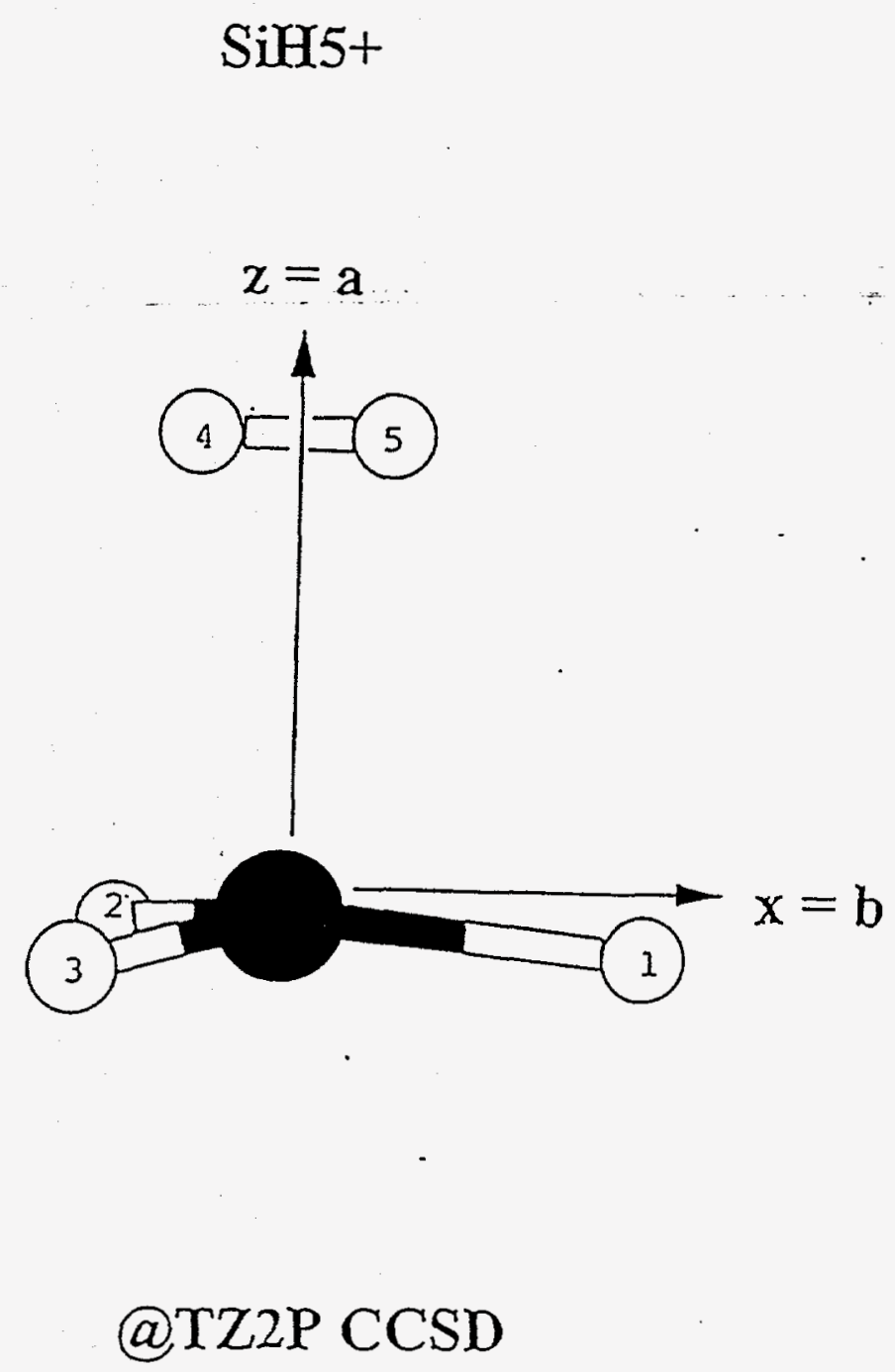

Fig. 3 
Intensity(arb.)

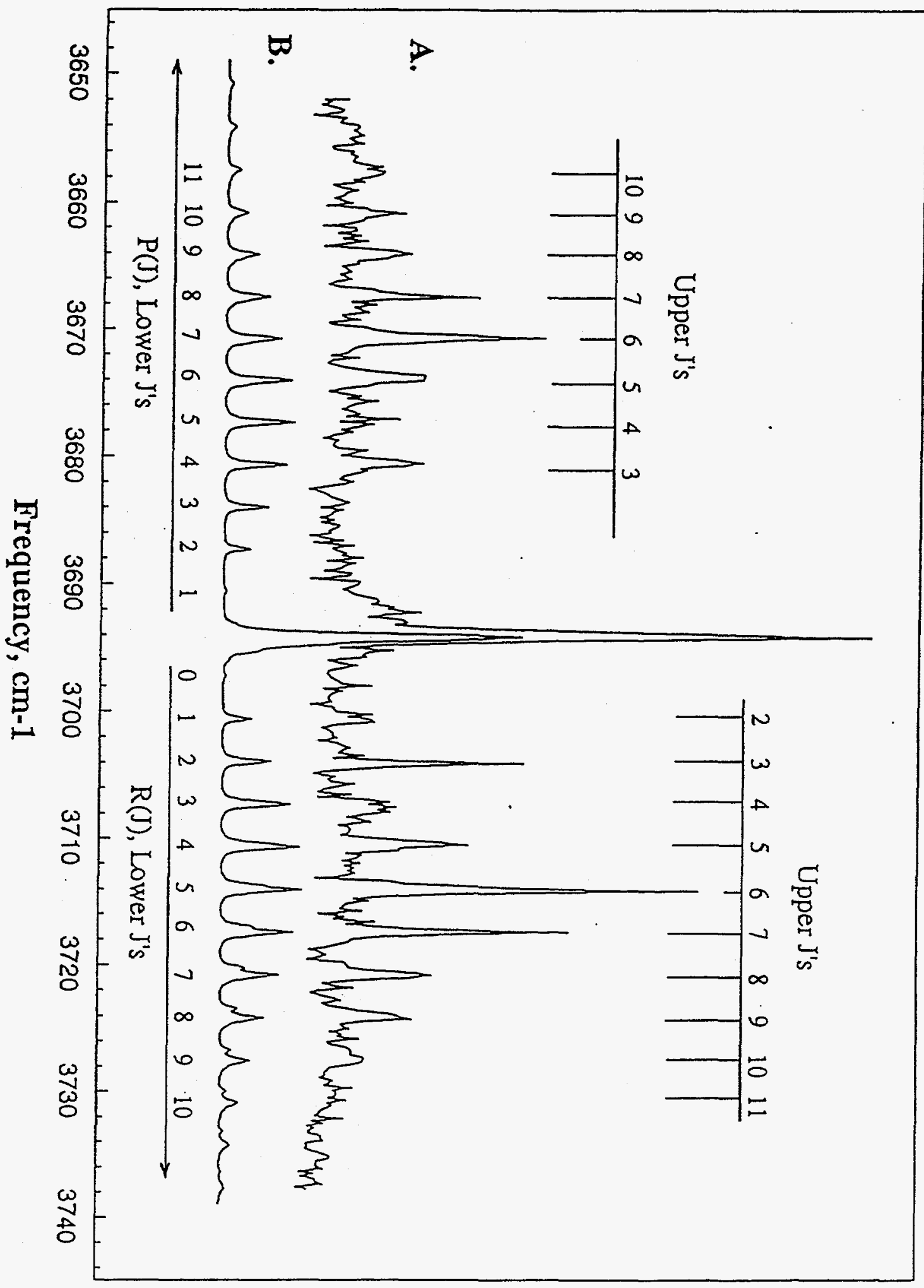

Fig. 4 